\author{
Universidade de Brasília \\ Faculdade de Ciências da Saúde \\ Departamento de Enfermagem \\ Programa de Pós Graduação em Enfermagem
}

\author{
JANAINA MEIRELLES SOUSA
}

\title{
COMPETÊNCIAS REQUERIDAS DO ENFERMEIRO PARA O CUIDADO PALIATIVO NA ATENÇÃO DOMICILIAR
}

BRASÍLIA

2015 


\author{
Universidade de Brasília \\ Faculdade de Ciências da Saúde \\ Departamento de Enfermagem \\ Programa de Pós Graduação em Enfermagem
}

\title{
JANAINA MEIRELLES SOUSA
}

\section{COMPETÊNCIAS REQUERIDAS DO ENFERMEIRO PARA O CUIDADO PALIATIVO NA ATENÇÃO DOMICILIAR}

Tese apresentada como requisito parcial para a obtenção do Título de Doutor em Enfermagem pelo Programa de PósGraduação em Enfermagem da Universidade de Brasília.

Área de Concentração: Políticas, Práticas e Cuidado em Saúde e Enfermagem.

Linha de Pesquisa: Gestão da atenção à saúde e organização dos serviços de saúde.

Orientador: Dr. Elioenai Dornelles Alves 
Ficha catalografica elaborada automaticamente, com os dados fornecidos pelo(a) autor(a) Cuidado paliativo na Atenço Doniciliar / Janaina Meirelies Sousa; orientador Blicenal Dornelles Alves. -- Brasilia, 2015.

$167 \mathrm{p}$.

Tese (Doutorado - Doutorado em Rnfernagea) =Unfveraidade de Brasilia, 2015.

1. Analatência Doniciliar, 2, Culdadon Paliativos. 3. Competéneía Profiasional. 4. Bnfernagen de Cuidados Paliativos na Terninalidade da Vida, 5. Enfermagen Donieiliar. I. Alves, Rlioenai Dornelles, orient. II. Titulo. 


\section{JANAINA MEIRELLES SOUSA}

\section{COMPETÊNCIAS REQUERIDAS DO ENFERMEIRO PARA O CUIDADO PALIATIVO NA ATENÇÃO DOMICILIAR}

Tese apresentada como requisito parcial para a obtenção do Título de Doutor em Enfermagem pelo Programa de PósGraduação em Enfermagem da Universidade de Brasília.

Aprovado em: 06 de março de 2015.

\section{BANCA EXAMINADORA}

Prof. Dr. Elioenai Dornelles Alves Instituição: Universidade de Brasília

\section{Presidente}

Prof. Dr. Moema da Silva Borges Instituição: Universidade de Brasília Membro

Prof. Dr. Pedro Sadi Monteiro Instituição: Universidade de Brasília Membro

Prof. Dr. Tânia Cristina M. S. B. Rehem Instituição: Universidade de Brasília Membro

Prof. Dr. Monica Martins Trovo Instituição: Universidade de Guarulhos/SP Membro

Prof. Dr. Silvana Schwerz Funghetto Instituição: Universidade de Brasília Membro 


\section{AGRADECIMENTOS}

Ao meu filho Miguel Meirelles Sousa Sant'Anna pela enorme paciência, pelo companheirismo nas horas difíceis, confortando meu cansaço com seus abraços e beijinhos. Filho, você é uma benção em minha vida!

À minha irmã Marise de Meirelles Sousa pelo companheirismo e apoio logístico em minhas aventuras na busca do conhecimento.

À minha mãe Nair Rangel de Meirelles Sousa (in memorian) que em sua condição de terminalidade pela doença de Alzheimer muito me ensinou sobre o tempo do cuidado e as dificuldades de ser cuidador e família.

Aos meus familiares, que mesmo à distância sempre me apoiaram na minha caminhada.

Ao meu orientador Elioenai Dornelles Alves, pela paciência e ajuda na realização deste estudo. Sua sabedoria e humildade foram importantes para o meu aprendizado acadêmico.

À amiga Monica Martins Trovo que me trouxe de volta para a assistência em cuidados paliativos. Serei eternamente grata por seus ensinamentos e companheirismo.

Ás amigas Cris Renata Grou Volpe e Diane Aparecida Kun Lago pelo companheirismo e incentivo. Sem o apoio de vocês teria sido mais difícil transpor alguns obstáculos.

A todo corpo docente do Programa de Pós-graduação em Enfermagem da UnB, e à Prof. Dra. Olgamir Francisco Carvalho, pela oportunidade de reflexão acerca dos temas discutidos nas disciplinas de doutorado, e pelo muito que contribuíram com o meu crescimento.

Aos membros da banca de defesa professores Moema da Silva Borges, Pedro Sadi Monteiro, Tânia Cristina M. S. B. Rehem, Silvana Schwerz Funghetto, pelas valiosas contribuições.

Aos professores amigos da Faculdade de Ceilândia, pelo constante incentivo na conclusão deste doutorado.

Aos enfermeiros Leiliane Alcantara Brito, Flávia Firmino e Renato Rodrigues Camarão que gentilmente aceitaram participar da construção desta pesquisa.

Aos enfermeiros participantes do estudo pelas preciosas contribuições e sugestões na elaboração deste estudo. 
"Assim, quando chegarmos ao fim de nossos dias tendo trabalhado, sofrido, nos doado e nos divertido, voltaremos ar estágio por onde começamos, e se fecha o ciclo da vida" (Elisabeth Kubler-Ross) 


\section{RESUMO}

SOUSA, Janaina Meirelles. Competências requeridas do enfermeiro para o cuidado paliativo na atenção domiciliar. 2015. 167 p. Tese (Doutorado) - Departamento de Enfermagem, Faculdade de Ciências da Saúde, Universidade de Brasília, Brasília, 2015.

Este estudo reflexiona o campo de competências do enfermeiro para o cuidado paliativo na atenção domiciliar, tendo como objetivos: identificar as competências gerais e específicas requeridas dos enfermeiros para o cuidado paliativo na atenção domiciliar; analisar as competências gerais e específicas para o cuidado paliativo sob a ótica das Diretrizes Curriculares Nacionais do Curso de Graduação em Enfermagem; e elencar competências para o ensino de cuidados paliativos no nível de graduação em enfermagem. Estudo exploratório, de abordagem quantitativa, que utilizou o método Delphi para identificar o consenso de enfermeiros que atuam nas Equipes Multiprofissionais de Atenção Domiciliar - EMAD para com 43 competências elencadas em um questionário, com inclusão de escala de Likert de cinco pontos. Na amostra de 20 enfermeiros, houve consenso para 18 competências gerais e 25 específicas com percentuais acima de $75 \%$ de concordância, e coeficiente alfa de Cronbach de 0,7 para todas as competências elencadas. Do consenso emergiram 29 competências para o ensino no nível de graduação em enfermagem. O elenco de competências apresentou confiabilidade interna e fornece afirmações assertivas sobre a atuação do enfermeiro em cuidado paliativo, além de indicar o reconhecimento dos cuidados paliativos como prática assistencial de enfermagem na atenção domiciliar. As competências consensuadas são convergentes com a amplidão das competências descritas nas Diretrizes Curriculares Nacionais do Curso de Graduação em Enfermagem, e constituem-se em subsídio para a construção de referenciais assistenciais e de ensino, permitindo a proposição de competências para o ensino de cuidados paliativos na graduação em enfermagem emparelhada com as áreas de conteúdos propostos por essas diretrizes. Sinaliza a necessidade de aprendizagem de conteúdos sobre cuidados paliativos desde a graduação em enfermagem, permeando a educação permanente, como caminhos possíveis para a sustentação desta prática nos contextos de saúde, rumo a um cuidado de qualidade, integral e resolutivo, aos pacientes em fase final de vida.

Descritores: Assistência Domiciliar; Cuidados Paliativos; Competência Profissional; Enfermagem de Cuidados Paliativos na Terminalidade da Vida; Enfermagem Domiciliar; Serviços de Assistência Domiciliar. 


\begin{abstract}
SOUSA, Janaina Meirelles. Nurse's required competencies for palliative care in home care. 2015. 167 p. Thesis (Doctoral) - Department of Nursing, Health Science Faculty, University of Brasília, Brasília, 2015.

This study reflects on the field of nurses' competencies for palliative care in home care, and has as objectives: identifying the general and specific competencies required of nurses for palliative care in the home; analyze the general and specific competencies for palliative care in view of the National Curriculum Guidelines for Undergraduate Nursing Course; and list competencies for teaching palliative care at the graduate level in nursing. An he exploratory study with a quantitative approach, which used the Delphi method to identify the consensus of nurses who work in Multidisciplinary Teams of Home Care - EMAD with 43 competencies listed in a questionnaire, with the inclusion of the Likert scale of five points. In the sample of 20 nurses, there was a consensus to 18 general and 25 specific competencies with percentages above $75 \%$ agreement, and Cronbach's alpha coefficient of 0.7 for all listed competencies. From the consensus 29 competencies emerged for teaching at undergraduate level in nursing. The list of competencies presented internal reliability and provides assertive statements about the work of nurses in palliative care, and indicates the recognition of palliative care as a clinical nursing practice in home care. The consensual competencies are converging with the breadth of competencies described in the National Curriculum Guidelines for Undergraduate Nursing Course, and constitute a subsidy for the construction of care reference and teaching, allowing the proposition of competencies for palliative care education in nursing degree paired with content areas proposed by these guidelines. Signals the need for learning about palliative care content in undergraduate nursing, permeating the continued education, as possible ways to sustain this practice in health contexts, towards quality care, integral and effective, for patients in the final stage of life.
\end{abstract}

Keywords: Home Nursing; Palliative Care; Professional Competence; Hospice and Palliative Care Nursing; Home Health Nursing; Home Care Services. 


\section{RESUMEM}

SOUSA, Janaina Meirelles. Competencias requieridas del enfermero para el cuidado paliativo en la atención domiciliaria. 2015. 167 p. Tesis (Doctoral) - Departamento de Enfermería, Facultad de Ciencias de la Salud, Universidad de Brasília, Brasília, 2015.

Este estudio reflexiona el campo de competencias del enfermero a los cuidados paliativos en la atención domiciliaria y tiene como objetivos: identificar las competencias generales y específicas que si requieren de los enfermeros del cuidados paliativos en la atención domiciliaria; analizar las competencias generales y específicas de cuidados paliativos en la otica de las Diretrizes Curriculares Nacionales para el Curso de Graduación en Enfermería y listar competencias para la enseñanza de los cuidados paliativos al nivel de posgrado en enfermería. Estudio exploratorio con descrición cuantitativa, que utilizó el método Delphi para identificar el consenso de los enfermeros que trabajan como Equipos Multidisciplinarios de Home Care - EMAD 43 competencias que se presentan en una encuesta, con la inclusión de la escala Likert de cinco puntos. En la muestra de 20 enfermeros, hubo consenso en 18 competencias generales y 25 específicas con porcentajes por encima de $75 \%$ y el alfa de Cronbach de 0,7 para las demas competências. Del consenso, lograron 29 competencias para la enseñanza al nivel de licenciatura en enfermería. La lista de competencias presentó confiabilidad interna y forneció afirmativas asertivas de los trabajos delenfermero en los cuidados paliativos y, además indicó el reconocimiento de los cuidados paliativos como una práctica clínica de enfermería en la atención domiciliaria. Las competencias consensuales son convergentes con la amplitud de las competencias que se describen en las Directrices Curriculares Nacionales para el Curso de Graduación en Enfermería, y constituyen una base para la construcción de referenciales a la atención y la enseñanza, lo que permite la capacidad de proposición para la educación en cuidados paliativos en licenciatura en enfermería emparejado con áreas de contenidos propuestos por estas directrices. Señala la necesidad de aprender sobre el contenido de cuidados paliativos desde la graduación en enfermería, hasta la educación permanente, como las posibles formas de mantener esta práctica en contextos de salud, hacia una atención de calidad, integral y eficiente, a los pacientes en la etapa final de la vida.

Descriptores: Atención Domiciliaria de Salud; Cuidados Paliativos; Competencia Profesional; Enfermería de Cuidados Paliativos al Final de La Vida; Cuidados de Enfermería en el Hogar; Servicios de Atención de Salud a Domicílio. 


\section{LISTA DE FIGURAS}

Figura 1 - Distribuição dos resumos de dissertações e teses segundo nível stricto sensu e ano

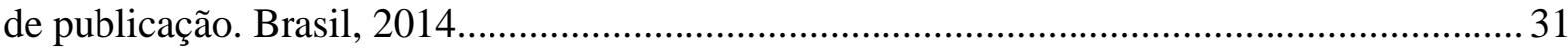




\section{LISTA DE QUADROS}

Quadro 1 - Distribuição dos resumos das dissertações e teses segundo instituição, ano de defesa e nível stricto sensu. Brasil, 2014.

Quadro 2 - Competências e conteúdos para o ensino de cuidados paliativos no curso de graduação em enfermagem. Brasília, 2014. 


\section{LISTA DE TABELAS}

Tabela 1 - Distribuição dos resumos de dissertações e teses segundo ranking das instituições e orientadores na área de cuidados paliativos. Brasil, 2014.

Tabela 2 - Distribuição dos resumos de dissertações e teses segundo cenário de pesquisa. Brasil, 2014

Tabela 3 - Distribuição dos resumos de dissertações e teses segundo sujeitos de pesquisa.. Brasil, 2014.

Tabela 4 - Distribuição dos resumos de dissertações e teses segundo referencial teórico. Brasil, 2014 35

Tabela 5 - Ranking das subáreas temáticas segundo frequência de aparecimento nos resumos de dissertações e teses. Brasil, 2014 44

Tabela 6 - Perfil socioprofissional dos enfermeiros participantes. Brasília, 2014. 74

Tabela 7 - Grau de concordância e coeficiente alfa de Cronbach do instrumento de avaliação das competências gerais. Brasília, 2014. 77

Tabela 8 - Grau de concordância e coeficiente alfa de Cronbach do instrumento de avaliação das competências específicas. Brasília, 2014. 


\section{LISTA DE SIGLAS}
ABEn Associação Brasileira de Enfermagem
AD Atenção Domiciliar
CNE Conselho Nacional de Educação
CEPEn Centro de Estudos e Pesquisas em Enfermagem
CES Câmara de Educação Superior
CFE Conselho Federal de Educação
CIPE Catálogo de Classificação Internacional para Prática de Enfermagem
DCN/ENF Diretrizes Curriculares Nacionais do Curso de Graduação em Enfermagem
DF Distrito Federal
ECS Estágio Curricular Supervisionado
EMAD Equipe Multiprofissional de Atenção Domiciliar
EMAP Equipe Multiprofissional de Apoio
ELNEC End-of-Life Nursing Education Consortium
GEAD Gerência de Atenção Domiciliar
GM Gabinete do Ministro
LDB Lei de Diretrizes e Bases da Educação
MEC Ministério da Educação
MS Ministério da Saúde
NANDA North American Nursing Diagnosis Association
NRAD Núcleo Regional de Atenção Domiciliar
OMS Organização Mundial da Saúde
PID Programa de Internação Domiciliar
RDC Resolução da Diretoria Colegiada
SAD Serviço de Atenção Domiciliar
SENADEn Seminários Nacionais de Diretrizes para a Educação em Enfermagem no Brasil
SES Secretaria de Saúde
SESu Secretaria de Educação Superior
SUS Sistema Único de Saúde
TCLE Termo de Consentimento Livre Esclarecido 


\section{SUMÁRIO}

APRESENTAÇÃO ............................................................................................................................. 15

1 INTRODUÇÃ

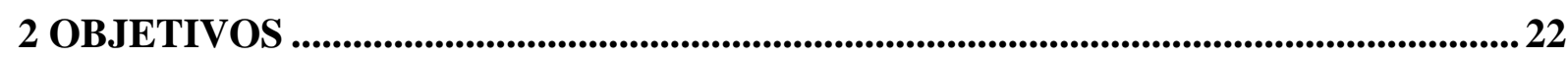

2.1 OBJETIVO GERAL …………………………………………………….... 22

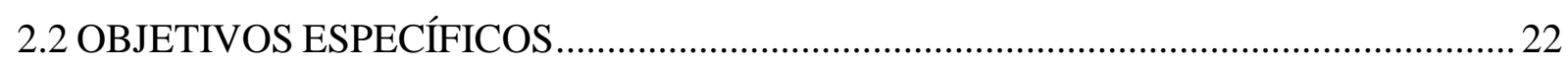

3 REFERENCIAL TEÓRICO .....................................................................................23

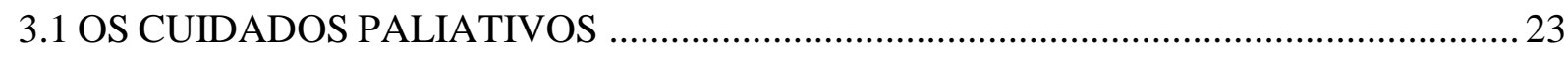

3.1.1 Perfil bibliométrico das teses e dissertações em enfermagem sobre cuidados

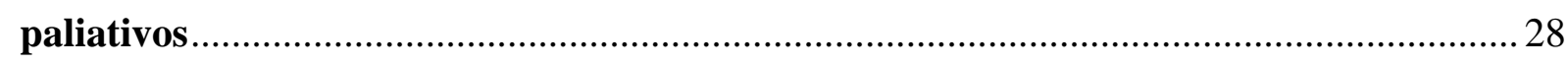

3.1.2 Cuidados Paliativos de Enfermagem na Atenção Domiciliar.................................... 39

3.2 O MODELO DE COMPETÊNCIA NO ÂMBITO DO TRABALHO ................................... 48

3.3 AS COMPETÊNCIAS NO ÂMBITO DA FORMAÇÃO PROFISSIONAL .........................53

3.4 AS COMPETÊNCIAS E A FORMAÇÃO PROFISSIONAL DE ENFERMAGEM ..........57

3.5 A ATENÇÃO DOMICILIAR NO ÂMBITO DO SISTEMA ÚNICO DE SAÚDE DO

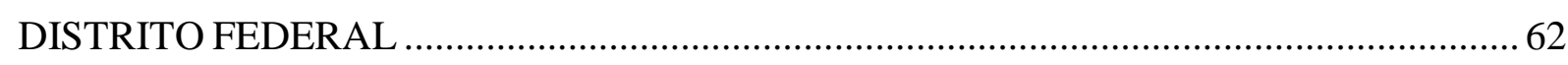

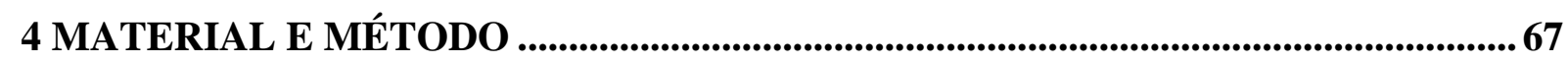

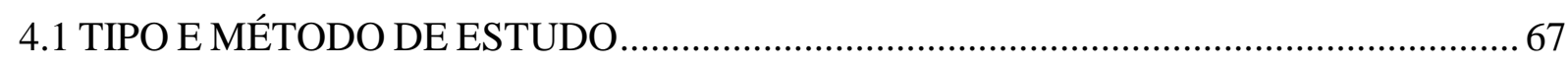

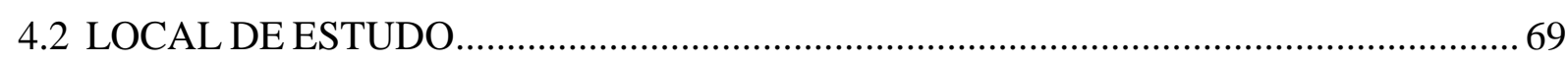

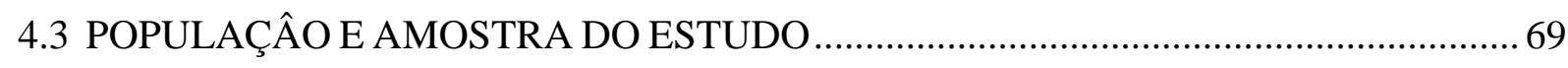

4.4 INSTRUMENTO E PROCEDIMENTO DE COLETA DE DADOS …………………..... 70

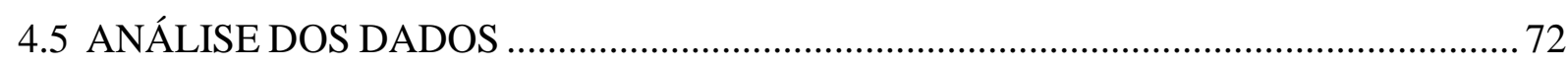

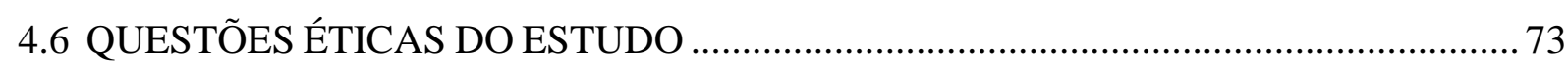

5 RESULTADOS E DISCUSSÃO ............................................................................. 74

5.1 PERFIL SOCIOPROFISSIONAL DOS PARTICIPANTES DO ESTUDO.......................... 74

5.2 COMPETÊNCIAS DO ENFERMEIRO PARA O CUIDADO PALIATIVO NA

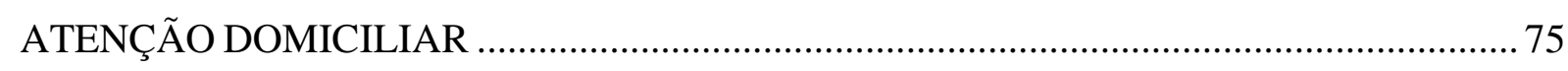

5.3 COMPETÊNCIAS PARA O CUIDADO PALIATIVO SOB A ÓTICA DAS DIRETRIZES CURRICULARES NACIONAIS DO CURSO DE GRADUAÇÃO EM ENFERMAGEM .... 82 
5.4 PROPOSIÇÃO DE COMPETÊNCIAS PARA O ENSINO DE CUIDADOS PALIATIVOS NO CURSO DE GRADUAÇÃO EM ENFERMAGEM ………………………………........93

6 CONSIDERAÇÕES FINAIS........................................................................................................101

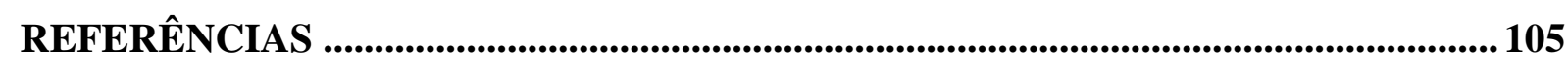

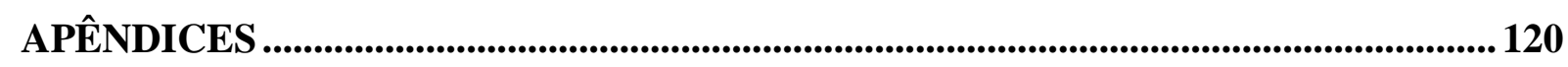

APÊNDICE A - ARTIGO 1: PERFIL BIBLIOMÉTRICO DAS TESES E DISSERTAÇÕES EM ENFERMAGEM SOBRE CUIDADOS PALIATIVOS ………………………………...... 120

APÊNDICE B - ARTIGO 2: CUIDADOS PALIATIVOS DE ENFERMAGEM NA

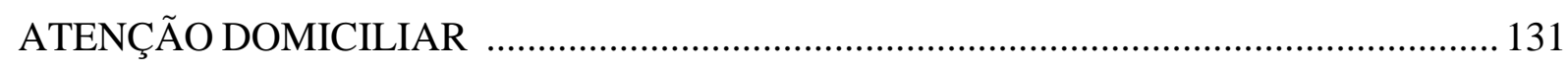

APÊNDICE C - TERMO DE CONSENTIMENTO LIVRE E ESCLARECIDO .................... 143

APÊNDICE D - INSTRUMENTO DE COLETA DE DADOS............................................... 144

APÊNDICE E - ARTIGO 3: COMPETÊNCIAS DO ENFERMEIRO PARA O CUIDADO PALIATIVO NA ATENÇÃO DOMICILIAR ................................................................ 148

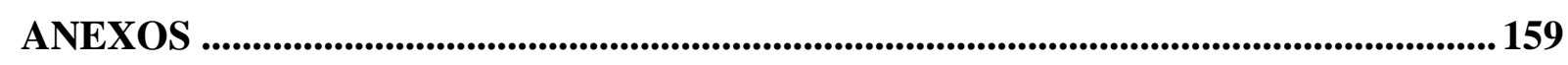

ANEXO A - DIRETRIZES CURRICULARES NACIONAIS DO CURSO DE

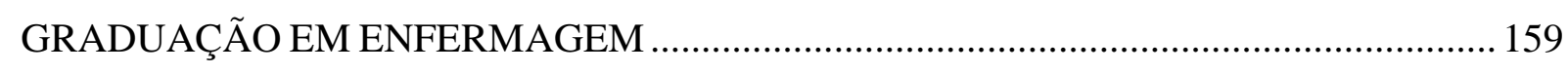

ANEXO B - PARECER CONSUBSTANCIADO DO CEP ……………………………..... 165 


\section{APRESENTAÇÃO}

Ter os Cuidados Paliativos como objeto de estudo, aponta para os primórdios da graduação há 23 anos.

O meu contato com a temática surgiu quando em contexto de estágio, durante a graduação, fui desafiada a cuidar de uma paciente com câncer de mama em condições de doença avançada. Ela era muda, somente se comunicava com meneios de cabeça e tinha uma expressão de intenso sofrimento estampada no rosto. Em busca da melhor abordagem, as professoras da disciplina de saúde mental ofereceram-me os conteúdos sobre a morte e o morrer de Elizabeth Kubler Ross. Os cuidados que prestei não venceram a doença, mas puderam abrandar-lhe o sofrimento quando seu sorriso ficou estampado no rosto ao presenteála com um pente e um pote de creme de cabelo, e fizemos um perfeito rabo de cavalo dois dias antes de sua morte.

A partir de então, cuidar e estudar sobre práticas aplicáveis a pacientes com doença avançada, principalmente com câncer, tornou-se uma satisfação profissional e pessoal.

Após a graduação trabalhei em uma unidade oncológica de um hospital geral, privado na cidade de São Paulo. Neste local, durante os plantões noturnos, pude colocar em prática o que acreditava ser a melhor assistência aos pacientes no final de vida. Aprendi muito, sobre manejo de sintomas, cuidado compartilhado com as famílias e como estar em pé no momento da morte.

Logo após a graduação entrei no programa de mestrado na saúde do adulto da Escola de Enfermagem da Universidade de São Paulo onde trabalhei com a temática da ansiedade, depressão e estratégias de enfrentamento em idosos. Ao terminar no ano 2000, fui para ensino de graduação onde permaneço até os dias atuais.

Até o ano de 2006, meus estudos se concentraram em outras formas de assistir aos pacientes, como as preconizadas pelas Práticas Integrativas e Complementares de Saúde. Estes estudos permitiram conhecer os limites da atuação de enfermagem em tais práticas, como também, ampliaram minha visão do ser humano e suas conexões com o "todo" a sua volta. Nesta época, fiz uma especialização em Antroposofia na Saúde, onde ao compreender 
outras possibilidades de ver o ser humano, entender como ele se coloca no mundo, me instigou novamente a querer buscar outras maneiras de cuidar daqueles em condições de final de vida.

A inquietação na busca por melhores formas de assistir aos pacientes culminou em 2007 com a Especialização em Cuidados Paliativos y Psico-Socio-Oncologia, pela Universidad Del Salvador - Facultad de Medicina, em Buenos Aires.

Desde 2009 ao fazer parte do corpo docente da Universidade de Brasília, a temática morte e cuidados paliativos sempre foi minha tônica preferida no ensino de graduação em enfermagem. E por esta razão, ao me inscrever para o Programa de Pós-Graduação em Enfermagem da Universidade de Brasília, a temática de estudo não poderia deixar de permear os cuidados paliativos.

Incluir os cuidados paliativos nos diversos contextos de atenção à saúde é um enorme desafio de universalização da atenção. O Brasil tem proporções geográficas extensas, com diferenças regionais nas suas estruturas de saúde, e com diferenças culturais com respeito ao trato com a morte. No atual cenário dos cuidados paliativos a formação em diferentes níveis, graduação e pós-graduação, parece ser um dos caminhos para a sustentação desta prática nos contextos de saúde.

Neste estudo busco descrever e analisar as competências requeridas do enfermeiro para o cuidado paliativo na atenção domiciliar sob a ótica das Diretrizes Curriculares Nacionais dos Cursos de Graduação em Enfermagem, com a intenção de aproximar a prática requerida na atuação profissional, dos cenários de ensino de graduação em enfermagem.

Não tenho a pretensão, com esse estudo, de esgotar as análises acerca das competências do enfermeiro para o cuidado paliativo na atenção domiciliar, nem tampouco propor "fórmulas" para o ensino de cuidados paliativos na graduação em enfermagem. Há muito que se estudar e aprofundar no tema proposto, a fim de colaborar com mudanças no cenário das práticas de cuidados paliativos, com vista a alcançar um cuidado de qualidade, integral e resolutivo, aos pacientes em fase final de vida. 


\section{INTRODUÇÃO}

O cenário da saúde no Brasil evidencia a necessidade de formar profissionais capazes de reinventar os cenários de atuação segundo as necessidades da realidade local em que está inserido e de novas propostas do sistema de saúde. A área de Cuidados Paliativos é um novo campo de atuação, que vislumbra novos cenários, bem como, novas formas de relação entre serviços de saúde e comunidade.

Os cuidados paliativos constituem um campo interdisciplinar de cuidados totais, ativos e integrais, dispensados aos pacientes com doenças avançadas e em fase terminal ${ }^{1}$, com foco no direito do paciente de viver com qualidade os dias que lhe restam e de morrer com dignidade. $^{1}$

Cuidados paliativos não se tratam de cuidados de segunda linha ou de menor qualidade, iniciados apenas quando o tratamento médico falhou, ou ainda a abdicação de recursos terapêuticos, mas de ações ativas que partem de uma abordagem especializada, aliada ao uso adequado da tecnologia do cuidado humano, do conhecimento científico e da habilidade da equipe interdisciplinar. ${ }^{2}$

Iniciativas brasileiras em direção ao cuidado paliativo encontram amarras no cenário de saúde, pois o difícil acesso aos serviços de assistência, as falhas nas diretrizes das políticas de saúde, a deficiência de formação de profissionais e a falta de informação ao paciente desafiam e confrontam os profissionais quando na necessidade de controlar a dor, aliviar os sintomas, e promover uma melhor qualidade de vida aos que necessitam de cuidados ao final da vida. ${ }^{3}$

O envelhecimento da população e a heterogeneidade demográfica, social e econômica observada em território brasileiro refletem os diferentes padrões de mortalidade e de morbidade por doenças crônicas não transmissíveis, exigindo respostas que envolvam as especificidades locais e que sejam adequadas às suas realidades. ${ }^{4-5}$

\footnotetext{
1 Neste estudo, as expressões "processo de morrer", "terminalidade", "ao fim da vida" e "fase final da vida" serão utilizadas como sinônimas, traduzindo o percurso compreendido entre o diagnóstico de uma doença sem possibilidade de cura e a morte propriamente dita.
} 
As doenças crônicas não transmissíveis (DCNT) correspondem a 72\% das causas de mortes no Brasil, com destaque para doenças do aparelho circulatório (31,3\%), câncer $(16,3 \%)$, diabetes $(5,2 \%)$, doença respiratória crônica $(5,8 \%)$, atingindo indivíduos de todas as camadas socioeconômicas e, principalmente, aqueles pertencentes a grupos vulneráveis, como os idosos e os de baixa escolaridade e renda. ${ }^{6}$ Este fato denuncia a crescente demanda de pessoas com doenças crônicas degenerativas que necessitam de cuidados ao final da vida. ${ }^{6}$

O Brasil ocupou a $38^{\mathrm{a}}$ posição, entre 40 países analisados, em um ranking de qualidade de morte realizado pela consultoria Economist Intelligence Unit na Grã-Bretanha em 2009. A Grã-Bretanha ficou em primeiro lugar como "líder global em termos de rede hospitalar e provisão de cuidados a pessoas no fim da vida", seguida da Austrália e Nova Zelândia. O documento aponta que mesmo os países que têm sistemas de saúde excelentes sofrem com morte de baixa qualidade, mesmo quando a morte ocorre naturalmente; isso ocorre porque a qualidade e a disponibilidade do tratamento paliativo antes da morte são baixas, e há deficiências na coordenação entre diferentes órgãos e departamentos para políticas sobre como lidar com a morte. ${ }^{7}$

A terminalidade da vida possibilita pensar na morte como resultante de um processo natural. A constituição dos cuidados paliativos surge imbricada a outros saberes que vêm permitindo a efetivação desse campo de conhecimentos, modificando práticas assistenciais e (re)definindo os sujeitos envolvidos nesse contexto: profissionais de saúde, pacientes e familiares. $^{4}$

É conhecida a dificuldade dos profissionais de saúde em lidar com o tema da morte, pois esta os confronta com o ideário profissional da cura, em detrimento do cuidado, onde se ignora o processo de morrer como parte do ciclo de vida do ser humano. Assistir pacientes que estão em processo de morrer é uma postura não ensinada e pouco discutida nos ambientes de formação profissional. A morte nos amedronta assim como ao paciente que sabe das suas condições reais de sobrevida física por conta do acometimento das doenças. ${ }^{2-3}$

Em épocas passadas, na década de 90, do período de graduação recordam-me os pacientes isolados em quartos, em processo de morrer por doenças oncológicas, quando a melhor tecnologia de cuidados para minimizar o odor das feridas ainda não estava implantada. Naquele tempo, ainda era possível "isolar” os pacientes em condições de terminalidade. Aos 
isolados, restava-lhes conviver com as dores de sua finitude sem um "manto" que pudesse abrandar seu sofrimento.

Atualmente, é visível o aumento da demanda por leitos hospitalares e para a assistência à saúde, inviabilizando os "isolamentos" por doenças em condições de terminalidade. Os que estão em processo de morrer nos saltam aos olhos nos diferentes ambientes de saúde na esperança de que alguém os acolha e ofereça alternativas para viver ativo o tempo que lhes cabe, com dignidade. ${ }^{1}$

À medida que os pacientes são incentivados a buscar alternativas de cuidado que aliviem os sintomas e promovam maior conforto, espera-se que os profissionais estejam legalmente amparados para realizar a prática paliativista, tornando-se justificada a necessidade emergente de formação e capacitação profissional que possibilite tal prática. ${ }^{1}$

$\mathrm{Na}$ assistência oferecida pelas equipes multidisciplinares de cuidado paliativo, o enfermeiro é indispensável à constituição das equipes e, como membro, lhe cabe estabelecer uma relação de ajuda com paciente e família, por meio da comunicação efetiva, controle dos sintomas, medidas para alívio do sofrimento e apoio aos familiares frente à morte. ${ }^{2}$

A profissão é constituída por um conjunto de missões, funções e tarefas que o sujeito deve assegurar, não somente em seu emprego, mas em relação com os outros atores, onde as tarefas profissionais requeridas não são necessariamente tarefas precisas, particulares, mas também papéis e funções almejados. Espera-se que o profissional caracterize-se por uma forte trabalhabilidade, o que envolve: dominar bem suas competências e ter suficiente distanciamento em relação a elas, para que possa adaptar-se às mudanças de empregos ou de setores de atividade. ${ }^{8}$

$\mathrm{Na}$ definição de competências considera-se a natureza do processo de trabalho em saúde, a teia de relações que esse profissional tem com outros componentes do processo de trabalho, seu grau de autonomia e independência, suas atividades em face de situações diferenciadas, as condições de trabalho e, sobretudo, as relações entre o legitimado pelas normas reguladoras da profissão e o real exercício do trabalho. ${ }^{9}$

As competências incluem capacidades, atividades e contextos, em uma combinação de conhecimentos, destrezas, experiências e qualidades pessoais usadas apropriadamente em

\footnotetext{
2 Cuidados Paliativos engloba assistência interdisciplinar aos pacientes com doença avançada, buscando aliviar seus sintomas mais estressantes, oferecendo-lhes um "manto" protetor. Paliativo deriva do latim pallium, que significa manto, coberta. ${ }^{3}$
} 
resposta às circunstâncias postas pela prática profissional. $\mathrm{O}$ enunciado de uma competência explicita capacidades às que o trabalhador recorre para a realização de uma determinada atividade específica sob o contexto técnico-profissional e sociocultural. Assim, possibilita-se conhecer a utilidade para os beneficiários de suas ações, onde o usuário de saúde não é um ser abstrato ou distante, de quem são ignoradas as verdadeiras necessidades e os modos de vida. ${ }^{9}$

Na atenção domiciliar os cuidados paliativos são apontados como uma adequada estratégia de saúde pública, pelo alinhamento à filosofia dos cuidados propostos pela Organização Mundial da Saúde, por diminuir os gastos nos orçamentos hospitalares por meio da liberação de leitos hospitalares, e por aproximar-se da concepção de dignidade na morte, onde é dada ao paciente a opção de morrer em casa, perto dos familiares. Aliado a isso, os cuidados paliativos em domicílio permite as famílias, pela proximidade e enquadramento sociocultural, serem mais sensíveis a essas variações culturais e de valores, a prestarem cuidados de qualidade. ${ }^{10}$

A assistência domiciliar permite a expressão da autonomia e do caráter liberal do exercício profissional do enfermeiro, onde as atividades de enfermagem contemplam as funções assistencial, administrativa, educativa e de pesquisa. ${ }^{11}$

Clarificar o campo de competências do enfermeiro em cuidados paliativos na atenção domiciliar é uma necessidade atual, tendo em vista o planejamento dos serviços de enfermagem que contribuam para o alcance da equidade, do acesso, da qualidade e da sustentabilidade dos serviços de saúde. Os cuidados paliativos, ao serem apropriados, passam pelo filtro da ciência e adquirem legitimidade para regular nossas práticas na assistência à saúde, minimizando as ansiedades dos indivíduos e suas famílias frente à terminalidade da vida. $^{1,3}$

O deslocamento da prestação de cuidados aos doentes em ambientes hospitalares para a promoção da saúde, transferindo os cuidados para o domicílio das pessoas, vem exigindo ações operacionalizadas por meio da visita e da internação domiciliar, envolvendo atividades que abrangem a educação, prevenção, recuperação e manutenção da saúde dos indivíduos e seus familiares no contexto de suas residências, assim como, cuidados ao final da vida, o que configura a assistência domiciliar. Frente a esse cenário, questiona-se que competências são necessárias aos enfermeiros para o Cuidado Paliativo na Atenção Domiciliar? 
Neste contexto, espera-se que a formação acadêmica responda às especificidades de atuação do enfermeiro, conferindo-lhe competências que mobilizem conhecimentos e o coloquem em relação e ação. A discussão acerca de mudanças na formação dos profissionais de saúde aproximando-a das necessidades sociais foi reforçada mediante a proposição das Diretrizes Curriculares Nacionais para o Curso de Graduação em Enfermagem que enfatizam a necessidade de formar profissionais competentes, críticos e comprometidos com a saúde da população. Diante disso, questiona-se - as competências requeridas do enfermeiro para o cuidado paliativo na atenção domiciliar estão contempladas nas Diretrizes Curriculares Nacionais para o Curso de Graduação em Enfermagem? Quais competências de cuidados paliativos poderiam ser estimuladas para o ensino na graduação em enfermagem?

A título de contribuição, espera-se que este estudo colabore com a Instituição onde os dados foram coletados, proporcionando recursos para a melhoria da qualidade da assistência de enfermagem prestada às pessoas e com a educação permanente em serviço. Que contribua com subsídios literários e científicos para a profissão de enfermagem em cuidados paliativos, assim como contribuir para diminuir a lacuna de conhecimento referente à temática em estudo, instigando a produção de novas pesquisas na área. Espera-se, também, que o estudo possa valorizar o ensino de cuidados paliativos nos cursos de formação em enfermagem com a ampliação do olhar acadêmico quando no planejamento dos projetos políticos pedagógicos dos cursos de graduação em enfermagem. Esses são os desafios diante do qual este estudo se coloca, concretizando-se nos objetivos que se seguem. 


\section{OBJETIVOS}

\subsection{OBJETIVO GERAL}

- Analisar as competências gerais e específicas requeridas dos enfermeiros para o cuidado paliativo na atenção domiciliar.

\subsection{OBJETIVOS ESPECÍFICOS}

- Identificar competências gerais e específicas para o cuidado paliativo na Atenção Domiciliar.

- Interpretar as competências gerais e específicas para o cuidado paliativo sob a ótica das Diretrizes Curriculares Nacionais do Curso de Graduação em Enfermagem.

- Propor competências para o ensino de cuidados paliativos no curso de graduação em enfermagem. 


\section{REFERENCIAL TEÓRICO}

Na busca por compreender os caminhos a serem percorridos neste estudo, este capítulo propõe-se a contextualizar o leitor sobre os conceitos e a filosofia dos cuidados paliativos, e fornecer elementos para a discussão das competências em cuidados paliativos no âmbito da Atenção Domiciliar, com a identificação de conceitos que possibilitem a compreensão do trabalho em saúde e sua articulação com o ensino de graduação em enfermagem.

\subsection{OS CUIDADOS PALIATIVOS}

O movimento hospice é um movimento social voltado para a assistência de pacientes com doenças avançadas e terminais, nascido na Inglaterra no final da década de 1960, que comporta dois amplos programas: os cuidados paliativos e o cuidado hospice.$^{12}$

O cuidado hospice teve início em séculos passados na Europa, especificamente no século IV, em estabelecimentos que albergavam cristãos em peregrinação, com caráter de acolhimento ao viajante que necessitava recuperar suas forças para seguir adiante sua caminhada. Dessa época, a palavra hospice permaneceu no movimento hospice, na perspectiva do caráter acolhedor e da noção da doença como uma jornada a ser percorrida pelo paciente e por sua família ou cuidador. ${ }^{12-13}$

Os pioneiros hospices britânicos surgiram no terço final do século XIX e diferenciavase de outros estabelecimentos de saúde até então existentes, hospitais ou instituições filantrópicas, pela particularidade de que apenas quem estava morrendo poderia ser para lá encaminhado. Esses locais acolhiam pessoas marginalizadas e pobres, gravemente doentes, que morreriam em breve, vítimas de suas doenças, e que eram recusadas pelos hospitais da época. Os principais motivadores para o surgimento dos hospices foram o desinteresse dos hospitais, que se estabeleciam como centros de cura; a falta de provisão de cuidados médicos, de enfermagem e religiosos nos precários domicílios da população pobre; e a necessidade das instituições religiosas, ante a crescente erosão das crenças religiosas, de conquistar as almas 
supostamente desviantes - prática especialmente significativa no limiar entre a vida e a morte. $^{14}$

Os hospices que surgiram no terço final do século XIX preservaram suas características de assistência até cerca de cem anos depois, quando em 1967 Cicely Saunders funda o St. Christopher's Hospice, surgindo a partir de então o movimento hospice. Os anseios de Saunders corroboravam as necessidades da época, de uma mudança de paradigma no que diz respeito ao cuidado de pessoas em processo de morrer. ${ }^{12,15}$

O pioneirismo de Saunders na atenção aos pacientes terminais desencadeou discussões fora da Inglaterra, incitando profissionais de outros países a capacitar-se no Saint Christopher Hospice, divulgando o movimento hospice e consagrando essa instituição como modelo de assistência, ensino e pesquisa no cuidado de pacientes terminais e de suas famílias. ${ }^{16}$

Alicerçada na visão holística do ser humano, Saunders articulou o local de desenvolvimento específico de cuidado para estes pacientes a uma filosofia de trabalho que objetivava oferecer suporte ao doente e às famílias no período final da vida. Esta autora cunhou o termo "dor total" para expressar a ideia de que o sofrimento tem uma natureza multidimensional, o que torna necessário ir além do atendimento físico, emocional, social e espiritual ao paciente e suas famílias. ${ }^{14,17}$

Em 1969, foi criada a Equipe de Cuidados Domiciliares do Saint Christopher's Hospice para atender o desejo de muitos pacientes morrerem em casa, junto de seus familiares. Essas equipes assessoravam os médicos e enfermeiros dos serviços de saúde local, próximos do domicílio do paciente. ${ }^{12,16}$

Na década de 1970, os cuidados paliativos foram incorporados aos hospitais do Reino Unido, embora na época já existissem os hospices e a possibilidade do paciente morrer no domicílio. Até a década de 70 os hospices acolhiam pacientes adultos, cenário que muda em meados da década de 80 com ambientes voltados especificamente para crianças, a exemplo da Helen House, em Oxford, fundado pela Irmã Francisca Dominica. ${ }^{13}$

Os hospices para crianças atendem principalmente pacientes com enfermidades neurológica, degenerativas, frequentemente associadas a alterações metabólicas congênitas, com característica de internações destinadas a oferecer descanso às famílias, que se repetem a intervalos regulares a cada 2 a 3 meses, durante poucos ou muitos anos. ${ }^{13}$ 
Atualmente, hospices são locais especialmente construídos para receber pacientes que irão morrer em um tempo não muito distante. ${ }^{12}$ Esses locais oferecem a combinação da especificidade de um hospital, a hospitalidade de uma casa e o calor de uma família. ${ }^{14}$

No Brasil, em 1944 na cidade do Rio de Janeiro, no bairro da Penha, foi fundado pelo então diretor do Serviço Nacional de Cancerologia, Mário Kroeff, o chamado Asilo da Penha, que tinha por função assistir pacientes pobres com câncer avançado que não conseguiam vaga nos hospitais gerais nem no Serviço Nacional de Cancerologia. ${ }^{12}$

A partir da década de 1980 foram surgindo outras unidades ou centros de cuidados paliativos no Brasil, a maior parte vinculada ao tratamento de pacientes com câncer e/ou a centros de tratamento de dor crônica, nos estados do Rio Grande do Sul, Santa Catarina, Paraná, São Paulo e Rio de Janeiro. ${ }^{14}$

A prática de cuidados paliativos surge em contraponto à prática médica eminentemente tecnológica e institucionalizada, onde o paciente é excluído da possibilidade de tomada de decisão sobre sua vida e da própria morte, oferecendo uma proposta de assistência não curativa voltada a cuidar e aplacar o sofrimento humano. ${ }^{18}$

Os cuidados paliativos e o cuidado hospice incitam uma nova forma de cuidar da pessoa com doença grave e terminal, deslocando o paradigma da cura para o cuidado. ${ }^{3}$

Os princípios dos cuidados paliativos são aplicáveis a pacientes que padecem de enfermidades progressivas que limitam a vida, tais como SIDA, câncer, portadores de insuficiência cardíaca avançada, quadro demencial de várias etiologias, pacientes pneumopatas crônicos com quadro de hipoxemia grave, sequelados de vários episódios de isquemia cerebral, pacientes com esclerose lateral amiotrófica e com outras doenças neurológicas degenerativas progressivas, etc. ${ }^{18}$

Em 2002, a Organização Mundial da Saúde publicou princípios que norteiam a filosofia dos cuidados, embasados em conhecimentos inerentes a várias disciplinas, com o objetivo de promover o alívio da dor e de outros sintomas desagradáveis, afirmando a vida e considerando a morte um processo normal da vida, com vistas a não adiar nem acelerar a morte, mas integrar os aspectos psicológicos e espirituais no cuidado ao paciente, a fim de oferecer um sistema de suporte que possibilite ao paciente viver tão ativamente quanto possível até o momento da sua morte. Dentre os princípios não se 
esquece da família, do suporte para auxiliá-la durante a doença do paciente e no luto, com abordagem multiprofissional focada em suas necessidades e nas do paciente, buscando-se melhorar a qualidade de vida e influenciar positivamente o curso da doença. ${ }^{17,19}$

Como meta da assistência paliativista, encontra-se a morte com o mínimo sofrimento possível, aliada à busca da expressão de sentimentos e a resolução de pendências financeiras, materiais, emocionais e afetivas, num processo de decisões compartilhadas. ${ }^{20}$

Critérios que indicam o início do cuidado paliativo a pacientes fora de possibilidades terapêuticas de cura foram elaborados por organizações como a Organização Nacional de Hospice dos Estados Unidos, na tentativa de amparar os profissionais de saúde na hora da tomada de decisão. Escalas de desempenho, como a escala de Karnofsky e a escala adaptada de Harlos, a PPS (Palliative Performace Scale), têm auxiliado profissionais de saúde na escolha dos procedimentos para a fase em que se encontra o doente. Percebe-se que o bom senso de um profissional de saúde é o melhor aliado dentro da área de cuidados paliativos, visto que cada doença apresentada pelo paciente tem sua característica de evolução e sua sobrevida individualizada, dificultando o seguimento de parâmetros fechados de classificação. $^{18,21}$

O cuidado paliativo contempla modalidades de atendimento como unidades de ambulatório, internação hospitalar, hospedaria e internação domiciliar. O acompanhamento ambulatorial destina-se a pacientes com doença avançada de forma precoce, bem como a seu familiar/cuidador, em uma fase em que a doença tenha pouco impacto sobre o perfil funcional do doente. Espera-se que nesta fase o controle de sintomas e a abordagem emocional, através do trabalho multiprofissional, possam contribuir para a melhoria da qualidade de vida, com a possibilidade de ter impacto também sobre a sobrevida do doente. ${ }^{22}$

A modalidade de internação domiciliar visa aos portadores de doença avançada, em progressão, com necessidade contínua de monitoramento de sintomas. Uma equipe de referência realiza visitas periódicas e, dependendo da necessidade de assistência, fornece os insumos necessários à continuidade do cuidado, como medicamentos e material médicohospitalar. $^{22}$

A hospedaria é uma modalidade que acolhe pacientes relativamente estáveis, com grau variado de dependência funcional e sintomas bem controlados ou de intensidade leve a moderada. Abrigam pacientes que apesar de terem condições de permanecerem em seus 
domicílios não o fazem por distintos fatores, como, por exemplo, falta de cuidador habilitado. $^{22}$

Embora cada modalidade vise a atender aos pacientes em suas necessidades específicas, advoga-se que a permanência do paciente em domicílio e ao lado da família assegura maior qualidade de vida. ${ }^{23}$

Segundo a Organização Mundial da Saúde (OMS) muitos países carecem de uma abordagem de saúde pública capaz de abranger as demandas dos pacientes/familiares elegíveis para os cuidados paliativos, e no intuito de assegurar a qualidade preconiza que esses serviços sejam implementados de modo integrado aos demais serviços do sistema de saúde, adaptados às realidades culturais e sociais de cada nação e prestados por profissionais com formação profissional na área. ${ }^{24}$

A OMS recomenda como medidas essenciais à implementação dos cuidados paliativos: que o cuidado paliativo seja considerado uma política de governo, de modo a assegurar à integração destes serviços a estrutura de financiamento do sistema nacional de saúde; que se formate uma política educacional, que forneça suporte para a formação dos profissionais de saúde, dos voluntários e dos próprios cidadãos que implementarão estas ações; que haja adoção de uma política de medicamentos que garanta a disponibilidade de medicamentos essenciais para o manejo da dor e de outros sintomas, em especial, os analgésicos opióides ${ }^{24-25}$

Para integrar um tema às políticas nacionais é necessário, além de torná-lo conhecido, demonstrar sua importância para determinado grupo. No caso dos cuidados paliativos, no Brasil, esta tarefa tem sido realizada por membros das sociedades de geriatria, oncologia clínica, pela OMS, Academia Nacional de Cuidados Paliativos (ANCP), Associação Brasileira de Cuidados Paliativos (ABCP), pelo Ministério da Saúde por meio dos Centros de Alta Complexidade em Oncologia (CACON), Rede Nacional de Cuidados Paliativos, com o incentivo a estratégias de controle da dor e expansão dos cuidados paliativos. ${ }^{14,23}$

$\mathrm{Na}$ pretensão de ampliar a percepção da atuação de enfermagem nos cuidados paliativos elaborou-se os estudos que se seguem, sendo que o primeiro visa caracterizar a produção de teses e dissertações em cuidados paliativos, e o segundo busca aprofundar as discussões acerca da atuação do profissional de enfermagem em cuidados paliativos na atenção domiciliar. 


\subsubsection{Perfil bibliométrico das teses e dissertações em enfermagem sobre cuidados paliativos. $^{3}$}

A filosofia dos cuidados paliativos aborda paciente e família como unidade de cuidado. Ao paciente busca-se oferecer suporte no processo de doença que lhe ameaça a vida, com vista à prevenção, manejo e controle de sinais e sintomas, nas dimensões física, social, psicológica e espiritual. ${ }^{26}$ À família uma assistência que lhe permita sentir-se amparada para participar do cuidado ao paciente até o momento da chegada da morte. ${ }^{27}$

A família configura um braço assistencial das equipes de cuidados paliativos e o suporte financeiro, social e emocional de pacientes. É merecedora de cuidados para que não adoeça devido à sobrecarga de trabalho, o estresse de lidar com a possibilidade de morte iminente e ao processo de luto. ${ }^{28}$

A prática dos cuidados paliativos pode ser evidenciada em diferentes contextos de saúde que prestem assistência a pacientes que enfrentam doenças que ameaçam a vida, na experiência de cronicidade ou terminalidade de vida, como unidades hospitalares, ambulatórios, domicílio, casas de apoio, hospices e centro-dia. Abarca pacientes em diferentes etapas da vida, desde o nascimento até a idade adulta avançada. ${ }^{29}$

$\mathrm{Na}$ assistência às crianças observa-se um olhar diferenciado com respeito a sua especificidade biológica, de desenvolvimento, de preferência pelo cuidado domiciliar, com o envolvimento dos pais no cuidado e processos de tomada de decisão, e devida atenção ao momento de transição para uma abordagem exclusivamente paliativa. Essa postura assistencial visa ao aumento de qualidade de vida para a criança e o suporte para a família no enfrentamento do sofrimento imposto pela doença, quando esta ameaça à vida. ${ }^{30}$

A postura do profissional de saúde em cuidados paliativos permeia os princípios éticos da beneficência, não maleficência, autonomia, justiça, veracidade, proporcionalidade terapêutica, referencial do duplo efeito, prevenção, não abandono, expresso tanto pelo trabalho interdisciplinar como pela atuação individual humanizada. ${ }^{31-32}$

\footnotetext{
3 Artigo elaborado e encaminhado à Revista Eletrônica de Enfermagem em 01 de dezembro de 2014. O artigo na íntegra encontra-se no item APÊNDICE A.
} 
A assistência paliativa possui caráter interdisciplinar e requer dos envolvidos a conjugação do saber e do fazer de diferentes profissionais, em um somatório de ações de cuidado que se complementam e transformam-se em ferramentas de cuidado na busca por uma prática totalizadora, sem fragmentações, de forma organizada, diversificada e humana.

A enfermagem de cuidados paliativos caminha na direção da promoção do ser humano na sua integralidade, em consonância com os princípios da ética e da bioética. Integralidade aqui entendida como a capacidade do profissional para responder ao sofrimento humano manifesto no contexto de cada encontro, numa postura de apreensão ampliada das necessidades do sujeito, de forma a abarcar ações de assistência e de prevenção de sofrimento, adequando a oferta de cuidado ao contexto e momento propício para tal. ${ }^{33}$

O cuidar em enfermagem de cuidados paliativos solicita do profissional um olhar atento ao contexto, em um movimento duplo por parte dos profissionais na articulação de ações preventivas e assistenciais. Isso envolve a disponibilidade em apreender de modo ampliado as necessidades de saúde e analisar o significado do sofrimento expresso pelo paciente frente os recursos disponíveis para responder a necessidade apreendida, de modo a eleger o que deve ser realizado de imediato e o que pode ser respondido futuramente em novos encontros de cuidado. $^{28,33}$

O plano terapêutico da enfermagem emerge do diálogo e negociação entre profissionais de saúde, pacientes e familiares. Ações preventivas são ditadas a partir do conhecimento do profissional de enfermagem que necessita de qualificação em cuidados paliativos, seja na abordagem paliativa ou de especialidade, para que ao assistir o paciente seja capaz de identificar as causas de sofrimento manifesto, dar uma resposta imediata à necessidade, e reconhecer a necessidade de ações preventivas, quer seja de encaminhamento a outros profissionais de saúde ou de educação em práticas de manejo e controle de sintomas geradores de sofrimento. ${ }^{34}$

Neste contexto, a enfermagem é referenciada como uma das categorias profissionais que mais publica sobre cuidados paliativos e que apresenta uma proposta de cuidado humanizado, como um ato de respeito e solidariedade, em ações de conforto para além do âmbito fisiopatológico, intermediando a realização dos anseios, desejos e vontades do paciente. ${ }^{35}$

Enfermagem de cuidados paliativos está presente nos diferentes contextos de saúde brasileiro, mas ainda distante da visibilidade que almejamos. Por isso, o estudo que se segue 
busca caracterizar a produção de teses e dissertações em cuidados paliativos, quantificar a produção científica, reconhecer as instituições de enfermagem que reflexionam sobre cuidados paliativos, identificar os sujeitos alvo de discussão em pesquisas sobre a temática, e apontar lacunas na difusão do conhecimento que porventura possam existir. Optou-se por um estudo descritivo, exploratório, de abordagem bibliométrica. A bibliometria é uma técnica que se utiliza de métodos quantitativos na busca por uma avaliação objetiva da produção e disseminação do conhecimento científico. ${ }^{36}$

O uso da bibliometria no Brasil data a década de 1970, na busca por indicadores da produção científica, com vista a planejamentos nacionais de pesquisa científica, análise de temas de pesquisa emergentes, dentre outros. Na atualidade, observa-se subcampos como a bibliometria, a informetria, a cienciometria e a webometria, que se diferenciam quanto ao objeto de estudo, as variáveis, os métodos específicos de análise e aos objetivos. ${ }^{36-38}$

A unidade de análise escolhida foram publicações científicas listadas nos catálogos do Centro de Estudos e Pesquisas em Enfermagem - CEPEn, que apresenta informações sobre pesquisas e pesquisadores em enfermagem, por meio de resumos de teses e dissertações. ${ }^{39}$

Diante da população de pesquisa definida, utilizou-se a técnica de amostragem não probabilística intencional, a fim de assegurar a representatividade dos dados. Ao todo foram analisados 13 catálogos que compilam 6.355 resumos de teses e dissertações defendidas no período de 1985 a 2012. A amostra constituiu-se de 85 resumos que estão disponíveis online pelo Catálogo de Informações sobre Pesquisas e Pesquisadores em Enfermagem, na web site da Associação Brasileira de Enfermagem - ABEn. ${ }^{39}$

O critério de seleção dos resumos foi a figuração das seguintes palavras em seus títulos, resumos ou palavras-chaves: cuidados paliativos, cuidados a doentes terminais, terminalidade, doente terminal, assistência terminal. Diante dos resumos foi feita a leitura analítica na busca das variáveis: instituição de ensino, ano de defesa, nível stricto sensu, orientadores de pesquisa, cenário de estudo, sujeitos de pesquisa e referencial teórico.

A análise quantitativa dos resumos (Figura 1) mostra que 80\% (68) foi produto de dissertações de mestrado seguida de $20 \%$ (17) de teses de doutorado. O total dos resumos (85) corresponde a 1,3\% das publicações nos catálogos, e apresenta crescimento oscilante a partir de 1999, expondo o ano de 2011 como de maior produção com 14 defesas. 


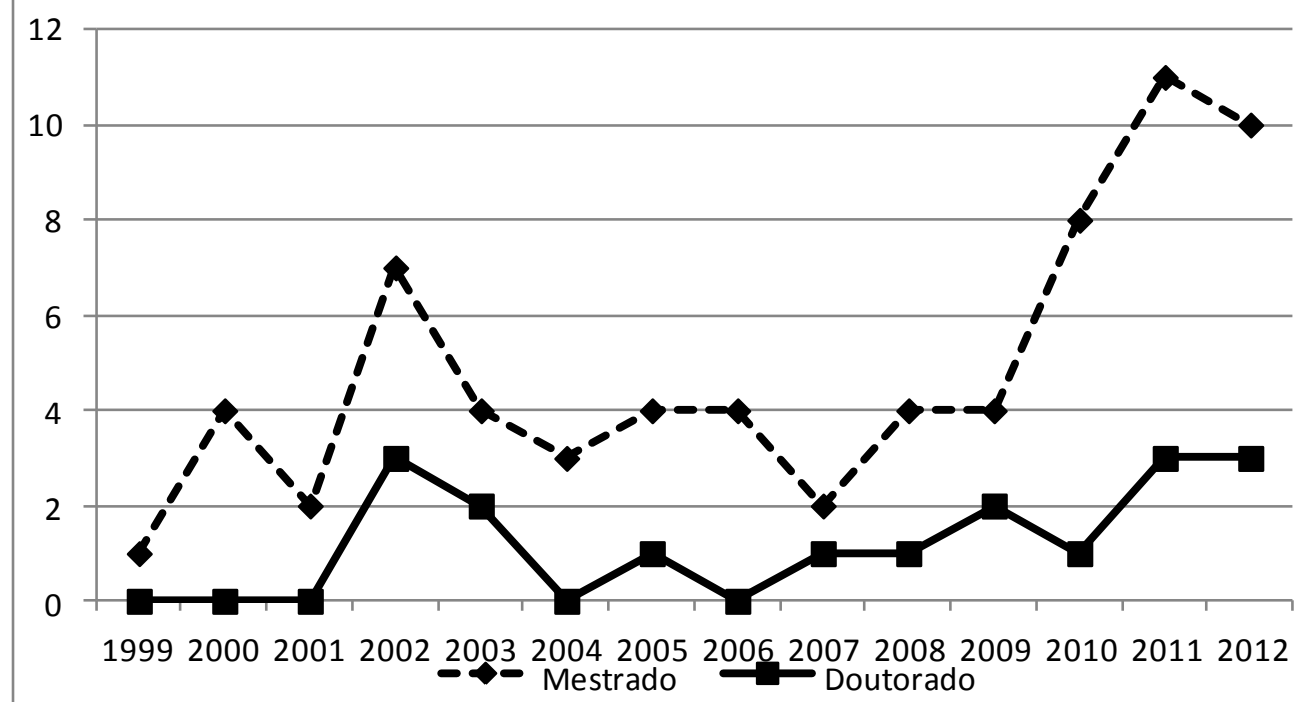

Figura 1 - Distribuição dos resumos de dissertações e teses segundo nível stricto sensu e ano de publicação. Brasil, 2014.

Na Tabela 1 observa-se um quantitativo de 59 orientadores na temática, expondo que 17 realizaram mais de uma orientação e 42 deles uma orientação.

Dentre as 16 instituições com programas de pós-graduação (Tabela 1), a Universidade de São Paulo - Escola de Enfermagem $(21,2 \%)$ e a Universidade de São Paulo - Escola de Enfermagem de Ribeirão Preto (15,3\%) apresentaram mais que um terço da produção (36,5\%). As instituições da região sudeste se destacaram com a maior produção $(64,7 \%)$, seguido da região sul $(22,3 \%)$ e nordeste $(13 \%)$.

Em relação aos cenários onde as pesquisas foram realizadas, a Tabela 2 aponta a incidência do cenário hospitalar em $47 \%$ dos resumos, seguido do domicílio com 14,15\% e ambulatório com 10,5\%. 
Tabela 1 - Distribuição dos resumos de dissertações e teses segundo ranking das instituições e orientadores na área de cuidados paliativos. Brasil, 2014.

\begin{tabular}{|c|c|c|}
\hline Instituição/Orientadores & $\mathbf{n}$ & $\%$ \\
\hline \multicolumn{3}{|l|}{ Instituição/ Programa de Pós Graduação (n=85) } \\
\hline Universidade de São Paulo - Escola de Enfermagem & 18 & 21,2 \\
\hline Universidade de São Paulo - Escola de Enfermagem de Ribeirão Preto & 13 & 15,3 \\
\hline Universidade Federal do Rio de Janeiro. Escola de Enfermagem Anna & 08 & 9,4 \\
\hline \multicolumn{3}{|l|}{ Nery } \\
\hline Universidade Federal de Santa Catarina & 07 & 8,2 \\
\hline $\begin{array}{l}\text { Universidade Federal do Estado do Rio de Janeiro. Escola de } \\
\text { Enfermagem Alfredo Pinto }\end{array}$ & 06 & 7,0 \\
\hline Universidade Federal da Bahia & 05 & 5,9 \\
\hline Universidade Federal de Minas Gerais & 05 & 5,9 \\
\hline Universidade Federal do Rio Grande do Sul & 05 & 5,9 \\
\hline Universidade Estadual de Maringá & 04 & 4,7 \\
\hline Universidade Federal da Paraíba & 04 & 4,7 \\
\hline Universidade do Estado do Rio de Janeiro & 03 & 3,5 \\
\hline Universidade Federal de Santa Maria & 03 & 3,5 \\
\hline Universidade Estadual de Campinas & 01 & 1,2 \\
\hline Universidade Federal do Ceará & 01 & 1,2 \\
\hline Universidade Guarulhos & 01 & 1,2 \\
\hline $\begin{array}{l}\text { Universidade Federal de Pernambuco - Doutorado em saúde da } \\
\text { criança e do adolescente }\end{array}$ & 01 & 1,2 \\
\hline \multicolumn{3}{|l|}{ Orientadores $(n=59)$} \\
\hline Pesquisadores com uma orientação & 42 & 71,2 \\
\hline Pesquisadores com duas orientações & 11 & 18,6 \\
\hline Pesquisadores com três orientações & 03 & 5,1 \\
\hline Pesquisadores com quatro orientações & 03 & 5,1 \\
\hline
\end{tabular}


Tabela 2 - Distribuição dos resumos de dissertações e teses segundo cenário de pesquisa. Brasil, 2014.

\begin{tabular}{llc}
\hline Cenário de pesquisa & N & \% \\
\hline Hospital & 19 & 22,4 \\
Domicílio & 10 & 11,7 \\
Ambulatório & 09 & 10,6 \\
Hospital - unidade de terapia intensiva & 09 & 10,6 \\
Hospital - unidade de pediatria & 06 & 7,0 \\
Base de Dados & 05 & 5,8 \\
Hospital - unidade de terapia intensiva pediátrica & 04 & 4,7 \\
Serviço de internação domiciliar & 02 & 2,4 \\
Atenção Básica & 01 & 1,2 \\
Casa de Apoio & 01 & 1,2 \\
Clínica de Oncologia & 01 & 1,2 \\
Hospital - unidade de terapia intensiva neonatal & 01 & 1,2 \\
Hospital - unidade de transplante de células-tronco hematopoiéticas & 01 & 1,2 \\
Acervo cinematográfico & 01 & 1,2 \\
Cenário de pesquisa não informado & 15 & 17,6 \\
\hline Total & $\mathbf{8 5}$ & $\mathbf{1 0 0}$ \\
\hline
\end{tabular}

Os sujeitos alvo de investigação com maior incidência entre os resumos foram enfermeiros $(24,7 \%)$, a equipe de enfermagem $(11,7 \%)$, o paciente oncológico $(9,3 \%)$ e a família $(9,3 \%)$, conforme Tabela 3. 
Tabela 3 - Distribuição dos resumos de dissertações e teses segundo sujeitos de pesquisa. Brasil, 2014.

\begin{tabular}{lll}
\hline Sujeitos de pesquisa & $\mathbf{N}$ & $\mathbf{\%}$ \\
\hline Enfermeiros & 21 & 24,7 \\
Equipe de enfermagem & 10 & 11,7 \\
Paciente oncológico & 08 & 9,3 \\
Família & 08 & 9,3 \\
Profissionais de saúde & 07 & 8,2 \\
Cuidadores & 06 & 7,0 \\
Publicações científicas & 05 & 5,8 \\
Enfermeiros/Médicos & 02 & 2,4 \\
Equipe da Estratégia da Saúde da Família & 02 & 2,4 \\
Paciente em tratamento quimioterápico & 02 & 2,4 \\
Paciente oncológico/família & 02 & 2,4 \\
Paciente portador HIV/AIDS & 02 & 2,4 \\
Alunos de ensino médio de enfermagem & 01 & 1,2 \\
Crianças/pais & 01 & 1,2 \\
Cuidadores/estudantes/profissionais de saúde & 01 & 1,2 \\
Equipe de saúde & 01 & 1,2 \\
Filmes & 01 & 1,2 \\
Mães de crianças e adolescentes com doença oncológica & 01 & 1,2 \\
Pacientes & 01 & 1,2 \\
Pacientes/familiares & 01 & 1,2 \\
Pacientes/familiares/enfermeiros & 01 & 1,2 \\
Sujeito não informado & 01 & 1,2 \\
\hline Total & $\mathbf{8 5}$ \\
\hline & & $\mathbf{1 0 0}$ \\
\hline & & \\
\hline
\end{tabular}

No que se refere à abordagem metodológica $82,4 \%$ das publicações utilizaram abordagem qualitativa, $14,1 \%$ da quantitativa e $3,5 \%$ da abordagem quanti-qualitativa. Os resumos analisados apontam a opção dos pesquisadores pelo referencial teórico da Fenomenologia de Martin Heidegger, pelo Interacionismo Simbólico e pela Filosofia dos Cuidados Paliativos para reflexão dos resultados de pesquisas (Tabela 4). Se somarmos a 
incidência do referencial da fenomenologia (17,3\%) verificaremos que este foi o mais utilizado pelos pesquisadores.

Tabela 4 - Distribuição dos resumos de dissertações e teses segundo referencial teórico. Brasil, 2014.

\begin{tabular}{|c|c|c|}
\hline Referenciais Teóricos & $\mathbf{n}^{*}$ & $\%$ \\
\hline Fenomenologia - Martin Heidegger & 8 & 9,20 \\
\hline Interacionismo Simbólico & 8 & 9,20 \\
\hline Filosofia dos Cuidados Paliativos & 5 & 5,80 \\
\hline Representações Sociais & 4 & 4,60 \\
\hline Fenomenologia & 3 & 3,50 \\
\hline Fenomenologia - Merleau Ponty & 2 & 2,30 \\
\hline Fenomenologia - Alfred Schutz & 2 & 2,30 \\
\hline Teoria de Michel Foucault & 2 & 2,30 \\
\hline Análise Existencial de Viktor Emil Frankl & 1 & 1,14 \\
\hline Antropologia Interpretativa & 1 & 1,14 \\
\hline Antropologia Médica & 1 & 1,14 \\
\hline Bioética & 1 & 1,14 \\
\hline Ciência da Complexidade & 1 & 1,14 \\
\hline Comunicação Interpessoal em saúde, & 1 & 1,14 \\
\hline Conceito de vulnerabilidade & 1 & 1,14 \\
\hline Educação Libertadora & 1 & 1,14 \\
\hline Educação Problematizadora & 1 & 1,14 \\
\hline Método Explicativo de Vigotski & 1 & 1,14 \\
\hline Perspectiva Evolucionária de Rodgers & 1 & 1,14 \\
\hline Prática Baseada em Evidência & 1 & 1,14 \\
\hline Referencial Teórico Cuidar/Cuidado & 1 & 1,14 \\
\hline Referencial de Elisabeth Kubler-Ross & 1 & 1,14 \\
\hline Sistematização da Assistência de Enfermagem & 1 & 1,14 \\
\hline Sociopoética & 1 & 1,14 \\
\hline Teoria de Carl Ransom Rogers & 1 & 1,14 \\
\hline Teoria de Madeleine Leininger & 1 & 1,14 \\
\hline Teoria do Cuidado Transpessoal de Jean Watson & 1 & 1,14 \\
\hline Teoria do Déficit de Autocuidado de Orem & 1 & 1,14 \\
\hline Teoria Humanística de Enfermagem & 1 & 1,14 \\
\hline Não informado & 32 & 36,86 \\
\hline Total & 87 & 100 \\
\hline
\end{tabular}

* Dois estudos utilizaram mais de um referencial teórico.

Os resumos dispostos nos catálogos apresentaram palavras chaves somente após o volume 30-2011, publicado em outubro de 2012, inviabilizando a análise da articulação das 
diferentes subáreas da enfermagem com a temática cuidados paliativos.

A linha cronológica das publicações expõe um crescimento oscilante, mas contínuo desde 1999, o que pode ter sido impulsionado pela publicação do conceito e dos princípios dos cuidados paliativos pela Organização Mundial da Saúde no ano de 2002, instigando pesquisadores à reflexão sobre a temática. ${ }^{29}$

Os resultados evidenciam um quantitativo de orientadores que somado ao número de orientados que elaboraram as dissertações e teses, apontam a existência de um contingente expressivo de pesquisadores na temática. Salienta-se que a enfermagem de cuidados paliativos haverá de amadurecer e ser legitimada à medida que o retorno das pesquisas que se debruçam sobre ela evidenciarem os ajustes necessários à realização da sua prática. A busca pela identidade da enfermagem brasileira no que tange aos cuidados paliativos aponta a necessidade de expansão das reflexões sobre a temática aos espaços assistenciais para além dos grandes centros de pesquisa, num esforço compartilhado de pesquisadores na construção do conhecimento.

Os programas de pós-graduação da região sudeste se destacaram com as maiores porcentagens de teses e dissertações na temática cuidados paliativos. A literatura aponta a existência de 63 programas de pós-graduação em enfermagem stricto sensu, que concentram 89 cursos distribuídos na região sudeste (44), nordeste (18), região sul (17), centro-oeste (8) e norte (2), o que provavelmente colaborou com os achados deste estudo, pois é de se esperar uma maior concentração de publicações nas regiões com maior número de programas e cursos. ${ }^{40}$ Observa-se que os cuidados paliativos se inserem, mesmo que de forma tímida, como área de conhecimento e especialidade em enfermagem, oportunizado pela divulgação de pesquisas à comunidade científica, permitindo o aprofundamento de conhecimentos específicos e o diálogo com os pares. A ausência de teses e dissertações em regiões como o centro-oeste e norte suscita a existência de lacunas na compreensão dos saberes e fazeres de enfermagem de cuidados paliativos em território brasileiro.

Em relação aos cenários onde as pesquisas foram realizadas, observa-se a incidência do cenário hospitalar, domicílio e ambulatório expondo que os pacientes que enfrentam doenças que ameaçam a vida são usuários de diferentes espaços de saúde, requerendo dos profissionais de enfermagem preparo, ou pelo menos sensibilização, para a assistência paliativa. Frente a esta realidade, sugere-se a integralização dos conteúdos de cuidados 
paliativos nos currículos de formação em enfermagem como um caminho possível de disseminação do conhecimento. ${ }^{34}$

A atuação do enfermeiro na assistência ambulatorial de cuidados paliativos apoia-se na autonomia do paciente, de modo que ele saiba lidar com as limitações resultantes da enfermidade, além de abordar efetivamente os sintomas de caráter físico e emocional que surgem com o avançar da doença. Em ambiente domiciliar, a assistência consiste em oferecer ao paciente e sua família o apoio necessário em todo o processo de doença e morte em sua própria casa. Valoriza-se o cuidado individualizado, de acordo com as situações encontradas, com avaliação constante do plano de cuidados conforme a evolução da doença. Quando a assistência acontece em ambiente hospitalar, destacam-se medidas que minimizam o sofrimento neste ambiente, como a adoção de quartos individuais, a presença da família $24 \mathrm{hs}$, a flexibilização de visitas, a fim de minimizar os efeitos negativos da hospitalização até que o quadro clínico se estabilize e o paciente e família possam retornar para casa. ${ }^{27-28}$

Os resultados evidenciaram o paciente oncológico entre os sujeitos de alvo de estudo com maior incidência, corroborando com a literatura quando refere que desde a década de 1980 os cuidados paliativos a pacientes com câncer tem sido progressivamente reconhecido, mas que existe uma demanda insatisfeita para cuidados paliativos em problemas crônicos de saúde como HIV/SIDA, insuficiência cardíaca congestiva, doença cerebrovascular, doenças neurodegenerativas, doenças respiratórias crônicas e a tuberculose resistente a drogas. ${ }^{29}$

O interesse pelos cuidadores se fez presente como objeto de estudo nos resumos e merece valorização pelo papel que exercem junto à assistência de enfermagem em domicílio. A existência do cuidador na assistência ao paciente em cuidados paliativos é essencial para que se garanta uma assistência de qualidade, pois os cuidadores são os responsáveis por colocar em prática o plano assistencial elaborado pela equipe de saúde. Acrescenta-se que os cuidadores necessitam ser educados para o cuidado e assistidos nas suas necessidades de compreensão e adaptação às mudanças físicas, sociais, emocionais e de sobrecarga, acarretados pela responsabilidade de cuidar em domicílio. ${ }^{41}$

No que se refere à abordagem metodológica a maior parte dos resumos explicitou ou o uso da abordagem qualitativa, seguida da quantitativa e da abordagem quanti-qualitativa. A abordagem metodológica, assim como, o referencial teórico são elementos essenciais na elaboração dos desenhos de pesquisa, pois delimitam e conduzem a análise reflexiva dos 
fenômenos. A abordagem quantitativa possibilita identificar lacunas na literatura e fenômenos pouco entendidos que requerem estudo qualitativo. Por sua vez, a abordagem qualitativa auxilia no desenvolvimento e desenho de teorias, na implementação e refinamento de estudos quantitativos. $^{42}$

A análise dos resumos evidenciou que em alguns estudos a opção pela abordagem quantitativa ou qualitativa foi insuficiente para responder a realidade observada sendo utilizada, nestes casos, como complementares. A interação entre as duas abordagens favorece o acúmulo de uma vasta ordem de resultados e a prática baseada em evidência. ${ }^{42-43}$ Cabe ressaltar que independente da abordagem utilizada os resultados de pesquisa configuram uma das possíveis verdades acerca do fenômeno estudado sob a regência do pesquisador.

O referencial da Fenomenologia propõe-se a descrever o fenômeno e compreendê-lo a partir do significado da experiência vivida dos seres humanos na sua interação com o mundo. Neste estudo o uso da fenomenologia pelos pesquisadores aponta uma inquietude de quem centra o foco do seu cuidar no ser humano, com a preocupação em privilegiar a escuta e o olhar do profissional, com vista a responder questões que envolvem a complexidade do ser e a compreensão do seu vivido. $^{44}$

O quantitativo de resumos que não explicitaram o referencial teórico e o cenário de estudo expõe a necessidade dos pesquisadores atentarem para a elaboração dos resumos de suas pesquisas, pois estes são sínteses que instigarão o interesse de novos pesquisadores, para novos estudos, além de configurem como fontes de informação que permitem a disseminação do conhecimento na área de enfermagem.

Os resultados obtidos indicam o cuidado paliativo como área de conhecimento e de especialidade em enfermagem pela possibilidade interativa e associativa de contribuição social, em diferentes espaços e campos de atuação, onde é possível ampliar e dar a conhecer o seu campo de intervenção. ${ }^{45} \mathrm{~A}$ área de especialidade em cuidados paliativos é reconhecida por conselhos profissionais, como o de medicina e terapia ocupacional, sendo que na enfermagem não está oficialmente instituída. ${ }^{46}$

Acreditamos que ao reconhecer os limites do cuidado paliativo em enfermagem seja possível potencializar e articular conhecimentos, no sentido de superar as lacunas existentes. O cuidado paliativo compreende uma assistência integral ao paciente e família na busca pela melhor qualidade de vida possível frente a doenças que ameaçam a vida, em um agir 
permeado de interações múltiplas e complexas advindas da dimensão física, mental, social e espiritual do sofrimento humano.

O quantitativo de teses e dissertações de enfermagem sobre cuidados paliativos mostrase incipiente frente à totalidade das produções explicitadas no Catálogo de Informações sobre Pesquisas e Pesquisadores em Enfermagem, mas estimulador, quando observados pela perspectiva de que a enfermagem ao identificar e buscar compreender as relações existentes em seus espaços cotidianos de prática, participa do exercício da reflexão e da conscientização dos profissionais em busca de uma nova percepção do cuidar em cuidados paliativos.

Os resumos apontam que somos um número expressivo de pesquisadores capazes de alavancar a produção de conhecimento na área de enfermagem de cuidados paliativos. Expõe a responsabilidade dos pesquisadores em enfermagem com esse novo olhar, tanto em direção à produção de conhecimentos, quanto para a compreensão de novos saberes e fazeres visto a abrangência dos cenários e sujeitos de pesquisa, assim como dos referenciais teóricos para discussão dos resultados.

Por fim, muito se tem a caminhar quando se trata de cuidados paliativos, e os profissionais necessitam conhecer e explorar melhor essa temática que possibilita pensar novas formas de cuidar, educar, acolher, amparar, advogar, aliviar desconfortos e controlar sintomas, em atividades cotidianas de enfermagem. ${ }^{26}$

\subsubsection{Cuidados Paliativos de Enfermagem na Atenção Domiciliar ${ }^{4}$}

A enfermagem paliativa caracteriza-se como o cuidado para pessoas em suas semanas ou meses finais de vida, com o objetivo de evitar e aliviar o sofrimento provendo a melhor qualidade de vida. Trata-se de uma área da enfermagem que lida com o cuidado de pacientes que enfrentam doenças que ameaçam a vida em diferentes cenários de assistência, como o ambulatorial, domiciliar e hospitalar. ${ }^{47}$ Acrescentam-se os espaços emergentes de atuação da enfermagem, como as unidades de pronto atendimento, hospedarias e centros-dia. ${ }^{48}$

$\mathrm{Na}$ atenção domiciliar, os cuidados paliativos configuram um cenário desafiador diante da demanda estimada da população que virá a necessitar desse tipo de assistência. No

\footnotetext{
4 Artigo aceito e publicado na Revista REUOL em 01/02/2015. O artigo na íntegra encontra-se no item APÊNDICE B.
} 
mundo todo, estima-se que a cada ano 20 milhões de pessoas necessitem de cuidados paliativos no fim da vida, sendo a maioria adulta com mais de 60 anos (69\%) somados a 6\% de $_{\text {crianças. }}{ }^{29}$

Iniciativas governamentais contribuem no avançar da rede de cuidados no fim da vida, mas ainda estamos distantes do que é preconizado mundialmente para atendimento mínimo nesse campo. O Brasil oferece prestação de cuidados paliativos de forma isolada, caracterizada por um crescimento irregular desse tipo de assistência, com pequeno número de serviços especializados de cuidados paliativos e acesso limitado considerando o tamanho da população. $^{29}$

Em território nacional, os cuidados paliativos estão inseridos em portarias de saúde, mas ainda distante da agenda política para implantação de uma política nacional de cuidados paliativos. A Portaria GM/MS n. 2.439/2005, que trata da Política Nacional de Atenção Oncológica, abarca a implementação dos Centros de Alta Complexidade em Oncologia (Cacon) e preconiza a organização de equipes de cuidados paliativos com atenção integral a pacientes no âmbito hospitalar, ambulatorial e domiciliar. Corrobora a prática dos cuidados paliativos a Portaria n. 3.150, de 12 de dezembro de 2006, que instituiu a câmara técnica em controle da dor e cuidados paliativos, e a Portaria n. 963, de 27 de maio de 2013, que redefine a atenção domiciliar no âmbito do Sistema Único de Saúde (SUS). ${ }^{49-51}$

O cuidado paliativo integra a rede de atenção à saúde por meio do serviço de atenção domiciliar, que se responsabiliza pelo gerenciamento e operacionalização das Equipes Multiprofissionais de Atenção Domiciliar (EMAD) e Equipes Multiprofissionais de Apoio (EMAP), que incluem na modalidade de atendimento tipo 2 os usuários com necessidade de cuidados paliativos. ${ }^{51}$

O suporte domiciliar em cuidados paliativos apresenta-se como possibilidade de morte em domicílio, em ambiente conhecido, onde é possível que o paciente mantenha suas atividades laborais, seus hábitos e hobbies de forma autônoma; onde os familiares possam cuidar de seus entes queridos, o que de, certa forma, colabora na prevenção do luto patológico; assim como representa a possibilidade da redução de internações hospitalares longas e de alto custo, muitas vezes permeadas por tratamentos desnecessários ou futilidade terapêutica. $^{52}$ 
As equipes de atenção primária podem oferecer assistência em cuidados paliativos, onde os casos mais complexos seriam encaminhados a equipes especializadas de cuidados paliativos domiciliares. ${ }^{53} \mathrm{~A}$ organização de serviços especializados ainda está atrelada à especialidade oncológica, pois esta encontra respaldo na Política Nacional de Atenção Oncológica, o que permite sua articulação nos diferentes âmbitos de atenção. O Brasil carece de diretrizes para organização e provisão de serviços de cuidados paliativos que não sejam os da especialidade oncológica, para que se possa apoiar e responder às demandas da atenção básica e da atenção especializada de média e alta complexidade.

A incidência de pacientes para assistência paliativa cresce de forma rápida, diante da morbidade populacional e a visibilidade desse tipo de assistência. Nesse cenário, a sensibilização e qualificação de profissionais de saúde em diferentes níveis poderia ser uma estratégia propulsora de mudanças. Preconiza-se que o cuidado paliativo possa ser oferecido em níveis que englobam a abordagem paliativa, intervenções especializadas e cuidados paliativos ministrados por especialistas. ${ }^{29}$

Pela abordagem paliativa, o cuidado pode ser oferecido por todos os profissionais de saúde envolvidos no cuidar de pessoas em condição de enfermidade que ameaça a vida. ${ }^{53}$ Para tanto, faz-se necessário capacitação que envolva a abordagem sintomática básica, compreensão das experiências de pacientes em situação de terminalidade e de suas famílias, o uso da comunicação de forma a oportunizar interação e acolhimento e perspectivas de encaminhamento quando as necessidades dos pacientes fujam ao âmbito de conhecimento individual do profissional. ${ }^{54}$

Verifica-se que a atenção domiciliar compõe um braço assistencial necessário à abordagem dos cuidados paliativos na atenção básica, de forma a permitir o acesso a uma assistência integral ao ser humano que experiência sua última etapa da vida, onde morte é um processo natural que não deve ser retardado ou acelerado, mas vivido com a melhor qualidade de vida possível até o momento de sua chegada.

Nesse contexto, o estudo que se segue justifica-se pela necessidade de aprofundar as discussões acerca da atuação do profissional de enfermagem em cuidados paliativos na atenção domiciliar, com base na avaliação objetiva da literatura, com vistas à disseminação do conhecimento especializado. Com esse intuito, buscou-se identificar a produção científica em enfermagem sobre cuidados paliativos na atenção domiciliar. Para tanto, optou-se por um 
estudo descritivo exploratório, com abordagem bibliométrica, realizado por meio da análise dos resumos de dissertações e teses publicadas nos catálogos do Centro de Estudos e Pesquisas em Enfermagem (CEPEn), que apresenta informações sobre pesquisas e pesquisadores em enfermagem. ${ }^{39}$

Para a coleta de dados utilizou-se dos resumos disponibilizados on-line pelo Catálogo de Informações sobre Pesquisas e Pesquisadores em Enfermagem, no website da Associação Brasileira de Enfermagem (ABEn). A temática principal de busca foi cuidados paliativos na atenção domiciliar, onde os assuntos utilizados para a busca de resumos foram: cuidados paliativos, cuidados a pacientes terminais, terminalidade, paciente terminal, assistência terminal. Além disso, recorreu-se aos seguintes assuntos: cuidados domiciliares de saúde, assistência domiciliar, pacientes domiciliares, serviço de assistência domiciliar. Ao todo, foram analisados 13 catálogos, que abarcam 6.355 resumos no período de 1985 a 2012. Do total de resumos, 13 abordam a temática cuidados paliativos na atenção domiciliar, onde 11 puderam ser localizados para análise do estudo na íntegra, sendo que para 2 foram utilizadas as informações contidas no resumo descrito no catálogo.

Diante dos dados, foi realizada a leitura analítica dos resumos em busca das variáveis: instituição de ensino, ano de defesa, nível stricto sensu, subáreas temáticas e sujeitos de pesquisa. Após a análise, os dados foram organizados e descritos em tabelas segundo as variáveis estabelecidas.

Os resultados (Quadro 1) demonstram que os cuidados paliativos na atenção domiciliar foi foco de estudo de dissertações e teses defendidas em 10 instituições brasileiras, localizadas nas regiões Sudeste (7), Sul (4) e Nordeste (2) do Brasil, em programas de pósgraduação em enfermagem, com predominância em nível de mestrado (11).

A cronologia do ano de publicação aponta um crescimento descontínuo entre 2000 e 2008, com estabilidade a partir de 2009. A literatura demonstra que o cuidado paliativo na atenção domiciliar ganhou visibilidade com a Portaria GM n. 2.527, de 27/10/2011, revogada pela Portaria GM n. 963 de 27/05/2013, que redefine a atenção domiciliar no âmbito do SUS, no art. 23, que apresenta como critérios de inclusão para cuidados na modalidade AD2 (destina-se aos usuários que possuam problemas de saúde e dificuldade ou impossibilidade física de locomoção até uma unidade de saúde e que necessitem de maior frequência de cuidado, recursos de saúde e acompanhamento contínuos) a necessidade de cuidados 
paliativos. $^{51}$ Esse fato retira os cuidados paliativos da invisibilidade, permitindo que os profissionais se posicionem em relação ao reconhecimento da nova temática, favorecendo publicações na área.

As dissertações e teses em sua totalidade utilizaram a abordagem qualitativa e explicitaram como sujeitos de pesquisa: pacientes oncológicos em cuidado no domicílio, cuidadores e familiares de pacientes oncológicos em cuidado no domicílio, enfermeiros de serviço de internação domiciliar de um centro de suporte terapêutico oncológico, profissionais de uma equipe de cuidados paliativos oncológicos domiciliares, familiares de pacientes atendidos por um programa de assistência e internamento domiciliar, cuidador familiar de pacientes oncológicos vinculados ao serviço de internação domiciliar e profissional da Estratégia Saúde da Família (ESF). A literatura indica que desde a década de 1980 os cuidados paliativos a pacientes com câncer tem sido progressivamente reconhecido, mas existe uma demanda insatisfeita para cuidados paliativos em problemas crônicos de saúde, como HIV/AIDS, insuficiência cardíaca congestiva, doença cerebrovascular, doenças neurodegenerativas, doenças respiratórias crônicas e a tuberculose resistente a drogas. ${ }^{29}$

Quadro 1 - Distribuição dos resumos das dissertações e teses segundo instituição, ano de defesa e nível stricto sensu. Brasil, 2014.

\begin{tabular}{|c|c|c|c|c|c|c|c|c|}
\hline \multirow[t]{2}{*}{ Instituição } & \multicolumn{7}{|c|}{ Ano de Defesa } & \multirow{2}{*}{$\begin{array}{c}\text { Nível } \\
\text { stricto } \\
\text { sensu }\end{array}$} \\
\hline & $\begin{array}{l}1999 / \\
2000\end{array}$ & $\begin{array}{l}2001 / \\
2002\end{array}$ & $\begin{array}{c}2003 / \\
2004\end{array}$ & $\begin{array}{c}2005 / \\
2006\end{array}$ & $\begin{array}{c}2007 / \\
2008\end{array}$ & $\begin{array}{c}2009 / \\
2010\end{array}$ & $\begin{array}{c}2011 / \\
2012\end{array}$ & \\
\hline \multirow{4}{*}{$\begin{array}{l}\text { Universidade de São Paulo - Escola de } \\
\text { Enfermagem } \\
\text { Universidade de São Paulo - Escola de } \\
\text { Enfermagem de Ribeirão Preto }\end{array}$} & - & - & $\overline{-}$ & - & - & - & - & $\bar{M}$ \\
\hline & - & - & - & - & - & - & 1 & $\mathrm{D}$ \\
\hline & - & - & - & - & - & - & 1 & $\mathrm{M}$ \\
\hline & - & - & - & - & - & 1 & - & $\mathrm{D}$ \\
\hline \multirow{2}{*}{ Universidade Estadual de Maringá } & - & - & - & & - & 1 & - & $\mathrm{M}$ \\
\hline & - & - & - & - & - & - & - & $\mathrm{D}$ \\
\hline \multirow[t]{2}{*}{ Universidade Federal da Bahia } & 1 & - & - & - & - & - & - & $\mathrm{M}$ \\
\hline & - & - & - & - & - & - & - & $\mathrm{D}$ \\
\hline \multirow[t]{2}{*}{ Universidade Federal da Paraíba } & - & - & - & - & - & & 1 & $\mathrm{M}$ \\
\hline & - & - & - & - & - & - & - & $\mathrm{D}$ \\
\hline \multirow[t]{2}{*}{ Universidade Federal de Minas Gerais } & - & - & 1 & - & - & - & - & $\mathrm{M}$ \\
\hline & - & - & - & - & - & - & - & $\mathrm{D}$ \\
\hline \multirow[t]{2}{*}{ Universidade Federal de Santa Catarina } & 1 & 1 & - & - & - & - & - & $\mathrm{M}$ \\
\hline & - & - & - & - & - & - & - & $\mathrm{D}$ \\
\hline \multirow[t]{2}{*}{ Universidade Federal de Santa Maria } & - & - & - & - & & 1 & - & M \\
\hline & - & - & - & - & - & - & - & $\mathrm{D}$ \\
\hline \multirow{4}{*}{$\begin{array}{l}\text { Universidade Federal do Estado do Rio } \\
\text { de Janeiro - Escola de Enfermagem } \\
\text { Alfredo Pinto } \\
\text { Universidade Federal do Rio de Janeiro } \\
\text { - Escola de Enfermagem Anna Nery }\end{array}$} & - & - & - & 1 & - & - & - & M \\
\hline & - & - & - & - & - & - & - & $\mathrm{D}$ \\
\hline & - & 1 & - & - & 1 & - & - & $\mathrm{M}$ \\
\hline & - & - & - & - & - & - & - & $\mathrm{D}$ \\
\hline
\end{tabular}


Nota-se nas teses e dissertações (Tabela 5) uma variedade de subtemas, sendo os prevalentes: cuidadores, neoplasias, família, morte, acolhimento, atenção primária à saúde, cuidados de enfermagem, Estratégia Saúde da Família. Os subtemas permeiam a recomendação brasileira para o trabalho das equipes de atenção domiciliar nos cuidados paliativos, onde se preconiza: a) atuação com competência cultural, com ênfase no respeito as característica observadas no espaço íntimo do evento morte no domicilio; b) comunicação eficaz que favoreça a interação e expressão de sentimentos; c) ações de controle de sintomas, com ênfase na dor; d) apoio emocional a pacientes e familiares no enfrentamento da morte; e) instrumentalização de cuidadores e familiares para o cuidado paliativo em domicílio; f) oferecimento de suporte e segurança, com vistas à promoção da qualidade de vida e dignidade entre pacientes e familiares. ${ }^{52}$

Tabela 5 - Ranking das subáreas temáticas segundo frequência de aparecimento nos resumos de dissertações e teses. Brasil, 2014.

\begin{tabular}{lcc}
\hline Subáreas temáticas & $\mathbf{n = 2 7}$ & \% \\
\hline Cuidadores & 6 & 22,2 \\
Neoplasias & 5 & 18,6 \\
Família & 4 & 14,8 \\
Morte & 3 & 11,1 \\
Acolhimento & 2 & 7,4 \\
Atenção primária à saúde & 2 & 7,4 \\
Cuidados de enfermagem & 2 & 7,4 \\
Estratégia Saúde da Família & 2 & 7,4 \\
Outras temáticas * & 1 & 3,7 \\
\hline
\end{tabular}

* Antropologia cultural, Atitude diante da morte, Consternação, Enfermagem oncológica, Equipe de assistência ao paciente, Gerenciamento clínico, Idoso, Internação domiciliar, Método clínico-qualitativo, Percepção, Psicologia social, Relações interpessoais, Serviços preventivos de saúde, Úlcera de pressão, Valores sociais.

Os profissionais da ESF abordados nos estudos referem-se aos cuidados paliativos como modalidade de cuidados de conforto, que abrange as dimensões biológica, psicológica, social e espiritual do ser humano, oferecido de forma interdisciplinar mediante assistência humanizada, com a finalidade de promover a qualidade de vida, minimização do sofrimento e boa morte. A presença do familiar é compreendida como fonte de apoio e estímulo para o doente no enfrentamento do processo da enfermidade e da terminalidade. ${ }^{56}$

O cuidar do idoso em situação final de vida requer dos profissionais da Estratégia da Saúde da Família a superação de desafios pessoais para o acolhimento honesto, com 
comunicação aberta, disponibilidade e manutenção do vínculo conquistado. O processo de cuidar ocorre por meio da identificação da problemática da situação, planejamento e manejo de novas estratégias para o cuidado e avaliação da trajetória de cuidado. ${ }^{57}$

A liberdade e autonomia nos horários de refeições, higiene, sono, lazer e recebimento de visitas foram apontados por cuidadores de pacientes oncológicos como aspectos benéficos da internação domiciliar, entretanto, o cuidado no domicílio favorece a sobrecarga, privação e maior responsabilização, decorrentes, por vezes, de situações de falta de apoio social. ${ }^{58}$

O cuidador familiar percebe a internação domiciliar, direcionada ao paciente oncológico em fase avançada, como possibilidade de acesso fácil a recursos materiais e humanos necessários ao cuidado realizado em domicílio, pois se acredita que ser referenciado por uma equipe de saúde favorece em caso de necessidade de atendimento nas unidades de urgência de serviços hospitalares. ${ }^{58}$

Para a equipe de um serviço de internação domiciliar oferecido a pacientes oncológicos, o despreparo para a nova prática, o cenário domiciliar, o convívio com pacientes de câncer em fase avançada, a conspiração do silêncio, e as emoções advindas do compartilhar o sofrimento dos pacientes e dos seus familiares ao lidar com a morte são desafios a ser superados. Referem concretizar ações de interdisciplinaridade por meio de reuniões de equipe, na busca por um consenso sobre os cuidados ao paciente e à família. ${ }^{59}$

O lidar com a morte é fato irrevogável dos contextos de atenção domiciliar a pacientes em condição de doenças que ameaçam a vida e o despreparo de profissionais para lidar com situações de morte e morrer tornaram-se evidentes nos estudos analisados. ${ }^{57,59-61}$ Reportam-se as brincadeiras, demonstrações de afetividade e encontros sociais regularmente planejados, como forma de apoio mútuo na equipe, assim como a espiritualidade e o convívio familiar é utilizado como recursos no enfrentamento individual das situações de morte e morrer. ${ }^{59}$

A vivência da terminalidade por parte de familiares de pacientes com câncer revela que estar ao lado de pacientes significa romper com a ilusão de eternidade, devido à coexistência da morte, e eles a relatam como uma experiência dolorosa, de abnegação da própria vida, com ausência de acolhimento em suas dores, associado à rede de suporte familiar deficiente. ${ }^{62}$ 
O sofrimento de familiares pela morte de um ente querido cuidado em domicílio é abrandado em determinado período de tempo, mas há uma trajetória a se percorrida no qual necessita de ajuda do profissional de enfermagem. Deste solicita-se uma postura compreensiva e acolhedora diante das experiências e da percepção vivenciada pelo familiar, com disponibilidade de escuta, acompanhamento em seu pesar e olhar atento às possíveis manifestações de luto patológico. Cabe mencionar que a atuação do enfermeiro deve ser compartilhada e convergir com o plano de cuidados proposto pela equipe multidisciplinar. ${ }^{61}$

O tornar-se cuidador domiciliar é uma difícil e desafiante experiência, no qual o cuidado do paciente em fase final de uma doença no domicílio é percebido como um trabalho complexo e criativo que resulta em crescimento pessoal, às vezes marcado pelo cuidado solitário. Paralelamente, observa-se nos cuidadores uma capacidade de transcender suas limitações pessoais e de adquirir conhecimento técnico para o cuidado. ${ }^{63}$

A problemática das úlceras por pressão foi observada nos estudos analisados, constatando-se que a prevenção da úlcera por pressão em indivíduos com câncer avançado, com mobilização restrita, contribui favoravelmente a melhoria da qualidade de vida. A informação a cuidadores sobre úlcera por pressão e estímulo para que possam desenvolver sua capacidade natural de cuidar são estratégias que contribuem para a diminuição do surgimento de úlceras. ${ }^{64}$

Os resultados expostos evidenciam que os pesquisadores apropriaram-se da temática cuidados paliativos por meio de discussões de subtemas relacionados ao paciente, aos cuidadores, ao familiar enlutado, a atuação da equipe multiprofissional e aos limites da equipe assistencial.

Aspectos éticos que comumente envolvem os cuidados paliativos não foram observados. A literatura aponta como princípios bioéticos relacionados à temática dos cuidados paliativos a beneficência, não maleficência, autonomia, justiça, ampliados pela discussão de referenciais éticos como veracidade, proporcionalidade terapêutica, referencial do duplo efeito, prevenção e não abandono. ${ }^{65-66}$ Estudos que abordem como os profissionais de saúde percebem o desejo do paciente de participar das decisões compartilhadas; como motivar os pacientes a expor suas preferências a partir das opções colocadas; identificação dos conflitos morais vivenciados em contexto de domicílio poderiam auxiliar os profissionais de enfermagem a compreender os limites do cuidado, ou mesmo a dimensionar o impacto da 
existência de conflitos éticos na qualidade de vida de pacientes que enfrentam doenças que ameaçam a vida. ${ }^{67}$

Verifica-se que os cuidados paliativos na enfermagem é uma área de assistência incipiente, mas promissora para a consolidação dos cuidados integrais ao paciente e à família, tendo em vista a capacidade do profissional de responder ao sofrimento humano nas dimensões física, psicológica, social e espiritual, ao experienciar a fragilidade diante do processo de morrer em domicílio.

Os achados deste estudo apontam uma baixa produtividade na temática cuidados paliativos na atenção domiciliar, com crescimento descontínuo, mas incipiente se considerarmos que os cuidados paliativos passaram a ter maior visibilidade após 2002, com uma publicação da Organização Mundial da Saúde (OMS) sobre os conceitos e princípios norteadores dessa prática. ${ }^{19}$

No entanto, os estudos explicitam um compromisso da enfermagem na assistência ao paciente em situação de terminalidade da vida, no âmbito domiciliar, visto que as publicações abarcaram a percepção de profissionais, pacientes, cuidadores e familiares sobre esse tipo de assistência, com abordagem de contextos da ESF e serviços de internação domiciliar oncológicos.

A ausência de uma rede articulada e integrada de serviços de cuidados paliativos no Brasil não permite perceber o impacto exercido por tais cuidados sobre as políticas de saúde existentes. Para tanto, estudos que descrevam e reflexionem sobre a articulação dos cuidados paliativos na atenção básica e que apontem formas de articulação entre serviços e programas se fazem necessários.

A assistência domiciliar enfrenta desafios no estabelecimento de parceria com a família, em aprender a trabalhar em conjunto com a comunidade, no estabelecimento de rede de apoio social e de retaguarda em serviços de saúde nos diferentes níveis de atenção, configurando entraves ao provimento de uma melhor qualidade de vida aos pacientes portadores de doenças que ameaçam a vida. ${ }^{68}$

A falta de qualificação dos profissionais de saúde evidenciada nos estudos consiste em uma das principais barreiras para a implementação dos cuidados paliativos na atenção básica. A iniciativa governamental da publicação dos Cadernos da Atenção Domiciliar, com um 
caderno dedicado a atenção domiciliar em cuidados paliativos, demonstra um primeiro passo para a sensibilização dos profissionais acerca dessa modalidade de cuidado. Entretanto, para mudar esse cenário, é preciso que os profissionais de enfermagem assumam o desafio da assistência a pacientes que enfrentam doenças que ameaçam a vida na proposição de ações de educação permanente em serviço.

Necessitamos avançar para a qualificação de enfermeiros especialistas em cuidados paliativos, segundo um modelo de ensino que permita aos profissionais responder as demandas da população brasileira. Nesse sentido, estudos que reflexionem sobre os cuidados em domicílio demandados por pacientes em condição de doença que ameaça a vida; que discutam possibilidades de intervenção de enfermagem diante de sinais e sintomas comuns; e que discutam a tomada de decisão em situações complexas características do contexto domiciliar podem contribuir para a construção do saber de enfermagem em cuidados paliativos, possibilitando estratégias eficazes e resolutivas de cuidado em saúde. Além disso, investimentos governamentais na educação permanente em saúde, sob a perspectiva do aprender e ensinar incorporados ao cotidiano do trabalho e das organizações poderia colaborar para mudanças substanciais na consolidação desse tipo de assistência.

\subsection{O MODELO DE COMPETÊNCIA NO ÂMBITO DO TRABALHO}

O modelo de competências é um movimento social que se concretiza na instauração dos sistemas de competências, cujas consequências fazem sentir-se nos mundos do trabalho e da educação.

A noção de competência surge quando o aparente equilíbrio gerado pelo sistema de acumulação denominado fordismo-Keynesianismo, que caracterizou o período do pós-guerra, começou a demonstrar sinais de esgotamento. A organização da produção estabelecida por postos de trabalho com determinados requisitos em crescente grau de complexidade a serem exigidos de seus ocupantes, passa a ser questionada pelas novas formas de organização do trabalho que começa a exigir um novo tipo de trabalhador, ou seja, trabalhadores com iniciativa e capazes de assumir responsabilidades. ${ }^{69-70}$ 
Nesse contexto, a noção de qualificação perde espaço nos discursos empresariais e acadêmicos, onde o termo competência passa a ser evocado como mais expressivo das novas demandas requeridas dos trabalhadores pelo setor produtivo: autonomia, iniciativa, flexibilidade, polivalência, multifuncionalidade e cooperação. ${ }^{69}$

A publicação do artigo de McClelland, em 1973, intitulado "Testing for competence rather than intelligence" (Testando por competências em vez de inteligência), é apontado como o início do debate sobre competência entre psicólogos e administradores nos Estados Unidos, e traz o conceito de competência como uma característica subjacente a uma pessoa casualmente relacionada com um desempenho superior na realização de uma tarefa ou em uma determinada situação. ${ }^{71-72}$

Richard Boyatzis, na década de 80, em estudos realizados sobre competências gerenciais, identificou um conjunto de características e traços que culminaram no modelo de Boyatzis (McBer and Company), baseado no método de avaliação de competências no cargo. O conceito de competência é pensado como conjunto de conhecimentos, habilidades e atitudes que justificam um alto desempenho, de forma que os melhores desempenhos estão fundamentados na inteligência e personalidade das pessoas. ${ }^{71-72}$

Tanto na literatura acadêmica como nos textos que fundamentam a prática administrativa, a referência que baliza o conceito de competência é a tarefa, e o conjunto de tarefas prescritas de um cargo. Enquanto prevalecia esse modelo de organização do trabalho, a qualificação era definida pelos requisitos associados à posição ou ao cargo, ou pelos saberes ou estoque de conhecimentos da pessoa, que podem ser classificados e certificados pelo sistema educacional. ${ }^{71-72}$

Na década de 70 o debate francês sobre competências surge do questionamento do conceito de qualificação e do processo de formação profissional, principalmente técnica, na tentativa de aproximar o ensino às reais necessidades das empresas, visando aumentar o nível de qualificação dos trabalhadores e as oportunidades de emprego. Buscava-se estabelecer a relação entre competências e os saberes - o saber agir - no referencial do diploma e do emprego. Do campo educacional, o conceito de competências passou às relações trabalhistas, empregado para avaliar as qualificações necessárias ao posto de trabalho, surgindo daí, o inventário de competências, bilan de compétences. ${ }^{72}$ 
Em um esforço de delimitar na literatura corrente o significado do conceito competência, Barbosa e Rodrigues ${ }^{73}$ apontam que o emprego do termo apresenta diferentes conotações e ênfases associadas a aspectos múltiplos e variados do mundo do trabalho, da educação, da gerência e da gestão de pessoas.

Remetida ao nível individual, a discussão sobre competências busca configurar novas práticas de gestão de pessoas, privilegiando a criação de valor e resultados. No âmbito dos recursos humanos, embora a identificação de capacidades únicas da empresa possa parecer simples, uma vez que se refere à base de recursos previamente disponíveis, essa tarefa é repleta de dificuldades. Isso é ilustrado, por exemplo, tanto na natureza incompleta e fragmentada dos dados e informações, quanto na elevada incerteza que decorre da imbricação de redes e fluxos de relacionamentos entre recursos e capacidades. ${ }^{73}$

Assim, no que se refere às competências individuais, embora seja possível estabelecer inferências com base na experiência efetiva dos empregados, nas descrições ocupacionais, nos níveis de qualificação e outros atributos relacionados, essas fontes, na realidade, são insatisfatórias e limitadas para expressar a capacidade das pessoas. Esses motivos talvez expliquem a variedade de entendimentos sobre o que são competências e, particularmente, as dificuldades de identificá-las, na etapa inicial da construção de sistemas de gerenciamento fundados nesse enfoque. ${ }^{73}$

O discurso das competências surge como uma prática gerencial de importância significativa, em construção, que tem sido submetida a uma ação operacional no âmbito das empresas, com diferentes resultados e impactos. O conceito de competências entendido na maioria das empresas é de um conjunto de conhecimentos, habilidades e atitudes traduzidos em resultados. ${ }^{73}$

Le Boterf, pesquisador francês, apresenta competência como conhecimentos, habilidades e atitudes que são mobilizados pelos trabalhadores para realização de uma ação específica, onde o indivíduo só é considerado competente em situação real. ${ }^{74}$

Agir com competência em uma situação é combinar e mobilizar recursos pessoais (recursos físicos e fisiológicos, conhecimento, especialização técnica, expertise metodológica, expertise relacional, habilidades cognitivas, conhecimentos e experiência, recursos emocionais) e de suporte (ferramentas de suporte - protocolos, grades de análise, base de dados, redes de cooperação, outros ofícios) ao implementar a prática profissional, 
considerando as suas necessidades e contexto particular, para produzir resultados (produtos, serviços) que respondam a certos critérios de desempenho para o destinatário (cliente, paciente, usuários).$^{75}$

A prática profissional é o lugar das decisões, ações e interações aplicadas pelo sujeito com referência à atividade prescrita. Ela é observável, relacionável, sustentada e organizada por esquemas operacionais ou padrão de conduta, que têm o papel de alocação de recursos a serem mobilizados. Nesse contexto, o trabalho consiste na lacuna entre prescrição e prática que permite redefinir e interpretar em ação uma missão, um objetivo, uma receita ou uma tarefa. $^{75}$

O indivíduo competente é aquele que se compromete e conhece em sua prática os recursos apropriados que precisa mobilizar. Não basta que seja detentor das competências para que nele se possa confiar inteiramente, mas sobretudo se faz importante que ele seja capaz de associar e de mobilizar, com pertinência , numa situação de trabalho. ${ }^{75-76}$

A dinâmica posta por um profissional que age com competência compreende três dimensões, a saber: a primeira, é a dimensão dos recursos disponíveis que ele pode mobilizar para agir; a segunda surge da dimensão da ação e dos resultados que ela produz, ou seja, a das práticas profissionais e do desempenho; e por fim a dimensão da reflexibilidade, que consiste no distanciamento em relação às duas dimensões anteriores. ${ }^{76}$

Para agir de forma pertinente o profissional deve saber combinar e por em prática um conjunto coerente de recursos pessoais (conhecimentos, saber-fazer, capacidades cognitivas, recursos emocionais, competências comportamentais, saber-fazer oriundo da experiência, aptidões físicas e sensoriais), e recursos disponíveis no contexto em que a pessoa se insere (base de dados, rede de cooperação científica, manuais de instruções, competências de colegas ou de pessoas de outras profissões). ${ }^{76}$

A segunda dimensão da competência corresponde às práticas profissionais a que se recorre em relação às exigências de uma situação profissional e aos seus resultados. A prática profissional é um conjunto de atos que um sujeito executa para realizar uma atividade prescrita, para resolver uma situação/um problema ou para enfrentar um determinado acontecimento. $^{74,76}$ 
O profissional competente sabe articular com pertinência uma sequência de ações, tendo em vista alcançar um objetivo que faça sentido, onde compreende, igualmente, o porquê e o como agir. ${ }^{74,76}$

A terceira dimensão da competência consiste em ser capaz de reflexividade, de distanciamento, onde é possível marcar uma separação entre o próprio e as suas práticas. É nesta dimensão que se concretiza a análise das práticas, por meio do distanciamento para uma tomada de consciência, no sentido de formalizá-las ou conceitualizar, verbalizando-as (em forma de discurso) ou dando-lhes outra forma (esquema). Trata-se, da construção de esquemas operatórios, de modelos cognitivos, de esquemas de ação que poderão dar lugar a generalizações e que contribuirão para a construção do profissionalismo da pessoa envolvida. $^{74,76}$

O processo de trabalho em saúde tem como característica a complexidade, a heterogeneidade e a fragmentação. Neste contexto, a complexidade decorre da diversidade das profissões, dos profissionais, dos usuários, das tecnologias utilizadas, das relações sociais e interpessoais, das formas de organização do trabalho, dos espaços e ambientes de trabalho; a heterogeneidade revela-se pela diversidade dos vários processos de trabalho que coexistem nas instituições de saúde e que têm, muitas vezes, uma organização própria e funcionam sem se articular, de forma adequada, com os demais processos de trabalho. Já a fragmentação encerra várias dimensões que vão desde a fragmentação conceitual, ou seja, a separação entre o pensar e o fazer, à fragmentação técnica, caracterizada pela presença cada vez maior de profissionais especializados, e a fragmentação social, que estabelece relações rígidas de hierarquia e subordinação, configurando a divisão social do trabalho no interior e entre as diversas categorias profissionais. ${ }^{77}$

Por tratar-se de profissionais de saúde que atuam diretamente na atenção ao usuário/cliente, a competência humana se expressa fundamentalmente na capacidade de um ser humano cuidar de outro, de colocar em ação os conhecimentos necessários para prevenir e resolver problemas de saúde, mobilizando e disponibilizando tecnologias importantes para o ato de cuidar. Na medida em que as bases da competência profissional podem ser objeto de ensino, o profissional que atuará em Enfermagem deverá responder às necessidades e demandas dos indivíduos e coletividades aos quais assiste, mediante o exercício eficiente do seu trabalho, a participação ativa, consciente e crítica no mundo do trabalho e na esfera social, contribuindo para a qualidade de vida dos mesmos. ${ }^{77}$ 
No aprimoramento do modelo assistencial brasileiro de saúde, os princípios da integralidade e equidade estão no cerne e sua operacionalização inclui a produção, a divulgação e o uso de indicadores de saúde apropriados para compreender as políticas distintas para diferentes problemas que afligem grupos específicos. $O$ trabalho interdisciplinar, apesar de preconizado, é implementado com restrições, que vão da precária formação dos alunos na graduação até a defesa corporativa das profissões, passando por relações de trabalho que deverão incorporar princípios do trabalho em equipe, prevenção, reabilitação, inclusão da família e paliativismo. ${ }^{78}$

A investigação de competências a ser conduzida neste estudo busca os elementos centrais, constitutivos, inerentes à prática de enfermagem em cuidado paliativo na atenção domiciliar. Na perspectiva da competência como a expressão dos recursos que o indivíduo articula e mobiliza, construída na relação com o outro, no processo cotidiano de trabalho.

\subsection{AS COMPETÊNCIAS NO ÂMBITO DA FORMAÇÃO PROFISSIONAL}

No Brasil, a estruturação da educação profissional aponta para a formação por competências, modularização da formação, articulação com o setor empresarial e oferta de formação profissional estruturada a partir das demandas do mercado. ${ }^{79}$

O cidadão que procura um curso profissionalizante busca desenvolver competências profissionais que o conduzam a um exercício profissional competente e que lhe possibilitem aumentar suas condições de navegabilidade no mundo do trabalho. O compromisso ético das instituições de educação profissional e tecnológica para com seus alunos está vinculado ao desenvolvimento dos saberes profissionais que propiciem aos novos trabalhadores a capacidade de mobilizar, articular e colocar em ação conhecimentos, habilidades, atitudes, valores e emoções necessários para a promoção de um desempenho eficiente e eficaz nas atividades profissionais requeridas pela natureza do trabalho. Neste contexto, o conhecimento é o saber conhecer, que engloba a teoria e a prática; a habilidade diz respeito ao saber fazer, que transcende o tradicional estágio de treinamento operacional para o desenvolvimento de automatismos para a realização da ação motora; e os valores, as atitudes e as emoções se expressam no saber ser e no saber conviver, que está interligada ao julgamento da pertinência da ação, com a qualidade do trabalho, a ética do comportamento, a convivência participativa e solidária. ${ }^{80}$ 
Na perspectiva de Perrenoud, a competência é a capacidade de mobilizar diversos recursos cognitivos para enfrentar situações diversificadas apoiadas em quatro aspectos: as competências não são elas mesmas saberes ou atitudes, mas mobilizam, integram e orquestram tais recursos; essa mobilização só é pertinente em situação, sendo cada situação singular, mesmo que se possa tratá-la em analogia com outras já encontradas; o exercício da competência passa por operações mentais complexas, subentendidas por esquemas de pensamento que permitem determinar (mais ou menos consciente e rapidamente) e realizar (de modo mais ou menos eficaz) uma ação relativamente adaptada à situação; e as competências profissionais constroem-se em formação, mas também ao sabor da navegação diária de um professor, de uma situação de trabalho a outra. ${ }^{81}$

Ramos apresenta uma definição comumente usada que considera competência como o conjunto de conhecimentos, qualidades, capacidades e aptidões que habilitam o sujeito para a discussão, a consulta, a decisão de tudo o que concerne a um ofício, supondo conhecimentos teóricos fundamentados, acompanhados das qualidades e da capacidade que permitem executar as decisões sugeridas. ${ }^{82}$

No âmbito do trabalho essa noção torna-se plural - "competências" -, designando os conteúdos particulares de cada função em uma organização de trabalho. Já no âmbito da formação, a transferência dos conteúdos de formação por meio do desenvolvimento das competências é chamada de pedagogia das competências. ${ }^{82}$

A pedagogia das competências visa também a institucionalizar novas formas de educar os trabalhadores no contexto político-econômico neoliberal, com instauração nas diversas práticas sociais pela quais as pessoas se educam, compondo o conjunto de novos signos e significados talhados na cultura do estágio de acumulação flexível do capital, desempenhando um papel específico na representação dos processos de formação e de comportamento do trabalhador na sociedade. ${ }^{82}$

O desafio para as instituições educacionais é o de preparar profissionais que tenham aprendido a aprender e a gerar autonomamente um conhecimento atualizado, inovador, criativo e operativo, o qual incorpore as mais recentes contribuições científicas e tecnológicas das diferentes áreas do saber. A formação profissional assume como uma de suas finalidades essenciais a de preparar as pessoas para que tenham efetivas condições de disponibilizar, 
durante seu desempenho profissional, os atributos adquiridos na vida social, escolar, pessoal e laboral, de forma a permitir lidar com a incerteza e o inusitado na resolução de problemas. ${ }^{80}$

A transição do paradigma taylorista/fordista para o novo paradigma técnico econômico, fundado na flexibilização, traz como consequência uma nova concepção de formação profissional, que solicita um papel cada vez mais complexo da formação profissional enquanto agente de socialização dos jovens e enquanto meio de proporcionar a estes, e aos trabalhadores em geral, as capacidades profissionais e os conhecimentos exigidos pelo setor produtivo. ${ }^{83}$

A abordagem profissional pelas competências, com o deslocamento da qualificação para o plano de trabalho por competências, provocou no plano pedagógico o deslocamento do ensino centrado em saberes disciplinares para um ensino definido pela produção de competências verificáveis em situações e tarefas específicas, definidas com referência às situações que os alunos deverão ser capazes de compreender e dominar. Portanto, tanto no ensino geral quanto no ensino profissionalizante, as noções do saber, saber-fazer e objetivos devem estar associadas e acompanhadas de uma explicitação das atividades em que elas podem se materializar e se fazer compreender. ${ }^{82}$

Percebe-se uma mudança na forma de se conceber os currículos profissionalizantes. Se anteriormente estes eram derivados de uma teoria de racionalidade técnica ou de um conjunto pré-definido de conhecimentos, para os quais era esperado o desempenho de uma variedade de tarefas previsíveis e rotineiras, a pesquisa mais recente aponta no sentido de se dar maior relevância à capacidade de resolver problemas imprevistos e de desenvolver novos conhecimentos. $^{83}$

Essa redefinição pedagógica ganha sentido mediante o estabelecimento de uma correspondência entre escola e empresa, por meio dos chamados referenciais, que no Brasil configuram-se nas diretrizes e referenciais curriculares nacionais produzidos pelo Ministério da Educação para a escola, e na Classificação Brasileira de Ocupações, produzida pelo Ministério do Trabalho. Esses referenciais utilizam as competências como base, constituindose ferramentas de comunicação entre os agentes da instituição escolar e os representantes dos meios profissionais, como, também, suportes para a avaliação tanto na formação inicial, como na continuada e no ensino técnico, possibilitando a correlação entre a oferta de formação e a distribuição das atividades profissionais. ${ }^{82}$ 
As Diretrizes Curriculares Nacionais permitiram que cada área revisasse o processo de formação de seus profissionais, porque além de ser uma regulamentação legal no âmbito de reforma educacional é o centro de interesse das instituições de saúde, dos docentes, alunos, gestores e profissionais da área de saúde, que atuam nos variados campos de interesse social. $^{84}$

As discussões em torno das mudanças na educação em Enfermagem giraram em torno da construção de propostas pedagógicas críticas, currículos integrados à realidade de cada região, articulados com os interesses da população nas comunidades, concentrando-se nos conteúdos a serem transmitidos, bem como nas estratégias a serem utilizadas nessa transmissão, com vista a uma formação de qualidade. As discussões ocorridas nos Seminários Nacionais de Diretrizes para a Educação em Enfermagem (SENADEn), nos Fóruns de Escolas de Graduação em Enfermagem e com base na Carta de Florianópolis (aprovada no $51^{\circ}$ Congresso Brasileiro de Enfermagem e $10^{\circ}$ Congreso Panamericano de Enfermería) culminaram com a proposta que contemplou: o perfil do profissional numa perspectiva generalista, crítica e reflexiva, com definição de competências e habilidades gerais e específicas. $^{84}$

Diante das várias concepções de competências cabe enfatizar que as escolhas em educação não são neutras e que os conceitos expressam as características e os interesses dos grupos e das forças sociais que os elaboram. A noção de competência é, assim, uma construção social, e por isso alvo de disputas políticas em torno do seu significado social. Torna-se imprescindível enfrentar o desafio de propor alternativas ao modelo de educação profissional vigente, calcado na noção de competências em suas concepções não críticas, que enfrentem e deem respostas à dinâmica e às transformações do mundo do trabalho, na perspectiva dos interesses dos protagonistas sociais: os trabalhadores. ${ }^{71}$

Observa-se a necessidade de se reflexionar a prática clínica do enfermeiro, para que essa se constitua integral e resolutiva, centrada no usuário, considerando sua singularidade e respeitando a autonomia do sujeito que necessita de cuidados. Aos cursos de enfermagem está posta a incumbência de preparar os futuros enfermeiros para acompanhar as mudanças, habilitando-os a desenvolver uma atitude crítica e criativa que possibilite sua atuação como transformadores da realidade de saúde brasileira. 


\subsection{AS COMPETÊNCIAS E A FORMAÇÃO PROFISSIONAL EM ENFERMAGEM}

O homem é entendido como ser que se constrói permanentemente na relação consigo mesmo, com a natureza e com a sociedade de seu tempo e as sociedades do passado. As reformas que vêm se efetuando na educação em forma de políticas governamentais e de Estado são, sem dúvida, consequências das transformações que vêm ocorrendo no mundo da produção. A Educação também é espaço de transformação da vida social e onde, ao mesmo tempo em que é modificada pelo mundo da produção, também é capaz de modificá-lo. ${ }^{83}$

O desafio é redimensionar a ação educativa dentro do cenário sociopolítico e econômico e do discurso educacional, de forma que se estabeleçam relações concretas com o processo social. ${ }^{83}$

Educação é aqui entendida como processo de formação e de aprendizagem socialmente elaborado e destinado a contribuir na promoção da pessoa humana enquanto sujeito da transformação social, que transforma e é transformado. ${ }^{86}$

O mundo econômico em nosso redor é muito competitivo, e a educação para o exercício de uma multiplicidade de papéis pessoais e profissionais e para o trabalho não pode deixar de considerar a economia que temos. Mas a educação para o trabalho deve ser sempre educação para a vida toda, mesmo que focada na preparação para um exercício profissional concreto. ${ }^{86}$

A literatura aponta a importância de definirmos sempre aonde queremos chegar, em termos educativos, em qualquer processo de educação. Refere que na pedagogia o seu próprio e verdadeiro alcance é a dignidade de cada pessoa, na sua revelação única, onde o estabelecimento de perfis de competências não é erro, é uma tarefa, entre outras, desde que esse perfil não deixe de lado nenhuma parte do que é humano. ${ }^{86}$

A prática clínica do enfermeiro é uma prática social, que se realizada a partir de necessidades sociais de cada momento histórico e que se constitui e se transforma na dinâmica das relações com outras práticas. ${ }^{85}$

O marco cronológico da consolidação do processo de formação do enfermeiro foi em 1890 com a criação da Escola Profissional de Enfermeiros e Enfermeiras (EPEE), no Rio de Janeiro, e na sequência a Escola do Hospital Samaritano, em São Paulo, em 1895, a da Cruz 
Vermelha Brasileira, em São Paulo, em 1914, e no Rio de Janeiro, em 1917, a escola da Policlínica Botafogo. ${ }^{87}$

O Decreto $\mathrm{n}^{\circ} 20.109$ de 1931 e a Lei $\mathrm{n}^{\circ}$ 775/49 marcaram as estruturas do ensino e estabeleceram os primeiros currículos de enfermagem no país. O referido decreto, além de fixar o exercício profissional no Brasil, estabeleceu a instituição do "padrão Anna Nery" no ensino da enfermagem, onde para funcionar, as escolas de enfermagem do país deveriam equiparar-se aos moldes da Escola de Enfermagem Anna Nery. A exigência do "padrão Anna Nery" se encerrou com a promulgação da Lei $\mathrm{n}^{\circ} 775 / 49$, que dentre outros aspectos positivos, fixou a criação do curso de auxiliar de enfermagem, como uma tentativa de sanar o problema da falta de pessoal para as atividades hospitalares, assim como definiu atribuições específicas para as categorias de profissionais de enfermagem. ${ }^{87-88}$

O reconhecimento da enfermagem como profissão de nível superior aconteceu quando da promulgação da Lei $\mathrm{n}^{\circ} 4.024 / 61$, a primeira Lei de diretrizes e Bases da Educação Nacional, que dentre várias determinações estabeleceu que o acesso ao nível superior dar-seia somente através da conclusão do ensino secundário, dando oportunidade da profissão de se consolidar em nível superior. ${ }^{87-88}$ Também oficializa um novo nível de formação para enfermagem, passando a existir três níveis: auxiliar de enfermagem (formação primária); técnico de enfermagem (formação secundária) e enfermeira (formação superior). ${ }^{88}$

Posteriormente, o Parecer 271/62-CFE (Conselho Federal de Educação) confirmou o ensino da enfermagem como superior, mas excluiu áreas do conhecimento como a saúde pública, e centrava a formação nas disciplinas práticas orientadas para a ação, com diminuição da carga horária destinada ao desenvolvimento das habilidades técnicas. Dessa forma, os rumos da enfermagem foram alterados, pois, nos anos anteriores, seu desenvolvimento era evidenciado para a saúde da totalidade da população, passando, por intermédio desse parecer, a se concentrar na assistência prestada aos pacientes hospitalizados. Em decorrência das falhas dessa proposta curricular e das críticas a ela, originou-se um movimento de mudança, que foi apoiado pela reforma universitária. ${ }^{89}$

Por meio do Parecer 163/72-CFE, fixou-se o currículo mínimo para os cursos de graduação em enfermagem e obstetrícia, o qual incorporava mais conhecimentos científicos, porém com pouca contribuição para a resolução dos problemas básicos de saúde pública. Dessa maneira, privilegiava-se a formação do enfermeiro sob o modelo biomédico de 
assistência hospitalar. O currículo foi dividido em ciclo básico e profissionalizante, formação geral e habilitações nas áreas de saúde pública, obstetrícia e médico-cirúrgica. ${ }^{89}$

A Portaria 1.721/94-MEC aprovou a proposta de duração mínima do curso de enfermagem para quatro anos, com carga horária mínima de 3.500horas/aula, extinguiu as habilitações e definiu que o currículo deveria ter disciplinas relativas às Ciências Biológicas e Humanas, em áreas temáticas, tais como: Biológicas e Sociais da Enfermagem, Fundamentos da Enfermagem, Assistência de Enfermagem e Administração em Enfermagem. Essa portaria enfatizou a necessidade da indissociabilidade entre ensino, pesquisa e extensão, visando à formação do aluno para atuar na sua realidade, de forma crítica e transformadora. ${ }^{89-90}$ Atualmente, a carga horária mínima dos cursos de graduação em enfermagem, bacharelado, é de 4.000 horas, com limite mínimo para integralização de cinco anos. ${ }^{91}$

Em 23 de dezembro de 1996, foi publicada no Diário Oficial da União a nova Lei de Diretrizes e Bases da Educação (LDB), Lei n.9.394 de 20 de dezembro de 1996, que trouxe novas responsabilidades para as Instituições de Ensino Superior, docentes, discentes e sociedade, pois incentiva a formação de diferentes perfis profissionais a partir da vocação de cada curso/escola, esperando melhor adaptação ao "mundo do trabalho", visto que as instituições têm liberdade para definir parte considerável de seus currículos plenos. ${ }^{92-93}$

Em 1997, o Ministério da Educação e Cultura (MEC), por intermédio da Secretaria de Educação Superior do Ministério da Educação- SESu/MEC, tornou público e convocou as Instituições de Ensino e as associações profissionais interessadas a participar e apresentar propostas para discussão das novas Diretrizes Curriculares para os cursos superiores. Tal convocação desencadeou a realização de Seminários Nacionais de Diretrizes para a Educação em Enfermagem no Brasil (SENADEn), promovidos pela Associação Brasileira de Enfermagem (ABEn), com o objetivo geral de discutir e estabelecer as diretrizes gerais para a educação em enfermagem, articulando os diversos níveis de formação. ${ }^{93}$

O desfecho da articulação das Instituições de Ensino e das associações profissionais de enfermagem culminou no Parecer CNE/CES 1133/2001, da Câmara de Educação Superior do Conselho Nacional de Educação sobre as Diretrizes Curriculares Nacionais dos Cursos de Graduação em Enfermagem, Medicina e Nutrição. O objetivo dessa Diretriz Curricular é levar os alunos a aprender a aprender que engloba aprender a ser, aprender a fazer, aprender a viver juntos e aprender a conhecer, na perspectiva da capacitação de profissionais com 
autonomia e discernimento que assegurem a integralidade da atenção, como também a qualidade e humanização do atendimento prestado a indivíduos, famílias e comunidades. ${ }^{94}$

Nesta perspectiva, a educação ao longo da vida estaria apoiada em quatro pilares: o aprender a conhecer, que combinado a uma cultura geral, suficientemente ampla, possibilite estudar, em profundidade, um número reduzido de assuntos, e possibilite o beneficiar-se das oportunidades oferecidas pela educação ao longo da vida; o aprender a fazer, a fim de adquirir não só uma qualificação profissional, mas a competência que torna a pessoa apta a enfrentar numerosas situações e a trabalhar em equipe, no âmbito das diversas experiências sociais ou de trabalho, de forma espontânea na sequência do contexto local ou nacional; o aprender a conviver, desenvolvendo a compreensão do outro e a percepção das interdependências no respeito pelos valores do pluralismo, da compreensão mútua e da paz; e aprender a ser, para desenvolver, o melhor possível, a personalidade e estar em condições de agir com uma capacidade cada vez maior de autonomia, discernimento e responsabilidade pessoal. Com essa finalidade, a educação deve considerar todas as potencialidades de cada indivíduo: memória, raciocínio, sentido estético, capacidades físicas e a aptidão para comunicar-se. $^{95}$

Do parecer CNE/CES 1133/2001, originou-se a Resolução CNE/CES No 3, de 7 de novembro de 2001, que institui Diretrizes Curriculares Nacionais do Curso de Graduação em Enfermagem. O conjunto disposto nessa Resolução aborda o perfil do formando egresso/profissional, as competências e habilidades gerais e específicas para a formação do enfermeiro, os conteúdos curriculares essenciais para o curso, o estágio supervisionado e as atividades complementares, além da referência ao acompanhamento e avaliação do projeto político-pedagógico do curso, à avaliação dos alunos e ao uso de metodologias e critérios para acompanhamento e avaliação do processo ensino-aprendizagem. ${ }^{96-97}$

Em relação à formação do egresso/profissional, a Resolução CNE/CES n ${ }^{\circ}$ 3/ 01 recomenda uma formação generalista, humanista, crítica e reflexiva, com base no rigor científico e intelectual, pautada em princípios éticos. Espera-se que o egresso seja capaz de conhecer os problemas/situações de saúde-doença mais prevalentes no perfil epidemiológico nacional e neles intervenha, dando ênfase à sua região de atuação e identificando as dimensões biopsicossociais de seus determinantes. Recomenda que o enfermeiro com Licenciatura em Enfermagem esteja capacitado para atuar na Educação Básica e na Educação Profissional em Enfermagem. ${ }^{96-97}$ 
$\mathrm{Na}$ formação do profissional enfermeiro outro componente relevante é o Estágio Curricular Supervisionado (ECS) estruturado com o currículo mínimo de 1972, por meio do estabelecimento das habilitações e da ampliação da carga horária prática dos cursos. Nessa década, surge uma legislação específica sobre estágio curricular no âmbito do Ministério Público do Trabalho, que trouxe uma nova forma de articular educação e trabalho, com vistas a garantir a contribuição do estágio à formação e a defesa do estudante quanto ao trabalho precarizado. Um grande avanço para o ensino é vivido com o currículo de 1994, construído coletivamente pela enfermagem a partir dos princípios do SUS e do conceito ampliado de saúde, que trouxe a exigência da realização do estágio tanto na rede básica quanto na hospitalar; medida atualizada e mantida pelas Diretrizes Curriculares de 2001. ${ }^{96,98}$

O ECS tem o intuito de integrar a atenção individual e coletiva, teoria e prática, ensino e serviço, na perspectiva de formar um profissional apto a atender as demandas de saúde da população brasileira e contribuir ativamente com a construção do SUS. ${ }^{96,98}$

A literatura aponta que a materialização do idealizado ao ECS tem ocorrido com atropelos, pois antigos e novos problemas somam-se, como a desarticulação entre ensinoserviço e docente/assistencial, dificuldades na relação público/privado, problemas com a legislação profissional de enfermagem que interfere na preceptoria, escassez e superlotação dos campos de estágio, algo que tem se intensificado com a expansão do ensino na esfera privada. ${ }^{98}$

No Brasil e na maioria dos países da América Latina a formação por competências tornou-se o carro-chefe nos sistemas educacionais. A concepção baseada no desenvolvimento de capacidades, habilidades e competências para que o indivíduo possa vincular-se com maior facilidade ao mundo do trabalho e atender às mudanças constantes dos setores econômicos visa a contribuir para o desenvolvimento econômico da nação, bem como para o aumento de sua empregabilidade. A formação profissional deve ser capaz de responder à nova ordem econômica e ser capaz de contribuir para a inserção e a permanência dos trabalhadores no mercado de trabalho. Tendo como referência a compreensão de que os trabalhadores devem vivenciar práticas continuadas de formação profissional, o que permitirá a eles a aquisição e a atualização permanente das competências laborais, entende-se que a formação profissional deve ter por finalidade a adaptação dos aprendizes/trabalhadores às modificações laborais que possam ocorrer ao longo da vida. ${ }^{79}$ 


\subsection{A ATENÇÃO DOMICILIAR NO ÂMBITO DO SISTEMA ÚNICO DE SAÚDE DO DISTRITO FEDERAL}

A modalidade de assistência domiciliar data de 1997, com sua regulamentação no Sistema Único de Saúde, e o funcionamento dos serviços que prestam atenção domiciliar a partir de janeiro de 2006, pela Resolução da Diretoria Colegiada - RDC no 11 da Agência Nacional de Vigilância Sanitária. ${ }^{99-100}$

A Resolução - RDC N 11, dispõe sobre o Regulamento Técnico de funcionamento de Serviços que prestam Atenção Domiciliar, com o objetivo de estabelecer os requisitos de funcionamento dos Serviços de Atenção Domiciliar. Nesta resolução define-se: a) Cuidador é a pessoa com ou sem vínculo familiar que está capacitada para auxiliar o paciente em suas necessidades e atividades da vida cotidiana; b) Atenção Domiciliar (AD) é o termo genérico que envolve ações de promoção à saúde, prevenção, tratamento de doenças e reabilitação desenvolvidas em domicílio; c) Assistência Domiciliar é o conjunto de atividades de caráter ambulatorial, programadas e continuadas desenvolvidas em domicílio; d) Internação Domiciliar envolve um conjunto de atividades prestadas no domicílio, caracterizadas pela atenção em tempo integral ao paciente com quadro clínico mais complexo e com necessidade de tecnologia especializada. ${ }^{99}$

A Internação Domiciliar (ID) deve ser uma modalidade assistencial inserida nos sistemas locais de saúde do SUS, que integram ações da área hospitalar, urgência e emergência e rede básica. ${ }^{99}$

A Portaria n ${ }^{\circ}$ 963, de 27 de maio de 2013 que redefine a Atenção Domiciliar no âmbito do Sistema Único de Saúde (SUS), considera Serviço de Atenção Domiciliar (SAD) como um serviço substitutivo ou complementar à internação hospitalar ou ao atendimento ambulatorial, que responde pelo gerenciamento e operacionalização das Equipes Multiprofissionais de Atenção Domiciliar (EMAD) e Equipes Multiprofissionais de Apoio (EMAP). Nessa portaria, a Atenção Domiciliar é caracterizada por um conjunto de ações de promoção à saúde, prevenção e tratamento de doenças e reabilitação prestadas em domicílio, com garantia de continuidade de cuidados e integrada às redes de atenção à saúde. ${ }^{101}$ 
O SAD se organiza em três modalidades, de acordo com os níveis de complexidade como os que se seguem:

\begin{abstract}
- A Modalidade AD1 destina-se aos usuários que possuam problemas de saúde controlados/compensados e com dificuldade ou impossibilidade física de locomoção até uma unidade de saúde; que necessitam de cuidados de menor complexidade, incluídos os de recuperação nutricional, de menor frequência, com menor necessidade de recursos de saúde e dentro da capacidade de atendimento das Unidades Básicas de Saúde; e não se enquadrem nos critérios previstos para as modalidades AD2 e AD3 descritos nesta Portaria.

- A modalidade AD2 destina-se aos usuários que possuam problemas de saúde e dificuldade ou impossibilidade física de locomoção até uma unidade de saúde e que necessitem de maior frequência de cuidado, recursos de saúde e acompanhamento contínuo, podendo ser oriundos de diferentes serviços da rede de atenção.

- A modalidade AD3 destina-se aos usuários que possuam problemas de saúde e dificuldade ou impossibilidade física de locomoção até uma unidade de saúde, com necessidade de maior frequência de cuidado, recursos de saúde, acompanhamento contínuo e uso de equipamentos, podendo ser oriundos de diferentes serviços da rede de atenção à saúde. ${ }^{101}$
\end{abstract}

No que se refere à responsabilidade da assistência, cabe às equipes de atenção básica a assistência à saúde na modalidade AD1, por meio de visitas regulares em domicílio, no mínimo uma vez por mês, e são apoiadas pelos Núcleos de Apoio à Saúde da Família e ambulatórios de especialidades e de reabilitação. A prestação de assistência à saúde na modalidade AD2 e AD3 é de responsabilidade da EMAD e da EMAP, onde a EMAD realizará visitas regulares, no mínimo uma vez por semana, e a EMAP realizará visitas em domicílio a critério clínico, quando solicitado pela EMAD. ${ }^{101}$

Os profissionais que compõem a EMAD são: médicos, enfermeiros, fisioterapeuta e/ou assistente social, auxiliares/técnicos de enfermagem. A EMAP é composta por: fisioterapeuta; assistente social, fonoaudiólogo, nutricionista, odontólogo, psicólogo, farmacêutico e terapeuta ocupacional. ${ }^{101}$

A Atenção Domiciliar constitui uma atividade necessária a ser realizada na Atenção Básica, que requer a participação ativa da família e dos profissionais envolvidos, no atendimento às pessoas que estão incapacitadas de se locomoverem aos serviços de saúde, temporária ou permanentemente. ${ }^{101}$

A adoção da assistência e internação domiciliar na década de 90 teve um crescente significativo, sob a justificativa de redução de infecção hospitalar, mais vagas nos hospitais, humanização do atendimento e redução dos custos. Somaram-se a essas a necessidade de promover uma maior integração e colaboração entre os serviços hospitalares e os extrahospitalares, com vistas a um novo modelo de atenção que possibilitasse a assistência 
contínua e a integralidade. ${ }^{102}$

A literatura aponta que existem atualmente quatro campos de motivações para o desenvolvimento da atenção domiciliar: a desospitalização de internações desnecessárias; os processos de "alta precoce" com vistas a ampliar a rotatividade dos leitos hospitalares e evitar complicações clínicas; busca de períodos maiores livres de intercorrências hospitalares em pacientes crônicos; e oferta de cuidados paliativos aos que precisam de alívio da dor e uma boa morte. $^{103}$

A atual portaria de $\mathrm{AD}$ objetiva a reorganização do processo de trabalho das equipes de saúde, que prestam cuidado domiciliar, com a pretensão de redução da demanda por atendimento hospitalar, redução do período de permanência de pacientes internados e a desinstitucionalização, ampliada pela humanização da atenção e da autonomia dos usuários. ${ }^{101}$

A internação domiciliar caracteriza-se por atividade contínua, com oferta de tecnologias e de recursos humanos, equipamentos, materiais e medicamentos, para usuários em estados mais complexos, revelando-se uma opção segura e eficaz, direcionada a usuários portadores de doenças crônicas ou agudas. ${ }^{103-104}$ Esta deve ser utilizada no intuito de humanizar e garantir maior conforto à população quando as condições clínicas do usuário e a situação da família o permitirem. ${ }^{105}$

Em processo de ascensão nas práticas de saúde em nosso país, a internação domiciliar não está completamente inserida nos sistemas de atendimento à saúde e na formação e/ou capacitação dos profissionais de saúde. Em face disto, enfoca-se a necessidade de se buscar colaboração para essa formação mediante a inserção acadêmica nas equipes de Internação Domiciliar, com vistas a expandir esse modelo. ${ }^{103}$

No Distrito Federal, iniciativas no âmbito da internação domiciliar surgiram em 1994, quando profissionais de saúde da SES-DF criaram na Regional de Saúde de Sobradinho, o SAMED - Serviço de Assistência Multiprofissional em Domicílio, tornando-se em 2000 no NAMID - Núcleo de Assistência Médica a Internados em Domić́lio. O serviço oferecido pelo SAMED/NAMID culminou na criação da Coordenação de Internação Domiciliar, com objetivo de expansão do Programa às demais Regionais de Saúde do Distrito Federal. Essa Coordenação foi incorporada após a edição da Portaria/MS 2.529 à atual GEAD - Gerência de Atenção Domiciliar. ${ }^{106}$ 
A organização do sistema de saúde no Distrito Federal comporta 07 regiões de saúde (oeste, norte, centro norte, sudoeste, sul, centro sul e leste), 15 coordenações gerais de saúde e 31 regiões administrativas. As atividades desenvolvidas no âmbito da atenção domiciliar pelas equipes multiprofissionais incluem atenção domiciliar nas modalidades AD1, AD2, AD3, coleta de exames complementares em domicílio, educação em saúde no contexto domiciliar e comunitário, empréstimo de equipamentos hospitalares necessários ao tratamento do paciente, fornecimento de dieta enteral para pacientes em internação domiciliar em parceria com a Gerência de Nutrição da SES/DF, admissão ao Programa de Oxigenoterapia Domiciliar, realização de encontros de cuidadores e de terapia comunitária, realização de cursos de extensão para capacitação de profissionais de saúde em internação domiciliar, e desenvolvimento do Programa de Cuidados Paliativos em parceria com a Gerência de Câncer da Secretaria de Saúde do Distrito Federal. ${ }^{107}$

A atenção Domiciliar no Distrito Federal organiza-se por equipes multiprofissionais compostas por profissionais médicos, enfermeiros, nutricionistas, assistentes sociais, fisioterapeutas, terapeutas ocupacionais, psicólogos, técnicos e auxiliares de enfermagem. Atualmente, conta com 15 equipes que compõem os Núcleos Regionais de Atenção Domiciliar (NRAD) nas regiões: Asa Norte, Asa Sul, Brazlândia, Ceilândia, Gama, Guará, Núcleo Bandeirante, Paranoá, Planaltina, Recanto das Emas, Samambaia, Santa Maria, São Sebastião, Sobradinho e Taguatinga. ${ }^{107}$

A atenção domiciliar destina-se aos usuários que possuam problemas de saúde e dificuldade ou impossibilidade física de locomoção até uma unidade de saúde, e que necessitem de maior frequência de cuidado, recursos de saúde e acompanhamento contínuo, podendo ser oriundos de diferentes serviços da rede de atenção. Para ser admitido no Programa de Internação Domiciliar (PID) da SES/DF é necessário que o paciente seja encaminhado ao serviço por meio de relatório médico detalhado, proveniente dos serviços da rede de saúde como Clínica da Família, Centros de Saúde, Hospitais (Fluxo de desospitalização) e Unidade de Pronto Atendimento. Os critérios de admissão comportam: residência e domicílio comprovado no Distrito Federal; cuidador identificado e quadro clínico compatível com o perfil do serviço. ${ }^{108}$

O PID apresenta limitações físicas e estruturais de atendimento, o que não permite a admissão de pacientes com necessidades de ventilação mecânica invasiva contínua e enfermagem intensiva. ${ }^{108}$ 
Os Núcleos Regionais de Atenção Domiciliar possuem espaço físico definido nos Hospitais Regionais de Saúde do Distrito Federal e na Clínica de Família, onde pacientes, familiares, e comunidade podem ter acesso para recebimento de informações e orientações acerca do Programa de Internação Domiciliar. 


\section{MATERIAL E MÉTODO}

\subsection{TIPO E MÉTODO DE ESTUDO}

Trata-se de um estudo descritivo, exploratório, de abordagem quantitativa que busca descrever e analisar as competências requeridas do enfermeiro na assistência domiciliar em cuidados paliativos. Para tanto, optou-se pelo Método Delphi que permite ser utilizado quando há falta de acordo ou conhecimentos incompletos acerca da natureza ou dos componentes de uma situação, geralmente de origem técnico-científica. O procedimento do Delphi mobiliza os participantes da pesquisa a pensarem mais sobre o assunto em questão, considerando que estes podem ser agentes multiplicadores do tema abordado. ${ }^{109-111}$

O Método Delphi baseia-se num processo estruturado para a recolha e síntese de conhecimentos de um grupo de especialistas por meio de uma série de questionários, acompanhados de um feedback organizado de opiniões. ${ }^{109-111}$

Criado como parte integrante de um movimento pós-guerra, o método Delphi buscava a previsão dos possíveis efeitos do desenvolvimento tecnológico na regeneração econômica e social. Os estudos de previsão tecnológica foram iniciados pela Empresa Douglas Aircraft, em 1946, e estes argumentavam que na ausência de uma base de evidência estabelecida, os campos emergentes da investigação poderiam começar a construir essa base através da recolha e sintetização de estudos de especialistas em diferentes domínios. O método Delphi consistiu, por isso, numa tentativa de "alinhar" as posições por vezes conflituosas dos especialistas numa perspectiva coerente e unificada. ${ }^{112-113}$

A literatura aponta que atualmente o método ainda é essencialmente o mesmo, consistindo na consulta a especialistas, de modo a obter respostas que reflitam a opinião desse conjunto sobre temas de interesse. A consulta é feita por meio de um questionário, elaborado pela equipe responsável pela pesquisa. É assegurado anonimato às respostas e, em rodadas sucessivas (em geral duas ou três), os especialistas têm a oportunidade de conhecer as opiniões dos seus pares, podendo rever seu posicionamento ao longo das rodadas, o que favorece a convergência e a obtenção de consenso sobre as questões tratadas. O Delphi é, em síntese, um processo estruturado de comunicação coletiva, que permite a um grupo de indivíduos lidarem com um problema complexo. ${ }^{114-115}$ 
Aponta-se, entretanto, que são necessárias três condições para assegurar a autenticidade do método: (a) deve ser assegurado o anonimato dos respondentes, para evitar a influência prévia de uns sobre os outros e eventuais constrangimentos devido a mudanças de opinião durante o processo; (b) retorno (feedback) das respostas, para que os especialistas possam, conhecendo as opiniões do grupo, reavaliar e aprofundar suas visões; e (c) tratamento estatístico das respostas, para que cada especialista possa se posicionar em relação ao grupo. O tratamento estatístico também é necessário para que a equipe de coordenação possa acompanhar a evolução das respostas em direção ao consenso. ${ }^{111,114}$

As principais vantagens do método Delphi são: possibilidade de reflexão individual e coletiva sobre os temas tratados, sem as desvantagens que as reuniões presenciais costumam apresentar, além das dificuldades de organização e dos custos que acarretam; integração e a sinergia de ideias e visões entre os especialistas e consequentemente dos setores, organizações e visões que estes normalmente representam; e agregação do conhecimento ao processo, não só pelas respostas - que incorporam esforço de reflexão e opiniões de especialistas nos temas tratados - mas também porque o próprio processo incita, através das rodadas, a reformulação e o aprimoramento das questões formuladas. ${ }^{114}$

Após a devolução dos instrumentos da primeira rodada, os dados recebem o tratamento estatístico adequado e são confrontados com o nível de consenso estipulado, onde a literatura científica revela que não há uma regra pré-determinada para estabelecê-lo, sendo o nível de consenso definido pelo pesquisador, de forma arbitrária, e decidido antes da análise dos dados coletados, com variações entre 50 e $80 \%$. $^{110}$

A partir do consenso da primeira rodada, lança-se a segunda rodada, com a redefinição do questionário de coleta de dados para esse momento, onde serão excluídas as questões que obtiveram o consenso estipulado pelo pesquisador na primeira rodada e será apresentado o feedback das questões expostas anteriormente, ou seja, as questões que não obtiveram consenso na primeira rodada serão novamente apresentadas com a exposição estatística atingida em cada resposta, conforme a escolha do grupo. Nesse momento, o participante é solicitado a reavaliar seu posicionamento perante a previsão estatística do grupo, em cada questão. As situações expostas nas questões abertas devem ser confrontadas com a literatura científica atualizada da área da enfermagem e com os objetivos da pesquisa e, caso seja considerado pertinente, novas questões podem ser introduzidas nessa nova rodada. ${ }^{110}$ 
Esse processo se repete em rodadas subsequentes até que se atinja o consenso previamente definido ou até que o nível de discordância se reduza em nível de saturação. Ou seja, ao serem realizadas três a quatro rodadas e ainda haver questões em que o consenso não foi atingido. Recomenda-se que as questões que não atingiram consenso sejam descritas, analisadas e discutidas no escopo do trabalho. O prazo usual para aplicação completa da pesquisa utilizando o método Delphi é de quatro a doze meses. ${ }^{110,113}$

A literatura aponta que o método Delphi tem sido utilizado por uma variedade de campos como a economia, administração, ciências sociais, educação e outros. Também tem sido aplicado para pesquisa e educação na resolução de problemas, planejamento e avaliação, assim como, apresenta potencial para o desenvolvimento de pesquisas quantitativas, quando se pretende estabelecer consenso, perspectivas, ideias qualificadas, podendo subsidiar estudos científicos na área da enfermagem. ${ }^{109-111}$

O Delphi possibilitou a Witt ${ }^{116}$ estudar as competências da enfermeira na atenção básica, com identificação de competências gerais e específicas, permitindo a análise da contribuição das competências para a constituição das Funções Essenciais de Saúde Pública.

Neste estudo utilizou-se o Método Delphi com a intenção de apreender as competências a partir da experiência de quem está diretamente engajado na atenção domiciliar, de forma a permitir maior compreensão e aproximação da Enfermagem de Cuidados Paliativos com o mundo real do trabalho.

\subsection{LOCAL DO ESTUDO}

O estudo foi realizado em locais sugeridos pelos enfermeiros participantes após agendamento telefônico. A coleta de dados aconteceu nas dependências dos Núcleos Regionais de Atenção Domiciliar das regiões: Asa Norte, Asa Sul, Brazlândia, Ceilândia, Gama, Guará, Núcleo Bandeirante, Paranoá, Planaltina, Recanto das Emas, Samambaia, Santa Maria, São Sebastião, Sobradinho e Taguatinga.

\subsection{POPULAÇÂO E AMOSTRA DO ESTUDO}

A definição dos participantes do estudo foi em função dos parâmetros metodológicos postos pelo método Delphi, que propõe que seja obtido um consenso de grupo a respeito de um determinado fenômeno. Para este consenso, recomenda-se atentar para que a constituição 
do grupo seja de profissionais que estejam engajados com a área onde se está desenvolvendo a pesquisa, pela experiência e/ou por seus conhecimentos técnicos.

A população de estudo foi constituída pelo grupo de 23 enfermeiros vinculados às Equipes Multiprofissionais de Atenção Domiciliar da Secretaria de Saúde do Distrito Federal, no período de coleta de dados. Considera-se que o grupo é dotado de perspectivas a respeito do Cuidado Paliativo na Atenção Domiciliar, e que possa contribuir para a construção de um consenso acerca das competências, por meio da comparação das diversas opiniões.

A amostra foi composta por conveniência e constituída de 20 enfermeiros que aceitaram participar do estudo. Os critérios de inclusão no estudo foram enfermeiros vinculados a uma Equipe Multiprofissional de Atenção Domiciliar - EMAD da Secretaria de Saúde do Distrito Federal - SES-DF, no período de coleta de dados, que aceitassem colaborar mediante assinatura do Termo de Consentimento Livre e Esclarecido - TCLE. Os critérios de exclusão incluíram enfermeiros que não possuíam vínculo com uma EMAD da SES-DF e que não concordassem em assinar o TCLE.

\subsection{INSTRUMENTO E PROCEDIMENTO DE COLETA DE DADOS}

O desenvolvimento do estudo aconteceu em 4 fases. A primeira fase foi de composição de uma lista de competência, elaborada pela pesquisadora, baseada em literatura nacional e internacional advinda de artigos científicos, manuais de cuidados paliativos e livros

específicos sobre o tema. ${ }^{117-132}$ Esta fase compreendeu os meses de fevereiro a outubro de 2013.

A segunda fase foi de análise da lista de competência por um júri de três enfermeiros brasileiros que possuem experiência em cuidados paliativos e estão atualmente engajados em programas de atenção à saúde em cuidados paliativos. O júri foi composto por enfermeiros que trabalham em unidade hospitalar, ambulatorial e de assistência domiciliar, que não possuíam vínculo com Equipe Multiprofissional de Atenção Domiciliar - EMAD da Secretaria de Saúde do Distrito Federal - SES-DF. O contato com o júri foi feito pessoalmente, onde a pesquisadora explicitou os objetivos do estudo e a forma de colaboração dos mesmos. Esta fase ocorreu de outubro de 2013 a março de 2014, sendo enviada ao júri por email a lista de competência elaborada pela pesquisadora com 44 itens . A devolução da 
análise do júri também foi por meio eletrônico, considerando-se que ao devolver as contribuições os membros estariam consentindo sua participação no estudo, dispensando a assinatura do Termo de Consentimento Livre Esclarecido. O objetivo nesta fase do estudo foi de verificar a aplicabilidade das competências, clareza das informações e eliminar ambiguidades. Da análise do júri foi sugerido a retirada de 01 competência por apresentar ambiguidade.

$\mathrm{Na}$ terceira fase ocorreu a validação da lista de competência pelos Enfermeiros vinculados às Equipes Multiprofissionais de Atenção Domiciliar da Secretaria de Saúde do Distrito Federal, utilizando o Método Delphi, por meio de um questionário constituído da lista de 43 competências, acrescido de uma escala de Likert onde os participantes deveriam optar por um "item likert" disposto entre "discordo totalmente, discordo parcialmente, neutro, concordo parcialmente, concordo totalmente" para se obter o grau de concordância das competências pelos Enfermeiros. Nesse, consta uma questão aberta onde o participante poderia acrescentar competências que considerasse pertinente ao consenso e que não foram abarcadas no questionário proposto. $\mathrm{Na}$ parte inicial do questionário foi solicitado o preenchimento de dados que caracterizassem a amostra como: idade, sexo, estado civil, função exercida, carga horária de trabalho, tempo de trabalho no NRAD, outros vínculos empregatícios, tempo de formado na profissão, especializações cursadas, e participação em cursos que abordassem a temática de cuidados paliativos. O período de coleta de dados ocorreu entre os meses de março a junho do ano de 2014.

A primeira rodada do Método aconteceu em encontros presenciais agendados por telefone com os enfermeiros onde a pesquisadora, no agendamento, explicou sobre a o estudo e convidou-os a participar. Os questionários foram aplicados em locais sugeridos pelos enfermeiros. No dia de coleta a pesquisadora explicou os objetivos do estudo aos enfermeiros e os que aceitaram participar receberam o Termo de Consentimento Livre e Esclarecido (Apêndice - C) para assinatura e após, o Instrumento de coleta de dados para autopreenchimento (Apêndice - D). A pesquisadora ficou no ambiente de coleta enquanto os participantes respondiam ao questionário com o propósito de sanar dúvidas que porventura pudessem surgir.

Após a coleta de dados da primeira rodada, esses receberam o tratamento estatístico e foram confrontados com o nível de consenso estipulado de $70 \%$. A literatura científica revela que não há uma regra pré-determinada para estabelecê-lo, sendo o nível de consenso definido 
pelo pesquisador, de forma arbitrária, e decidido antes da análise dos dados coletados, com variações entre 50 e $80 \% .^{110}$

Após análise dos resultados da primeira rodada observou-se que não seria necessário a segunda rodada, pois a totalidade das competências obteve consenso acima do grau estipulado que foi de $70 \%$.

As situações expostas na questão aberta foram confrontadas com a literatura científica atualizada da área da enfermagem e com os objetivos do estudo e, não foram consideradas pertinentes para elaboração de novas competências, pois se referiam a posicionamentos pessoais generalizados sobre o papel do enfermeiro na condução dos cuidados paliativos na atenção domiciliar.

Cabe ressaltar que o Delphi não pretende realizar um levantamento estatisticamente representativo da opinião de um determinado grupo amostrado, mas sim uma consulta a um grupo limitado de especialistas, que por meio de sua capacidade de raciocínio lógico, da sua experiência e da troca objetiva de informações procura chegar a consensos sobre as questões propostas. $^{113}$

A quarta fase do estudo foi de descrição e análise dos dados conforme descrito no item que se segue.

\subsection{ANÁLISE DOS DADOS}

Para o tratamento dos dados criou-se um banco de dados na interface do programa Excel 2007 que possibilitou processamento e análise dos dados, com frequência e porcentagem das respostas obtidas com a escala de Likert, na busca de informações para o feedback do nível de concordância das respostas dos participantes do estudo e verificação da necessidade de outras rodadas de consenso. Os resultados foram expressos em frequência simples e percentual por meio de tabelas. Para a análise estatística de confiabilidade da lista de competências aplicou-se o coeficiente alfa de Cronbach considerando-se o conjunto das competências gerais e específicas.

Para analisar as competências gerais e específicas para o Cuidado Paliativo, requeridas dos enfermeiros que atuam na Atenção Domiciliar, sob a ótica das Diretrizes Curriculares Nacionais do Curso de Graduação em Enfermagem utilizou-se a Resolução CNE/CES $N^{\circ} 3$, 
de 7 de novembro de 2001, denominada Diretrizes Curriculares Nacionais do Curso de Graduação em Enfermagem (Anexo A). A mesma resolução foi utilizada para embasar a proposição de competências para o ensino de cuidados paliativos no curso de graduação em enfermagem.

\subsection{QUESTÕES ÉTICAS DO ESTUDO}

O presente estudo foi submetido ao Comitê de Ética em Pesquisa da Secretaria do Estado de Saúde do Distrito Federal (SES/DF) com aquisição de parecer favorável sob $\mathrm{n}^{\circ}$ 204.480 (Anexo B) autorizando a coleta de dados, sendo que para tal observou-se a Resolução do Conselho Nacional de Saúde no. 466/12.

Os participantes foram esclarecidos dos objetivos e sobre a existência de riscos e dos benefícios resultantes do estudo, assim como, o destino dos resultados que é a publicação científica. O risco que os participantes estavam expostos é o de exposição de informações pessoais, mas foi assegurado que seu nome não apareceria, sendo mantido o mais rigoroso sigilo por meio da omissão total de quaisquer informações que permitissem identificá-los quando na publicação dos resultados.

Informações adicionais foram fornecidas antes, durante e após a realização da coleta de dados estando o participante livre para desistir no momento em que optasse por esta decisão, sem que esta acarretasse danos pessoais ou profissionais para ele ou para a instituição em que trabalha. Os dados serão arquivados pela pesquisadora por cinco anos e após este período serão incinerados. 


\section{RESULTADOS E DISCUSSÃO}

\subsection{PERFIL SOCIOPROFISSIONAL DOS PARTICIPANTES DO ESTUDO}

Participaram desse estudo 20 enfermeiros sendo 95\% (19) do sexo feminino e 5\% (1) do sexo masculino. A média etária do grupo foi de 38,5 anos com desvio-padrão de 8,99. No que tange ao estado civil 50\% (10) são casados, $25 \%$ (5) solteiros e $25 \%$ (5) divorciados.

Observa-se na Tabela 1 as características socioprofissionais dos participantes, onde a maioria dos enfermeiros $(90 \%)$ possuía pós-graduação lato sensu; $65 \%$ referiram ter participado de cursos que abordassem a temática cuidados paliativos; $40 \%$ possuíam tempo de experiência profissional nos Núcleos Regionais de Atenção Domiciliar de 1mês a 2 anos, $40 \%$ de 3 a 5 anos; e $75 \%$ trabalhavam com dedicação exclusiva.

Tabela 6 - Perfil socioprofissional dos enfermeiros participantes. Brasília, 2014.

\begin{tabular}{|c|c|c|c|}
\hline Variáveis & Categoria & $\mathbf{n}$ & $\%$ \\
\hline \multirow[t]{3}{*}{ Tempo de graduação em enfermagem $(n=20)$} & 1 a 10 anos & 13 & 65 \\
\hline & 11 a 20 anos & 5 & 25 \\
\hline & 21 a 30 anos & 2 & 10 \\
\hline \multirow[t]{3}{*}{ Titulação acadêmica $(\mathrm{n}=\mathbf{2 0})$} & Graduação & 2 & 10 \\
\hline & Especialização* & 17 & 85 \\
\hline & Mestrado & 1 & 5 \\
\hline \multirow{2}{*}{$\begin{array}{l}\text { Participação em curso com conteúdos sobre } \\
\text { cuidados paliativos }(n=20)\end{array}$} & Sim & 13 & 65 \\
\hline & Não & 7 & 35 \\
\hline \multirow[t]{4}{*}{ Tempo de vínculo na EMAD/EMAP $(\mathrm{n}=20)$} & 1 mês a 2 anos & 8 & 40 \\
\hline & 3 anos a 5 anos & 8 & 40 \\
\hline & Mais que seis anos & 1 & 5 \\
\hline & Não informado & 3 & 15 \\
\hline \multirow{3}{*}{$\begin{array}{l}\text { Carga horária semanal de trabalho na } \\
\text { EMAD/EMAP }(\mathbf{n}=20)\end{array}$} & 20 horas & 2 & 10 \\
\hline & 40 horas & 17 & 85 \\
\hline & 60 horas & 1 & 5 \\
\hline \multirow[t]{2}{*}{ Outros vínculos empregatícios $(\mathrm{n}=\mathbf{2 0})$} & Sim & 5 & 25 \\
\hline & Não & 15 & 75 \\
\hline
\end{tabular}

* Especializações referidas: administração hospitalar, auditoria em saúde, docência do ensino superior, enfermagem do trabalho, enfermagem em terapia intensiva, enfermagem psiquiátrica, estomaterapia, gerontologia, gestão e auditoria em saúde, neonatologia, obstetrícia, pediatria, regulação em saúde, saúde coletiva, saúde da família, saúde pública, teologia, terapia intensiva, transporte aeromédico, urgência e emergência, unidade de terapia intensiva neonatal. 


\subsection{COMPETÊNCIAS DO ENFERMEIRO PARA O CUIDADO PALIATIVO NA ATENÇÃO DOMICILIAR ${ }^{5}$}

Cuidado de qualidade ao fim da vida depende de uma equipe interdisciplinar de saúde emparelhada com habilidades interpessoais fortes, conhecimento clínico, competência técnica e respeito para com os indivíduos. ${ }^{133}$

O cuidado paliativo como atividade assistencial requerida dos profissionais de saúde que trabalham na atenção domiciliar, aliado ao aumento da morbidade e mortalidade por doenças crônicas degenerativas a nível mundial, insufla a necessidade de assistência multiprofissional a pacientes que enfrentam doenças que ameaçam a vida. Nesse contexto, a Organização Mundial de Saúde propõe conceitos e diretrizes para esse cuidado, onde impera uma abordagem que permita a melhor qualidade de vida a pacientes e suas famílias, por meio da identificação, avaliação e tratamento de problemas de ordem física, psicossocial e espiritual. $^{29,131,134}$

$\mathrm{Na}$ equipe multidisciplinar de cuidados paliativos, os profissionais de enfermagem estão na linha de frente para prover cuidado, conforto e aconselhamento de famílias e pacientes. Nesta interação, o sucesso na execução do cuidado advém da relação estabelecida entre paciente-enfermagem e do interesse e vontade desses para exercer os cuidados ao fim da vida. ${ }^{133,135}$

O lidar com a morte e o morrer no cotidiano dos enfermeiros associado à inexperiência clínica, a falta de treinamentos e suporte emocional adequado, são apontados como obstáculos ao atendimento de qualidade a pacientes que se encontram em final de vida, e em última instância, influenciam na expressão da competência desses profissionais. ${ }^{136}$

Ao administrar uma situação complexa a competência profissional consiste em saber mobilizar e combinar de modo pertinente um conjunto de recursos pessoais e do meio. A construção de competências favorece a formação de esquemas de mobilização de recursos que permitem ao sujeito aplicá-los em suas atividades cotidianas, em função de um projeto que comporta para ele uma significação, ao qual ele dá um sentido. ${ }^{137}$

5 Artigo submetido à Revista ACTA Paulista de Enfermagem em 18/10/2014 e aceito para publicação em 15/12/2014. O artigo na íntegra encontra-se no item APÊNDICE E. 
A operacionalização das competências resulta da qualidade da interface entre o homem e a situação de trabalho, onde o profissionalismo e a competência emergem de um saber agir, de um querer, e de um poder agir. Assim, o mapeamento de competências agrega valor econômico e valor social a indivíduos e organizações, na medida em que contribuem para a consecução dos objetivos organizacionais e expressam o reconhecimento social sobre a capacidade das pessoas. Cabe salientar que as competências requeridas de um profissional permeiam a competência desejada no indivíduo e o sistema de papéis estabelecido entre os atores sociais. $^{138}$

A competência revela-se no saber agir responsável que é reconhecido pelos outros, numa dinâmica que implica em saber mobilizar, integrar e transferir recursos, conhecimentos e habilidades num contexto profissional determinado. Assim, para atender ao objetivo de identificar competências do enfermeiro para o cuidado paliativo na atenção domiciliar utilizou-se do Método Delphi, que consiste num processo estruturado para recolha e síntese de conhecimentos de um grupo de profissionais por meio de uma série de questionários, acompanhados de um feedback de opiniões, que se repete em rodadas subsequentes até que se atinja o consenso previamente definido ou até que o nível de discordância se reduza em nível de saturação. ${ }^{139}$

Das 43 competências apresentadas para julgamento dos enfermeiros, obtiveram consenso favorável, com porcentagem acima de 75\%, 18 competências gerais e 25 competências específicas. Na tabela 1 e tabela 2 observa-se coeficiente alfa de Cronbach acima de 0,7 para todas as competências elencadas.

Os resultados apontaram consenso no grau de concordância total para 17 das competências gerais e apenas 01 competência ("constatar mudanças dinâmicas na demografia da população") obteve consenso com o grau de concordância parcial. No que tange as competências específicas estas obtiveram consenso na sua totalidade no grau de concordância total.

Para realizar uma atividade com competência o profissional constrói um esquema operacional próprio que lhe permite executar atividades com competência, organizando sua conduta profissional. Neste caminho, regras são cumpridas e servem para dizer para onde devemos ir, indicando que o percurso é singular, pois impera a possibilidade de se resolver um problema com competência de diversas formas. ${ }^{138}$ 
Tabela 7 - Grau de concordância e coeficiente alfa de Cronbach do instrumento de avaliação das competências gerais. Brasília, 2014.

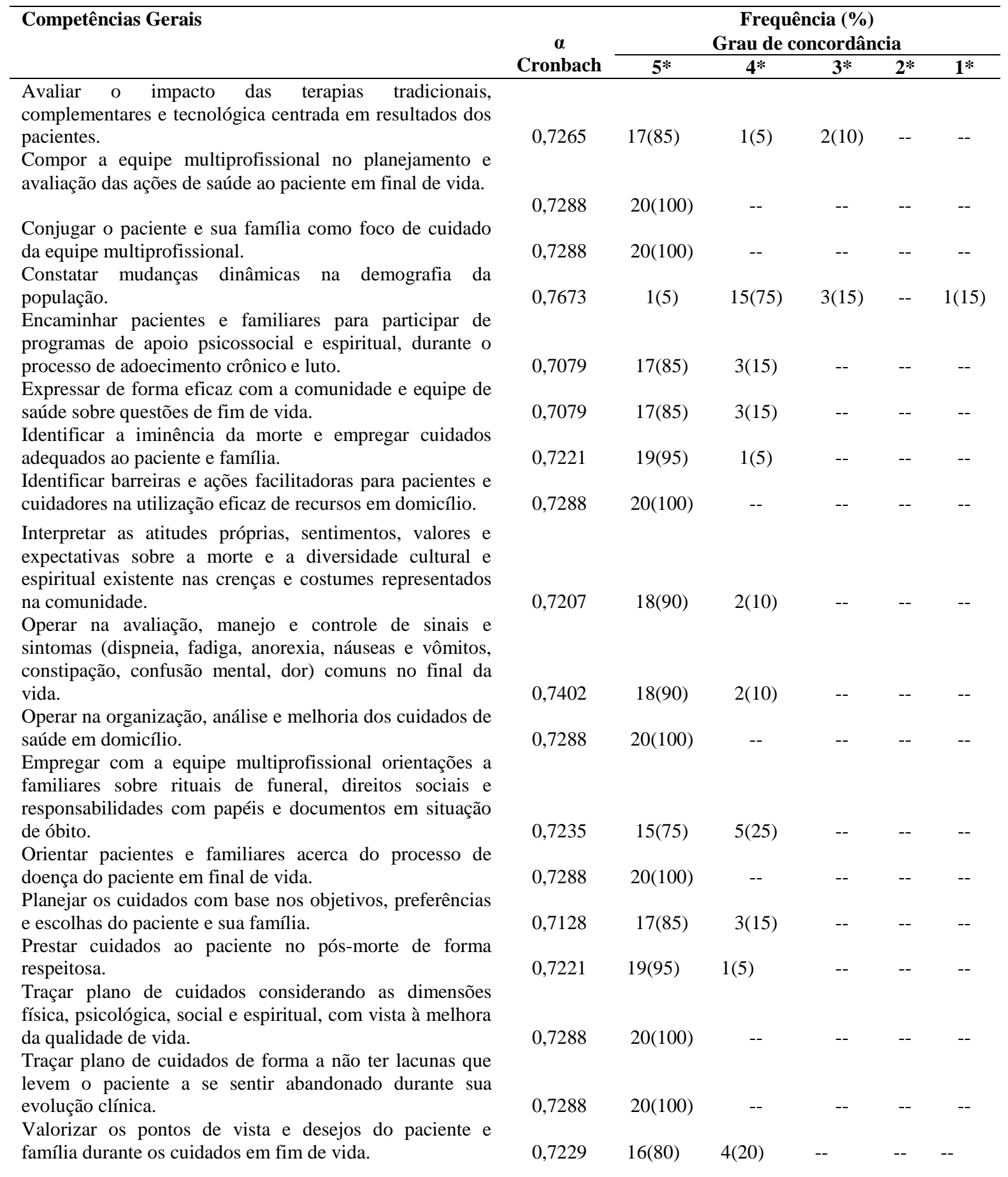

*Grau de concordância - 5(concordo totalmente), 4(concordo parcialmente), 3(neutra), 2(discordo parcialmente) e 1(discordo totalmente) 
Tabela 8 - Grau de concordância e coeficiente alfa de Cronbach do instrumento de avaliação das competências específicas. Brasília, 2014.

(continua)

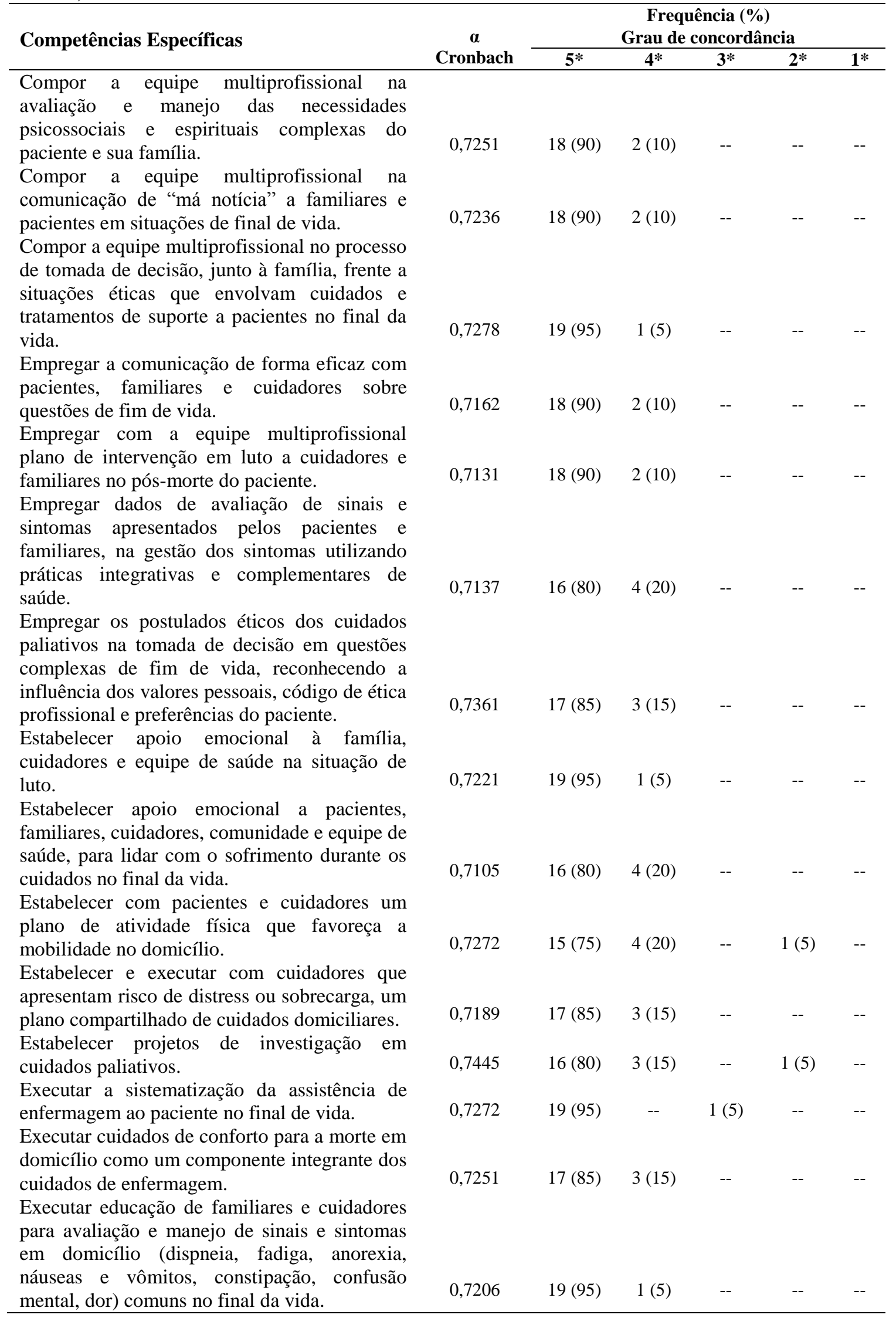


Tabela 8 - Grau de concordância e coeficiente alfa de Cronbach do instrumento de avaliação das competências específicas. Brasília, 2014.

(conclusão)

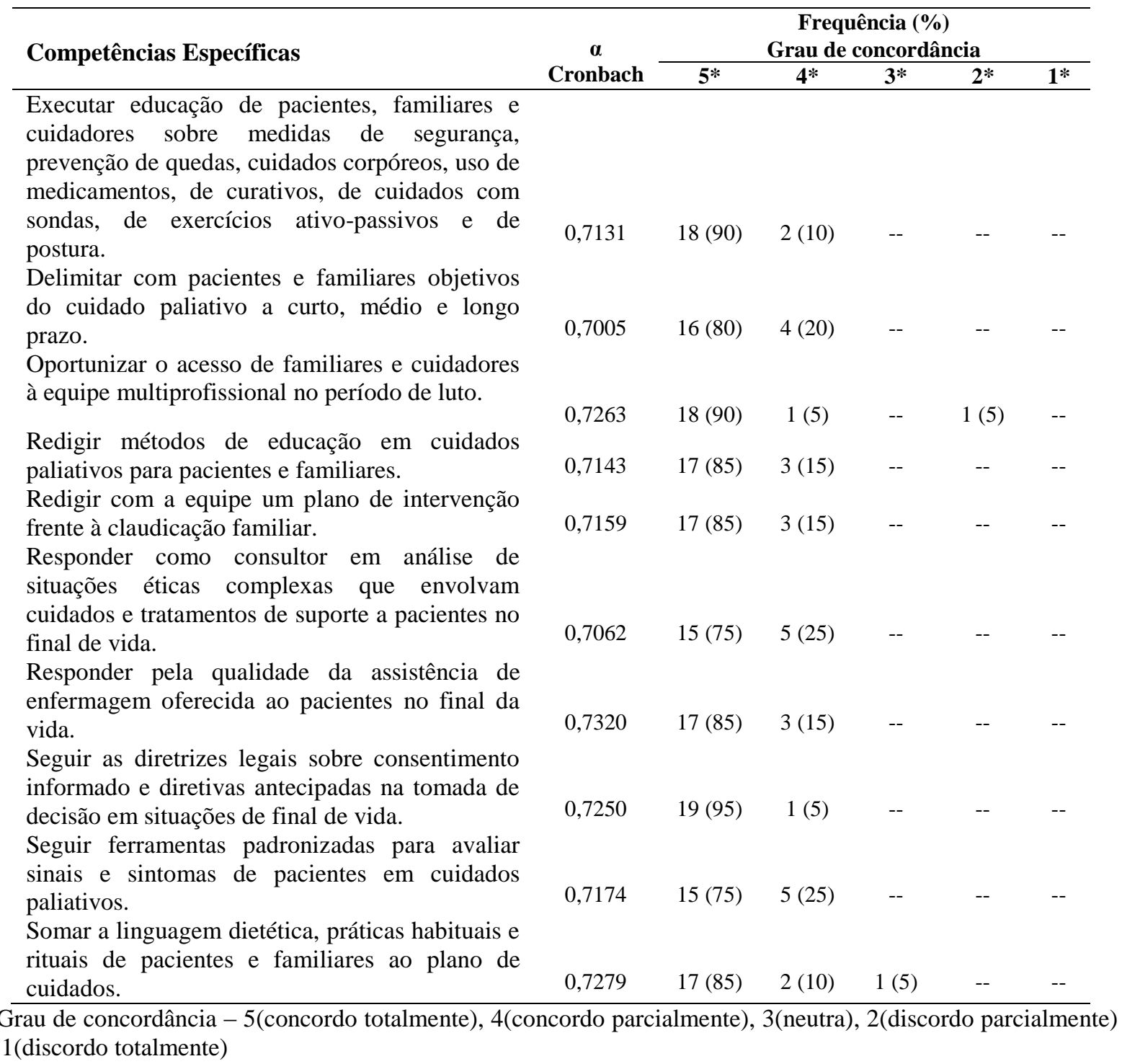

$\mathrm{Na}$ resolução de um problema o indivíduo implementa o que aprendeu a organizar durante a sua experiência profissional, e na possibilidade de situações repetidas ele não deveria fazer igual, mas poderá responder de forma semelhante. Diante disso, chama-se a atenção para o risco de um perfil comportamental único, que engesse o profissional numa postura assistencial que impossibilite a singularidade, o inesperado ou o inusitado contido nos eventos. A competência se revela em saber como agir, no aqui e agora, para além do que está prescrito, quando defrontamos com eventos de aparência conhecida, mas de expressão inesperada. ${ }^{138}$ 
No contexto dos cuidados paliativos, a atenção domiciliar é imprescindível para garantir a continuidade do processo de cuidados e dar respostas às múltiplas necessidades sociossanitárias que apresentam os pacientes que enfrentam doenças que ameaçam a vida, principalmente em países onde há limitações de recursos na saúde e acesso reduzido a cuidados institucionais. O desafio nessa modalidade de assistência consiste em evitar a fragmentação assistencial por meio de práticas organizativas e de integração de serviços de saúde e sociais. $^{140}$

No estudo, o consenso unânime em 6 competências gerais (Tabela 7) expõe a concordância dos enfermeiros com a postura paliativista de trabalho interdisciplinar, com foco nas necessidades do paciente e família, na busca da melhor qualidade de vida. Cabe ressaltar o desafio aqui posto pelo trabalho em equipe, que consiste no partilhar uma filosofia comum de cuidados e objetivos comuns. ${ }^{141}$

O coeficiente alfa de Cronbach que avalia a magnitude em que os itens de um instrumento estão correlacionados revelou que a lista de competências proposta apresentou confiabilidade na amostra onde foi aplicada. As competências gerais e específicas consensuadas pelos enfermeiros do estudo corroboram aos achados na literatura por refletirem a autonomia, dignidade, comunicação, relação entre doente e profissional de cuidados de saúde, abordagem multiprofissional, qualidade de vida, posição em relação à vida e à morte, perda e luto, e educação pública como elementos centrais para assistência em cuidado paliativo. $^{123-124,142}$

A competência geral identificada "constatar mudanças dinâmicas na demografia da população", obteve consenso no grau de concordância parcial pela maioria dos enfermeiros, o que pode indicar que o conhecimento sobre a abordagem da territorialidade é incipiente enquanto saberes e fazeres a serem compartilhados na multidisciplinaridade. Esse conhecimento contribui para a produção do cuidado à saúde, assim como, para a constituição das redes de cuidado, na medida em que reconhece e utiliza os equipamentos sociais nos fluxos assistenciais. A doença que limita a vida tem impacto nas relações interpessoais dos doentes e famílias, e perceber quando e como referenciar para uma ajuda especializada, oportuniza o acesso a recursos adicionais pra que pacientes e familiares sejam capazes de manter uma boa qualidade de vida no fim da vida. ${ }^{131,141-142}$ 
O contido nos enunciados das competências foi reconhecido enquanto saberes e fazeres do enfermeiro em cuidados paliativos. O consenso nas competências específicas no grau de concordância total aponta uma confiança no potencial paliativista do enfermeiro por afirmarem serem capazes de antecipar e responder as necessidades de cuidados paliativos, bem como compreender as suas próprias limitações e a necessidade de procurarem ajuda para ações complexas. ${ }^{131}$

O baixo percentual assinalado pelos enfermeiros no grau de concordância parcial e discordância em algumas competências específicas (Tabela 8), pode indicar a necessidade de aquisição de conhecimentos acerca dos cuidados paliativos para manter e desenvolver suas próprias competências profissionais. A maioria dos enfermeiros afirmou ter participado de cursos que abordassem a temática cuidados paliativos, e a literatura aponta que todos os profissionais de saúde devem adquirir educação sobre os princípios e as práticas dos cuidados paliativos, num crescente que perpasse a formação inicial chegando a um nível de conhecimento especializado, principalmente aqueles cujo trabalho está focado na prestação de cuidados paliativos. ${ }^{123}$

A originalidade desta pesquisa impele a novos estudos nesse contexto, onde espera-se que a comunidade acadêmica refute ou amplie a reflexão dos resultados apresentados, contribuindo para a consolidação dos cuidados paliativos enquanto disciplina e especialidade em enfermagem.

O consenso favorável obtido nas competências propostas indica o reconhecimento do cuidado paliativo como prática assistencial de enfermagem na atenção domiciliar, e fornece afirmações assertivas sobre a competência do enfermeiro em cuidado paliativo na atenção domiciliar.

Os resultados oferecem subsídios a instituições quando na formulação de competências esperadas do profissional enfermeiro na assistência domiciliar, assim como, aponta limites dessa atuação no contexto interdisciplinar da atenção domiciliar. Contribui como ponto de partida para construção de competências em enfermagem de cuidados paliativos e reforça a necessidade de preparação específica para se garantir adequada implementação dos cuidados paliativos no cenário nacional. 


\subsection{COMPETÊNCIAS PARA O CUIDADO PALIATIVO SOB A ÓTICA DAS DIRETRIZES CURRICULARES NACIONAIS DO CURSO DE GRADUAÇÃO EM ENFERMAGEM.}

O trabalho em saúde solicita uma postura reflexiva onde as decisões a serem tomadas estejam articuladas aos diversos saberes que provêm de bases científicas e instrumentais, com ênfase no conhecimento científico, nas bases tecnológicas, no conhecimento técnico, na experiência de trabalho, mediados pela dimensão ético-política. ${ }^{96}$

Ampliar a qualificação dos trabalhadores em saúde, tanto na dimensão técnica especializada, quanto na dimensão ético-política, comunicacional e de inter-relações pessoais, é fundamental para que possam participar como sujeitos integrais no mundo do trabalho em saúde contemporâneo. ${ }^{71,143}$

O ensino na perspectiva da formação profissional requer que se estimulem os alunos a aprender e construir conhecimentos passíveis de serem empregados de forma eficiente na realidade. As contingências do mundo contemporâneo exigem trabalhadores capazes de enfrentar os desafios de uma realidade cambiante, onde o processo de se instrumentalizar recai sobre os ombros dos trabalhadores que precisam identificar quais competências desenvolver, de forma que os mantenham ativos no mercado de trabalho. ${ }^{144}$

Neste enfoque, espera-se que o enfermeiro seja capaz de avaliar e gerir a qualidade de suas ações, o que implica em compreender qual a qualidade requerida nos vários contextos onde ocorre o cuidado em enfermagem, ponderar as opções possíveis e realizá-las, tendo como meta a eliminação dos riscos envolvidos na assistência. Para tanto, há a necessidade de combinar as bases científicas, instrumentais e tecnológicas de conhecimentos, habilidades e atitudes com as exigências da prática específica, incorporando a ética como elemento indissociável de um desempenho competente.

Cuidar de pacientes com uma doença limitante de vida pode acontecer em todos os cenários de saúde. O fenômeno natural de morrer inevitavelmente atinge os seres humanos, e reflexões acerca do tema deveriam perfazer a formação desde o período escolar, para que, na formação dos profissionais de saúde e, sobretudo na prática dos profissionais em exercício, 
estes pudessem estar preparados para o acompanhamento de pacientes em final de vida.

Os cuidados paliativos abrangem uma perspectiva de cuidado onde o indivíduo é visto dentro das dimensões que o compõem, considerando não somente sua dimensão física, mas também as preocupações psicológicas, sociais e espirituais do existir humano. Neste contexto, o tratamento paliativo é uma parte dos cuidados paliativos que visa ao controle da dor e de outros sintomas físicos como fadiga, problemas respiratórios, desordem mental, orgânica, etc. O cuidado paliativo amplia-se na capacitação do indivíduo que está morrendo a viver o mais plenamente possível a própria morte, onde o tratamento paliativo oferece suporte para o controle de sintomas físicos que interfeririam em outras atividades como dialogar com família e amigos, dentre outras, que sejam significativas para o indivíduo nesse processo de morrer. ${ }^{145}$

As competências explicitadas nas Diretrizes Curriculares dos cursos de graduação em Enfermagem - DCN/ENF traduzem-se no exercício de competências gerais e específicas necessárias para atuação no mundo do trabalho. ${ }^{96}$

Os enfermeiros participantes deste estudo consensuaram competências gerais e específicas para o desempenho dos cuidados paliativos na atenção domiciliar, e nos parágrafos que se seguem as competências gerais são apresentadas por domínios de competências conforme explicitadas nas DCN/ENF. Cabe ressaltar que a fragmentação das competências gerais por domínios só é possível enquanto abstração com caráter analítico, pois na prática profissional se configuram num conjunto em constante articulação.

As competências gerais são abordadas pela prática profissional de atenção à saúde (estar apto a desenvolver ações de prevenção, promoção, proteção e reabilitação da saúde, no nível individual e coletivo), tomada de decisões (capacidade de tomar decisões, por meio da competência e habilidade de avaliar, sistematizar e decidir as condutas mais adequadas), comunicação (uso da comunicação verbal, não verbal e de habilidades de escrita e leitura, com domínio da língua estrangeira e de tecnologias de comunicação e informação), liderança (refere-se ao trabalho em equipe multiprofissional para assumir posições de liderança), administração e gerenciamento (profissionais aptos a tomar iniciativa, a realizar o gerenciamento e administração da força de trabalho, recursos físicos e materiais e de informação), e educação permanente (capacidade de aprender continuamente na formação e na prática). Essas competências são esperadas do exercício profissional do enfermeiro com os 
demais profissionais de saúde. ${ }^{96}$

Ao relacionarmos o domínio atenção à saúde com as competências: "conjugar o paciente e sua família como foco de cuidado da equipe multiprofissional", "operar na avaliação, manejo e controle de sinais e sintomas (dispneia, fadiga, anorexia, náuseas e vômitos, constipação, confusão mental, dor) comuns no final da vida", "planejar os cuidados com base nos objetivos, preferências e escolhas do paciente e sua família", "traçar plano de cuidados considerando as dimensões física, psicológica, social e espiritual, com vista à melhora da qualidade de vida", verificamos a dimensão humana e ética da assistência por meio da valorização profissional dos julgamentos do paciente, ou de seu familiar, sobre aspectos de saúde que ele identifique como facilitares da melhora de sua condição.

O controle adequado de sintomas é fundamental em cuidados paliativos, pois estes geram sofrimento que pode consumir os pacientes e tirar-lhes a vontade de viver. Os sintomas não controlados comprometem a qualidade de vida dos pacientes, dificultam suas interações com os entes queridos e interferem na sua capacidade de cuidar de questões importantes no final da vida. ${ }^{146}$

Para ocorrer o cuidado domiciliar é preciso a presença do cuidador, que pode ser ou não um familiar, que se disponibiliza a prestar os cuidados de maneira contínua e regular, em conformidade com as ações pactuadas entre paciente, família, equipe e cuidador, num contínuo que permita a democratização dos saberes, poderes e responsabilidades. Observa-se com muita frequência que o papel do cuidador é exercido por um familiar, devido às dificuldades financeiras da maioria das famílias em pagar os serviços de um cuidador formal. ${ }^{147}$

$\mathrm{Na}$ abordagem paliativa a família é simultaneamente prestadora e receptora de cuidados. Por vezes, é o familiar que melhor consegue interpretar sinais que indiquem desconforto e sofrimento do paciente, quando há limitações na manifestação em virtude de seu estado clínico. ${ }^{148}$

Quando em uma família um membro recebe o diagnóstico de doença sem possibilidades de cura, sua organização e funcionamento sofrem alterações, tornando-se evidentes os conflitos internos pré-existentes. O impacto da doença no ambiente familiar depende da personalidade e circunstâncias pessoais do paciente, da natureza e qualidade das 
relações familiares, das reações do paciente e da família em perdas anteriores, da estrutura prévia da família e do apoio da comunidade. ${ }^{149}$

Na atuação da equipe de atenção domiciliar, a escuta das preferências e necessidades do paciente e cuidador, permitem não somente a recolha de informações como o planejamento em conjunto das intervenções pertinentes, favorecendo a definição dos papéis assistências da equipe e do cuidador. ${ }^{147}$

No cuidado domiciliar é preciso delegar à família e ao cuidador o cuidado, mas para isto, se faz necessário inicialmente à instrumentalização da família, com ensino e supervisão do cuidado por parte dos profissionais de saúde. ${ }^{147}$

Uma rotina permeada pela disposição pessoal para uma rotina de trabalho complexa, com valorização da escuta ativa entre os membros, com troca precisa de informações e compartilhamento das responsabilidades e das dificuldades vividas pela equipe, é o diferencial para ações de sucesso na equipe multiprofissional de cuidados paliativos. ${ }^{150}$

$\mathrm{Na}$ tomada de decisões competências como: "avaliar o impacto das terapias tradicionais, complementares e tecnológica centrada em resultados dos pacientes", “compor a equipe multiprofissional no planejamento e avaliação das ações de saúde ao paciente em final de vida", "identificar a iminência da morte e empregar cuidados adequados ao paciente e família", "prestar cuidados ao paciente no pós-morte de forma respeitosa", "operar na organização, análise e melhoria dos cuidados de saúde em domicílio", refletem a atenção do profissional no uso apropriado de recursos, com vistas à eficácia nos procedimentos e práticas, solicitando que se avalie, sistematize e decida por condutas adequadas aos contextos de domicílio

Uma das características essenciais do cuidado paliativo em domicílio são previsões de complicações futuras e medidas pertinentes para sua resolução, conforme o quadro clínico de cada paciente, considerando-se as características do universo de cuidados e cuidadores. Facilitar o uso de recursos, como por exemplo, prever e prover medicamentos básicos e treinamento do cuidador para sua administração permite que o cuidado seja efetivo, evitando deslocamentos desnecessários a serviços de emergências. ${ }^{53}$

$\mathrm{Na}$ equipe multidisciplinar em cuidados paliativos as decisões tomadas devem partir de uma reflexão conjunta expressa num consenso, para que ao transmitir informações ao 
paciente, familiares e demais cuidadores não haja divergência de opiniões. Esse consenso deve ser registrado no prontuário do paciente para que se possa reafirmar e validar a conduta da equipe. ${ }^{2}$

Reconhecer o processo iminente de morte em cuidados paliativos não é uma tarefa fácil, mas consiste em perceber que a partir de um determinado momento da evolução de um paciente, as disfunções são irreversíveis e todo tratamento que se pretenda oferecer implica em prolongamento do sofrimento. Nesta fase, o quadro clínico do paciente é avaliado mais que uma vez ao dia para que novas condutas possam ser tomadas com prontidão. ${ }^{151}$

Nas "ultimas horas" sinais e sintomas como anorexia e nenhuma ingestão de líquidos, imobilidade, sonolência, alteração cognitiva, delirium, mioclônus, exacerbação de dor, colapso periférico (palidez cutânea, extremidades frias, pele marmórea, cianose periférica), falências funcionais, ronco (respiração ruidosa, plena de secreções) podem surgir e acompanhar o paciente progressivamente até que a morte aconteça. Neste processo, geralmente os familiares percebem a gravidade e irreversibilidade do quadro e ao se preservar a tranquilidade na execução dos cuidados ao paciente e ao tratar os sinais e sintomas exacerbados, a espiritualidade da família transforma o momento de partida, onde a morte acontece com serenidade. Cabe ressaltar que as decisões são mutáveis até as vias finais, porém, uma vez acordado sobre o provável local de falecimento, é preciso buscar antecipadamente os recursos necessários para que isto ocorra com tranquilidade. ${ }^{53,151}$

No que tange a comunicação, as competências: "orientar pacientes e familiares acerca do processo de doença do paciente em final de vida", "expressar de forma eficaz com a comunidade e equipe de saúde sobre questões de fim de vida", expressam a necessidade dessa ferramenta como facilitadora da acessibilidade do paciente ao cuidado, e como intermediadora das relações interpessoais com a equipe e comunidade.

Ao depara-se com situações de dor, sofrimento e incertezas na etapa final da vida, é necessária uma atenção exímia e diferenciada às múltiplas facetas do sofrimento, sendo as habilidades de comunicação imprescindíveis ao profissional de saúde, em virtude de contribuírem para o impecável controle de dor e sintomas, além de possibilitarem o acesso e a atenção às necessidades emocionais, espirituais e sociais do paciente e seu núcleo familiar. ${ }^{2}$

Pacientes em cuidados paliativos tem que viver com a incerteza, a finitude, a vulnerabilidade e os limites que o processo de morte impõe. Assim sendo, a comunicação 
sobre o tema da morte pode ajudar a clarificar crenças, sentimentos, comportamentos sobre o que é prioritário em nossas vidas, assim como, oferece expectativas realistas permitindo algum grau de controle, de qualidade e de finalidade durante o tempo de vida, permitindo o diálogo e favorecendo a tomada de providências neste momento tão difícil como é o da morte. $^{152}$

Observa-se com frequência que o enfermeiro pelo contato constante com os sentimentos vividos pelos pacientes e familiares com a aproximação da morte, coloca-se diante do conflito de como posicionar-se frente ao sofrimento e a dor, que nem sempre pode aliviar, e também têm que elaborar perdas de pacientes com quem criou vínculos mais estreitos. O convívio com a dor, morte e perda acarreta para o enfermeiro a vivência de seus processos internos, de sua fragilidade, vulnerabilidade, medos e incertezas, muitas vezes sem espaço para compartilhamento, levando-o a uma sobrecarga, conhecida como Síndrome de Burnout (colapso que se manifesta por sintomas físicos e psíquicos que em circunstâncias mais graves conduz ao adoecimento e à incapacitação para o trabalho). ${ }^{152}$ Saber expressar-se de forma eficaz com a equipe multiprofissional sobre os dilemas pessoais que surgem frente ao sofrimento do paciente, auxiliam na manutenção da saúde do profissional neste contexto de trabalho.

$\mathrm{Na}$ liderança, administração e gerenciamento, competências como: "constatar mudanças dinâmicas na demografia da população", "encaminhar pacientes e familiares para participar de programas de apoio psicossocial e espiritual, durante o processo de adoecimento crônico e luto", "empregar com a equipe multiprofissional orientações a familiares sobre rituais de funeral, direitos sociais e responsabilidades com papéis e documentos em situação de óbito", "identificar barreiras e ações facilitadoras para pacientes e cuidadores na utilização eficaz de recursos em domicílio", "traçar plano de cuidados de forma a não ter lacunas que levem o paciente a se sentir abandonado durante sua evolução clínica", explicitam o compromisso, responsabilidade, habilidade para tomada de decisões, comunicação e gerenciamento das ações em prol da qualidade do cuidado oferecido ao paciente e família em final de vida.

As famílias necessitam de informação sobre como fornecer um conforto melhor, como falar com outros membros da família a respeito da doença do paciente, como lidar com o tratamento e com os efeitos colaterais da medicação, e como antecipar as mudanças dentro da condição do paciente e dentro da família. A informação deve ser focada às necessidades do 
momento e aos desafios do dia-a-dia. Dar atenção às necessidades dos membros da família auxilia para que os esforços de cuidados possam ser mantidos. Neste cenário, observa-se que os enfermeiros têm as melhores condições para planejar, implementar, e avaliar estratégias de apoio às famílias, incluindo apoio para lidar com a perda, com as incertezas a respeito da doença, com a possibilidade de morte iminente, com a comunicação dentro da família e com o próprio estresse psicológico de cada um. ${ }^{149}$

Devido às características dos pacientes que recebem cuidados paliativos, e da filosofia que orienta o cuidado paliativo, ao gerenciar os cuidados de enfermagem, o enfermeiro deve considerar a importância de se valorizar o preparo dos profissionais que atuam nessa área. Nesse sentido, é necessário que os enfermeiros aprendam a tomar decisões, a partir do olhar de como a ética se insere no processo do planejamento da assistência paliativista. Sabemos que muito depende de cada profissional quanto a procurar conhecimento e trabalhar seus próprios conflitos com compromisso, a fim de assistir o paciente com responsabilidade.

No gerenciamento em cuidado paliativo as relações de trabalho se desenvolvem por meio do fluxo de informação e comunicação, das necessidades e conflitos que surgem durante o processo de trabalho, e são influenciadas pelo ambiente no qual o profissional desenvolve suas potencialidades, bem como pelos padrões de conduta assumidos pelo grupo. Portanto, a efetividade das ações de enfermagem também depende das relações de trabalho que se estabelecem entre a equipe multidisciplinar e a equipe de enfermagem ao longo do processo. $^{153}$

A equipe de enfermagem está predisposta a maior vulnerabilidade quando na presença de determinadas carências, como competência, autonomia e recursos de trabalho reduzidos (realização de procedimentos sem condições adequadas), pois esses influenciam as ações de enfermagem propostas, por comprometerem a coordenação, desenvolvimento e avaliação, reduzindo a capacidade da equipe de atender as necessidades dos pacientes, e em última instância à qualidade da assistência prestada. ${ }^{153}$

A prática de cuidados paliativos requer da equipe de assistência domiciliar preparo para esta intervenção, para que a abordagem integral do paciente e seu entorno aconteça desde o controle de sintomas ao auxílio à criação de redes de apoio para o cuidado domiciliar no final da vida. ${ }^{53}$ 
No que tange a educação permanente, as competências: "interpretar as atitudes próprias, sentimentos, valores e expectativas sobre a morte e a diversidade cultural e espiritual existente nas crenças e costumes representados na comunidade", "valorizar os pontos de vista e desejos do paciente e família durante os cuidados em fim de vida", expõem a necessidade da aquisição contínua de competências que estejam de acordo com as necessidades dos cenários de saúde, para que resultem em atitudes que sejam capazes de mudanças qualitativas no processo de trabalho.

Em cuidados paliativos observa-se que as necessidades dos pacientes transcendem à dor física, às rupturas sociais e aos transtornos psiquiátricos. As dimensões espirituais dos cuidados paliativos incluem a consideração de práticas religiosas do paciente, mas também contempla aquilo que pode ser descrito como questões existenciais do indivíduo. Preocupações como a perda do sentido de significado, relacionamentos desfeitos com pessoas queridas, dificuldades com o conceito pessoal de divindade, sentimentos de raiva ou culpa e sentimentos de desespero, entre outras, estão na lista de fatores que somados a necessidades religiosas não resolvidas, causam sofrimento espiritual e também podem gerar transtornos psiquiátricos como depressão ou ansiedade, além de acentuar as sensações de dor física do paciente. $^{146}$

Os profissionais de saúde ao assistir a família enlutada, necessitam estar atentos à própria história de luto e atitudes para com a morte, o ato de morrer e a perda. A experiência pessoal é a base para que se possa auxiliar os outros a expressarem seus sentimentos. É inevitável que os enfermeiros tragam à tona suas experiências do passado para fazer face ao presente, pois precisam distinguir entre sua própria maneira de responder e a forma com que as outras pessoas respondem. A busca de conhecimento sobre perda e luto é necessária quando se pretende estar presente com a família nos estágios do luto. $\mathrm{O}$ enfermeiro precisa ser capaz de reconhecer e facilitar a expressão de sentimentos por parte do paciente e da família, e não ter experiência pessoal ou educação quanto ao luto e perda pode levá-los a se sentir excluídos. $^{154}$

No que se referem às competências específicas, as DCN/ENF colocam que o enfermeiro deve possuir competências técnico-científicas, ético-políticas e socioeducativas contextualizadas que permitam estabelecer relações, compreender os contextos sociais de prática em saúde, reconhecer as relações de trabalho, atuar nos programas de saúde em cenários diversos, intervir nos processo de saúde/doença, planejar e gerenciar o processo de 
trabalho em enfermagem, dentre outras. ${ }^{96}$

Nesta perspectiva, no parágrafo que se segue, fragmentamos as competências específicas consensuadas neste estudo, sob afirmativas que conferem pertinência as competências requeridas do enfermeiro para o cuidado paliativo na atenção domiciliar.

A competência do enfermeiro em cuidados paliativos na atenção domiciliar se legitima,

... pela natureza do processo de trabalho ao:

- executar cuidados de conforto para a morte em domicílio como um componente integrante dos cuidados de enfermagem;

- responder pela qualidade da assistência de enfermagem oferecida ao pacientes no final da vida;

... pela teia de relações com os outros componentes do processo de trabalho ao:

- compor a equipe multiprofissional na avaliação e manejo das necessidades psicossociais e espirituais complexas do paciente e sua família;

- compor a equipe multiprofissional na comunicação de "má notícia" a familiares e pacientes em situações de final de vida;

- compor a equipe multiprofissional no processo de tomada de decisão, junto à família, frente a situações éticas que envolvam cuidados e tratamentos de suporte a pacientes no final da vida;

- empregar com a equipe multiprofissional plano de intervenção em luto a cuidadores e familiares no pós-morte do paciente;

- oportunizar o acesso de familiares e cuidadores à equipe multiprofissional no período de luto;

... pelo grau de autonomia e independência ao:

- estabelecer apoio emocional a pacientes, familiares, cuidadores, comunidade e equipe de saúde, para lidar com o sofrimento durante os cuidados no final da vida; 
- empregar dados de avaliação de sinais e sintomas apresentados pelos pacientes e familiares, na gestão dos sintomas utilizando práticas integrativas e complementares de saúde;

- estabelecer e executar com cuidadores que apresentam risco de distress ou sobrecarga, um plano compartilhado de cuidados domiciliares;

- estabelecer com pacientes e cuidadores um plano de atividade física que favoreça a mobilidade no domicílio;

- executar educação de familiares e cuidadores para avaliação e manejo de sinais e sintomas em domicílio (dispneia, fadiga, anorexia, náuseas e vômitos, constipação, confusão mental, dor) comuns no final da vida;

- executar educação de pacientes, familiares e cuidadores sobre medidas de segurança, prevenção de quedas, cuidados corpóreos, uso de medicamentos, de curativos, de cuidados com sondas, de exercícios ativo-passivos e de postura;

- responder como consultor em análise de situações éticas complexas que envolvam cuidados e tratamentos de suporte a pacientes no final de vida;

- redigir métodos de educação em cuidados paliativos para pacientes e familiares.

... por atuar em face às situações diferenciadas ao:

- estabelecer apoio emocional à família, cuidadores e equipe de saúde na situação de luto;

- redigir com a equipe um plano de intervenção frente à claudicação familiar;

- somar a linguagem dietética, práticas habituais e rituais de pacientes e familiares ao plano de cuidados;

...por estarem atentas às condições do trabalho em cuidado paliativo ao:

- delimitar com pacientes e familiares objetivos do cuidado paliativo a curto, médio e longo prazo;

- empregar a comunicação de forma eficaz com pacientes, familiares e cuidadores sobre questões de fim de vida;

- estabelecer projetos de investigação em cuidados paliativos; 
... por articular as relações entre o legitimado pelas normas reguladoras da profissão e o real exercício do trabalho ao:

- empregar os postulados éticos dos cuidados paliativos na tomada de decisão em questões complexas de fim de vida, reconhecendo a influência dos valores pessoais, código de ética profissional e preferências do paciente;

- executar a sistematização da assistência de enfermagem ao paciente no final de vida;

- seguir as diretrizes legais sobre consentimento informado e diretivas antecipadas na tomada de decisão em situações de final de vida;

- seguir ferramentas padronizadas para avaliar sinais e sintomas de pacientes em cuidados paliativos.

Ao identificar um perfil de competências, espera-se que esse surja dos atores representativos da profissão que será objeto de reflexão, pois os critérios, parâmetros e padrões advêm dessa avaliação para designar uma base de referência para julgamento. A competência não substitui a profissão, mas lhe dá um novo significado que permitirá a redefinição das pertinências e das identidades.

A competência é individual e social ao mesmo tempo, onde a distribuição das competências requeridas não concerne a indivíduos isolados, mas a parceiros de um sistema. Não existe uma competência sem a referência a um contex to no qual ela se materializa. ${ }^{74}$

As competências gerais e específicas consensuadas neste estudo reafirmam os cuidados paliativos como corpo de conhecimento e objeto de trabalho dos profissionais de enfermagem frente a pacientes que enfrentam doenças que ameaçam a vida. Refletem as dimensões ética, humanista e social que orientam as práticas do enfermeiro para atender as necessidades sociais de saúde, com ênfase no SUS. Congrega com os pilares do trabalho das equipes de atenção domiciliar no que tange: ao atuar com competência cultural; comunicar-se de forma eficiente; atingir o maior nível de controle dos sintomas; preparar pacientes e familiares para a morte dentro dos limites de cada um; instrumentalizar cuidadores e familiares para o cuidado paliativo domiciliar; e proporcionar qualidade de vida e dignidade no processo de morte em domicílio. ${ }^{52}$

As competências requeridas para o trabalho do enfermeiro em cuidado paliativo na atenção domiciliar são convergentes em relação à amplitude de competências descritas nas DCN/ENF, e constituem-se em subsídio para a construção de referenciais assistenciais e de 
ensino, que atendam as necessidades de articulação do trabalho com a educação na perspectiva da integralidade e qualidade da atenção, assim como, da humanização da assistência.

\subsection{PROPOSIÇÃO DE COMPETÊNCIAS PARA O ENSINO DE CUIDADOS PALIATIVOS NO CURSO DE GRADUAÇÃO EM ENFERMAGEM}

As DCN/ENF propõem que conteúdos para o curso de graduação em enfermagem estejam relacionados com o processo saúde-doença do cidadão, da família e da comunidade, integrados à realidade epidemiológica e profissional de forma a instigar a integralidade das ações do cuidar em enfermagem. Os conteúdos devem abranger as áreas de Ciências Biológicas e da Saúde, Ciências Humanas e Sociais, e Ciências da EnfermagemFundamentos de Enfermagem, Assistência de Enfermagem, Administração de Enfermagem, Ensino de Enfermagem. ${ }^{96}$

Educar para o exercício de uma profissão compreende conferir ao aluno conhecimentos que possam garantir-lhe sobreviver no próprio grupo profissional, como também no conjunto formado por outras profissões existentes num determinado espaço social. Implica em treinar ou ajudar-lhe a implementar boas práticas sobre os tipos de situações que precisa gerir e a ter uma boa mobilização combinatória de recursos, e não somente para que ganhe novos recursos.

Neste estudo, para responder ao objetivo de proposição de competências para o ensino do cuidado paliativo na graduação em enfermagem, analisamos as competências gerais e específicas consensuadas pelos enfermeiros participantes, segundo as propostas de ensino em cuidados paliativos de entidades internacionais, embasados pelo conceito e filosofia dos cuidados paliativos colocados pela OMS. Após análise e seleção, alocamos as competências segundo as áreas de conhecimento propostas pelas DCN/ENF, e propusemos conteúdos que tangenciam os cuidados paliativos nas respectivas áreas, conforme se verifica na figura 1. 
Quadro 2 - Competências e conteúdos para o ensino de cuidados paliativos no curso de graduação em enfermagem. Brasília, 2014.

(continua)

\section{COMPETÊNCIAS}

Área de conhecimento: Ciências Biológicas e da Saúde

- Operar na avaliação de sinais e sintomas (dispneia, fadiga, anorexia, náuseas e vômitos, constipação, confusão mental, dor) comuns no final da vida.

\section{Conteúdos}

Abordagem: dos princípios básicos de funcionalidade dos sistemas corporais perto do fim da vida; da fisiologia dos sintomas (dispneia, fadiga, anorexia, náuseas e vômitos, constipação, confusão mental, dor) quando em desequilíbrio do funcionamento dos sistemas orgânicos.

\section{Área de conhecimento: Ciências Humanas e Sociais}

- Conjugar o paciente e sua família como foco de cuidado da equipe multiprofissional.

- Constatar mudanças dinâmicas na demografia da população.

- Empregar os postulados éticos dos cuidados paliativos na tomada de decisão em questões complexas de fim de vida, reconhecendo a influência dos valores pessoais, código de ética profissional e preferências do paciente.

- Interpretar as atitudes próprias, sentimentos, valores e expectativas sobre a morte e a diversidade cultural e espiritual existente nas crenças e costumes representados na comunidade.

- Prestar cuidados ao paciente no pós-morte de forma respeitosa.

- Seguir as diretrizes legais sobre consentimento informado e diretivas antecipadas na tomada de decisão em situações de final de vida.

- Valorizar os pontos de vista e desejos do paciente e família durante os cuidados em fim de vida.

\section{Conteúdos}

Abordagem: de questões éticas e preocupações legais no fim de vida/cuidados paliativos; da influência cultural sobre as atitudes e crenças sobre a morte e o morrer representadas na comunidade; da influência cultural sobre concepções de religião e espiritualidade representadas na comunidade; dos princípios bioéticos aplicáveis em cuidados paliativos; da articulação do perfil epidemiológico de mortalidade com as políticas e programas de saúde vigentes no Sistema Único de Saúde. 
Quadro 2 - Competências e conteúdos para o ensino de cuidados paliativos no curso de graduação em enfermagem. Brasília, 2014.

(continuação)

\section{COMPETÊNCIAS}

\section{Área de conhecimento: Ciências da Enfermagem/ Fundamentos de Enfermagem}

- Executar educação de pacientes, familiares e cuidadores sobre medidas de segurança, prevenção de quedas, cuidados corpóreos, uso de medicamentos, de curativos, de cuidados com sondas, de exercícios ativo-passivos e de postura.

- Seguir ferramentas padronizadas para avaliar sinais e sintomas de pacientes em cuidados paliativos.

\section{Conteúdos}

Abordagem: das definições e princípios básicos dos cuidados paliativos dentro de uma estrutura de qualidade de vida; das necessidades físicas, psicológicas, sociais e espirituais dos pacientes em fim de vida; dos instrumentos de avaliação de sintomas em cuidados paliativos (Escala de Zubrod-ECOG, Escala de Karnofsky, Escala de Zarit, Escalas de Avaliação de Dor); do papel do enfermeiro em cuidados paliativos; uso de taxonomia (NANDA, CIPE) para classificação das práticas de enfermagem.

\section{Área de conhecimento: Ciências da Enfermagem/Administração de Enfermagem}

- Compor a equipe multiprofissional no planejamento e avaliação das ações de saúde ao paciente em final de vida.

- Compor a equipe multiprofissional no processo de tomada de decisão, junto à família, frente a situações éticas que envolvam cuidados e tratamentos de suporte a pacientes no final da vida.

- Empregar com a equipe multiprofissional orientações a familiares sobre rituais de funeral, direitos sociais e responsabilidades com papéis e documentos em situação de óbito.

- Operar na organização, análise e melhoria dos cuidados de saúde em domicílio.

- Traçar plano de cuidados de forma a não ter lacunas que levem o paciente a se sentir abandonado durante sua evolução clínica.

\section{Conteúdos}

Abordagem: do impacto socioeconômico da oferta de serviços de cuidados paliativos; da gestão dos procedimentos no momento real da morte do paciente; da organização do trabalho multidisciplinar em cuidados paliativos e em domicílio; do uso de tecnologias em cuidados paliativos; dos modelos assistências em cuidados paliativos; das formas de inclusão de pacientes que necessitam de cuidados paliativos na rede de atenção a saúde; dos recursos humanos de enfermagem para assistência em cuidados paliativos. 
Quadro 2 - Competências e conteúdos para o ensino de cuidados paliativos no curso de graduação em enfermagem. Brasília, 2014.

(conclusão)

\section{COMPETÊNCIAS}

\section{Área de conhecimento: Ciências da Enfermagem/Assistência de Enfermagem}

- Avaliar o impacto das terapias tradicionais, complementares e tecnológica centrada em resultados dos pacientes.

- Compor a equipe multiprofissional na avaliação e manejo das necessidades psicossociais e espirituais complexas do paciente e sua família.

- Compor a equipe multiprofissional na comunicação de "má notícia" a familiares e pacientes em situações de final de vida.

- Empregar a comunicação de forma eficaz com pacientes, familiares e cuidadores sobre questões de fim de vida.

- Encaminhar pacientes e familiares para participar de programas de apoio psicossocial e espiritual, durante o processo de adoecimento crônico e luto.

- Estabelecer apoio emocional à família, cuidadores e equipe de saúde na situação de luto.

- Estabelecer apoio emocional a pacientes, familiares, cuidadores, comunidade e equipe de saúde, para lidar com o sofrimento durante os cuidados no final da vida.

- Estabelecer e executar com cuidadores que apresentam risco de distress ou sobrecarga, um plano compartilhado de cuidados domiciliares.

- Executar a sistematização da assistência de enfermagem ao paciente no final de vida.

- Executar cuidados de conforto para a morte em domicílio como um componente integrante dos cuidados de enfermagem.

- Expressar de forma eficaz com a comunidade e equipe de saúde sobre questões de fim de vida.

- Identificar a iminência da morte e empregar cuidados adequados ao paciente e família.

- Operar no manejo e controle de sinais e sintomas (dispneia, fadiga, anorexia, náuseas e vômitos, constipação, confusão mental, dor) comuns no final da vida.

- Traçar plano de cuidados considerando as dimensões física, psicológica, social e espiritual, com vista à melhora da qualidade de vida.

\section{Conteúdos}

Abordagem: das intervenções farmacológicas e não farmacológicas no manejo e controle da dor e outros sintomas comuns em doença avançada; das formas de manejo do conforto do paciente em final de vida; do papel do enfermeiro na gestão dos sintomas comuns em doença avançada; dos conceitos básicos da experiência de perda, sofrimento e luto para os pacientes/famílias/enfermeiros; das intervenções de apoio emocional; dos conceitos e intervenções frente ao desgaste do cuidador de pacientes em final de vida; dos instrumentos de comunicação em cuidados de fim de vida. 
Observa-se na figura 1 que as competências elencadas são passíveis de serem inseridas nas diferentes áreas de conhecimento, num contínuo que se inicia nas disciplinas de base e concretiza-se no ciclo de disciplinas profissionalizantes. Cabe salientar que esta é uma proposta que visa ampliar a competência do enfermeiro nos seus cenários de prática, e não tem a pretensão de modificar o rótulo "generalista" para "especialista" no perfil do egresso dos cursos de graduação em enfermagem. Trata-se das possibilidades de atuação do enfermeiro, para além da promoção, prevenção, proteção e reabilitação à saúde, na perspectiva da qualidade de vida, pois em cuidados paliativos o cuidado é dirigido ao paciente/família que enfrentam doenças que limitam a vida.

A Enfermagem cuida de pessoas, seres vivos que tem um ciclo de vida, ou seja, nascem, se desenvolvem, e morrem. Esse ciclo é visível, assim como as características dentro das quais a vida transcorre. O cuidado paliativo volta-se para essa última fase do ciclo, a morte. Não somente ao fato em si, mas aos processos de vida que permeiam tal acontecimento.

As concepções a respeito do cuidado paliativo ampliam-se no entendido como: morrer como processo natural; prioridade do cuidado sobre a cura; comunicação baseada em veracidade e honestidade; qualidade de vida; cuidado integral com ênfase nos aspectos físicos, psicossociais e espirituais do indivíduo e família; cuidado baseado na abordagem humanística e de valorização da vida; controle e alívio da dor e dos demais sintomas; cuidado que experiencia as questões éticas sobre a vida e a morte; cuidado de abordagem multidisciplinar; atenção à espiritualidade e o apoio ao luto. ${ }^{156}$

No ensino de cuidados paliativos, entre saber que as pessoas morrem e traçar um plano de cuidados considerando as dimensões física, psicológica, social e espiritual, com vista à melhora da qualidade de vida, há um longo caminho a percorrer. A transferência de conhecimentos não é automática, adquire-se por meio do exercício e de uma prática reflexiva, em situações que possibilitem mobilizar saberes, transpô-los, combiná-los, e inventar uma estratégica original. ${ }^{155}$

A competência se manifesta na ação, e se faltam recursos a mobilizar, não há competência. Se os recursos estão presentes, mas não são mobilizados em tempo útil e conscientemente, é como se eles não existissem. ${ }^{155}$ 
Os cuidados paliativos integra uma área de intervenção em saúde na qual os cuidados de enfermagem são os pilares de sustentação. Por isso, o paciente espera dos enfermeiros ao longo de um percurso mais ou menos longo, a garantia da qualidade de vida e a defesa de sua dignidade. Instrumentos de referência como o Catálogo de Classificação Internacional para Prática de Enfermagem (CIPE) - Cuidados paliativos para uma morte digna foram criados e estão disponíveis para dar suporte para a reflexão e aprofundamento do exercício profissional em cuidados paliativos. ${ }^{117}$

O ensino de cuidados paliativos nos anos iniciais da graduação em enfermagem é relatado como fator que favorece a desmistificação do cuidado àquele que está morrendo, permitindo uma menor evasão de estudantes para o cuidado, assim como, atitudes menos negativas frente ao cuidado daquele que está morrendo. ${ }^{157,158}$

Estudo realizado com estudantes de enfermagem apontou que uma exposição sistemática bem organizada, didática e com componentes de experiência em cuidados paliativos pode resultar em aumento de atitudes positivas para o cuidado com aquele que está morrendo. O estudo mencionado utilizou-se do pacote educativo ELNEC (End-of-Life Nursing Education Consortium) num treinamento de 6 semanas, observando-se melhora das atitudes dos estudantes para com os cuidados com o indivíduo que está morrendo após a $4^{\mathrm{a}}$ semana; e como métodos de ensino: dramatizações, estudos de caso, processo de grupo e interação com o paciente. ${ }^{158} \mathrm{O}$ programa ELNEC atualmente já alcançou 11 países na África, 15 na Ásia, 33 na Europa, 6 na América do Norte, 7 na América do Sul, Austrália e Nova Zelândia, denunciando que os profissionais de saúde ao redor do mundo estão atentos a essa área de atuação, na busca por melhoria da assistência a ser oferecida aos pacientes no final da vida. $^{159}$

Inquérito realizado em 52 cursos de graduação em enfermagem no Reino Unido apresentou que os cuidados paliativos faziam parte dos conteúdos de ensino com média de horas de ensino em torno de 44,71, e que métodos de ensino utilizados incluíam palestra, dramatização, leituras (livros, artigos, livros didáticos e artigos de jornal), seminários/discussões em grupos, discussão de estudos de caso, vídeo/filmes, simulações, visitas a casas funerárias, e visitas a hospices (casa ou lugar onde são atendidos os pacientes fora de possibilidades terapêuticas de cura). Nesse ensino foi apontado que o enfermeiro está à frente da educação, mas que outros profissionais foram convidados a participar das atividades de ensino como: médicos, psicólogos, assistentes sociais, 
sociólogos, teólogos, filósofos, advogados, bem como pacientes usuários de serviços de cuidados paliativos. ${ }^{160}$

A literatura mostra que na Inglaterra todas as escolas de enfermagem e medicina incluem cuidados paliativos no conteúdo de seus currículos de graduação e pós-graduação. Já na América do Sul, as primeiras experiências relativas à educação formal em cuidados paliativos surgiram na década de 1990, em Buenos Aires, pela parceria de profissionais de saúde de organizações não governamentais que prestavam assistência paliativista com instituições de ensino superior, por meio de cursos de extensão e pós-graduação em cuidados paliativos. $^{2}$

No cenário internacional, modelos de educação em cuidados paliativos têm sido apresentados e disponibilizados em websites como da International Association of Hospice and Palliative Care (IAHPC), da International Society of Nurses in Cancer Care (ISNCC), Canadian Hospice Palliative Care Nursing, Center for Palliative Care Research and Education, dentre outras, que de maneira geral apresentam similaridades entre si com módulos de conteúdo referentes ao conceito de cuidados paliativos, a aspectos éticos, controle e manejo de sintomas clínicos, manejo de situações de emergência, cuidados nas últimas horas de vida, atenção a familiares e cuidadores, experiências de perda, pesar e luto, e trabalho em equipe. ${ }^{132,161-163}$

Compreende-se a deficiência no conhecimento em cuidados paliativos entre profissionais de saúde no Brasil, devido ao fato de que o tema não faz parte da grade curricular de graduação das diferentes especialidades da área da saúde. Com o crescimento da demanda e da estruturação de serviços de cuidados paliativos, o assunto tem sido abordado em algumas escolas, porém não de maneira obrigatória e contínua, mas diluído em aulas e cursos ligados à oncologia, dor e morte. Percebe-se também, que são poucos os serviços de cuidados paliativos que oferecem treinamento aos seus colaboradores, obrigando os profissionais a buscarem aprimoramento no assunto de forma autodidata ou em especializações fora do país. ${ }^{164}$

Aponta-se que ao educar para o cuidado em processo de morte, o caminho da reflexão do existir humano, do pensar e do aceitar a finitude parece viável, uma vez que ao compreender a própria morte e o próprio existir é possível projetar possibilidades de educar para o cuidar nesse processo. Enfoca-se que todo profissional de saúde que lida com 
indivíduos em iminência de morte deve refletir sobre sua pretensa onipotência e sua equivocada obrigação de curar sempre, pois, mesmo sem possibilidade terapêutica de cura temos muito a fazer para melhorar a qualidade de vida dos pacientes em final de vida. ${ }^{165}$

Se ao final do processo de graduação os alunos estiverem confortáveis para educar o paciente e sua família sobre o processo de morrer, estarão prontos para responder aos pacientes que pedem ajuda para morrer, a dar más notícias ao paciente e família, e ajudar pacientes a viver com qualidade até o final da vida, pois dessa forma terão enfim, cumprido seu papel na educação de indivíduos no encerramento das questões da vida. 


\section{CONSIDERAÇÕES FINAIS}

O cuidado paliativo no Brasil está em pleno desenvolvimento, e nestes últimos anos observa-se o crescimento de unidades e serviços dentro dos hospitais públicos e privados, assim como, da assistência ambulatorial, de internação e cuidado domiciliar. Este é um cenário de oportunidades, mas também de ameaças, pois cotidianamente observamos o risco de desgaste profissional por falta de habilidades no trabalho em equipe; a criação de serviços sem controle de qualidade, sem formação especializada, oferecendo serviços de baixa qualidade; e a resistência acadêmica nas universidades em incorporar o ensino de cuidados paliativos. Os atuais e os futuros profissionais de saúde necessitam estar orientados sobre a prestação de cuidados paliativos para que possam se adequar a essa nova realidade, sendo a educação a força propulsora capaz de sustentar tais mudanças. ${ }^{118}$

Com corpo de conhecimento específico, o cuidado paliativo requer atitudes e aptidões bem determinadas e expressas em documentos com recomendações curriculares para diferentes níveis, nomeadamente nível básico, para graduação, nível intermediário, pósgraduação, e nível especializado, pós-graduação avançada para profissionais dedicados a resolver situações complexas e em dedicação completa a esta área. $\mathrm{O}$ campo de trabalho dos cuidados paliativos é o paciente com doença avançada e prognóstico limitado, em que a ação é o alívio global do sofrimento e a promoção do conforto e da qualidade de vida do paciente, família e/ou dos que lhe são significativos. ${ }^{166}$

Neste estudo, ao caracterizar a produção em enfermagem de cuidados paliativos por meio da análise dos resumos de dissertações e teses publicadas em catálogos do Centro de Estudos e Pesquisas em Enfermagem - CEPEn, evidenciou-se em um período de 14 anos um quantitativo de 85 publicações, defendidas em 16 instituições, orientadas por 59 pesquisadores. Os contextos, hospitalar, de domicílio e ambulatório foram explorados como cenários de estudo, demonstrando o compromisso dos profissionais de enfermagem em resignificar seus fazeres e melhorar a qualidade da assistência em seus ambientes de prática. Observou-se que o cuidado paliativo como área de conhecimento e especialidade encontra-se legitimado e em ascensão no cotidiano das práticas de enfermagem. 
O resultado exposto anteriormente aponta uma incongruência, pois há mais de uma década reconhecemos os cuidados paliativos enquanto área de conhecimento e de prática, apontamos a necessidade de formação neste campo, mas não corporificamos seus conteúdos nos currículos de formação.

Observamos que a morte é barrada nos currículos de graduação em saúde, pelos defensores da integralidade do cuidado numa perspectiva ética e humanista, os professores, que em última instância são profissionais de saúde. Cabe salientar, que esse processo contém múltiplas casualidades, com bases na frustração profissional de não alcançar a cura, perpassando os medos da própria morte e a do outro, chegando aos tabus sociais impostos pela contemporaneidade. Mas, são barreiras que precisam ser transpostas se quisermos avançar no desenvolvimento de competências para o cuidar em cuidados paliativos.

Os profissionais de saúde se esquecem de que a diferença entre eles e as pessoas em geral, é que na vida deles a morte integra seu cotidiano, tornando-se companheira de trabalho. $^{152}$

Na caracterização da produção científica em enfermagem sobre cuidados paliativos na atenção domiciliar, evidenciou-se o cuidado na atenção domiciliar com caráter multidisciplinar, voltado à qualidade de vida tanto dos pacientes como de seus familiares, com o desafio da qualificação profissional e da integralidade dos cuidados na atenção à saúde. Lacunas na abordagem do conhecimento foram evidenciadas, como no campo da bioética em final de vida, onde se verificou a necessidade de estudos que abordem: como os profissionais de saúde percebem o desejo do paciente de participar das decisões compartilhadas; como motivar os pacientes a expor suas preferências a partir das opções colocadas; e identificação dos conflitos morais vivenciados em contexto de domicílio, com a intenção de auxiliar os profissionais de enfermagem a compreender os limites do cuidado, ou mesmo a dimensionar o impacto da existência de conflitos éticos na qualidade de vida de pacientes que enfrentam doenças que ameaçam a vida.

A necessidade de estabelecer os cuidados paliativos como área de diferenciação, como uma competência, advém, por um lado, da necessidade de se garantir a qualidade na formação ao estabelecer um conhecimento estandardizado fundamental para acompanhar doentes e suas famílias, e por outro, do reconhecimento da falta de um número maior de profissionais com esta formação. Ao credibilizar esta área de conhecimento instiga-se a qualidade global das 
práticas de saúde e a melhor valorização das práticas paliativas. ${ }^{166}$

Este estudo permitiu identificar as competências requeridas do enfermeiro para o cuidado paliativo na atenção domiciliar por meio do consenso de 43 competências, sendo 18 competências gerais e 25 específicas, e verificar que as mesmas estão alinhadas aos princípios e fundamentos propostos pelas Diretrizes Curriculares Nacionais do Curso de Graduação em Enfermagem, no que tange a competências gerais e específicas. O elenco de competências apresentou confiabilidade interna e fornece afirmações assertivas sobre a atuação do enfermeiro em cuidado paliativo na atenção domiciliar, além de indicar o reconhecimento dos cuidados paliativos como prática assistencial de enfermagem na atenção domiciliar. As competências consensuadas permitiram a construção de um elenco de competências para o ensino de cuidados paliativos na graduação em enfermagem emparelhado com as áreas de conteúdos propostos pelas DCN/ENF.

Os resultados deste estudo apontam que o cuidado paliativo é aplicável a todos os níveis de assistência, dos hospitais terciários a atenção primária, assim como nos diversos ambientes de cuidado. Todos os enfermeiros devem ser capazes de fornecer cuidados paliativos apropriados e, portanto, precisam ser capacitados para fornecer o melhor padrão de cuidado, a fim de atender às necessidades desafiadoras de pacientes e familiares, independente do diagnóstico.

A competência se expressa na capacidade do enfermeiro em cuidar do outro, em fase final de vida, de colocar em ação os conhecimentos necessários para avaliar, manejar e controlar sinais e sintomas que geram sofrimento, mobilizando e disponibilizando tecnologias para o ato de cuidar; como também, na capacidade de responder satisfatoriamente às necessidades e demandas do paciente, família e comunidade aos quais assiste, mediante o exercício eficiente do seu trabalho, a participação ativa, consciente e crítica, nos espaços da atenção domiciliar e na esfera social, contribuindo para a qualidade de vida dos mesmos.

A identificação do consenso de enfermeiros sobre as competências para o cuidado paliativo na atenção domiciliar e sua análise à luz das DCN/ENF nos permitem inferir que a interface saúde, educação e trabalho, parecem ser um caminho saudável rumo à construção de uma aprendizagem significativa e transformadora que responda às demandas sociais e profissionais que se apresentam na contemporaneidade. Verifica-se a necessidade de aprendizagem de conteúdos sobre cuidados paliativos desde a graduação em enfermagem num 
contínuo aprofundamento na perspectiva da educação permanente, de forma a atender as necessidades de formação e regulação da prática, assim como, de oportunizar o desenvolvimento de atitudes críticas e reflexiva, como instrumentos para a prática interdisciplinar em cuidados paliativos.

A atuação do enfermeiro em cuidados paliativos perpassa o processo de trabalho em saúde/enfermagem e transcende o exposto neste estudo, necessitando de mais estudos que possam clarificar os modos de ser e fazer em enfermagem de cuidados paliativos. Acreditamos ser a formação em cuidados paliativos uma das possibilidades de se corrigir preconceitos e ideias errôneas, contribuindo para um desenvolvimento sustentado, com qualidade, dos cuidados prestados a paciente em final de vida.

Por fim, quando perguntaram a Jorge se ele tinha medo de morrer, o velho sábio respondeu: "De jeito nenhum. Eu tenho medo de não morrer!". ${ }^{167}$ É sobre esta certeza de que a morte é o fim de uma jornada existencial e que o fim deve ser brindado com a mesma alegria que o nascimento, que deveríamos orientar nossas reflexões para construir processos de morrer mais dignos e humanos. 


\section{REFER̂̂ENCIAS}

01.Floriani CA; Schramm FR. Cuidados paliativos: conflitos, interfaces e necessidades.Ciênc Saúde Coletiva [Internet].2008 [citado em 10 Jan 2012]; 13 (supl 2):123-32. Disponível em: http://www.scielosp.org/scielo.php?script=sci_arttext\&pid=S1413-81232008000900017.

02.Araújo MMT. Comunicação em cuidados paliativos: proposta educacional para profissionais de saúde [tese]. São Paulo: Universidade de São Paulo, Escola de Enfermagem da Universidade de São Paulo; 2011 [citado em 20 Jan 2014]. Disponível em: http://www.teses.usp.br/teses/disponiveis/7/7139/tde-31052011-123633/pt-br.php.

03.Boemer MR. Sobre cuidados paliativos. Rev. esc. enferm. USP [Internet]. 2009 sept. [citado em 18 Jan 2012]; 43(3). Disponível em: http://dx.doi.org/10.1590/S008062342009000300001 .

04. Floriani CA; Schramm FR. Desafios morais e operacionais da inclusão dos cuidados paliativos na rede de atenção básica. Cad. Saúde Pública [Internet]. 2007 [citado em 18 jan. 2012]; 23(9):2072-80. Disponível em: http://www6.ensp.fiocruz.br/repositorio/resource/357027.

05.Veras R. Envelhecimento populacional contemporâneo: demandas, desafios e inovações. Rev Saude Publica [Internet]. 2009 [citado em 18 Jan 2012]; 43(3):548-44. Disponível em: http://www.scielo.br/scielo.php?pid=S0034-89102009005000025\&script=sci_arttext.

06.Ministério da Saúde (BR), Secretaria de Vigilância em Saúde,Departamento de Análise de Situação de Saúde. Plano de ações estratégicas para o enfrentamento das doenças crônicas não transmissíveis (DCNT) no Brasil 2011-2022 / Ministério da Saúde. Brasília (DF): Ministério da 2011. Saúde, Disponível em: http://bvsms.saude.gov.br/bvs/publicacoes/plano_acoes_enfrent_dcnt_2011.pdf.

07.Economist Intelligence Unit. The quality of death. Ranking end-of-life care across the world.[Internet]. 2010 [citado em 17 Abr 2012]. Disponível em: http://graphics.eiu.com/upload/QOD_main_final_edition_Jul12_toprint.pdf.

08.Depresbiteris L. Competências na educação profissional - é possível avaliá-las? B. Téc. Senac: a R. Educ. Prof. [Internet]. 2005 Maio/Ago [citado em 18 Jan 2012]; 31(2). Disponível em: http://www.senac.br/BTS/312/boltec312a.htm.

09.Ministério da Saúde (BR),Secretaria de Gestão do Trabalho e da Educação na Saúde. Referências conceituais para a organização do sistema de certificação de competências/ PROFAE.[Internet]. 2000 [citado em 18 Jan 2012]. Disponível em: http://bvsms.saude.gov.br/bvs/publicacoes/scc_referencias_conceituais.pdf.

10.Capelas MLV, Coelho SPF. Pensar a organização de serviços de Cuidados Paliativos. Cuidados Paliativos [Internet]. 2014 [citado em 10 Dez 2014]; 1(1): 18-26. Disponível em: http://www.apcp.com.pt/uploads/revista_cp_vol_1_n_1.pdf. 
11.Dal Bem LW, Gaidzinski RR. Proposta de modelo para dimensionamento do pessoal de enfermagem em assistência domiciliária. Rev Esc Enferm USP [Internet]. 2007 [citado em 18 Jan 2012]; 41(1):97-103. Disponível em: http://www.scielo.br/scielo.php?script=sci_arttext\&pid=s0080-62342007000100013.

12. Floriani CA; Schramm FR. Casas para os que morrem: a história do desenvolvimento dos hospices modernos. História, Ciências, Saúde-Manguinhos [Internet]. 2010 [citado em 18 Jan de 2012]; 17(supl.1):165-180. Disponível em: http://www.scielo.br/scielo.php?pid=S010459702010000500010\&script=sci_arttext.

13.Twycross R. Medicina Paliativa: filosofía y Consideraciones éticas. Acta Bioethica [Internet]. 2000 [citado em 18 Jan de 2012]; 1( año VI). Disponível em: http://www.scielo.cl/scielo.php?script=sci_arttext\&pid=S1726-569X2000000100003.

14. Floriani CA. Moderno movimento hospice: fundamentos, crenças e contradições na busca da boa morte. [tese]. Rio de Janeiro: Escola Nacional de Saúde Pública Sergio Arouca, 2009 [citado em 18 Jan de 2012]. Disponível em: http://www.arca.fiocruz.br/handle/icict/2571.

15.Figueiredo MTA, Figueiredo MGMCA. Cuidados Paliativos. In: Santos FS, Incontri D. A Arte de Morrer - Visões Plurais. Bragança Paulista (SP): Editora Comenius; 2009. 303p.

16.Rodrigues IG. Cuidados paliativos: análise de conceito. [dissertação]. Ribeirão Preto (SP): Universidade de São Paulo, Enfermagem, Escola de Enfermagem de Ribeirão Preto; 2004 [citado em 18 Jan 2012]. Disponível em: http://www.teses.usp.br/teses/disponiveis/22/22132/tde-17082004-101459/pt-br.php.

17.Matsumoto DY. Cuidados Paliativos: conceito, fundamentos e princípios. In: Academia Nacional de Cuidados Paliativos. Manual de Cuidados Paliativos. Rio de Janeiro: Diagraphic; 2009. p. 14-19.

18.Chiba T. Relação dos Cuidados Paliativos com as diferentes profissões na área da saúde e especialidades. In: Conselho Regional de Medicina do Estado de São Paulo. Cuidado Paliativo. São Paulo: Conselho Regional de Medicina do Estado de São Paulo; 2008. p.46-54.

19.World Health Organization. Definition of palliative care [Internet]. Geneva: WHO; 2002 [citado em 16 Apr 2014]. Disponível em: http://www.who.int/cancer/palliative/definition/en.

20.Menezes RA. Reflexões em torno da Morte e o Morrer. In: Santos, FS. A Arte de Morrer - visões Plurais. v. 2. Bragança Paulista (SP): Editora Comenius; 2009.

21.Figueiredo MGMCA, Stano RCMT. O estudo da morte e dos cuidados paliativos: uma experiência didática no currículo de medicina. Revista Brasileira de Educação Médica [Internet]. 2013 [citado em 12 Abr 2012]; 37(2): 298-307. Disponível em: http://www.scielo.br/pdf/rbem/v37n2/19.pdf.

22.Maciel MGS. Organização de serviços de cuidados paliativos. In: Manual de Cuidados Paliativos da Academia Nacional de Cuidados Paliativos.1a.ed. Rio de Janeiro: Editora Diagraphic; 2009. p. 72-85. 
23.Barbosa MF. Pacientes sob cuidados paliativos oncológicos e utilização de medicamentos: perfil e satisfação [dissertação]. Rio de Janeiro: Escola Nacional de Saúde Pública Sergio Arouca; 2011 [citado em 12 Abr 2012]. Disponível em: bvssp.icict.fiocruz.br/lildbi/docsonline/get.php?id=2402.

24.Organização Mundial de Sáude (OMS). Palliative Care. Cancer control: knowledge into action: WHO guide for effective programmes; module 5. 2007. Disponível em: http://www.who.int/cancer/media/FINAL-PalliativeCareModule.pdf.

25.Stjernsward J, Foley KM, Ferris FD. Integrating palliative care into national policies. Journal of Pain and Symptom Management [Internet]. 2007 [citado em 12 Abr 2012]; 33(5):514-520.PubMed; PMID 17482040.

26. Pimenta CAM. Cuidados paliativos: uma nova especialidade do trabalho da enfermagem? Acta paul. Enferm. [Internet]. 2010 [citado em 20 Jun 2014]; 23(3). Disponível em: http://www.scielo.br/pdf/ape/v23n3/v23n3a01.pdf.

27.Vissers KCP, Brand MWM, Jacobs J, Groot M, Veldhoven C, Verhagen C, et al. Palliative Medicine Update: a multidisciplinary approach. Pain Practice [Internet]. 2013 [citado em 07 Out 2014]; 13(7):576-588. Disponível em: http://onlinelibrary.wiley.com/doi/10.1111/papr.12025/pdf.

28.Fonseca JVC, Rebelo T. Necessidades de cuidados de enfermagem do cuidador da pessoa sob cuidados paliativos. Rev Bras Enferm [Internet]. 2011 [citado em 07 Out 2014]; 64(1):180-4. Disponível em: http://www.scielo.br/pdf/reben/v64n1/v64n1a26.pdf.

29.Worldwide Palliative Care Alliance. Global atlas of palliative care at the end of life [Internet]. 2014 [citado em 10 Apr 2014]. Disponível em: http://www.who.int/cancer/publications/palliative-care-atlas/en/.

30.Docherty SL, Thaxton C, Allison C, Barfield RC, Tamburro RF. The nursing dimension of providing palliative care to children and adolescents with cancer. Clinical Medicine Insights: Pediatrics [Internet]. 2012 [citado em 07 Out 2014]; 6:75-88. Disponível em: http://www.ncbi.nlm.nih.gov/pmc/articles/PMC3620813/pdf/cmped-6-2012-075.pdf.

31.Andrade CG, Costa SFG, Vasconcelos MF, Zaccara AAL, Duarte MCS, Evangelista CB. Bioética, Cuidados Paliativos e Terminalidade: revisão integrativa da literatura. Rev enferm UFPE on line [Internet]. 2013 [citado em 07 Out 2014]; 7(esp):888-97. Disponível em: http://dx.doi.org/10.5205/reuol.3934-31164-1-SM.0703esp201309.

32. Sousa ATO, França JRFS, Santos MFO, Costa SFG, Souto MRM. Cuidados paliativos com pacientes terminais: um enfoque na Bioética. Rev Cubana Enfermer. [Internet]. 2010 [citado em 20 Jun 2014]; 26(3):123-135. Disponível em: http://scielo.sld.cu/scielo.php?script=sci_arttext\&pid=S086403192010000300004\&lng=es.

33. Mattos RA. A integralidade na prática (ou sobre a prática da integralidade). Cad. Saúde Pública. [Internet]. 2004 [citado em 20 Jun 2014]; 20(5):1411-6 . Disponível em: http://dx.doi.org/10.1590/S0102-311X2004000500037. 
34.Vasques TCS, Lunardi VL, Silveira RS, Lunardi Filho WD, Gomes GC, Pintanel AC. Percepções dos trabalhadores de enfermagem acerca dos cuidados paliativos. Rev. Eletr. Enf.[Internet]. 2013 [citado em 20 Jun 2014] 15(3):772-9. Disponível em: http://dx.doi.org/10.5216/ree.v15i3.20811.

35.Hermes HR, Lamarca ICA. Cuidados paliativos: uma abordagem a partir das categorias profissionais de saúde. Ciência \& Saúde Coletiva. [Internet]. 2013 [citado em 20 Jun 2014]; 18(9):2577-2588. Disponível em: http://www.scielo.br/scielo.php?script=sci_arttext\&pid=S1413-81232013000900012.

36.Araújo CA. Bibliometria: evolução histórica e questões atuais. Em Questão. Porto Alegre. [Internet]. 2006 [citado em 20 Jun 2014]; 12(1):11-32. Disponível em: http://revistas.univerciencia.org/index.php/revistaemquestao/article/viewFile/3707/3495.

37.Vanti NA. Da bibliometria à webometria: uma exploração conceitual dos mecanismos utilizados para medir o registro da informação e a difusão do conhecimento. Ciência da Informação. [Internet]. 2002 [citado em 20 Jun 2014]; 31(2):152-62. Disponível em: http://www.scielo.br/pdf/ci/v31n2/12918.pdf.

38.Glãnzel W. Bibliometric methods for detecting and analysing emerging research topics. El profesional de La información. [Internet]. 2012 [citado em 20 Jun 2014]; 21(1):194-201. Disponível em: http://elprofesionaldelainformacion.metapress.com/media/h0xf475yqg7tum4rlh87/contributio ns/p/5/6/8/p5681271034tq3j5.pdf.

39.Associação Brasileira de Enfermagem [Internet]. Centro de Estudos e Pesquisas em enfermagem (BR). [citado em 20 Jun 2014]. Informações sobre pesquisas e pesquisadores em enfermagem 2013. Disponível em: http://www.abennacional.org.br/home/tesesedissertacoescepen.htm.

40.Coordenação de Aperfeiçoamento de Pessoal de Nível Superior [Internet]. Diretoria de Avaliação (BR) [citado em 20 Jun 2014]. Documento de Área 2013 - Avaliação Trienal $2013 . \quad$ Disponível em: http://www.capes.gov.br/images/stories/download/avaliacaotrienal/Docs_de_area/Enfermage m_doc_area_e_comiss\%C3\%A3o_att08deoutubro.pdf.

41.Melo TM, Rodrigues IG, Schmidt DRC. Caracterização dos Cuidadores de Pacientes em Cuidados Paliativos no Domicílio. Revista Brasileira de Cancerologia [Internet]. 2009 [citado em 20 Jun 2014]; 55(4):365-74. Disponível em: http://www.inca.gov.br/rbc/n_55/v04/pdf/365_artigo6.pdf.

42.Driessnack M, Sousa VD, Mendes IAC. Revisão dos desenhos de pesquisa relevantes para a enfermagem: part 2: desenhos de pesquisa qualitativa. Rev Latino-am Enfermagem. [Internet]. 2007 [citado em 20 Jun 2014]; 15(4) Disponível em: http://www.scielo.br/pdf/rlae/v15n4/pt_v15n4a25.pdf.

43.Bruggemann OM, Parpinelli MA. Utilizando as abordagens quantitativa e qualitativa na produção do conhecimento. Rev Esc Enferm USP. [Internet]. 2008 [citado em 20 Jun 2014]; 42(3):563-8. Disponível em: http://www.scielo.br/pdf/reeusp/v42n3/v42n3a20.pdf. 
44.Almeida IS, Crivaro ET, Salimena AMO, Souza IEO. O caminhar da enfermagem em fenomenologia: revisitando a produção acadêmica. Rev. Eletr. Enf. [Internet]. 2009 [citado em 20 Jun 2014]; 11(3):695-9. Disponível em: http://www.fen.ufg.br/revista/v11/n3/v11n3a30.htm.

45.Erdmann AL, Fernades JV, Melo C, Carvalho BR, Menezes Q, Freitas R, EmarinonyE, Backes MTS. A visibilidade da profissão de enfermeiro: reconhecendo conquistas e lacunas. Rev Bras Enferm. [Internet]. 2009 [citado em 20 Jun 2014]; 62(4):637-43. Disponível em: http://www.scielo.br/pdf/reben/v62n4/25.pdf.

46.Vasconcelos EV, Santana ME, Silva SED. Desafios da enfermagem nos cuidados paliativos: revisão integrativa. Enfermagem em Foco. [Internet]. 2012 [citado em 20 Jun 2014]; 3(3):127-13. Disponível em: http://revista.portalcofen.gov.br/index.php/enfermagem/article/view/296.

47.Polastrini RTV, Yamashita CC, Kurashima AY. Enfermagem e o cuidado paliativo. In: Santos FS, editor. Cuidados paliativos: diretrizes, humanização e alívio de sintomas. São Paulo: Atheneu; 2011. p. 277-83.

48.Pastrana T, De Lima L, Wenk R, Eisenchlas J, Monti C, Rocafort J, et al. Atlas de cuidados paliativos de Latinoamérica ALCP. Houston (TX): IAPHC Press; 2012.

49.Brasil. Portaria n. 2.439/GM, de 8 de dezembro de 2005. Institui a Política Nacional de Atenção Oncológica: Promoção, Prevenção, Diagnóstico, Tratamento, Reabilitação e Cuidados Paliativos, a ser implantada em todas as unidades federadas, respeitadas as competências das três esferas de gestão [Internet]. Brasília (DF): Ministério da Saúde; 2005 $\begin{array}{lllll}\text { [citado em } & 07 & \text { Apr } & \text { 2014]. } & \text { Disponível }\end{array}$ em:http://dtr2001.saude.gov.br/sas/PORTARIAS/Port2005/GM/GM-2439.htm.

50.Brasil. Portaria n. 3.150, de 12 de dezembro de 2006. Institui a Câmara Técnica em Controle da Dor e Cuidados Paliativos [Internet]. Brasília (DF): Ministério da Saúde; 2006 [citado em 07 Apr 2014]. Disponível em: http://www.jusbrasil.com.br/diarios/827706/pg-111secao-1-diario-oficial-da-uniao-dou-de-13-12-2006.

51.Brasil. Portaria n. 963/GM, de 27 de maio de 2013. Redefine a Atenção Domiciliar no âmbito do Sistema Único de Saúde (SUS) [Internet]. Brasília (DF): Ministério da Saúde; 2013 $\begin{array}{lllll}\text { [citado em } & 07 & \text { Apr } & \text { 2014]. Disponível }\end{array}$ em:http://bvsms.saude.gov.br/bvs/saudelegis/gm/2013/prt0963_27_05_2013.html.

52.Ministério da Saúde (BR). Caderno de atenção domiciliar [Internet]. Brasília (DF): Ministério da Saúde; 2013 [citado em 07 de Apr 2014]. Disponível em: http://bvsms.saude.gov.br/bvs/publicacoes/caderno_atencao_domiciliar_melhor_casa.pdf.

53.Yamaguchi AM, Oliveira IB. Cuidados paliativos na assistência domiciliar. In: Santos FS, editor. Cuidados paliativos: diretrizes, humanização e alívio de sintomas. São Paulo: Atheneu; 2011. p. 31-8.

54.Aranda S. Padrão dos cuidados paliativos. In: O’Connor M, Aranda S. Guia prático de cuidados paliativos em enfermagem. São Paulo: Andrei; 2008. p. 17-20. 
55.Lopes S, Costa MT, Fernández-Llimós F, Amante MJ, Lopes PF. A bibliometria e a avaliação da produção científica: indicadores e ferramentas. In: XI Congresso Nacional de Bibliotecários, Arquivistas e Documentalistas; Oct 18-20, 2012; Lisboa, PT. Actas [Internet]. Lisboa: Fundação Calouste Gulbenkian; 2012 [citado em 07 de Apr 2014]. Disponível em: http://www.bad.pt/publicacoes/index.php/congressosbad/article/view/429.

56.Costa ICP. Cuidados paliativos na atenção básica: depoimentos de profissionais da saúde [dissertação]. João Pessoa: Universidade Federal da Paraíba; 2011 [citado em 10 Apr 2014]. Disponível em: http://bdtd.biblioteca.ufpb.br/tde_busca/arquivo.php?codArquivo=2649.

57.Silva L. Processo de cuidar de famílias de idosos em situação de final de vida na Estratégia Saúde da Família [tese]. São Paulo: Universidade de São Paulo; 2011 [citado em 10 Apr 2014]. Disponível em: http://www.teses.usp.br/teses/disponiveis/83/83131/tde-20092011083900/pt-br.php.

58. Oliveira SG. Representações sociais da internação domiciliar na terminalidade: o olhar do cuidador familiar [dissertação]. Santa Maria (RS): Universidade Federal de Santa Maria; 2010 [citado em 10 Apr 2014]. Disponível em: http://www.ufsm.br/ppgenf/Dissert_Stefanie.pdf.

59.Rodrigues IG. Significados do trabalho em equipe de cuidados paliativos oncológicos domiciliar: um estudo etnográfico (Os) [tese]. Ribeirão Preto (SP): Universidade de São Paulo; 2009 [citado em 10 Apr 2014]. Disponível em: http://www.teses.usp.br/teses/disponiveis/22/22132/tde08012010130039/publico/InesGimene sRodrigues.pdf

60.Santana ADA. Cuidados paliativos ao doente oncológico terminal em domicílio: representações sociais da família [dissertação]. Salvador: Universidade Federal da Bahia; 2000 [citado em 10 Apr 2014]. Disponível em: http://www.abennacional.org.br/home/tesesedissertacoescepen.htm.

61.Santos EM. Familiares enlutados: compreender para acolher [dissertação]. Maringá (PR): Universidade Estadual de Maringá; 2009 [citado em 10 Apr 2014]. Disponível em: http://www.pse.uem.br/documentos/dissert_andreia.pdf.

62.Fonseca COS. Vivências de familiares de pacientes com câncer em processo de terminalidade de vida: um estudo clínico-qualitativo [tese]. São Paulo: Universidade de São Paulo; 2012 [citado em 10 Apr 2014]. Disponível em: http://www.teses.usp.br/teses/disponiveis/22/22131/tde-05112012-160251/.

63.Marques SM. Singularidades do cuidado domiciliar durante o processo de morrer: a vivência de familiares cuidadores [dissertação]. Belo Horizonte: Universidade Federal de Minas Gerais; 2003 [citado em 10 Apr 2014]. Disponível em: http://www.abennacional.org.br/home/tesesedissertacoescepen.htm.

64.Pereira VS. Cuidado essencial humano: cuidadores não profissionais de saúde diante da prevenção da úlcera por pressão em indivíduos com câncer avançado [dissertação]. Rio de Janeiro: Universidade Federal do Estado do Rio de Janeiro; 2006 [citado em 10 Apr 2014]. Disponível em: http://www.abennacional.org.br/home/tesesedissertacoescepen.htm.

65.Pessini L. Bioética e cuidados paliativos: alguns desafios do cotidiano aos grandes dilemas. In: Pimenta CAM, Mota DDCF, Cruz DALM. Dor e cuidados paliativos: enfermagem, medicina e psicologia. Barueri (SP): Manole; 2006. p. 45-66. 
66.Nunes L. Ética em cuidados paliativos: limites ao investimento curativo. Revista Bioética [Internet]. 2008 [citado em 07 Apr 2014];16(1):41-50. Disponível em:http://revistabioetica.cfm.org.br/index.php/revista_bioetica/article/viewFile/54/57.

67.Silva KCO, Nietsche EA, Ilha S, Lima MGR. Doente terminal: a ética do cuidado no último processo da vida. Rev Enferm UFPE On Line [Internet]. 2014 [citado em 23 July 2014]; 8(Suppl 1):2256-62. Disponível em: http://www.revista.ufpe.br/revistaenfermagem/index.php/revista/article/viewFile/5059/pdf_56 28.

68.Queiroz AHAB, Pontes RJS, Souza AMA, Rodrigues TB. Percepção de familiares e profissionais de saúde sobre os cuidados no final da vida no âmbito da atenção primária à saúde. Ciênc Saúde Coletiva [Internet]. 2013 Sep [citado em 15 Jun 2014]; 18(9):2615-23. Disponível em: http://dx.doi.org/10.1590/S1413-81232013000900016.

69.Amaro, RA. Da qualificação à competência: deslocamento conceitual e individualização do trabalhador. RAM - Revista de Administração Mackenzie [Internet]. 2008 [citado em 15 Jun 2014]; 9(7): 89-111. Disponível em: http://www.scielo.br/scielo.php?pid=S167869712008000700005\&script=sci_abstract\&tlng=pt.

70.Hirata, H. Da polarização das qualificações ao modelo de competência. In: Ferreti,C. J. et al. (Org.). Novas tecnologias, trabalho e educação: um debate multidisciplinar. Rio de Janeiro: Vozes; 1994. p. 128-142.

71.Deluiz N. Neise. O Modelo das competências profissionais no mundo do trabalho e da educação: implicações para o currículo. B. Téc. Senac [Internet]. 2001[citado em 12 Jan 2012]; 27(3). Disponível em: http://www.senac.br/BTS/273/boltec273b.htm.

72.Fleury MT, Fleury A. Construindo o Conceito de Competência. RAC [Internet]. 2001[citado em 12 Jan 2012]; Edição Especial:183-196. Disponível em: http://www.scielo.br/scielo.php?pid=S1415-65552001000500010\&script=sci_arttext.

73.BARBOSA, Allan Claudius Queiroz; RODRIGUES, Marco Aurélio. Alternativas metodológicas para a identificação de competências. B. Téc. Senac [Internet]. 2006 maio/ago [citado em 12 Jan 2012]; 32(2). Disponível em: http://www.senac.br/BTS/322/bts32_2artigo2.pdf.

74. Le Boterf G. Desenvolvendo a competência dos profissionais. Porto Alegre, Artmed, 2003.

75. Le Boterf G. Repenser la compétence. Groupe Eyrolles, Paris, 2008 [citado em 20 Jan 2013].

Disponível em:http://ir.nmu.org.ua/bitstream/handle/123456789/137566/f2c57ce224735867172c19978b1 36b04.pdf? sequence $=1$.

76. Le boterf. Avaliar a competência de um profissional - três dimensões a explorar. Reflexão RH [Internet].2006 jun [citado em 12 Jan 2013]. Disponível em: http://www.guyleboterfconseil.com/Article\%20evaluation\%20version\%20directe\%20Pessoal.pdf. 
77.Ministério da Saúde (BR), Secretaria de Gestão em Investimentos em Saúde, ProfaeProjeto de Profissionalização dos Trabalhadores da área de Enfermagem. SCC Avaliação e Certificação de Competências Profissionais dos Auxiliares de Enfermagem (subsídios e parâmetros). Brasília: Ministério da Saúde, 2001.

78.Motta LB, Aguiar AC. Novas competências profissionais em saúde e o envelhecimento populacional brasileiro: integralidade, interdisciplinaridade e intersetorialidade. Ciênc. Saúde Coletiva [Internet]. 2007 mar/abr [citado em 20 Jan 2012]; 12(2):363-372. Disponível em: http://www.scielo.br/scielo.php?pid=S1413-81232007000200012\&script=sci_arttext.

79. Oliveira R. O consenso na educação profissional na América Latina. B. Téc. Senac: a R. Educ. Prof. [Internet]. 2010 set/dez [citado em 12 Jan de 2012]; 36(3). Disponível em: http://www.senac.br/BTS/363/artigo3.pdf.

80.Cordão FA. Considerações livres de um educador brasileiro sobre os 50 anos da nossa Lei de Diretrizes e Bases da Educação Nacional. B. Téc. Senac, a R. Educ. Prof. [Internet]. 2012 jan/abr [citado em 13 Dez 2012]; 38(1): 77-83. Disponível em:. http://www.senac.br/media/6632/artigo7.pdf.

81.Perrenoud, P. Novas competências para ensinar. Porto Alegre: Artmed Editora; 2000.

82.Ramos MN. Pedagogia das competências. In: Dicionário da Educação Profissional em Saúde. Fundação Oswaldo Cruz. Escola Politécnica de Saúde Joaquim Venâncio [documento na Internet]. 2009 [citado em 20 Apr 2012]. Disponível em: http://www.epsjv.fiocruz.br/dicionário/veerbetes/pedcom.html.

83.Carvalho OF, Kipnis B. Educação profissional em uma perspectiva internacional comparada e suas repercussões no Brasil. Linhas Críticas [Internet]. 2010 [citado em 1220 Apr 2012]; 16(30):49-70. Disponível em: http://periodicos.unb.br/index.php/linhascriticas/article/viewFile/1428/1064

84.Vale EG, Guedes MVC. Competências e habilidades no ensino de administração em enfermagem à luz das diretrizes Curriculares Nacionais. Rev. Bras Enferm [Internet]. 2004 [citado em 20 Apr 2012]; 57(4): 475-478. Disponível em: http://www.scielo.br/scielo.php?pid=S0034-

$71672004000400018 \&$ script=sci_abstract\&tlng=pt.

85.Rocha SMM, Almeida MCP. O processo de trabalho da enfermagem em saúde coletiva e a interdisciplinaridade. Rev.latino-am.enfermagem [Internet]. 2000 [citado em 12 Jan 2012]; 8(6): 96-101. Disponível em: http://www.scielo.br/scielo.php?script=sci_arttext\&pid=S010411692000000600014.

86.Azevedo E. Educação profissional, democracia e emancipação: avanços além das utopias. B. Téc. Senac, a R. Educ. Prof. [Internet]. 2012 [citado em 16 Dez 2012]; 38(1):84-89. Disponível em: http://www.senac.br/media/6635/entrevista.pdf.

87.Monteiro BA. Diretrizes e bases da educação nacional e escolas de enfermagem na década de 1960: uma visão histórica [dissertação]. São Paulo: Universidade de São Paulo, Mestrado em Administração em Serviços de Enfermagem, Escola de Enfermagem; 2009 [citado em 26 Apr 2012]. Disponível em: http://www.teses.usp.br/teses/disponiveis/7/7131/tde-20052009$110837 /$. 
88.Fonte AS. A Escola de Enfermagem Anna Nery e a nova ordem no campo da educação em Enfermagem [dissertação]. Rio de Janeiro: Universidade Federal do Rio de Janeiro, Programa de Pós-graduação em Enfermagem, Escola de Enfermagem Anna Nery; 2009. [citado em 26 Apr 2012]. Disponível em: http://saudepublica.bvs.br/pesquisa/resource/pt/lil558699 .

89.Paschoal AS. O discurso do enfermeiro sobre educação permanente no grupo focal [dissertação]. Curitiba: Universidade Federal do Paraná, Ciências da Saúde; 2004. [citado em 26 Apr 2012]. Disponível em: http://www.ppgenf.ufpr.br/Disserta\%C3\%A7\%C3\%A3oPaschoal.pdf.

90.Brasil. Portaria n.1721, de 15 de dezembro de 1994. Fixa os mínimos de conteúdos e duração do curso de enfermagem.Diário Oficial da União, Brasília. 1994. Disponível em: http://www.lex.com.br/doc_11078549_portaria_n_1721_de_15_de_dezembro_de_19.

91.Ministério da Educação (BR),Conselho Nacional de Educação. Câmara de Educação Superior. Resolução $\mathrm{n}^{\circ}$ 4, de 6 de abril de 2009 - Dispõe sobre carga horária mínima e procedimentos relativos à integralização e duração dos cursos de graduação em Biomedicina, Ciências Biológicas, Educação Física, Enfermagem, Farmácia, Fisioterapia, Fonoaudiologia, Nutrição e Terapia Ocupacional, bacharelados, na modalidade presencial. Brasília(DF): Ministério da Educação, 2009.

92. Brasil. Lei n.9.394, de 20 de dezembro de 1996. Estabelece as diretrizes e bases da educação nacional. Diário Oficial da União, Brasília, 1996. Disponível em: http://www.planalto.gov.br/ccivil_03/leis/19394.htm.

93.Galleguillos TGB; Oliveira MAC. A gênese e o desenvolvimento histórico do ensino de enfermagem no Brasil. Rev Esc Enf USP [Internet]. 2001 Mar [citado em 12 Apr 2012]; 35(1): 80-7. Disponível em: http://www.scielo.br/pdf/reeusp/v35n1/v35n1a12.

94.Conselho Nacional de Educação (BR), Câmara de Educação Superior. Parecer no 1133, de 07 de agosto de 2001. Diretrizes Curriculares Nacionais dos Cursos de Graduação em Enfermagem, Medicina e Nutrição. Diário Oficial da União, Brasília (DF), 2006. Disponível em: http://portal.mec.gov.br/dmdocuments/ces1133.pdf.

95.Delors J. A educação ou a utopia necessária. In: Educação - um tesouro a descobrir. Relatório para a UNESCO da Comissão Internacional sobre Educação para o século XXI. Tradução de Guilherme João de Freitas Teixeira. Brasília, UNESCO: jul, 2010.

96.Ministério da Educação (BR), Conselho Nacional de Educação. Câmara de Educação Superior. Resolução CNE/CES n 3 de 7/11/2001 - Diretrizes Curriculares Nacionais do Curso de Graduação em Enfermagem. Brasília (DF). 2001. Disponível em: http://portal.mec.gov.br/cne/arquivos/pdf/CES03.pdf.

97.Santana FR, et al. Diretrizes Curriculares Nacionais do curso de graduação em enfermagem: uma visão dialética. Revista Eletrônica de Enfermagem [Internet]. 2005 [citado em 26 Apr 2012]; 7(3): 295-302. Disponível em: http://www.revistas.ufg.br/index.php/fen/article/view/904.

98.Costa LM, Germano RM. Estágio curricular supervisionado na Graduação em Enfermagem: revisitando a história. Rev. bras. enferm. [Internet]. 2007 dec [citado em $20 \mathrm{Fev}$ 2012]; 60(6). Disponível em: http://dx.doi.org/10.1590/S0034-71672007000600016. 
99.Agência Nacional de Vigilância Sanitária (BR).Resolução Diretoria Colegiada n. 11, de 26 de janeiro de 2006. Dispõe sobre o regulamento técnico para o funcionamento de serviços que prestam atenção domiciliar. Diário Oficial da União, Brasília (DF). 2006. Disponível em: http://portal.anvisa.gov.br/wps/wcm/connect/1978e4804745973e9f9ddf3fbc4c6735/RDC+N $\%$ C2\%BA11-2006.pdf?MOD=AJPERES.

100.Brasil. Portaria n. 2416, de 23 de março de 1998. Estabelece requisitos para credenciamento de hospitais e critérios para realização de internação domiciliar no SUS. Diário Oficial da União, Brasília(DF). 1998. Disponível em: http://dtr2001.saude.gov.br/sas/portarias/port98/GM/GM-2416.html.

101.Brasil. Portaria n 963/GM de 27 de maio de 2013. Redefine a Atenção Domiciliar no âmbito do Sistema Único de Saúde (SUS). 2013. Disponível em: http://bvsms.saude.gov.br/bvs/saudelegis/gm/2013/prt0963_27_05_2013.html.

102.Pereira MJB, et al. Assistência domiciliar - Instrumento para potencializar processo de trabalho na assistência e na formação. In: MS/OPAS - Observatório de Recursos Humanos em Saúde no Brasil. Estudos e Análises, vol. 2, Brasília (DF), 2004. p. 71-80.

103.Feuerwerker LCM, Merhy EE. A contribuição da atenção domiciliar para a configuração de redes substitutivas de saúde: desinstitucionalização e transformação de práticas. Rev Panam Salud Publica [Internet]. 2008 [citado em 26 Jan 2012]; 24(3): 180-8. Disponível em: http://www.scielosp.org/pdf/rpsp/v24n3/a04v24n3.pdf.

104.Freitas AVS, Bittencourt CMM, Tavares JL. Atuação da enfermagem no serviço de internação domiciliar: relato de experiência. Revista Baiana de Enfermagem. 2000; 13(1/2): 103-7.

105.Silva KL, et al.Internação domiciliar no Sistema Único de Saúde. Rev. Saúde Pública [Internet]. 2005 [citado em 26 Jan 2012]; 39(3): 391-7. Disponível em: http://www.scielo.br/scielo.php?script=sci_arttext\&pid=S0034-89102005000300009.

106.Serafim AP, Ribeiro RAB. Internação domiciliar no SUS: breve histórico e desafios sobre sua implementação no Distrito Federal. Com. Ciências Saúde [Internet]. 2011[citado em 26 Jan 2012]; 22(2):163-8. Disponível em: http://www.escs.edu.br/pesquisa/revista/2011Vol\%2022_2_8_Internacao.pdf.

107.Bôas, MLCV. A experiência do Serviço de Atenção Domiciliar do Distrito Federal. In: XVI Fórúm de Atenção Domiciliar - O SAD que temos e o SAD que queremos, Ribeirão Preto(SP)[Internet]. 2013 Out [citado em 03 Ago 2014]. Disponível em: http://www.ribeiraopreto.sp.gov.br/ssaude/programas/sad/forum/2013/experiencia_servico.pd f.

108.Secretaria de Estado de Saúde do Distrito Federal (BR), Gerência de Atenção Domiciliar. Programas-Internação Domiciliar. 2014. [citado em 03 Ago 2014]. Disponível em: http://www.saude.df.gov.br/programas/287-programa-de-internacao-domiciliar.html.

109.Faro ACM. Técnica Delphi na validação das intervenções de enfermagem. Rev.Esc.Enf.USP [Internet]. 1997 Ago [citado em 26 Jan 2012]; 31(1): 257- 73. Disponível em: http://www.ee.usp.br/reeusp/upload/pdf/415.pdf. 
110.Scarparo AF, et al. Reflexões sobre o uso da técnica Delphi em pesquisas na enfermagem. Rev Rene [Internet]. 2012 [citado em 15 Dez 2012]; 13(1): 242-51. Disponível em: http://www.revistarene.ufc.br/revista/index.php/revista/article/view/36/31.

111.Silva RFS, Tanaka OU. Técnica Delphi: identificando as competências gerais do médico e do enfermeiro que atuam em atenção primária de saúde. Rev.Esc.Enf.USP [Internet]. 1999 [citado em 26 Jan 2012]; 33(3): 207- 16. Disponível em: http://www.ee.usp.br/reeusp/upload/pdf/685.pdf.

112.Spinola AWP. Delfos: proposta tecnológica alternativa [tese]. São Paulo (SP): Universidade de São Paulo, Faculdade de Saúde Pública; 1984.

113.Wright JTC; Giovinazzo RA. DELPHI - Uma ferramenta de apoio ao planejamento prospectivo. Caderno de Pesquisas em Administração [Internet]. 2000 [citado em 26 Jan 2012]; 1(12): 54-65. Disponível em: http://regeusp.com.br/arquivos/C12-art05.pdf

114.Cardoso LRA, et al. Prospecção de futuro e Método Delphi: uma aplicação para a cadeia produtiva da construção habitacional. Ambiente Construído (Porto Alegre) [Internet]. 2005 jul/set [citado em 26 Jan 2012]; 5(3): 63-78. Disponível em: http://www.seer.ufrgs.br/ambienteconstruido/article/view/3650.

115.Grisi CCH, Britto RP. Técnica de Cenários e o Método Delphi: uma aplicação para o ambiente brasileiro. In: Anais do Seminários em Administração FEA-USP. São Paulo, 2003. [citado em 19 Jan 2012]. Disponível em: http://www.ead.fea.usp.br/ Semead/6semead/MKT.htm.

116.Witt RR. Competências da enfermeira na atenção básica: contribuição à construção das Funções Essenciais de Saúde Pública [tese]. Ribeirão Preto (SP): Universidade de São Paulo, Enfermagem, Escola de Enfermagem de Ribeirão Preto; 2005. [citado em 26 Jan 2012]. Disponível em: http://www.teses.usp.br/teses/disponiveis/22/22133/tde-01062005-102741/ptbr.php.

117. ICN. Catáogo CIPE®: Cuidados Paliativos para uma morte digna. Lisboa (PT): Ordem dos Enfermeiros de Portugal; 2010 [citado em 12 Jan 2012]. Disponível em: http://www.ordemenfermeiros.pt/publicacoes/Documents/CIPE_Cuidados\%20Paliativos.pdf.

118.Asociacion LatinoAmericana de Cuidados Paliativos (ALCP) . Currículo de Enfermería para un Programa de Postgrado en Cuidados Paliativos. Houston: IAHPC Press; 2008.

119. Silva MJP, Araújo MT, Firmino F. Multidisciplinaridade e Interdisciplinaridade Enfermagem. In: Oliveira RA, (coord.). Cuidado paliativo. São Paulo: Conselho Regional de Medicina do Estado de São Paulo, 2008. p. 61-63.

120.Arrieira ICO, et al. Programa de Internação Domiciliar Interdisciplinar Oncológico: metodologia de trabalho. Cienc Cuid Saude [Internet]. 2009 [citado em 26 Jan 2012]; 8(spe):104-109. Disponível em: http://www.periodicos.uem.br/ojs/index.php/CiencCuidSaude/article/view/9725.

121.O Connor M, Aranda S. Guia Prático de Cuidados Paliativos em Enfermagem. São Paulo: Andrei; 2008. 422 p. 
122. Baliza MF, Bousso RS, Spineli Vívian Marina Calixto Damasceno, Lucía Silva, poloneses Kátia. Cuidados paliativos não Domicílio: Percepção de enfermeiras da Estratégia Saúde da Família. Acta paul. enferm. 2012 [citado em 13 Fev 2013]; 25(spe2):13-18. Disponível em: http://www.scielo.br/scielo.php?script=sci_arttext\&pid=S0103$21002012000900003 \& \operatorname{lng}=\mathrm{en}$.

123.Gamondi G, Larkin P, Payne S. Core competencies in palliative care: an EAPC White Paper on palliative care education - part 1. European Journal of Palliative Care [Internet]. 2013 [citado em 20 Jun 2014]; 20(2): 86-91. Disponível em: http://www.eapcnet.eu/LinkClick.aspx?fileticket=jtSAxBB-azI\%3D

124.Gamondi G, Larkin P, Payne S. Core competencies in palliative care: an EAPC White Paper on palliative care education - part 2. European Journal of Palliative Care [Internet]. 2013 [citado em 20 Jun 2014]; 20(3): 140-145. Disponível em: http://www.eapcnet.eu/LinkClick.aspx?fileticket=jtSAxBB-azI\%3D

125.Cannning D, Yates, P\& Rosenberg JP. Competency Standardas for Specialist Palliative Care Nursing Practice. Brisbane: Queensland University of Tchnology. 2005 [citado em 19 Jan 2012]. Disponível em: http://www.pcna.org.au/images/documents/competystds.pdf.

126.American Association of Colleges of Nursing. Peaceful Death: recommended competencie and curricular guidelines for end-of-life nursing. 2000 [citado em 19 Jan 2012]. Disponível em: www.aacn.nche.edu/elnec/publications/peaceful death

127. International Council of Nurses. Nurses' role in providing care to dying patients and their families. 2012 [citado em 19 Jan 2012]. Disponível em: http://www.icn.ch/images/stories/documents/publications/position_statements/A12_Nurses_R ole_Care_Dying_Patients.pdf.

128. Grantham D, O’Brien LA, Widger K, Bouvette M, McQuinn P. Canadian Hospice Palliative Care - Nursing Competencies. 2009 [citado em 19 Jan 2012] Disponível em: http://acsp.net/media/34461/Canadian_Hospice_Palliative_Care_Nursing_Competencies_Cas e_Examples_Revised_Feb_2010.pdf.

129.Connolly M, Charnley K, Regan J. A review of Palliative Care Competence Frameworks. 2012 [citado em 19 Jan 2012]. Disponível em: http://aiihpc.org/upload/education/files/1342606786_Palliative_Care_Competence_Framewor k_Report_R1.pdf.

130.Fishman SM, et. al. Core Competencies for Pain Management: Results of an Interprofissional Consensus Summit. Pain Medicine [Internet]. 2013 [citado em 19 Dez 2013]; 14: 971-981. Disponível em: http://www.ucdmc.ucdavis.edu/paineducation/happenings/painmedicinearticle2013.pdf.

131.Slatten K, Hatlevik O, Fagerstrom L. Validation of a new instrument for self-assessment of Nurses' core competencies in palliative care. Nurs Res Pract. [Internet]. 2014 [citado em 07 Out 2014]; 2014:615.498. Disponível em: http://www.ncbi.nlm.nih.gov/pmc/articles/PMC4124716/pdf/NRP2014-615498.pdf

132.Pimenta CAM, Mota DDCF. Educação em cuidados paliativos: componentes essenciais. In: Pimenta CAM, Mota DDCF, Cruz DALM. Dor e cuidados paliativos: enfermagem, medicina e psicologia. Barueri, SP: Manole, 2006. p. 29-44. 
133.Mutto EM, et al. Nursing Education: The Experience, Attitudes, and Impact of Caring for Dying Patients by Undergraduate Argentinian Nursing Students. Journal of Palliative Medicine. 2010; 13(12): 1445-50. PubMed.PMID 21155639.

134.Porto AR, Thofehrn MB, Amestoy SC, Gonzáles RIC, Oliveira NA. The essence of interdisciplinary practice in palliative care delivery to cancer patients. Invest. Educ. Enferm. [Internet]. 2012 [citado em 07 Out 2014]; 30(2):231-9. Disponível em: http://aprendeenlinea.udea.edu.co/revistas/index.php/iee/article/view/8362/11361

135.Kirby E, Broom A, Good P. The role and significance of nurses in managing transitions to palliative care: a qualitative study. BMJ Open [Internet]. 2014 [citado em 07 Out 2014]; 4(9):e006026. Disponível em: http://bmjopen.bmj.com/content/4/9/e006026.full.pdf+html.

136.Powazki R, Walsh D, Cothren B, Rybicki L, Thomas S, Morgan G, et al. Karius D, Mellar P. The Care of the Actively Dying in an Academic Medical Center: A Survey of Registered Nurses'. AM J HOSP PALLIAT CARE [Internet]. 2014 [citado em 07 Out 2014]; 31: 619. Disponível em: http://ajh.sagepub.com/content/31/6/619.

137.Le Boterf G. [Évaluer les compétences: quels jugements? quels critères? quelles instances?]. Education permanente [Internet]. 1998 [citado em 20 Jun 2014]; 135:143-15. Disponível

em: http://www.academia.edu/747449/Evaluer_les_competences_quels_jugements_quels_criteres _quelles_instances. Francês

138.Le Boterf G. [Apprendre à agir et à interagir en professionnel compétent et responsible]. Education Permanente [Internet]. 2011 [citado em 07 Out 2014]; 188(3):97-112. Disponível em:

https://www.usherbrooke.ca/ssf/fileadmin/sites/ssf/Perspectives_SSF/article_entretien_Guy_L e_Boterf_sur_professionnalisation.pdf . Francês

139.Sinha IP, Smyth RL, Williamson PR. Using the Delphi Technique to Determine Which Outcomes to Measure in Clinical Trials: Recommendations for the Future Based on a Systematic Review of Existing Studies. PLoS Med [Internet]. 2011 [ citado em 07 Out 2014]; 8(1):e1000393. Disponível em: http://www.plosmedicine.org/article/fetchObject.action?uri=info\%3Adoi\%2F10.1371\%2Fjou rnal.pmed.1000393\&representation=PDF

140.Nevado DC, Barbarro AA, Lozano MAR. [Continuidad de cuidados, innovación y redefinición de papeles profesionales en la atención a pacientes crónicos y terminales. Informe SESPAS 2012]. Gac Sanit, [Internet]. 2012 [citado em 20 Ago 2014]; 26(s):63-68. Disponível em:http://www.sciencedirect.com/science/article/pii/S0213911111003700.Espanhol

141.Vissers KCP, Brand MWM, Jacobs J, Groot M, Veldhoven C, Verhagen C, et al. Palliative Medicine Update: a multidisciplinary approach. Pain Practice [Internet]. 2013 [citado em 07 Out 2014]; 13(7):576-588. Disponível em: http://onlinelibrary.wiley.com/doi/10.1111/papr.12025/pdf.

142.Docherty SL, Thaxton C, Allison C, Barfield RC, Tamburro RF.The nursing dimension of providing palliative care to children and adolescents with cancer. Clinical Medicine Insights: Pediatrics [Internet]. 2012 [citado em 07 Out 2014]; 6:75-88. Disponível em: 
http://www.ncbi.nlm.nih.gov/pmc/articles/PMC3620813/pdf/cmped-6-2012-075.pdf

143.Ito EE, Peres AM, Takahashi RT, et al. O ensino de enfermagem e as diretrizes curriculares nacionais: utopia x realidade. Rev. esc. enferm. USP [Internet]. 2006 [citado em 20 Abr 2012]; 40(4). Disponível em: http://dx.doi.org/10.1590/S0080-62342006000400017.

144. Dolores A, Miranda MCG, Brasil SL. Formação de profissionais de saúde na perspectiva da integralidade. Revista Baiana de Saúde Pública [Internet]. 2007 Jun [citado em 20 Abr 2012]; 31(spe1):3-31.Disponível em: https://medicina.ufg.br/up/148/o/formacao_de_profissionais_de_saude_na_perspectiva_da_int egralidade.pdf.

145.Pessini L, Bertachini L. Nuevas perspectivas en cuidados paliativos. Acta Bioethica [Internet]. 2006 [citado em 20 Abr 2012]; 12(2):231-42. Disponível em: http://www.scielo.cl/scielo.php?pid=S1726-569X2006000200012\&script=sci_arttext.

146.Gutgsell TL, Kirsh KL, Meyer B. Cuidados Paliativos (Hospice) e medicina paliativa. In: South-Paul JE, Matheny SC, Lewis EL (org.). CURRENT medicina de família e comunidade: diagnóstico e tratamento. 3 ed. Porto Alegre: AMGH; 2014. p. 674-87.

147.Lacerda MR. Cuidado domiciliar: em busca da Autonomia do individuo e da Família na Perspectiva da área pública. Ciênc. saúde coletiva [Internet]. 2010 [citado em 20 Jun 2012]; 15(5):2621-2626. Disponível em: http://www.scielo.br/scielo.php?script=sci_arttext\&pid=S141381232010000500036\&l=en\&n $\mathrm{rm}=\mathrm{iso}$.

148. Abreu CBB. Questões éticas reconhecidas por profissionais de uma equipe de Cuidados Paliativos [tese]. São Paulo: Universidade de São Paulo, Faculdade de Saúde Pública; 2014 [citado em 20 Dez 2014]. Disponível http://www.teses.usp.br/teses/disponiveis/6/6135/tde-13032014-085314/pt-br.php.

149.Kristjanson L, Hudson P, Oldham L. Trabalho junto às famílias. In: O’Connor M, Aranda S. Guia prático de cuidados paliativos em enfermagem. São Paulo: Andrei; 2008. p. 298-313.

150.Fonseca A, Geovanini. Cuidados Paliativos na formação do profissional da área de saúde. Revista Brasileira de Educação Médica [Internet]. 2013[citado em 17 Abr 2014]; 37(1):120125. Disponível em: http://www.scielo.br/pdf/rbem/v37n1/17.pdf.

151. Américo AFQ. As últimas 48 horas de vida. In: Manual de Cuidados Paliativos da Academia Nacional de Cuidados Paliativos. ${ }^{a}$. Edição, Editora Diagraphic, Rio de Janeiro; 2009. p. 290-298.

152. Kóvacs MJ. Educação para a Morte - desafio na formação de profissionais de saúde e educação. São Paulo: Casa do Psicólogo - FAPESP; 2012.

153.Silva MF, Fernandes MFP. A ética do processo ante o gerenciamento de enfermagem em cuidado paliativo. O Mundo da Saúde [Internet] . 2006 [citado em 20 Abr 2012]; 30(2): 318325. Disponível em: http://www.scamilo.edu.br/pdf/mundo_saude/35/etica_processo_ante.pdf.

154.Milne D, Millard R. Luto. In: O’Connor M, Aranda S. Guia prático de cuidados paliativos em enfermagem. São Paulo: Andrei; 2008. p. 315-34. 
155.Perrenoud P. Construir competências é virar as costas aos saberes? Pátio. Revista pedagógica [Internet]. 1999 [citado em 20 Abr 2014]; 11: 15-19. Disponível em: http://egov.ufsc.br/portal/sites/default/files/anexos/29108-29126-1-PB.pdf

156.Silva EP; Sudigursky D. Concepções sobre cuidados paliativos: revisão bibliográfica. Acta paul. enferm. [Internet]. 2012 [citado em 18 Jan 2012]; 21(3). Disponível em: <http://dx.doi.org/10.1590/S0103-21002008000300020.

157. Schalairet M. End-of-life nursing care: statewide survey of nurses' education needs and effects of education. Journal of Professional Nursing [Internet]. 2009 may/june [citado em 20 Abr 2012]; 25(3): 170-177. PubMed; PMID 19450788.

158.Mallory JL. The Impact of a Palliative Care Educational Component on Attitudes Toward Care of the Dying in Undergraduate Nursing Students. Journal of Professional Nursing [Internet]. 2003 [citado em 20 Abr 2012]; 19(5):305-312. PubMed; PMID 14613070.

159.Malloy, P, et. al. Promoting Palliative Care Worldwide Through International Nursing Education. Journal of Transcultural Nursing [Internet]. 2014 [citado em 18 Dez 2014]; 25(4): 410-17. Disponível em: http://prc.coh.org/pdf/Promoting\%20Palliative\%20care\%20worldwide.pdf.

160.Dickinson GE, Clark D, Sque M. Palliative care and end of life issues in UK preregistration, undergraduate nursing programmes. Nurse Education Today [Internet]. 2008 [citado em 20 Jun 2013]; 28(2):163-170.PubMed; PMID 17452066.

161.Bickel-Swnson D, et al. End-of-Life Training in U.S. Medical Schools: A Systematic Literature Review. Journal Palliative Medicine [Internet]. 2007 [citado em 20 Abr 2012]; 10(1): 229-235. PubMed; PMID 17298271.

162.Paice JA, et al. Global efforts to improve palliative care: the International End-of- Life Nursing Education Consortium Training Programme. Journal of Advanced Nursing [Internet]. 2008 [citado em 20 Abr 2012]; 61(2): 173-180. PubMed; PMID 18186909.

163. Whittaker E, et al. The palliative care education needs of nursing home staff. Nurse Education Today [Internet]. 2006 [citado em 20 Abr 2012]; 26:501-510. PubMed; PMID 16517029.

164.Kira CM, Montagnini M, Barbosa SMM. Educação em Cuidados Paliativos. In: Oliveira RA. Cuidado Paliativo. São Paulo: Conselho Regional de Medicina do Estado de São Paulo; 2008. p. 595-609.

165.Pinho LMO, Barbosa MA. A relação docente-acadêmico no enfrentamento do morrer. Rev. esc. enferm. USP [Internet]. 2010 [citado em 20 Abr 2012]; 44(1): 101-112. Disponível em: http://www.scielo.br/scielo.php?script=sci_arttext\&pid=S0080-62342010000100015.

166.Neto IG, Marques AL, Gonçalves E, Domingos H, Feio M. A propósito da criação da Competência de Medicina Paliativa. Cuidados Paliativos [Internet]. 2014 [citado em 16 Dez 2014]; 1(1): 13-16. Disponível em: http://www.apcp.com.pt/uploads/revista_cp_vol_1_n_1.pdf.

167. HennezeL M, Jean-Yves L. A arte de morrer - Tradições religiosas e espiritualidade humanista diante da morte na atualidade. Petrópolis, RJ: Vozes, 2009. 


\section{APÊNDICES}

APÊEDICE A - Artigo 1: Perfil bibliométrico das teses e dissertações em enfermagem sobre cuidados paliativos

Janaina Meirelles Sousa, Enfermeira. Doutoranda do Programa de Pós-Graduação em Enfermagem da Universidade de Brasília. Professora Assistente do Curso de Enfermagem da Universidade de Brasília - Faculdade de Ceilândia. Distrito Federal, Brasil; email: sjana@unb.br.

Paulo Henrique Fernandes dos Santos, Enfermeiro da Secretaria de Saúde do Distrito Federal. Distrito Federal, Brasil; email: paulofs.enf@gmail.com.

Elioenai Dornelles Alves, Enfermeiro. Livre-docente. Professor Pesquisador Sênior no Departamento de Enfermagem da Universidade de Brasília. Docente permanente do Programa de Pós-Graduação em Ciências da Saúde e Enfermagem da Universidade de Brasília. Distrito Federal, Brasil; email: elioenai@ unb.br.

Colaborações: Sousa JM participou da concepção do projeto, coleta e interpretação dos dados, redação do artigo e aprovação final da versão a ser publicada. Santos PHF participou da concepção do projeto, interpretação dos dados, redação do artigo e aprovação final da versão a ser publicada. Alves ED contribuiu nas etapas de concepção do projeto, revisão crítica relevante do conteúdo intelectual e aprovação final da versão a ser publicada.

RESUMO: O estudo buscou caracterizar a produção de teses e dissertações em enfermagem de cuidados paliativos. Trata-se de uma pesquisa descritiva, com abordagem bibliométrica, realizada pela análise dos resumos de dissertações e teses publicadas em 13 catálogos do Centro de Estudos e Pesquisas em Enfermagem - CEPEn. Os resultados evidenciaram 85 publicações, defendidas em 16 instituições, orientadas por 59 pesquisadores, com predominância de dissertações $(80 \%)$ e defesas em instituições da região sudeste $(64,7 \%)$. O contexto hospitalar $(47 \%)$, de domicílio $(14,15 \%)$ e ambulatório $(10,5 \%)$, assim como, enfermeiros $(24,7 \%)$, equipe de enfermagem $(11,7 \%)$ e paciente oncológico $(9,3 \%)$ foram os mais pesquisados. A abordagem qualitativa $(82,4 \%)$ e os referenciais teóricos da Fenomenologia de Martim Heidegger (9,2\%), o Interacionismo Simbólico $(9,2 \%)$ e a Filosofia dos Cuidados Paliativos $(5,8 \%)$ se destacaram entre as publicações. Conclui-se que o cuidado paliativo como área de conhecimento e especialidade encontra-se legitimado e em ascensão no cotidiano das práticas de enfermagem.

Descritores: Cuidados Paliativos, Enfermagem de Cuidados Paliativos na Terminalidade da Vida, Pesquisa em Enfermagem, Bibliometria.

\section{INTRODUÇÃO}

A filosofia dos cuidados paliativos aborda paciente e família como unidade de cuidado. Ao paciente busca-se oferecer suporte no processo de doença que lhe ameaça a vida, com vista à prevenção, manejo e controle de sinais e sintomas, nas dimensões física, social, psicológica e espiritual $^{(1)}$. À família uma assistência que lhe permita sentir-se amparada para participar do cuidado ao paciente até o momento da chegada da morte ${ }^{(2)}$.

A família configura um braço assistencial das equipes de cuidados paliativos e o suporte financeiro, social e emocional de pacientes. É merecedora de cuidados para que não adoeça devido à sobrecarga de trabalho, o estresse de lidar com a possibilidade de morte iminente e ao processo de luto ${ }^{(3)}$. 
A prática dos cuidados paliativos pode ser evidenciada em diferentes contextos de saúde que prestem assistência a pacientes que enfrentam doenças que ameaçam a vida, na experiência de cronicidade ou terminalidade de vida, como unidades hospitalares, ambulatórios, domicílio, casas de apoio, hospices e centro-dia. Abarca pacientes em diferentes etapas da vida, desde o nascimento até a idade adulta avançada ${ }^{(4)}$.

$\mathrm{Na}$ assistência às crianças observa-se um olhar diferenciado com respeito a sua especificidade biológica, de desenvolvimento, de preferência pelo cuidado domiciliar, com o envolvimento dos pais no cuidado e processos de tomada de decisão, e devida atenção ao momento de transição para uma abordagem exclusivamente paliativa. Essa postura assistencial visa ao aumento de qualidade de vida para a criança e o suporte para a família no enfrentamento do sofrimento imposto pela doença, quando esta ameaça a vida ${ }^{(5)}$.

A postura do profissional de saúde em cuidados paliativos permeia os princípios éticos da beneficência, não maleficência, autonomia, justiça, veracidade, proporcionalidade terapêutica, referencial do duplo efeito, prevenção, não abandono, expresso tanto pelo trabalho interdisciplinar como pela atuação individual humanizada ${ }^{(6-7)}$.

A assistência paliativa possui caráter interdisciplinar e requer dos envolvidos a conjugação do saber e do fazer de diferentes profissionais, em um somatório de ações de cuidado que se complementam e transformam-se em ferramentas de cuidado na busca por uma prática totalizadora, sem fragmentações, de forma organizada, diversificada e humana.

A enfermagem de cuidados paliativos caminha na direção da promoção do ser humano na sua integralidade, em consonância com os princípios da ética e da bioética. Integralidade aqui entendida como a capacidade do profissional para responder ao sofrimento humano manifesto no contexto de cada encontro, numa postura de apreensão ampliada das necessidades do sujeito, de forma a abarcar ações de assistência e de prevenção de sofrimento, adequando a oferta de cuidado ao contexto e momento propício para tal ${ }^{(8)}$.

$\mathrm{O}$ cuidar em enfermagem de cuidados paliativos solicita do profissional um olhar atento ao contexto, em um movimento duplo por parte dos profissionais na articulação de ações preventivas e assistenciais. Isso envolve a disponibilidade em apreender de modo ampliado as necessidades de saúde e analisar o significado do sofrimento expresso pelo paciente frente os recursos disponíveis para responder a necessidade apreendida, de modo a eleger o que deve ser realizado de imediato e o que pode ser respondido futuramente em novos encontros de cuidado $^{(3,8)}$.

O plano terapêutico da enfermagem emerge do diálogo e negociação entre profissionais de saúde, pacientes e familiares. Ações preventivas são ditadas a partir do conhecimento do profissional de enfermagem que necessita de qualificação em cuidados paliativos, seja na abordagem paliativa ou de especialidade, para que ao assistir o paciente seja capaz de identificar as causas de sofrimento manifesto, dar uma resposta imediata à necessidade, e reconhecer a necessidade de ações preventivas, quer seja de encaminhamento a outros profissionais de saúde ou de educação em práticas de manejo e controle de sintomas geradores de sofrimento ${ }^{(9)}$.

Neste contexto, a enfermagem é referenciada como uma das categorias profissionais que mais publica sobre cuidados paliativos e que apresenta uma proposta de cuidado humanizado, como um ato de respeito e solidariedade, em ações de conforto para além do âmbito fisiopatológico, intermediando a realização dos anseios, desejos e vontades do paciente ${ }^{(10)}$.

Enfermagem de cuidados paliativos está presente nos diferentes contextos de saúde brasileiro, mas ainda distante da visibilidade que almejamos. Por isso, este estudo pretende apontar as dimensões de cuidado oferecido pela enfermagem em cuidados paliativos, quantificar a produção científica, reconhecer as instituições de enfermagem que reflexionam sobre cuidados paliativos, identificar os sujeitos alvo de discussão em pesquisas sobre a temática, e apontar lacunas na difusão do conhecimento que porventura possam existir. 
Espera-se com este instigar pesquisadores e potenciais pesquisadores à elaboração de novos estudos que contribuam para o avanço da enfermagem na construção do conhecimento em cuidados paliativos.

\section{METODOLOGIA}

Trata-se de um estudo descritivo, exploratório, de abordagem bibliométrica. A bibliometria é uma técnica que se utiliza de métodos quantitativos na busca por uma avaliação objetiva da produção e disseminação do conhecimento científico ${ }^{(11)}$.

O uso da bibliometria no Brasil data a década de 1970, na busca por indicadores da produção científica, com vista a planejamentos nacionais de pesquisa científica, análise de temas de pesquisa emergentes, dentre outros. Na atualidade, observa-se subcampos como a bibliometria, a informetria, a cienciometria e a webometria, que se diferenciam quanto ao objeto de estudo, as variáveis, os métodos específicos de análise e aos objetivos ${ }^{(11-13)}$.

A unidade de análise escolhida foram publicações científicas listadas nos catálogos do Centro de Estudos e Pesquisas em Enfermagem - CEPEn, que apresenta informações sobre pesquisas e pesquisadores em enfermagem, por meio de resumos de teses e dissertações ${ }^{(14)}$.

Diante da população de pesquisa definida, utilizou-se a técnica de amostragem não probabilística intencional, a fim de assegurar a representatividade dos dados. Ao todo foram analisados 13 catálogos que compilam 6.355 resumos de teses e dissertações defendidas no período de 1985 a 2012. A amostra constituiu-se de 85 resumos que estão disponíveis online pelo Catálogo de Informações sobre Pesquisas e Pesquisadores em Enfermagem, na web site da Associação Brasileira de Enfermagem - $\mathrm{ABEn}^{(14)}$.

O critério de seleção dos resumos foi a figuração das seguintes palavras em seus títulos, resumos ou palavras-chaves: cuidados paliativos, cuidados a doentes terminais, terminalidade, doente terminal, assistência terminal.

Diante dos dados foi feita a leitura analítica dos resumos na busca das variáveis: instituição de ensino, ano de defesa, nível stricto sensu, orientadores de pesquisa, cenário de estudo, sujeitos de pesquisa e referencial teórico Após análise, os dados foram organizados e descritos em tabelas e figuras segundo as variáveis estabelecidas.

\section{RESULTADOS}

A análise quantitativa dos resumos (Figura 1) mostra que $80 \%$ (68) foi produto de dissertações de mestrado seguida de $20 \%$ (17) de teses de doutorado. O total dos resumos (85) corresponde a $1,3 \%$ das publicações nos catálogos, e apresenta crescimento oscilante a partir de 1999, expondo o ano de 2011 como de maior produção com 14 defesas.

Dentre as 16 instituições com programas de pós-graduação (Tabela 1), a Universidade de São Paulo - Escola de Enfermagem (21,2\%) e a Universidade de São Paulo - Escola de Enfermagem de Ribeirão Preto $(15,3 \%)$ apresentaram mais que um terço da produção $(36,5 \%)$. As instituições da região sudeste se destacaram com a maior produção $(64,7 \%)$, seguido da região sul $(22,3 \%)$ e nordeste $(13 \%)$.

$\mathrm{Na}$ Tabela 1 observa-se um quantitativo de 59 orientadores na temática, expondo que 17 realizaram mais de uma orientação e 42 deles uma orientação. 
Figura 1 - Distribuição dos resumos segundo nível stricto sensu e ano de publicação. Brasília, DF, Brasil, 2014.

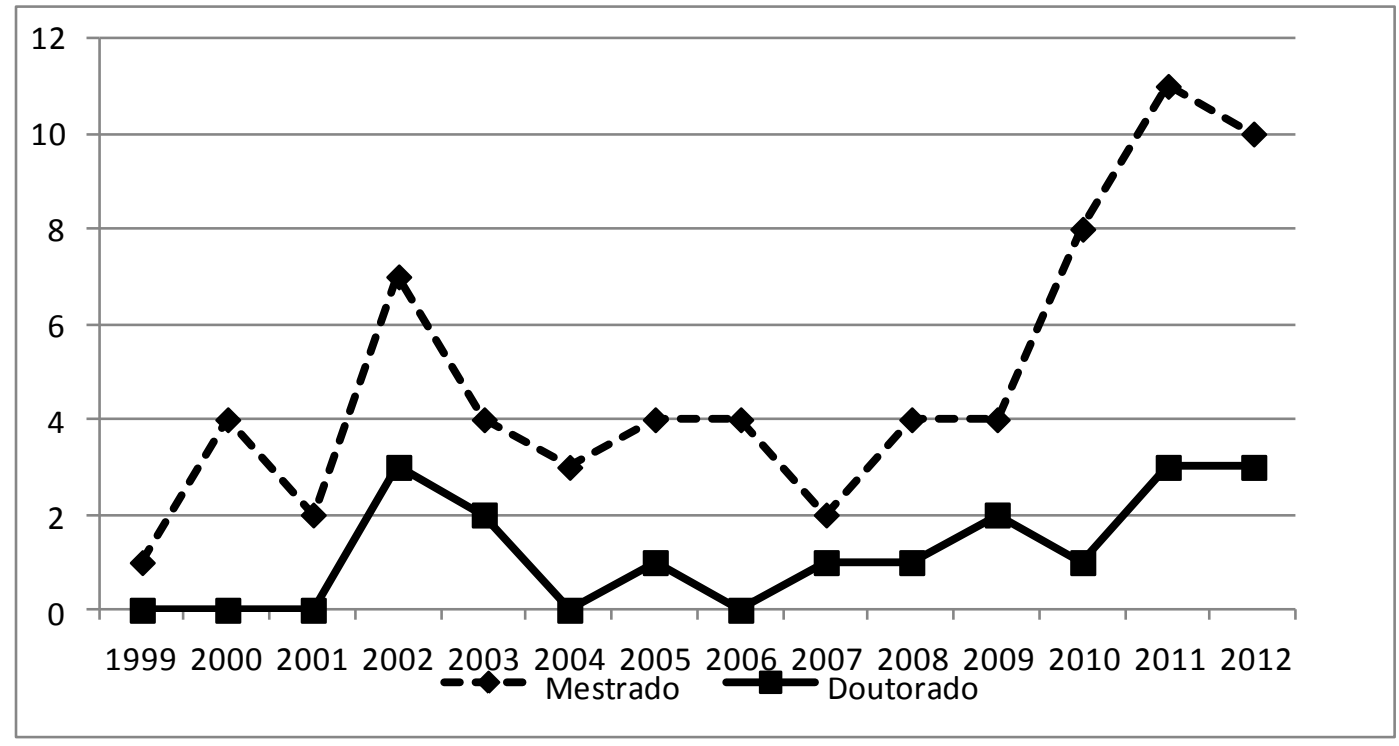

Tabela 1 - Distribuição dos resumos segundo ranking das instituições e orientadores na área de cuidados paliativos. Brasília, DF, Brasil, 2014.

\begin{tabular}{|c|c|c|}
\hline Instituição/Orientadores & $\mathbf{N}$ & $\%$ \\
\hline \multicolumn{3}{|l|}{ Instituição/ Programa de Pós Graduação $(n=85)$} \\
\hline Universidade de São Paulo - Escola de Enfermagem & 18 & 21,2 \\
\hline Universidade de São Paulo - Escola de Enfermagem de Ribeirão Preto & 13 & 15,3 \\
\hline & Nery & 9,4 \\
\hline Universidade Federal de Santa Catarina & 07 & 8,2 \\
\hline $\begin{array}{l}\text { Universidade Federal do Estado do Rio de Janeiro. Escola de } \\
\text { Enfermagem Alfredo Pinto }\end{array}$ & 06 & 7,0 \\
\hline Universidade Federal da Bahia & 05 & 5,9 \\
\hline Universidade Federal de Minas Gerais & 05 & 5,9 \\
\hline Universidade Federal do Rio Grande do Sul & 05 & 5,9 \\
\hline Universidade Estadual de Maringá & 04 & 4,7 \\
\hline Universidade Federal da Paraíba & 04 & 4,7 \\
\hline Universidade do Estado do Rio de Janeiro & 03 & 3,5 \\
\hline Universidade Federal de Santa Maria & 03 & 3,5 \\
\hline Universidade Estadual de Campinas & 01 & 1,2 \\
\hline Universidade Federal do Ceará & 01 & 1,2 \\
\hline Universidade Guarulhos & 01 & 1,2 \\
\hline $\begin{array}{l}\text { Universidade Federal de Pernambuco - Doutorado em saúde da } \\
\text { criança e do adolescente }\end{array}$ & 01 & 1,2 \\
\hline \multicolumn{3}{|l|}{ Orientadores $(\mathbf{n}=\mathbf{5 9})$} \\
\hline Pesquisadores com uma orientação & 42 & 71,2 \\
\hline Pesquisadores com duas orientações & 11 & 18,6 \\
\hline Pesquisadores com três orientações & 03 & 5,1 \\
\hline Pesquisadores com quatro orientações & 03 & 5,1 \\
\hline
\end{tabular}


Em relação aos cenários onde as pesquisas foram realizadas, a Tabela 2 aponta a incidência do cenário hospitalar em $47 \%$ dos resumos, seguido do domicílio com $14,15 \%$ e ambulatório com $10,5 \%$.

Tabela 2 - Distribuição dos resumos segundo cenário de pesquisa. Brasília, DF, Brasil, 2014.

\begin{tabular}{lcc}
\hline Cenário de pesquisa & $\mathbf{N}$ & $\mathbf{\%}$ \\
\hline Hospital & 19 & 22,4 \\
Domicílio & 10 & 11,7 \\
Ambulatório & 09 & 10,6 \\
Hospital - unidade de terapia intensiva & 09 & 10,6 \\
Hospital - unidade de pediatria & 06 & 7,0 \\
Base de Dados & 05 & 5,8 \\
Hospital - unidade de terapia intensiva pediátrica & 04 & 4,7 \\
Serviço de internação domiciliar & 02 & 2,4 \\
Atenção Básica & 01 & 1,2 \\
Casa de Apoio & 01 & 1,2 \\
Clínica de Oncologia & 01 & 1,2 \\
Hospital - unidade de terapia intensiva neonatal & 01 & 1,2 \\
Hospital - unidade de transplante de células-tronco hematopoéticas & 01 & 1,2 \\
Acervo cinematográfico & 01 & 1,2 \\
Cenário de pesquisa não informado & 15 & 17,6 \\
\hline Total & $\mathbf{8 5}$ & $\mathbf{1 0 0}$ \\
\hline
\end{tabular}

Tabela 3 - Distribuição dos resumos segundo sujeitos de pesquisa. Brasília, DF, Brasil, 2014.

\begin{tabular}{lcc}
\hline Sujeitos de pesquisa & $\mathbf{N}$ & $\mathbf{\%}$ \\
\hline Enfermeiros & 21 & 24,7 \\
Equipe de enfermagem & 10 & 11,7 \\
Paciente oncológico & 08 & 9,3 \\
Família & 08 & 9,3 \\
Profissionais de saúde & 07 & 8,2 \\
Cuidadores & 06 & 7,0 \\
Publicações científicas & 05 & 5,8 \\
Enfermeiros/Médicos & 02 & 2,4 \\
Equipe da Estratégia da Saúde da Família & 02 & 2,4 \\
Paciente em tratamento quimioterápico & 02 & 2,4 \\
Paciente oncológico/família & 02 & 2,4 \\
Paciente portador HIV/AIDS & 02 & 2,4 \\
Alunos de ensino médio de enfermagem & 01 & 1,2 \\
Crianças/pais & 01 & 1,2 \\
Cuidadores/estudantes/profissionais de saúde & 01 & 1,2 \\
Equipe de saúde & 01 & 1,2 \\
Filmes & 01 & 1,2 \\
Mães de crianças e adolescentes com doença oncológica & 01 & 1,2 \\
Pacientes & 01 & 1,2 \\
Pacientes/familiares & 01 & 1,2 \\
Pacientes/familiares/enfermeiros & 01 & 1,2 \\
Sujeito não informado & 01 & 1,2 \\
\hline Total & $\mathbf{8 5}$ & $\mathbf{1 0 0}$ \\
\hline
\end{tabular}


Os sujeitos alvo de investigação com maior incidência entre os resumos foram enfermeiros $(24,7 \%)$, a equipe de enfermagem $(11,7 \%)$, o paciente oncológico $(9,3 \%)$ e a família $(9,3 \%)$, conforme Tabela 3 .

No que se refere a abordagem metodológica $82,4 \%$ das publicações utilizaram abordagem qualitativa, $14,1 \%$ da quantitativa e $3,5 \%$ da abordagem quanti-qualitativa. Os resumos analisados apontam a opção dos pesquisadores pelo referencial teórico da Fenomenologia de Martin Heidegger, pelo Interacionismo Simbólico e pela Filosofia dos Cuidados Paliativos para reflexão dos resultados de pesquisas (Tabela 4). Se somarmos a incidência do referencial da fenomenologia $(17,3 \%)$ verificaremos que este foi o mais utilizado pelos pesquisadores.

Tabela 4 - Distribuição dos resumos segundo referencial teórico. Brasília, DF, Brasil, 2014.

\begin{tabular}{lcc}
\hline Referenciais Teóricos & $\mathbf{n} \mathbf{8 7}$ & $\mathbf{\%}$ \\
\hline Fenomenologia - Martin Heidegger & 8 & 9,20 \\
Interacionismo Simbólico & 8 & 9,20 \\
Filosofia dos Cuidados Paliativos & 5 & 5,80 \\
Representações Sociais & 4 & 4,60 \\
Fenomenologia & 3 & 3,50 \\
Fenomenologia - Merleau Ponty & 2 & 2,30 \\
Fenomenologia - Alfred Schutz & 2 & 2,30 \\
Teoria de Michel Foucault & 2 & 2,30 \\
Análise Existencial de Viktor Emil Frankl & 1 & 1,14 \\
Antropologia Interpretativa & 1 & 1,14 \\
Antropologia Médica & 1 & 1,14 \\
Bioética & 1 & 1,14 \\
Ciência da Complexidade & 1 & 1,14 \\
Comunicação Interpessoal em saúde, & 1 & 1,14 \\
Conceito de vulnerabilidade & 1 & 1,14 \\
Educação Libertadora & 1 & 1,14 \\
Educação Problematizadora & 1 & 1,14 \\
Método Explicativo de Vigotski & 1 & 1,14 \\
Perspectiva Evolucionária de Rodgers & 1 & 1,14 \\
Prática Baseada em Evidência & 1 & 1,14 \\
Referencial Teórico Cuidar/Cuidado & 1 & 1,14 \\
Referencial de Elisabeth Kubler-Ross & 1 & 1,14 \\
Sistematização da Assistência de Enfermagem & 1 & 1,14 \\
Sociopoética & 1 & 1,14 \\
Teoria de Carl Ransom Rogers & 1 & 1,14 \\
Teoria de Madeleine Leininger & 1 & 1,14 \\
Teoria do Cuidado Transpessoal de Jean Watson & 1 & 1,14 \\
Teoria do Déficit de Autocuidado de Orem & 1 & 1,14 \\
Teoria Humanística de Enfermagem & $\mathbf{8 7}$ & 1,14 \\
não informado & & 36,86 \\
\hline Total & $\mathbf{1 0 0}$ \\
\hline Dors esudos utilzanam mais & & \\
\hline
\end{tabular}

* Dois estudos utilizaram mais de um referencial teórico. 


\section{DISCUSSÃO}

Este estudo apresenta limitações no que tange a identificação de subtemas nos resumos analisados. Os resumos dispostos nos catálogos apresentaram palavras chaves somente após o volume 30-2011, publicado em outubro de 2012, inviabilizando a análise da articulação das diferentes subáreas da enfermagem com a temática cuidados paliativos.

A linha cronológica das publicações expõe um crescimento oscilante, mas contínuo desde 1999, o que pode ter sido impulsionado pela publicação do conceito e dos princípios dos cuidados paliativos pela Organização Mundial da Saúde no ano de 2002, instigando pesquisadores à reflexão sobre a temática ${ }^{(4)}$.

Os resultados evidenciam um quantitativo de orientadores que somado ao número de orientados que elaboraram as dissertações e teses, permitem inferir que somos um contingente expressivo de pesquisadores na temática. Salienta-se que a enfermagem de cuidados paliativos haverá de amadurecer e ser legitimada à medida que o retorno das pesquisas que se debruçam sobre ela evidenciarem os ajustes necessários à realização da sua prática. A busca pela identidade da enfermagem brasileira no que tange aos cuidados paliativos aponta a necessidade de expansão das reflexões sobre a temática aos espaços assistenciais para além dos grandes centros de pesquisa, num esforço compartilhado de pesquisadores na construção do conhecimento.

Os programas de pós-graduação da região sudeste se destacaram com as maiores porcentagens de teses e dissertações na temática cuidados paliativos. A literatura aponta a existência de 63 programas de pós-graduação em enfermagem stricto sensu, que concentram 89 cursos distribuídos na região sudeste (44), nordeste (18), região sul (17), centro-oeste (8) e norte (2), o que provavelmente colaborou com os achados deste estudo, pois é de se esperar uma maior concentração de publicações nas regiões com maior número de programas e $\operatorname{cursos}^{(15)}$. Observa-se que os cuidados paliativos se inserem, mesmo que de forma tímida, como área de conhecimento e especialidade em enfermagem, oportunizado pela divulgação de pesquisas à comunidade científica, permitindo o aprofundamento de conhecimentos específicos e o diálogo com os pares. A ausência de teses e dissertações em regiões como o centro-oeste e norte suscita a existência de lacunas na compreensão dos saberes e fazeres de enfermagem de cuidados paliativos em território brasileiro.

Em relação aos cenários onde as pesquisas foram realizadas, observa-se a incidência do cenário hospitalar, domicílio e ambulatório expondo que os pacientes que enfrentam doenças que ameaçam a vida são usuários de diferentes espaços de saúde, requerendo dos profissionais de enfermagem preparo, ou pelo menos sensibilização, para a assistência paliativa. Frente a esta realidade, sugere-se a integralização dos conteúdos de cuidados paliativos nos currículos de formação em enfermagem como um caminho possível de disseminação do conhecimento ${ }^{(9)}$.

A atuação do enfermeiro na assistência ambulatorial de cuidados paliativos apoia-se na autonomia do paciente, de modo que ele saiba lidar com as limitações resultantes da enfermidade, além de abordar efetivamente os sintomas de caráter físico e emocional que surgem com o avançar da doença. Em ambiente domiciliar, a assistência consiste em oferecer ao paciente e sua família o apoio necessário em todo o processo de doença e morte em sua própria casa. Valoriza-se o cuidado individualizado, de acordo com as situações encontradas, com avaliação constante do plano de cuidados conforme a evolução da doença. Quando a assistência acontece em ambiente hospitalar, destacam-se medidas que minimizam o sofrimento neste ambiente, como a adoção de quartos individuais, a presença da família $24 \mathrm{hs}$, a flexibilização de visitas, a fim de minimizar os efeitos negativos da hospitalização até que o quadro clínico se estabilize e o paciente e família possam retornar para casa ${ }^{(2-3)}$.

Os resultados evidenciaram o paciente oncológico entre os sujeitos de alvo de estudo 
com maior incidência, corroborando com a literatura quando refere que desde a década de 1980 os cuidados paliativos a pacientes com câncer tem sido progressivamente reconhecido, mas que existe uma demanda insatisfeita para cuidados paliativos em problemas crônicos de saúde como HIV/SIDA, insuficiência cardíaca congestiva, doença cerebrovascular, doenças neurodegenerativas, doenças respiratórias crônicas e a tuberculose resistente a drogas ${ }^{(4)}$.

$\mathrm{O}$ interesse pelos cuidadores se fez presente como objeto de estudo nos resumos e merece valorização pelo papel que exercem junto a assistência de enfermagem em domicílio. A existência do cuidador na assistência ao paciente em cuidados paliativos é essencial para que se garanta uma assistência de qualidade, pois eles são os responsáveis por colocar em prática o plano assistencial elaborado pela equipe de saúde. Acrescenta-se que os cuidadores necessitam ser educados para o cuidado e assistidos nas suas necessidades de compreensão e adaptação às mudanças físicas, sociais, emocionais e de sobrecarga, acarretados pela responsabilidade de cuidar em domicílio ${ }^{(16)}$.

No que se refere a abordagem metodológica a maior parte dos resumos explicitou ou o uso da abordagem qualitativa, seguida da quantitativa e da abordagem quanti-qualitativa. A abordagem metodológica, assim como, o referencial teórico são elementos essenciais na elaboração dos desenhos de pesquisa, pois delimitam e conduzem a análise reflexiva dos fenômenos. A abordagem quantitativa possibilita identificar lacunas na literatura e fenômenos pouco entendidos que requerem estudo qualitativo. Por sua vez, a abordagem qualitativa auxilia no desenvolvimento e desenho de teorias, na implementação e refinamento de estudos quantitativos $^{(17)}$.

A análise dos resumos evidenciou que em alguns estudos a opção pela abordagem quantitativa ou qualitativa foi insuficiente para responder a realidade observada sendo utilizada, nestes casos, como complementares. A interação entre as duas abordagens favorece o acúmulo de uma vasta ordem de resultados e a prática baseada em evidência ${ }^{(17-18)}$. Cabe ressaltar que independente da abordagem utilizada os resultados de pesquisa configuram uma das possíveis verdades acerca do fenômeno estudado sob a regência do pesquisador.

O referencial da Fenomenologia propõe-se a descrever o fenômeno e compreendê-lo a partir do significado da experiência vivida dos seres humanos na sua interação com o mundo. Neste estudo o uso da fenomenologia pelos pesquisadores aponta uma inquietude de quem centra o foco do seu cuidar no ser humano, com a preocupação em privilegiar a escuta e o olhar do profissional, com vista a responder questões que envolvem a complexidade do ser e a compreensão do seu vivido ${ }^{(19)}$.

O quantitativo de resumos que não explicitaram o referencial teórico e o cenário de estudo expõe a necessidade dos pesquisadores atentarem para a elaboração dos resumos de suas pesquisas, pois estes são sínteses que instigarão o interesse de novos pesquisadores, para novos estudos, além de configurem como fontes de informação que permitem a disseminação do conhecimento na área de enfermagem.

Os resultados obtidos indicam o cuidado paliativo como área de conhecimento e de especialidade em enfermagem pela possibilidade interativa e associativa de contribuição social, em diferentes espaços e campos de atuação, onde é possível ampliar e dar a conhecer o seu campo de intervenção ${ }^{(20)}$. A especialidade de cuidados paliativos é reconhecida por conselhos profissionais, como medicina, terapia ocupacional, e na enfermagem não está oficialmente instituído, mas encontra-se legitimado em publicações na área, como campo de conhecimento e atuação do profissional de enfermagem ${ }^{(21)}$. A filosofia dos cuidados paliativos nos impulsiona na busca por uma nova ótica de cuidado pautado em ações interdisciplinares e integradoras frente a multidimensionalidade do ser humano. Impulso que solicita-nos uma atitude responsável com a qualidade de vida daqueles que se colocam sob os cuidados de enfermagem. 


\section{CONCLUSÃO}

Acreditamos que ao reconhecer os limites do cuidado paliativo em enfermagem seja possível potencializar e articular conhecimentos, no sentido de superar as lacunas existentes. O cuidado paliativo é por natureza multidisciplinar e compreende uma assistência integral ao paciente e família na busca pela melhor qualidade de vida possível frente a doenças que ameaçam a vida, em um agir permeado de interações múltiplas e complexas advindas da dimensão física, mental, social e espiritual do sofrimento humano.

O quantitativo de teses e dissertações de enfermagem sobre cuidados paliativos mostrase incipiente frente a totalidade das produções explicitadas no Catálogo de Informações sobre Pesquisas e Pesquisadores em Enfermagem, mas estimulador, quando observados pela perspectiva de que a enfermagem ao identificar e buscar compreender as relações existentes em seus espaços cotidianos de prática, participa do exercício da reflexão e da conscientização dos profissionais em busca de uma nova percepção do cuidar em cuidados paliativos.

Este estudo aponta que somos um número expressivo de pesquisadores capazes de alavancar a produção de conhecimento na área de enfermagem de cuidados paliativos. Expõe a responsabilidade dos pesquisadores em enfermagem com esse novo olhar, tanto em direção à produção de conhecimentos, quanto para a compreensão de novos saberes e fazeres visto a abrangência dos cenários e sujeitos de pesquisa, assim como dos referenciais teóricos para discussão dos resultados.

Por fim, muito se tem a caminhar quando se trata de cuidados paliativos, e os profissionais necessitam conhecer e explorar melhor essa temática que possibilita pensar novas formas de cuidar, educar, acolher, amparar, advogar, aliviar desconfortos e controlar sintomas, em atividades cotidianas de enfermagem ${ }^{(1)}$.

\section{REFERÊNCIAS}

1. Pimenta CAM. Cuidados paliativos: uma nova especialidade do trabalho da enfermagem? Acta paul. Enferm. [Internet]. 2010 [acesso em: 20 Jun 2014]; 23(3). Disponível em: http://www.scielo.br/pdf/ape/v23n3/v23n3a01.pdf.

2. Vissers KCP, Brand MWM, Jacobs J, Groot M, Veldhoven C, Verhagen C, et al. Palliative Medicine Update: a multidisciplinary approach. Pain Practice [Internet]. 2013 [acesso em: 07 Out 2014]; 13(7):576-588. Disponível em: http://onlinelibrary.wiley.com/doi/10.1111/papr.12025/pdf.

3. Fonseca JVC, Rebelo T. Necessidades de cuidados de enfermagem do cuidador da pessoa sob cuidados paliativos. Rev Bras Enferm [Internet]. 2011 [acesso em: 07 Out 2014]; 64(1):180-4. Disponível em: http://www.scielo.br/pdf/reben/v64n1/v64n1a26.pdf.

4. Worldwide Palliative Care Alliance. Global Atlas of Palliative Care at the End of Life. [Internet]. 2014 [acesso em: 20 Jun 2014]. Disponível em: http://www.who.int/cancer/publications/palliative-care-atlas/en/.

5. Docherty SL, Thaxton C, Allison C, Barfield RC, Tamburro RF.The nursing dimension of providing palliative care to children and adolescents with cancer. Clinical Medicine Insights: Pediatrics [Internet]. 2012 [acesso em: 07 Out 2014]; 6:75-88. Disponível em: http://www.ncbi.nlm.nih.gov/pmc/articles/PMC3620813/pdf/cmped-6-2012-075.pdf

6. Andrade CG, Costa SFG, Vasconcelos MF, Zaccara AAL, Duarte MCS, Evangelista CB. Bioética, Cuidados Paliativos e Terminalidade: revisão integrativa da literatura. Rev enferm 
UFPE on line [Internet]. 2013 [acesso em: 07 Out 2014]; 7(esp):888-97. Disponível em: http://dx.doi.org/10.5205/reuol.3934-31164-1-SM.0703esp201309.

7. Sousa ATO, França JRFS, Santos MFO, Costa SFG, Souto MRM. Cuidados paliativos com pacientes terminais: um enfoque na Bioética. Rev Cubana Enfermer. [Internet]. 2010 [acesso em: 20 Jun 2014]; 26(3):123-135. Disponível em: http://scielo.sld.cu/scielo.php?script=sci_arttext\&pid=S086403192010000300004\&lng=es

8. Mattos RA. A integralidade na prática (ou sobre a prática da integralidade). Cad. Saúde Pública. [Internet]. 2004 [acesso em: 20 Jun 2014]; 20(5):1411-6 . Disponível em: http://dx.doi.org/10.1590/S0102-311X2004000500037.

9. Vasques TCS, Lunardi VL, Silveira RS, Lunardi Filho WD, Gomes GC, Pintanel AC. Percepções dos trabalhadores de enfermagem acerca dos cuidados paliativos. Rev. Eletr. Enf.[Internet]. 2013 [acesso em: 20 Jun 2014] 15(3):772-9. Disponível em: http://dx.doi.org/10.5216/ree.v15i3.20811 .

10. Hermes HR, Lamarca ICA. Cuidados paliativos: uma abordagem a partir das categorias profissionais de saúde. Ciência \& Saúde Coletiva. [Internet]. 2013 [acesso em: 20 Jun 2014]; 18(9):2577-2588. Disponível em: http://www.scielo.br/scielo.php?script=sci_arttext\&pid=S1413-81232013000900012

11. Araújo CA. Bibliometria: evolução histórica e questões atuais. Em Questão. Porto Alegre. [Internet]. 2006 [acesso em: 20 Jun 2014]; 12(1):11-32. Disponível em: http://revistas.univerciencia.org/index.php/revistaemquestao/article/viewFile/3707/3495

12. Vanti NA. Da bibliometria à webometria: uma exploração conceitual dos mecanismos utilizados para medir o registro da informação e a difusão do conhecimento. Ciência da Informação. [Internet]. 2002 [acesso em: 20 Jun 2014]; 31(2):152-62. Disponível em: http://www.scielo.br/pdf/ci/v31n2/12918.pdf.

13. Glãnzel W. Bibliometric methods for detecting and analysing emerging research topics. El profesional de La información. [Internet]. 2012 [acesso em: 20 Jun 2014]; 21(1):194-201. Disponível em: http://elprofesionaldelainformacion.metapress.com/ media/h0xf475yqg7tum4rlh87/contributions/p/5/6/8/p5681271034tq3j5.pdf.

14. Associação Brasileira de Enfermagem [Internet]. Centro de Estudos e Pesquisas em enfermagem (BR). [acesso em: 20 Jun 2014]. Informações sobre pesquisas e pesquisadores em enfermagem 2013. Disponível em: http://www.abennacional.org.br/home/tesesedissertacoescepen.htm.

15. Coordenação de Aperfeiçoamento de Pessoal de Nível Superior [Internet]. Diretoria de Avaliação (BR) [acesso em: 20 Jun 2014]. Documento de Área 2013 - Avaliação Trienal 2013.

Disponível

em:

http://www.capes.gov.br/images/stories/download/avaliacaotrienal/Docs_de_area/Enfermage m_doc_area_e_comiss\%C3\%A3o_att08deoutubro.pdf.

16. Melo TM, Rodrigues IG, Schmidt DRC. Caracterização dos Cuidadores de Pacientes em Cuidados Paliativos no Domicílio. Revista Brasileira de Cancerologia [Internet]. 2009 [acesso em: 20 Jun 2014]; 55(4):365-74. Disponível em: http://www.inca.gov.br/rbc/n_55/v04/pdf/365_artigo6.pdf.

17. Driessnack M, Sousa VD, Mendes IAC. Revisão dos desenhos de pesquisa relevantes para a enfermagem: part 2: desenhos de pesquisa qualitativa. Rev Latino-am Enfermagem. [Internet]. 2007 [acesso em: 20 Jun 2014]; 15(4) Disponível em: 
http://www.scielo.br/pdf/rlae/v15n4/pt_v15n4a25.pdf.

18. Bruggemann OM, Parpinelli MA. Utilizando as abordagens quantitativa e qualitativa na produção do conhecimento. Rev Esc Enferm USP. [Internet]. 2008 [acesso em: 20 Jun 2014]; 42(3):563-8. Disponível em: http://www.scielo.br/pdf/reeusp/v42n3/v42n3a20.pdf.

19. Almeida IS, Crivaro ET, Salimena AMO, Souza IEO. O caminhar da enfermagem em fenomenologia: revisitando a produção acadêmica. Rev. Eletr. Enf. [Internet]. 2009 [acesso em: 20 Jun 2014]; 11(3):695-9. Disponível em: http://www.fen.ufg.br/revista/v11/n3/v11n3a30.htm.

20. Erdmann AL, Fernades JV, Melo C, Carvalho BR, Menezes Q, Freitas R, EmarinonyE, Backes MTS. A visibilidade da profissão de enfermeiro: reconhecendo conquistas e lacunas. Rev Bras Enferm. [Internet]. 2009 [acesso em: 20 Jun 2014]; 62(4):637-43. Disponível em: http://www.scielo.br/pdf/reben/v62n4/25.pdf.

21. Vasconcelos EV, Santana ME, Silva SED. Desafios da enfermagem nos cuidados paliativos: revisão integrativa. Enfermagem em Foco. [Internet]. 2012 [acesso em: 20 Jun 2014]; 3(3):127-13. Disponível em: http://revista.portalcofen.gov.br/index.php/enfermagem/article/view/296. 
APÊNDICE B - Artigo 2: Cuidados Paliativos de Enfermagem na Atenção Domiciliar.

\section{PALLIATIVE NURSING CARE IN HOME CARE CUIDADOS PALIATIVOS DE ENFERMERÍA EN LA ATENCIÓN DOMICILIARIA}

Janaina Meirelles Sousa, Elioenai Dornelles Alves

Janaina Meirelles Sousa. Enfermeira. Mestre em Enfermagem. Doutoranda no Programa de Pós-Graduação em Enfermagem da Universidade de Brasília (UnB). Professora na Faculdade UnB Ceilândia (FCE). Brasília (DF), Brasil. E-mail: sjana@unb.br.

Elioenai Dornelles Alves. Enfermeiro. Professor Pesquisador Sênior no Departamento de Enfermagem do Programa de Pós-Graduação em Ciências da Saúde e Enfermagem da UnB. Brasília (DF), Brasil. E-mail: elioenai@unb.br.

\section{RESUMO}

Objetivo: identificar a produção científica em enfermagem sobre cuidados paliativos na atenção domiciliar. Método: estudo exploratório, com análise bibliométrica, realizado por meio da análise de resumos disponíveis em catálogos registrados na base de dados do Centro de Estudos e Pesquisas em Enfermagem (CEPEn). Resultados: a amostra de 13 resumos é proveniente de 2 teses e 11 dissertações, defendidas nas regiões Sudeste (7), Sul (4) e Nordeste (2) do Brasil. As subáreas temáticas observadas foram: cuidadores, neoplasias, família, morte, acolhimento, atenção primária à saúde, cuidados de enfermagem e Estratégia Saúde da Família. Conclusão: observa-se baixa produtividade e descontínuo crescimento da produção. Evidencia-se o cuidado paliativo na atenção domiciliar com caráter multidisciplinar, voltado à qualidade de vida tanto dos pacientes como de seus familiares, com o desafio da qualificação profissional e da integralidade dos cuidados na atenção à saúde. Descritores: assistência domiciliar; cuidados paliativos; enfermagem de cuidados paliativos na terminalidade da vida; enfermagem domiciliar.

\footnotetext{
ABSTRACT

Objective: identify the scientific production in nursing about palliative care in home care. Method: exploratory study, with bibliometric analysis, carried out by analyzing abstracts available in catalogs registered in the database of the Center for Study and Research in Nursing (CEPEn). Results: the sample of 13 abstracts was obtained from 2 theses and 11 dissertations, submitted in the Southeast (7), South (4), and Northeast (2) Brazilian regions. The thematic sub-areas observed were: caregivers, neoplasms, family, death, embracement, primary health care, nursing care, and Family Health Strategy. Conclusion: low productivity and discontinuous production growth are observed. Palliative care is evidenced in home care with a multidisciplinary nature, aimed at the quality of life of both patients and their family members, with the challenge of professional qualification and comprehensive assistance in health care. Descriptors: home care; palliative care; hospice and palliative care nursing; home health nursing.
} 


\section{RESUMEN}

Objetivo: identificar la producción científica en enfermería acerca de cuidados paliativos en la atención domiciliaria. Método: estudio exploratorio, con análisis bibliométrico, realizado a través del análisis de resúmenes disponibles en catálogos registrados en la base de datos del Centro de Estudio e Investigación en Enfermería (CEPEn). Resultados: la muestra de 13 resúmenes se obtuvo de 2 tesis y 11 disertaciones, sometidas en las regiones Sudeste (7), Sur (4) y Nordeste (2) de Brasil. Las sub-áreas temáticas observadas fueron: cuidadores, neoplasias, familia, muerte, acogimiento, atención primaria de salud, atención de enfermería y Estrategia Salud de la Familia. Conclusión: se observa baja productividad y discontinuo crecimiento de la producción. El cuidado paliativo se evidencia en la atención domiciliaria con un carácter multidisciplinar, orientado a la calidad de vida tanto de los pacientes y sus familiares, con el reto de la cualificación profesional y la integralidad de los cuidados en la atención de salud. Descriptores: atención domiciliaria de salud; cuidados paliativos; enfermería de cuidados paliativos al final de la vida; cuidados de enfermería en el hogar.

\section{INTRODUÇÃO}

A enfermagem paliativa caracteriza-se como o cuidado para pessoas em suas semanas ou meses finais de vida, com o objetivo de evitar e aliviar o sofrimento provendo a melhor qualidade de vida. Trata-se de uma área da enfermagem que lida com o cuidado de pacientes que enfrentam doenças que ameaçam a vida em diferentes cenários de assistência, como o ambulatorial, domiciliar e hospitalar. ${ }^{1}$ Acrescentam-se os espaços emergentes de atuação da enfermagem, como as unidades de pronto atendimento, hospedarias e centros-dia. ${ }^{2}$

$\mathrm{Na}$ atenção domiciliar, os cuidados paliativos configuram um cenário desafiador diante da demanda estimada da população que virá a necessitar desse tipo de assistência. No mundo todo, estima-se que a cada ano 20 milhões de pessoas necessitem de cuidados paliativos no fim da vida, sendo a maioria adulta com mais de 60 anos (69\%) somados a $6 \%$ de crianças. ${ }^{3}$

Iniciativas governamentais contribuem no avançar da rede de cuidados no fim da vida, mas ainda estamos distantes do que é preconizado mundialmente para atendimento mínimo nesse campo. O Brasil oferece prestação de cuidados paliativos de forma isolada, caracterizada por um crescimento irregular desse tipo de assistência, com pequeno número de serviços especializados de cuidados paliativos e acesso limitado considerando o tamanho da população. ${ }^{3}$

Em território nacional, os cuidados paliativos estão inseridos em portarias de saúde, mas ainda distante da agenda política para implantação de uma política nacional de cuidados paliativos. A Portaria GM/MS n. 2.439/2005, que trata da Política Nacional de Atenção Oncológica, abarca a implementação dos Centros de Alta Complexidade em Oncologia (Cacon) e preconiza a organização de equipes de cuidados paliativos com atenção integral a pacientes no âmbito hospitalar, ambulatorial e domiciliar. Corrobora a prática dos cuidados paliativos a Portaria n. 3.150, de 12 de dezembro de 2006, que instituiu a câmara técnica em controle da dor e cuidados paliativos, e a Portaria n. 963, de 27 de maio de 2013, que redefine a atenção domiciliar no âmbito do Sistema Único de Saúde (SUS). ${ }^{4-6}$ 
O cuidado paliativo integra a rede de atenção à saúde por meio do serviço de atenção domiciliar, que se responsabiliza pelo gerenciamento e operacionalização das equipes multiprofissionais de atenção domiciliar (Emad) e equipes multiprofissionais de apoio (Emap), que incluem na modalidade de atendimento tipo 2 os usuários com necessidade de cuidados paliativos. ${ }^{6}$

O suporte domiciliar em cuidados paliativos apresenta-se como possibilidade de morte em domicílio, em ambiente conhecido, onde é possível que o paciente mantenha suas atividades laborais, seus hábitos e hobbies de forma autônoma; onde os familiares possam cuidar de seus entes queridos, o que de, certa forma, colabora na prevenção do luto patológico; assim como representa a possibilidade da redução de internações hospitalares longas e de alto custo, muitas vezes permeadas por tratamentos desnecessários ou futilidade terapêutica. ${ }^{7}$

As equipes de atenção primária podem oferecer assistência em cuidados paliativos, onde os casos mais complexos seriam encaminhados a equipes especializadas de cuidados paliativos domiciliares. ${ }^{8}$ A organização de serviços especializados ainda está atrelada à especialidade oncológica, pois esta encontra respaldo na Política Nacional de Atenção Oncológica, o que permite sua articulação nos diferentes âmbitos de atenção. O Brasil carece de diretrizes para organização e provisão de serviços de cuidados paliativos que não sejam os da especialidade oncológica, para que se possa apoiar e responder às demandas da atenção básica e da atenção especializada de média e alta complexidade.

A incidência de pacientes para assistência paliativa cresce de forma rápida, diante da morbidade populacional e a visibilidade desse tipo de assistência. Nesse cenário, a sensibilização e qualificação de profissionais de saúde em diferentes níveis poderia ser uma estratégia propulsora de mudanças. Preconiza-se que o cuidado paliativo possa ser oferecido em níveis que englobam a abordagem paliativa, intervenções especializadas e cuidados paliativos ministrados por especialistas. ${ }^{3}$

Pela abordagem paliativa, o cuidado pode ser oferecido por todos os profissionais de saúde envolvidos no cuidar de pessoas em condição de enfermidade que ameaça a vida. ${ }^{8}$ Para tanto, faz-se necessário capacitação que envolva a abordagem sintomática básica, compreensão das experiências de pacientes em situação de terminalidade e de suas famílias, o uso da comunicação de forma a oportunizar interação e acolhimento e perspectivas de encaminhamento quando as necessidades dos pacientes fujam ao âmbito de conhecimento individual do profissional. ${ }^{9}$

Verifica-se que a atenção domiciliar compõe um braço assistencial necessário à abordagem dos cuidados paliativos na atenção básica, de forma a permitir o acesso a uma assistência integral ao ser humano que experiência sua última etapa da vida, onde morte é um processo natural que não deve ser retardado ou acelerado, mas vivido com a melhor qualidade de vida possível até o momento de sua chegada. Nesse contexto, este estudo justifica-se pela necessidade de aprofundar as discussões acerca da atuação do profissional de enfermagem em cuidados paliativos na atenção domiciliar, com base na avaliação objetiva da literatura, com vistas à disseminação do conhecimento especializado. Com esse intuito, tem-se por objetivo:

- Identificar a produção científica em enfermagem sobre cuidados paliativos na atenção domiciliar. 


\section{MÉTODO}

Para atender aos objetivos propostos, optou-se por um estudo descritivo exploratório, com abordagem bibliométrica, realizado por meio da análise dos resumos de dissertações e teses publicadas nos catálogos do Centro de Estudos e Pesquisas em Enfermagem (CEPEn), que apresenta informações sobre pesquisas e pesquisadores em enfermagem. ${ }^{10}$

A bibliometria é uma técnica que utiliza de métodos quantitativos na busca por uma avaliação objetiva da literatura e disseminação do conhecimento científico. O uso de métodos e técnicas bibliométricas no Brasil remonta à década de 1970 e, atualmente, observam-se alguns subcampos como a bibliometria, a informetria, a cienciometria e a webometria, que se diferenciam quanto ao objeto de estudo, as variáveis, os métodos específicos de análise e os objetivos. $^{11,12}$

Os dados bibliométricos como indicadores da produção científica têm sido utilizados para planejamento nacionais de atividades de pesquisa científica, análise do desenvolvimento da pesquisa científica e tecnológica dentro de uma instituição específica, análise de periódicos de uma área específica, análise da produtividade de pesquisadores, para determinar o acervo de palavras de um campo de atuação, como também, para detecção e análise de temas de pesquisa emergentes. ${ }^{11-13}$

Para a coleta de dados utilizou-se dos resumos disponibilizados on-line pelo Catálogo de Informações sobre Pesquisas e Pesquisadores em Enfermagem, no website da Associação Brasileira de Enfermagem (ABEn). A temática principal de busca foi cuidados paliativos na atenção domiciliar, onde os assuntos utilizados para a busca de resumos foram: cuidados paliativos, cuidados a pacientes terminais, terminalidade, paciente terminal, assistência terminal. Além disso, recorreu-se aos seguintes assuntos: cuidados domiciliares de saúde, assistência domiciliar, pacientes domiciliares, serviço de assistência domiciliar. Ao todo, foram analisados 13 catálogos, que abarcam 6.355 resumos no período de 1985 a 2012. Do total de resumos, 13 abordam a temática cuidados paliativos na atenção domiciliar, onde 11 puderam ser localizados para análise do estudo na íntegra, sendo que para 2 foram utilizadas as informações contidas no resumo descrito no catálogo.

Diante dos dados, foi realizada a leitura analítica dos resumos em busca das variáveis: instituição de ensino, ano de defesa, nível stricto sensu e subáreas temáticas. Após a análise, os dados foram organizados e descritos em tabelas segundo as variáveis estabelecidas.

\section{RESULTADOS E DISCUSSÃO}

O estudo apresenta limitações relativas ao acesso na íntegra a 2 dissertações, o que inviabilizou uma melhor compreensão dos achados de pesquisa, assim como a baixa produtividade sobre a temática restringiu as reflexões acerca da abrangência dos cuidados paliativos no contexto da atenção domiciliar.

Os resultados (Figura 1) demonstram que os cuidados paliativos na atenção domiciliar foi foco de estudo de dissertações e teses defendidas em 10 instituições brasileiras, localizadas nas regiões Sudeste (7), Sul (4) e Nordeste (2) do Brasil, em programas de pós-graduação em enfermagem, com predominância em nível de mestrado (11). 
A cronologia do ano de publicação aponta um crescimento descontínuo entre 2000 e 2008, com estabilidade a partir de 2009. A literatura demonstra que o cuidado paliativo na atenção domiciliar ganhou visibilidade com a Portaria GM n. 2.527, de 27/10/2011, revogada pela Portaria GM n. 963 de 27/05/2013, que redefine a atenção domiciliar no âmbito do SUS, no art. 23, que apresenta como critérios de inclusão para cuidados na modalidade AD2 (destinase aos usuários que possuam problemas de saúde e dificuldade ou impossibilidade física de locomoção até uma unidade de saúde e que necessitem de maior frequência de cuidado, recursos de saúde e acompanhamento contínuos) a necessidade de cuidados paliativos. ${ }^{6}$ Esse fato retira os cuidados paliativos da invisibilidade, permitindo que os profissionais se posicionem em relação ao reconhecimento da nova temática, favorecendo publicações na área.

As dissertações e teses em sua totalidade utilizaram a abordagem qualitativa e explicitaram como sujeitos de pesquisa: pacientes oncológicos em cuidado no domicílio, cuidadores e familiares de pacientes oncológicos em cuidado no domicílio, enfermeiros de serviço de internação domiciliar de um centro de suporte terapêutico oncológico, profissionais de uma equipe de cuidados paliativos oncológicos domiciliares, familiares de pacientes atendidos por um programa de assistência e internamento domiciliar, cuidador familiar de pacientes oncológicos vinculados ao serviço de internação domiciliar e profissional da Estratégia Saúde da Família (ESF). A literatura indica que desde a década de 1980 os cuidados paliativos a pacientes com câncer tem sido progressivamente reconhecido, mas existe uma demanda insatisfeita para cuidados paliativos em problemas crônicos de saúde, como HIV/aids, insuficiência cardíaca congestiva, doença cerebrovascular, doenças neurodegenerativas, doenças respiratórias crônicas e a tuberculose resistente a drogas. ${ }^{3}$

Nota-se nas teses e dissertações (Tabela 1) uma variedade de subtemas, sendo os prevalentes: cuidadores, neoplasias, família, morte, acolhimento, atenção primária à saúde, cuidados de enfermagem, Estratégia Saúde da Família. Os subtemas permeiam a recomendação brasileira para o trabalho das equipes de atenção domiciliar nos cuidados paliativos, onde se preconiza: a) atuação com competência cultural, com ênfase no respeito às característica observadas no espaço íntimo do evento morte no domicilio; b) comunicação eficaz que favoreça a interação e expressão de sentimentos; c) ações de controle de sintomas, com ênfase na dor; d) apoio emocional a pacientes e familiares no enfrentamento da morte; e) instrumentalização de cuidadores e familiares para o cuidado paliativo em domicílio; f) oferecimento de suporte e segurança, com vistas à promoção da qualidade de vida e dignidade entre pacientes e familiares. ${ }^{7}$

Os profissionais da ESF abordados nos estudos referem-se aos cuidados paliativos como modalidade de cuidados de conforto, que abrange as dimensões biológica, psicológica, social e espiritual do ser humano, oferecido de forma interdisciplinar mediante assistência humanizada, com a finalidade de promover a qualidade de vida, minimização do sofrimento e boa morte. A presença do familiar é compreendida como fonte de apoio e estímulo para o doente no enfrentamento do processo da enfermidade e da terminalidade. ${ }^{14}$ 


\begin{tabular}{|c|c|c|c|c|c|c|c|c|}
\hline \multirow[t]{2}{*}{ Instituição } & \multicolumn{7}{|c|}{ Ano de Defesa } & \multirow{2}{*}{$\begin{array}{l}\text { Nível } \\
\text { stricto } \\
\text { sensu }\end{array}$} \\
\hline & $\begin{array}{l}1999 / \\
2000\end{array}$ & $\begin{array}{l}2001 / \\
2002 \\
\end{array}$ & $\begin{array}{l}2003 / \\
2004 \\
\end{array}$ & $\begin{array}{l}2005 / \\
2006 \\
\end{array}$ & $\begin{array}{l}2007 / \\
2008 \\
\end{array}$ & $\begin{array}{l}2009 / \\
2010\end{array}$ & $\begin{array}{l}2011 / \\
2012\end{array}$ & \\
\hline \multirow{6}{*}{$\begin{array}{l}\text { Universidade de São Paulo - Escola } \\
\text { de Enfermagem } \\
\text { Universidade de São Paulo - Escola } \\
\text { de Enfermagem de Ribeirão Preto } \\
\text { Universidade Estadual de Maringá }\end{array}$} & - & - & - & - & - & - & - & $\bar{M}$ \\
\hline & - & - & - & - & - & - & 1 & $\mathrm{D}$ \\
\hline & - & - & - & - & - & - & 1 & M \\
\hline & - & - & - & - & - & 1 & - & D \\
\hline & - & - & - & & - & 1 & - & M \\
\hline & - & - & - & - & - & - & - & $\mathrm{D}$ \\
\hline \multirow[t]{2}{*}{ Universidade Federal da Bahia } & 1 & - & - & - & - & - & - & M \\
\hline & - & - & - & - & - & - & - & $\mathrm{D}$ \\
\hline \multirow[t]{2}{*}{ Universidade Federal da Paraíba } & - & - & - & - & - & & 1 & M \\
\hline & - & - & - & - & - & - & - & $\mathrm{D}$ \\
\hline \multirow{2}{*}{$\begin{array}{l}\text { Universidade Federal de Minas } \\
\text { Gerais }\end{array}$} & - & - & 1 & - & - & - & - & M \\
\hline & - & - & - & - & - & - & - & $\mathrm{D}$ \\
\hline \multirow{2}{*}{$\begin{array}{l}\text { Universidade Federal de Santa } \\
\text { Catarina }\end{array}$} & 1 & 1 & - & - & - & - & - & M \\
\hline & - & - & - & - & - & - & - & $\mathrm{D}$ \\
\hline \multirow[t]{2}{*}{ Universidade Federal de Santa Maria } & - & - & - & - & & 1 & - & $\mathrm{M}$ \\
\hline & - & - & - & - & - & - & - & $\mathrm{D}$ \\
\hline \multirow{2}{*}{$\begin{array}{l}\text { Universidade Federal do Estado do } \\
\text { Rio de Janeiro - Escola de } \\
\text { Enfermagem Alfredo Pinto }\end{array}$} & - & - & - & 1 & - & - & - & $\mathrm{M}$ \\
\hline & - & - & - & - & - & - & - & $\mathrm{D}$ \\
\hline \multirow{2}{*}{$\begin{array}{l}\text { Universidade Federal do Rio de } \\
\text { Janeiro - Escola de Enfermagem } \\
\text { Anna Nery }\end{array}$} & - & 1 & - & - & 1 & - & - & $\mathrm{M}$ \\
\hline & - & - & - & - & - & - & - & D \\
\hline
\end{tabular}

Figura 1. Distribuição das dissertações e teses segundo instituição, ano de defesa e nível stricto sensu.

* $\mathrm{M}$ (mestrado) $* * \mathrm{D}$ (doutorado)

Tabela 1. Ranking das subáreas temáticas segundo frequência de aparecimento nos resumos.

\begin{tabular}{lll}
\hline Subáreas temáticas & $\mathrm{n}=27$ & $\%$ \\
Cuidadores & 6 & 22,2 \\
Neoplasias & 5 & 18,6 \\
Família & 4 & 14,8 \\
Morte & 3 & 11,1 \\
Acolhimento & 2 & 7,4 \\
Atenção primária à saúde & 2 & 7,4 \\
Cuidados de enfermagem & 2 & 7,4 \\
Estratégia Saúde da Família & 2 & 7,4 \\
Outras temáticas * & 1 & 3,7 \\
\hline
\end{tabular}

* Antropologia cultural, Atitude diante da morte, Consternação, Enfermagem oncológica, Equipe de assistência ao paciente, Gerenciamento clínico, Idoso, Internação domiciliar, Método clínico-qualitativo, Percepção, Psicologia social, Relações interpessoais, Serviços preventivos de saúde, Úlcera de pressão, Valores sociais. 
O cuidar do idoso em situação final de vida requer dos profissionais da Estratégia da Saúde da Família a superação de desafios pessoais para o acolhimento honesto, com comunicação aberta, disponibilidade e manutenção do vínculo conquistado. O processo de cuidar ocorre por meio da identificação da problemática da situação, planejamento e manejo de novas estratégias para o cuidado e avaliação da trajetória de cuidado. ${ }^{15}$

A liberdade e autonomia nos horários de refeições, higiene, sono, lazer e recebimento de visitas foram apontados por cuidadores de pacientes oncológicos como aspectos benéficos da internação domiciliar, entretanto, o cuidado no domicílio favorece a sobrecarga, privação e maior responsabilização, decorrentes, por vezes, de situações de falta de apoio social. ${ }^{16}$

O cuidador familiar percebe a internação domiciliar, direcionada ao paciente oncológico em fase avançada, como possibilidade de acesso fácil a recursos materiais e humanos necessários ao cuidado realizado em domicílio, pois se acredita que ser referenciado por uma equipe de saúde favorece em caso de necessidade de atendimento nas unidades de urgência de serviços hospitalares. ${ }^{16}$

Para a equipe de um serviço de internação domiciliar oferecido a pacientes oncológicos, o despreparo para a nova prática, o cenário domiciliar, o convívio com pacientes de câncer em fase avançada, a conspiração do silêncio, e as emoções advindas do compartilhar o sofrimento dos pacientes e dos seus familiares ao lidar com a morte são desafios a ser superados. Referem concretizar ações de interdisciplinaridade por meio de reuniões de equipe, na busca por um consenso sobre os cuidados ao paciente e à família. ${ }^{17}$

O lidar com a morte é fato irrevogável dos contextos de atenção domiciliar a pacientes em condição de doenças que ameaçam a vida e o despreparo de profissionais para lidar com situações de morte e morrer tornaram-se evidentes nos estudos analisados. ${ }^{15,17-19}$ Reportam-se as brincadeiras, demonstrações de afetividade e encontros sociais regularmente planejados, como forma de apoio mútuo na equipe, assim como a espiritualidade e o convívio familiar são utilizados como recursos no enfrentamento individual das situações de morte e morrer. ${ }^{17}$

A vivência da terminalidade por parte de familiares de pacientes com câncer revela que estar ao lado de pacientes significa romper com a ilusão de eternidade, devido à coexistência da morte, e eles a relatam como uma experiência dolorosa, de abnegação da própria vida, com ausência de acolhimento em suas dores, associado à rede de suporte familiar deficiente. ${ }^{20}$

O sofrimento de familiares pela morte de um ente querido cuidado em domicílio é abrandado em determinado período de tempo, mas há uma trajetória a se percorrida no qual necessita de ajuda do profissional de enfermagem. Deste solicita-se uma postura compreensiva e acolhedora diante das experiências e da percepção vivenciada pelo familiar, com disponibilidade de escuta, acompanhamento em seu pesar e olhar atento às possíveis manifestações de luto patológico. Cabe mencionar que a atuação do enfermeiro deve ser compartilhada e convergir com o plano de cuidados proposto pela equipe multidisciplinar. ${ }^{19}$

O tornar-se cuidador domiciliar é uma difícil e desafiante experiência, no qual o cuidado do paciente em fase final de uma doença no domicílio é percebido como um trabalho complexo e criativo que resulta em crescimento pessoal, às vezes marcado pelo cuidado solitário. Paralelamente, observa-se nos cuidadores uma capacidade de transcender suas limitações pessoais e de adquirir conhecimento técnico para o cuidado. ${ }^{21}$

A problemática das úlceras por pressão foi observada nos estudos analisados, constatando- 
se que a prevenção da úlcera por pressão em indivíduos com câncer avançado, com mobilização restrita, contribui favoravelmente a melhoria da qualidade de vida. A informação a cuidadores sobre úlcera por pressão e estímulo para que possam desenvolver sua capacidade natural de cuidar são estratégias que contribuem para a diminuição do surgimento de úlceras. ${ }^{22}$

Os resultados expostos evidenciam que os pesquisadores apropriaram-se da temática cuidados paliativos por meio de discussões de subtemas relacionados ao paciente, aos cuidadores, ao familiar enlutado, a atuação da equipe multiprofissional e aos limites da equipe assistencial.

Aspectos éticos que comumente envolvem os cuidados paliativos não foram observados. A literatura aponta como princípios bioéticos relacionados à temática dos cuidados paliativos a beneficência, não maleficência, autonomia, justiça, ampliados pela discussão de referenciais éticos como veracidade, proporcionalidade terapêutica, referencial do duplo efeito, prevenção e não abandono. ${ }^{23,24}$ Estudos que abordem como os profissionais de saúde percebem o desejo do paciente de participar das decisões compartilhadas; como motivar os pacientes a expor suas preferências a partir das opções colocadas; identificação dos conflitos morais vivenciados em contexto de domicílio poderiam auxiliar os profissionais de enfermagem a compreender os limites do cuidado, ou mesmo a dimensionar o impacto da existência de conflitos éticos na qualidade de vida de pacientes que enfrentam doenças que ameaçam a vida. $^{25}$

Verifica-se que os cuidados paliativos na enfermagem é uma área de assistência incipiente, mas promissora para a consolidação dos cuidados integrais ao paciente e à família, tendo em vista a capacidade do profissional de responder ao sofrimento humano nas dimensões física, psicológica, social e espiritual, ao experienciar a fragilidade diante do processo de morrer em domicílio.

\section{CONCLUSÃO}

Os achados deste estudo apontam uma baixa produtividade na temática cuidados paliativos na atenção domiciliar, com crescimento descontínuo, mas incipiente se considerarmos que os cuidados paliativos passaram a ter maior visibilidade após 2002, com uma publicação da Organização Mundial da Saúde (OMS) sobre os conceitos e princípios norteadores dessa prática. $^{26}$

No entanto, os estudos explicitam um compromisso da enfermagem na assistência ao paciente em situação de terminalidade da vida, no âmbito domiciliar, visto que as publicações abarcaram a percepção de profissionais, pacientes, cuidadores e familiares sobre esse tipo de assistência, com abordagem de contextos da ESF e serviços de internação domiciliar oncológicos.

A ausência de uma rede articulada e integrada de serviços de cuidados paliativos no Brasil não permite perceber o impacto exercido por tais cuidados sobre as políticas de saúde existentes. Para tanto, estudos que descrevam e reflexionem sobre a articulação dos cuidados paliativos na atenção básica e que apontem formas de articulação entre serviços e programas se fazem necessários. 
A assistência domiciliar enfrenta desafios no estabelecimento de parceria com a família, em aprender a trabalhar em conjunto com a comunidade, no estabelecimento de rede de apoio social e de retaguarda em serviços de saúde nos diferentes níveis de atenção, configurando entraves ao provimento de uma melhor qualidade de vida aos pacientes portadores de doenças que ameaçam a vida. ${ }^{27}$

A falta de qualificação dos profissionais de saúde evidenciada nos estudos consiste em uma das principais barreiras para a implementação dos cuidados paliativos na atenção básica. A iniciativa governamental da publicação dos Cadernos da Atenção Domiciliar, com um caderno dedicado a atenção domiciliar em cuidados paliativos, demonstra um primeiro passo para a sensibilização dos profissionais acerca dessa modalidade de cuidado. Entretanto, para mudar esse cenário, é preciso que os profissionais de enfermagem assumam o desafio da assistência a pacientes que enfrentam doenças que ameaçam a vida na proposição de ações de educação permanente em serviço.

Necessitamos avançar para a qualificação de enfermeiros especialistas em cuidados paliativos, segundo um modelo de ensino que permita aos profissionais responder as demandas da população brasileira. Nesse sentido, estudos que reflexionem sobre os cuidados em domicílio demandados por pacientes em condição de doença que ameaça a vida; que discutam possibilidades de intervenção de enfermagem diante de sinais e sintomas comuns; e que discutam a tomada de decisão em situações complexas características do contexto domiciliar podem contribuir para a construção do saber de enfermagem em cuidados paliativos, possibilitando estratégias eficazes e resolutivas de cuidado em saúde. Além disso, investimentos governamentais na educação permanente em saúde, sob a perspectiva do aprender e ensinar incorporados ao cotidiano do trabalho e das organizações poderia colaborar para mudanças substanciais na consolidação desse tipo de assistência.

\section{REFERÊNCIAS}

1. Polastrini RTV, Yamashita CC, Kurashima AY. Enfermagem e o cuidado paliativo. In: Santos FS, editor. Cuidados paliativos: diretrizes, humanização e alívio de sintomas. São Paulo: Atheneu; 2011. p. 277-83.

2. Pastrana T, De Lima L, Wenk R, Eisenchlas J, Monti C, Rocafort J, et al. Atlas de cuidados paliativos de Latinoamérica ALCP. Houston (TX): IAPHC Press, 2012.

3. Worldwide Palliative Care Alliance. Global atlas of palliative care at the end of life [document on the internet]. 2014 [cited 2014 Apr 10]. Available from: http://www.who.int/cancer/publications/palliative-care-atlas/en/.

4. Brasil. Portaria n. 2.439/GM, de 8 de dezembro de 2005. Institui a Política Nacional de Atenção Oncológica: Promoção, Prevenção, Diagnóstico, Tratamento, Reabilitação e Cuidados Paliativos, a ser implantada em todas as unidades federadas, respeitadas as competências das três esferas de gestão [document on the internet]. Brasília (DF): Ministério da Saúde; 2005 [cited 2014 Apr 7]. Available from:

http://dtr2001.saude.gov.br/sas/PORTARIAS/Port2005/GM/GM-2439.htm. 
5. Brasil. Portaria n. 3.150, de 12 de dezembro de 2006. Institui a Câmara Técnica em Controle da Dor e Cuidados Paliativos [document on the internet]. Brasília (DF): Ministério da Saúde; 2006 [cited 2014 Apr 7]. Available from: ftp://ftp.saude.sp.gov.br/ftpsessp/bibliote/informe_eletronico/2006/iels.dezembro.06/iels237/ U_PT-MS-GM-3150_121206.pdf.

6. Brasil. Portaria n. 963/GM, de 27 de maio de 2013. Redefine a Atenção Domiciliar no âmbito do Sistema Único de Saúde (SUS) [document on the internet]. Brasília (DF): Ministério da Saúde; 2013 [cited 2014 Apr 7]. Available from: http://bvsms.saude.gov.br/bvs/saudelegis/gm/2013/prt0963_27_05_2013.html.

7. Brasil. Caderno de atenção domiciliar [document on the internet]. Brasília (DF): Ministério da Saúde; 2013 [cited 2014 Apr 7]. Available from: http://bvsms.saude.gov.br/bvs/publicacoes/caderno_atencao_domiciliar_melhor_casa.pdf.

8. Yamaguchi AM, Oliveira IB. Cuidados paliativos na assistência domiciliar. In: Santos FS, editor. Cuidados paliativos: diretrizes, humanização e alívio de sintomas. São Paulo: Atheneu; 2011. p. 31-8.

9. Aranda S. Padrão dos cuidados paliativos. In: O’Connor M, Aranda S. Guia prático de cuidados paliativos em enfermagem. São Paulo: Andrei; 2008. p. 17-20.

10. Associação Brasileira de Enfermagem. Informações sobre pesquisas e pesquisadores em enfermagem [document on the internet]. 2013 [cited 2014 Apr 7]. Available from: http://www.abennacional.org.br/home/tesesedissertacoescepen.htm.

11. Araújo CA. Bibliometria: evolução histórica e questões atuais. Em Questão [serial on the internet]. 2006 [cited 2014 Apr 7];12(1):11-32. Available from: http://revistas.univerciencia.org/index.php/revistaemquestao/article/viewFile/3707/3495.

12. Lopes S, Costa MT, Fernández-Llimós F, Amante MJ, Lopes PF. A bibliometria e a avaliação da produção científica: indicadores e ferramentas. In: XI Congresso Nacional de Bibliotecários, Arquivistas e Documentalistas; Oct 18-20, 2012; Lisboa, PT. Actas [document on the internet]. Lisboa: Fundação Calouste Gulbenkian; 2012 [cited 2014 Apr 7]. Available from: http://www.bad.pt/publicacoes/index.php/congressosbad/article/view/429.

13. Glãnzel W. Bibliometric methods for detecting and analysing emerging research topics. El profesional de La información [serial on the internet]. 2012 [cited 2014 Apr 7];21(1):194-201. Available

from: http://elprofesionaldelainformacion.metapress.com/media/h0xf475yqg7tum4rlh87/contributio ns/p/5/6/8/p5681271034tq3j5.pdf.

14. Costa ICP. Cuidados paliativos na atenção básica: depoimentos de profissionais da saúde. [document on the internet]. João Pessoa: Universidade Federal da Paraíba; 2011 [cited 2014 Apr 10]. Available from: http://bdtd.biblioteca.ufpb.br/tde_busca/arquivo.php?codArquivo=2649.

15. Silva L. Processo de cuidar de famílias de idosos em situação de final de vida na Estratégia Saúde da Família [thesis]. São Paulo: Universidade de São Paulo; 2011 [cited 2014 Apr 10]. Available from: http://www.teses.usp.br/teses/disponiveis/83/83131/tde-20092011083900/pt-br.php. 
16. Oliveira SG. Representações sociais da internação domiciliar na terminalidade: o olhar do cuidador familiar [dissertation]. Santa Maria (RS): Universidade Federal de Santa Maria; 2010 [cited 2014 Apr 10]. Available from: http://www.ufsm.br/ppgenf/Dissert_Stefanie.pdf.

17. Rodrigues IG. Significados do trabalho em equipe de cuidados paliativos oncológicos domiciliar: um estudo etnográfico (Os) [thesis]. Ribeirão Preto (SP): Universidade de São Paulo; 2009 [cited 2014 Apr 10]. Available from: http://www.teses.usp.br/teses/disponiveis/22/22132/tde08012010130039/publico/InesGimene sRodrigues.pdf.

18. Santana ADA. Cuidados paliativos ao doente oncológico terminal em domicílio: representações sociais da família [dissertation]. Salvador: Universidade Federal da Bahia; 2000 [cited 2014 Apr 10]. Available from: http://www.abennacional.org.br/home/tesesedissertacoescepen.htm.

19. Santos EM. Familiares enlutados: compreender para acolher [dissertation]. Maringá (PR): Universidade Estadual de Maringá; 2009 [cited 2014 Apr 10]. Available from: http://www.pse.uem.br/documentos/dissert_andreia.pdf.

20. Fonseca COS. Vivências de familiares de pacientes com câncer em processo de terminalidade de vida: um estudo clínico-qualitativo [thesis]. São Paulo: Universidade de São Paulo; 2012 [cited 2014 Apr 10]. Available from: http://www.teses.usp.br/teses/disponiveis/22/22131/tde-05112012-160251/.

21. Marques SM. Singularidades do cuidado domiciliar durante o processo de morrer: a vivência de familiares cuidadores [dissertation]. Belo Horizonte: Universidade Federal de Minas Gerais; 2003 [cited 2014 Apr 10]. Available from: http://www.abennacional.org.br/home/tesesedissertacoescepen.htm.

22. Pereira VS. Cuidado essencial humano: cuidadores não profissionais de saúde diante da prevenção da úlcera por pressão em indivíduos com câncer avançado [dissertation]. Rio de Janeiro: Universidade Federal do Estado do Rio de Janeiro; 2006 [cited 2014 Apr 10]. Available from: http://www.abennacional.org.br/home/tesesedissertacoescepen.htm.

23. Pessini L. Bioética e cuidados paliativos: alguns desafios do cotidiano aos grandes dilemas. In: Pimenta CAM, Mota DDCF, Cruz DALM. Dor e cuidados paliativos: enfermagem, medicina e psicologia. Barueri (SP): Manole; 2006. p. 45-66.

24. Nunes L. Ética em cuidados paliativos: limites ao investimento curativo. Revista Bioética [serial on the internet]. 2008 [cited 2014 Apr 7];16(1):41-50. Available from:

http://revistabioetica.cfm.org.br/index.php/revista_bioetica/article/viewFile/54/57.

25. Silva KCO, Nietsche EA, Ilha S, Lima MGR. Doente terminal: a ética do cuidado no último processo da vida. Rev Enferm UFPE On Line [serial on the internet]. 2014 [cited 2014 July 23];8(Suppl 1):2256-62. Available from: http://www.revista.ufpe.br/revistaenfermagem/index.php/revista/article/viewFile/5059/pdf_56 28.

26. World Health Organization. Definition of palliative care [document on the internet]. Geneva: WHO; 2002 [cited 2014 Apr 16]. Available from: http://www.who.int/cancer/palliative/definition/en. 
27. Queiroz AHAB, Pontes RJS, Souza AMA, Rodrigues TB. Percepção de familiares e profissionais de saúde sobre os cuidados no final da vida no âmbito da atenção primária à saúde. Ciênc Saúde Coletiva [serial on the internet]. 2013 Sep [cited 2014 June 15];18(9):2615-23. Available from: http://dx.doi.org/10.1590/S1413-81232013000900016.

Submissão: 24/07/2014

Aceito: $26 / 11 / 2014$

Publicado: 01/02/2014

Corresponding Address

Janaina Meirelles Sousa

Universidade de Brasília

Av. Centro Metropolitano, conjunto A, lote $01,2^{\circ}$ piso - Ceilândia

CEP: 72220-900 - Brasília (DF), Brazil 


\section{APÊNDICE C - Termo de Consentimento Livre e Esclarecido}

\section{Prezado Enfermeiro,}

O (a) Senhor(a) está sendo convidado(a) a participar do projeto: Competências requeridas do Enfermeiro para o cuidado paliativo na Atenção Domiciliar.

O objetivo desta pesquisa é identificar as competências requeridas dos Enfermeiros para o Cuidado Paliativo na Atenção Domiciliar e analisar essas competências sob a ótica das diretrizes Curriculares Nacionais do Curso de Graduação em Enfermagem, elencando competências gerais e específicas para o ensino de Cuidados Paliativos no nível de graduação em enfermagem.

$\mathrm{O}$ (a) senhor(a) receberá todos os esclarecimentos necessários antes e no decorrer da pesquisa, e esta não lhe trará nenhuma despesa. O risco que o Senhor(a) está exposto(a) com sua participação é o de exposição de informações pessoais, mas lhe asseguramos que seu nome não aparecerá, sendo mantido o mais rigoroso sigilo através da omissão total de quaisquer informações que permitam identificá-lo(a) quando na publicação dos resultados.

A sua participação será através de um questionário que o(a) senhor(a) deverá responder, com um tempo estimado para sua realização de 30 minutos. Informamos também, que gastará um tempo estimado de 15 minutos para que lhe sejam dados os esclarecimentos necessários sobre esta pesquisa e assinatura desse Termo de Consentimento Livre e Esclarecido. Não existe obrigatoriamente e um tempo pré-determinado para responder o questionário. Será respeitado o tempo de cada um para respondê-lo. Informamos que o(a) Senhor(a) pode se recusar a responder qualquer questão que lhe traga constrangimento, podendo desistir de participar da pesquisa em qualquer momento sem nenhum prejuízo para o(a) senhor(a).

Os resultados da pesquisa serão divulgados na Instituição Universidade de BrasíliaUnB, podendo ser publicados posteriormente. Os dados e materiais utilizados na pesquisa ficarão sobre a guarda do pesquisador.

Se o(a) Senhor(a) tiver qualquer dúvida em relação à pesquisa, por favor telefone para: Dr(a). Janaina Meirelles Sousa, na instituição Universidade de Brasília - Campus Ceilândia, telefone: (61) 3107-8419/3107-8415, no horário: 8:00 às 16:00hs.

Este projeto foi Aprovado pelo Comitê de Ética em Pesquisa da SES/DF. As dúvidas com relação à assinatura do TCLE ou os direitos do sujeito da pesquisa podem ser obtidos através do telefone: (61) 3325-4955.

Este documento foi elaborado em duas vias, uma ficará com o pesquisador responsável e a outra com o sujeito da pesquisa.

Nome / assinatura

JANAINA MEIRELLES SOUSA - Pesquisador Responsável

Brasília, de de 
APÊNDICE D - Instrumento de Coleta de Dados

Data:

1. Você trabalha em qual NRAD: ( ) Asa Norte （ ）Asa Sul （ )Brazlândia

( )Ceilândia ( )Gama ( )Guará ( )Núcleo Bandeirantes ( )Paranoá

( )Planaltina ( )Recanto das Emas ( )Samambaia ( )Santa Maria

( ) São Sebastião ( )Sobradinho ( )Taguatinga

- Você está lotado em uma equipe: （ ）EMADS （ )EMAPS

2. Idade:

3. Sexo: ( )Feminino ( ) Masculino

4. Estado civil: ( ) Solteiro(a) （ )Casado(a) ( )Divorciado(a) （ )Viúvo(a)

5. Dados relacionados ao trabalho:

a) Função: __ Carga horária:

Há quanto tempo trabalha no NRAD: __ (anos) ___ (meses)

b) Possui outros vínculos empregatícios: ( ) Sim （ ) Não

* Se sim cite-os:

6. Dados relacionados à formação:

a) Tempo de formado em Enfermagem: (anos) ___ (meses)

b) Especializações que cursou (mínimo de 360horas):

c) Já participou de algum curso que abordassem a temática Cuidados Paliativos:

( ) Sim ( ) Não

- Se você respondeu que sim, cite os cursos que participou e o ano da participação: 
Para responder ao questionário gostaria de lhe oferecer algumas informações.

As próximas perguntas visam identificar as competências gerais e específicas requeridas do enfermeiro para o Cuidado Paliativo na Atenção Domiciliar.

Competência tem sido relacionada na literatura científica como à capacidade de articular e mobilizar conhecimentos, habilidades e atitudes no enfrentamento de situações de imprevisibilidade em uma situação de trabalho. Compreende num conjunto de saberes e capacidades que os profissionais incorporam por meio da formação e experiência, somado à capacidade de integrá-los, utilizá-los e transferi-los em diferentes situações profissionais.

As competências gerais referem-se a comportamentos profissionais próprios de desempenho em diferentes setores ou atividades e usualmente relacionados à interação com tecnologias mais gerais. Nesta pesquisa seriam aquelas de todos os profissionais de saúde que atuam com o Cuidado Paliativo na Atenção Domiciliar.

As competências específicas são aquelas diretamente relacionadas com o exercício de ocupações concretas, não sendo facilmente transferíveis de um a outro âmbito profissional. São aquelas necessárias para o trabalho do enfermeiro em Cuidado Paliativo na Atenção Domiciliar.

Frente a cada competência apresentada solicito que você assinale com um X as opções que vão de "concordo totalmente" a "discordo totalmente" na escala, de forma que represente o quanto você concorda com as competências apresentadas.

Se você considerar a existência de outras competências gerais e específicas que não estejam listadas neste questionário, solicito que ao final do preenchimento você a descreva no item - SUGESTÂO, as competências que você considera relevante para a assistência de enfermagem em cuidado paliativo na Atenção Domiciliar.

Legenda: 1-Concordo Totalmente; 2-Concordo Parcialmente; 3-Neutro; 4-Discordo Parcialmente; 5-Discordo Totalmente.

\begin{tabular}{|c|c|c|c|c|c|c|}
\hline & ENUNCIADOS DAS COMPETÊNCIAS GERAIS & 1 & 2 & 3 & 4 & 5 \\
\hline 1 & $\begin{array}{l}\text { Avaliar o impacto das terapias tradicionais, complementares e } \\
\text { tecnológica centrada em resultados dos pacientes. }\end{array}$ & $(\quad)$ & ( ) & $($ ) & $($ ) & $($ ) \\
\hline 2 & $\begin{array}{l}\text { Compor a equipe multiprofissional no planejamento e avaliação } \\
\text { das ações de saúde ao paciente em final de vida. }\end{array}$ & $($ ) & $($ ) & $($ ) & ( ) & $($ ) \\
\hline 3 & $\begin{array}{l}\text { Conjugar o paciente e sua família como foco de cuidado da } \\
\text { equipe multiprofissional. }\end{array}$ & $($ ) & $($ ) & $(\quad)$ & $(\quad)$ & $($ ) \\
\hline 4 & Constatar mudanças dinâmicas na demografia da população. & $($ ) & $($ ) & $($ ) & $($ ) & $($ ) \\
\hline 5 & $\begin{array}{l}\text { Encaminhar pacientes e familiares para participar de programas } \\
\text { de apoio psicossocial e espiritual, durante o processo de } \\
\text { adoecimento crônico e luto. }\end{array}$ & ( ) & ( ) & $(\quad)$ & $(\quad)$ & $($ ) \\
\hline 6 & $\begin{array}{l}\text { Expressar de forma eficaz com a comunidade e equipe de saúde } \\
\text { sobre questões de fim de vida. }\end{array}$ & $($ ) & $($ ) & $($ ) & $($ ) & $($ ) \\
\hline 7 & $\begin{array}{l}\text { Identificar a iminência da morte e empregar cuidados adequados } \\
\text { ao paciente e família. }\end{array}$ & $($ ) & $($ ) & $($ ) & $($ ) & $($ ) \\
\hline 8 & $\begin{array}{l}\text { Identificar barreiras e ações facilitadoras para pacientes e } \\
\text { cuidadores na utilização eficaz de recursos em domicílio. }\end{array}$ & ( ) & ( ) & ( ) & $($ ) & ( ) \\
\hline 9 & $\begin{array}{l}\text { Interpretar as atitudes próprias, sentimentos, valores e } \\
\text { expectativas sobre a morte e a diversidade cultural e espiritual } \\
\text { existente nas crenças e costumes representados na comunidade. }\end{array}$ & $($ ) & $($ ) & $($ ) & () & $($ ) \\
\hline 10 & $\begin{array}{l}\text { Operar na avaliação, manejo e controle de sinais e sintomas } \\
\text { (dispneia, fadiga, anorexia, náuseas e vômitos, constipação, } \\
\text { confusão mental, dor) comuns no final da vida. }\end{array}$ & ( ) & ( ) & $(\quad)$ & $(\quad)$ & ( ) \\
\hline 11 & $\begin{array}{l}\text { Operar na organização, análise e melhoria dos cuidados de saúde } \\
\text { em domicílio. }\end{array}$ & ( ) & $($ ) & $($ ) & $($ ) & $($ ) \\
\hline 12 & $\begin{array}{l}\text { Empregar com a equipe multiprofissional orientações a familiares } \\
\text { sobre rituais de funeral, direitos sociais e responsabilidades com } \\
\text { papéis e documentos em situação de óbito. }\end{array}$ & ( ) & ( ) & $($ ) & $($ ) & $($ ) \\
\hline
\end{tabular}




\begin{tabular}{|c|c|c|c|c|c|c|}
\hline & ENUNCIADOS DAS COMPETÊNCIAS GERAIS & 1 & 2 & 3 & 4 & 5 \\
\hline 13 & $\begin{array}{l}\text { Orientar pacientes e familiares acerca do processo de doença do } \\
\text { paciente em final de vida. }\end{array}$ & $(\mathbf{)}$ & $($ ) & $($ ) & $($ ) & $(\quad)$ \\
\hline 14 & $\begin{array}{l}\text { Planejar os cuidados com base nos objetivos, preferências e } \\
\text { escolhas do paciente e sua família. }\end{array}$ & $(\quad)$ & $($ ) & $($ ) & $($ ) & $($ ) \\
\hline 15 & Prestar cuidados ao paciente no pós-morte de forma respeitosa. & $(\quad)$ & $(\quad)$ & $(\quad)$ & $(\quad)$ & $($ ) \\
\hline 16 & $\begin{array}{l}\text { Traçar plano de cuidados considerando as dimensões física, } \\
\text { psicológica, social e espiritual, com vista à melhora da qualidade } \\
\text { de vida. }\end{array}$ & $(\quad)$ & $(\quad)$ & $($ ) & $(\quad)$ & $($ ) \\
\hline 17 & $\begin{array}{l}\text { Traçar plano de cuidados de forma a não ter lacunas que levem o } \\
\text { paciente a se sentir abandonado durante sua evolução clínica. }\end{array}$ & $($ ) & $($ ) & $($ ) & $($ ) & $($ ) \\
\hline 18 & $\begin{array}{l}\text { Valorizar os pontos de vista e desejos do paciente e família } \\
\text { durante os cuidados em fim de vida. }\end{array}$ & $(\quad)$ & $(\quad)$ & () & $(\quad)$ & () \\
\hline & ENUNCIADOS DAS COMPETÊNCIAS ESPECÍFICAS & 1 & 2 & 3 & 4 & 5 \\
\hline 19 & $\begin{array}{l}\text { Compor a equipe multiprofissional na avaliação e manejo das } \\
\text { necessidades psicossociais e espirituais complexas do paciente e } \\
\text { sua família. }\end{array}$ & $(\quad)$ & $(\quad)$ & $(\quad)$ & $(\quad)$ & $(\quad)$ \\
\hline 20 & $\begin{array}{l}\text { Compor a equipe multiprofissional na comunicação de "má } \\
\text { notícia" a familiares e pacientes em situações de final de vida. }\end{array}$ & $($ ) & $(\quad)$ & $(\quad)$ & $(\quad)$ & $($ ) \\
\hline 21 & $\begin{array}{l}\text { Compor a equipe multiprofissional no processo de tomada de } \\
\text { decisão, junto à família, frente a situações éticas que envolvam } \\
\text { cuidados e tratamentos de suporte a pacientes no final da vida. }\end{array}$ & $(\quad)$ & $(\quad)$ & $($ ) & $(\quad)$ & $($ ) \\
\hline 22 & $\begin{array}{l}\text { Empregar a comunicação de forma eficaz com pacientes, } \\
\text { familiares e cuidadores sobre questões de fim de vida. }\end{array}$ & $(\quad)$ & $($ ) & $($ ) & $($ ) & $($ ) \\
\hline 23 & $\begin{array}{l}\text { Empregar com a equipe multiprofissional plano de intervenção } \\
\text { em luto a cuidadores e familiares no pós-morte do paciente. }\end{array}$ & $(\quad)$ & $(\quad)$ & $($ ) & ( ) & $($ ) \\
\hline 24 & $\begin{array}{l}\text { Empregar dados de avaliação de sinais e sintomas apresentados } \\
\text { pelos pacientes e familiares, na gestão dos sintomas utilizando } \\
\text { práticas integrativas e complementares de saúde. }\end{array}$ & $(\quad)$ & $(\quad)$ & $($ ) & $(\quad)$ & $($ ) \\
\hline 25 & $\begin{array}{l}\text { Empregar os postulados éticos dos cuidados paliativos na tomada } \\
\text { de decisão em questões complexas de fim de vida, reconhecendo } \\
\text { a influência dos valores pessoais, código de ética profissional e } \\
\text { preferências do paciente. }\end{array}$ & $($ ) & $(\quad)$ & $($ ) & $(\quad)$ & $($ ) \\
\hline 26 & $\begin{array}{l}\text { Estabelecer apoio emocional à família, cuidadores e equipe de } \\
\text { saúde na situação de luto. }\end{array}$ & $($ ) & ( ) & $($ ) & ( ) & $($ ) \\
\hline 27 & $\begin{array}{l}\text { Estabelecer apoio emocional a pacientes, familiares, cuidadores, } \\
\text { comunidade e equipe de saúde, para lidar com o sofrimento } \\
\text { durante os cuidados no final da vida. }\end{array}$ & $(\quad)$ & $(\quad)$ & $($ ) & $(\quad)$ & $($ ) \\
\hline 28 & $\begin{array}{l}\text { Estabelecer com pacientes e cuidadores um plano de atividade } \\
\text { física que favoreça a mobilidade no domicílio. }\end{array}$ & $(\quad)$ & $($ ) & $($ ) & $($ ) & $($ ) \\
\hline 29 & $\begin{array}{l}\text { Estabelecer e executar com cuidadores que apresentam risco de } \\
\text { distress ou sobrecarga, um plano compartilhado de cuidados } \\
\text { domiciliares. }\end{array}$ & $(\quad)$ & $(\quad)$ & $($ ) & $(\quad)$ & $($ ) \\
\hline 30 & Estabelecer projetos de investigação em cuidados paliativos. & $(\quad)$ & $(\quad)$ & () & $(\quad)$ & () \\
\hline 31 & $\begin{array}{l}\text { Executar a sistematização da assistência de enfermagem ao } \\
\text { paciente no final de vida. }\end{array}$ & $(\quad)$ & $(\quad)$ & () & () & () \\
\hline 32 & $\begin{array}{l}\text { Executar cuidados de conforto para a morte em domicílio como } \\
\text { um componente integrante dos cuidados de enfermagem. }\end{array}$ & $(\quad)$ & () & $($ ) & () & $($ ) \\
\hline 33 & $\begin{array}{l}\text { Executar educação de familiares e cuidadores para avaliação e } \\
\text { manejo de sinais e sintomas em domicílio (dispneia, fadiga, } \\
\text { anorexia, náuseas e vômitos, constipação, confusão mental, dor) } \\
\text { comuns no final da vida. }\end{array}$ & $(\quad)$ & () & () & $(\quad)$ & () \\
\hline 34 & $\begin{array}{l}\text { Executar educação de pacientes, familiares e cuidadores sobre } \\
\text { medidas de segurança, prevenção de quedas, cuidados corpóreos, } \\
\text { uso de medicamentos, de curativos, de cuidados com sondas, de } \\
\text { exercícios ativo-passivos e de postura. }\end{array}$ & $(\quad)$ & () & () & $(\quad)$ & () \\
\hline 35 & $\begin{array}{l}\text { Delimitar com pacientes e familiares objetivos do cuidado } \\
\text { paliativo a curto, médio e longo prazo. }\end{array}$ & $(\quad)$ & () & () & $(\quad)$ & () \\
\hline 36 & $\begin{array}{l}\text { Oportunizar o acesso de familiares e cuidadores à equipe } \\
\text { multiprofissional no período de luto. }\end{array}$ & $(\quad)$ & ( ) & $($ ) & ( ) & $($ ) \\
\hline
\end{tabular}




\begin{tabular}{|c|c|c|c|c|c|c|}
\hline & ENUNCIADOS DAS COMPETÊNCIAS ESPECÍFICAS & 1 & 2 & 3 & 4 & 5 \\
\hline 37 & $\begin{array}{l}\text { Redigir métodos de educação em cuidados paliativos para } \\
\text { pacientes e familiares. }\end{array}$ & $($ ) & () & $(\quad)$ & () & () \\
\hline 38 & $\begin{array}{l}\text { Redigir com a equipe um plano de intervenção frente à } \\
\text { claudicação familiar. }\end{array}$ & $($ ) & $($ ) & $($ ) & $($ ) & $($ ) \\
\hline 39 & $\begin{array}{l}\text { Responder como consultor em análise de situações éticas } \\
\text { complexas que envolvam cuidados e tratamentos de suporte a } \\
\text { pacientes no final de vida. }\end{array}$ & $($ ) & $($ ) & $(\quad)$ & $(\quad)$ & ( ) \\
\hline 40 & $\begin{array}{l}\text { Responder pela qualidade da assistência de enfermagem } \\
\text { oferecida ao pacientes no final da vida. }\end{array}$ & $($ ) & $($ ) & $($ ) & $($ ) & $($ ) \\
\hline 41 & $\begin{array}{l}\text { Seguir as diretrizes legais sobre consentimento informado e } \\
\text { diretivas antecipadas na tomada de decisão em situações de final } \\
\text { de vida. }\end{array}$ & $($ ) & $($ ) & $(\quad)$ & $($ ) & $($ ) \\
\hline 42 & $\begin{array}{l}\text { Seguir ferramentas padronizadas para avaliar sinais e sintomas de } \\
\text { pacientes em cuidados paliativos. }\end{array}$ & () & () & $(\quad)$ & () & () \\
\hline 43 & $\begin{array}{l}\text { Somar a linguagem dietética, práticas habituais e rituais de } \\
\text { pacientes e familiares ao plano de cuidados. }\end{array}$ & () & () & $(\quad)$ & () & () \\
\hline
\end{tabular}


APÊNDICE E - Artigo 3: Competências do Enfermeiro para o Cuidado Paliativo na Atenção Domiciliar.

Janaina Meirelles Sousa Elioenai Dornelles Alves

\section{Submetido}

18 de outubro de 2014

Aceito

15 de Dezembro de 2014

Universidade de Brasília, Brasília, DF, Brasil.

Conflitos de interesse: não há conflito de interesses a declarar.

\section{Autor correspondente}

Janaina Meirelles Sousa

Campus Universitário Centro Metropolitano 1, Conjunto A, Ceilândia, DF, Brasil, CEP 72220-900, sjana@unb.br

\section{Resumo}

Objetivo: Identificar competências do enfermeiro para o cuidado paliativo na atenção domiciliar.

Métodos: Estudo exploratório que utilizou o método Delphi para identificar o consenso de enfermeiros que atuam na atenção domiciliar para com 43 competências elencadas em um questionário, com inclusão de escala de Likert de cinco pontos.

Resultados: Na amostra de 20 enfermeiros, houve consenso para 18 competências gerais e 25 específicas com percentuais acima de $75 \%$ de concordância, e coeficiente alfa de Cronbach de 0,7 para todas as competências elencadas. $\mathrm{O}$ consenso favorável às competências propostas indica o reconhecimento do cuidado paliativo como prática assistencial de enfermagem na atenção domiciliar.

Conclusão: O elenco de competências apresentou confiabilidade interna e fornece afirmações assertivas sobre a atuação do enfermeiro em cuidado paliativo na atenção domiciliar.

Descritores: Enfermagem de atenção primária; /enfermagem; Pesquisa em enfermagem; Cuidados paliativos; Serviços de assistência domiciliar. 


\section{Introdução}

Cuidado de qualidade ao fim da vida depende de uma equipe interdisciplinar de saúde emparelhada com habilidades interpessoais fortes, conhecimento clínico, competência técnica e respeito para com os indivíduos. ${ }^{(1)}$

O cuidado paliativo como modalidade assistencial requerida dos profissionais de saúde que trabalham na atenção domiciliar, aliado ao aumento da morbidade e mortalidade por doenças crônicas degenerativas a nível mundial, insufla a necessidade de assistência multiprofissional a pacientes que enfrentam doenças que ameaçam a vida. Nesse contexto, a Organização Mundial de Saúde propõe conceitos e diretrizes para esse cuidado, onde impera uma abordagem que permita a melhor qualidade de vida a pacientes e suas famílias, por meio da identificação, avaliação e tratamento de problemas de ordem física, psicossocial e espiritual. $^{(2-4)}$

Na equipe multidisciplinar de cuidados paliativos, os profissionais de enfermagem estão na linha de frente para prover cuidado, conforto e aconselhamento de famílias e pacientes. Nesta interação, o sucesso na execução do cuidado advém da relação estabelecida entre paciente-enfermagem e do interesse e vontade desses para exercer os cuidados ao fim da vida. ${ }^{(1,5)}$

O lidar com a morte e o morrer no cotidiano dos enfermeiros associado à inexperiência clínica, a falta de treinamentos e suporte emocional adequado, são apontados como obstáculos ao atendimento de qualidade a pacientes que se encontram em final de vida, e em última instância, influenciam na expressão da competência desses profissionais. ${ }^{(6)}$

Ao administrar uma situação complexa a competência profissional consiste em saber mobilizar e combinar de modo pertinente um conjunto de recursos pessoais e do meio. A construção de competências favorece a formação de esquemas de mobilização de recursos que permitem ao sujeito aplicá-los em suas atividades cotidianas, em função de um projeto que comporta para ele uma significação, ao qual ele dá um sentido. ${ }^{(7)}$

A operacionalização das competências resulta da qualidade da interface entre o homem e a situação de trabalho, onde o profissionalismo e a competência emergem de um saber agir, de um querer, e de um poder agir. Assim, o mapeamento de competências agrega valor econômico e valor social a indivíduos e organizações, na medida em que contribuem para a consecução dos objetivos organizacionais e expressam o reconhecimento social sobre a capacidade das pessoas. Cabe salientar que as competências requeridas de um profissional permeiam a competência desejada no indivíduo e o sistema de papéis estabelecido entre os atores sociais. $^{(8)}$ 
A competência revela-se no saber agir responsável que é reconhecido pelos outros, numa dinâmica que implica em saber mobilizar, integrar e transferir recursos, conhecimentos e habilidades num contexto profissional determinado. Assim, o objetivo desta pesquisa foi identificar competências do enfermeiro para o cuidado paliativo na atenção domiciliar.

\section{Métodos}

Trata-se de uma pesquisa descritiva, exploratória, de abordagem quantitativa. O primeiro momento da pesquisa constituiu-se na construção de uma lista de competências pela pesquisadora, baseada em literatura nacional e internacional advinda de artigos científicos, manuais de cuidados paliativos e livros específicos sobre o tema. O segundo momento foi de análise da lista de competência por um júri de três enfermeiros brasileiros que possuem experiência em cuidados paliativos e estão atualmente engajados em programas de atenção em saúde em cuidados paliativos. Após análise do júri as sugestões foram analisadas à luz da literatura científica, e a lista de competência foi revista pela pesquisadora resultando em 43 competências que foram apresentadas no terceiro momento da pesquisa aos enfermeiros para obtenção de consenso.

A definição do local de pesquisa e dos enfermeiros participantes foi em função dos parâmetros postos pelo Método Delphi, que consiste num processo estruturado para recolha e síntese de conhecimentos de um grupo de profissionais que estejam engajados com a área onde se está desenvolvendo a pesquisa, pela experiência e/ou por seus conhecimentos técnicos, a respeito de um determinado fenômeno. Esse processo acontece por meio de uma série de questionários, acompanhados de um feedback organizado de opiniões, que se repete em rodadas subsequentes até que se atinja o consenso previamente definido ou até que o nível de discordância se reduza em nível de saturação. ${ }^{(9)}$

A população foi constituída por enfermeiros vinculados as Equipes Multiprofissionais de Atenção Domiciliar - EMAD, da Secretaria de Saúde do Distrito Federal - SES-DF, no período de coleta de dados. Os critérios de inclusão foram enfermeiros vinculados a uma Equipe Multiprofissional de Atenção Domiciliar que aceitassem colaborar com a pesquisa mediante assinatura do Termo de Consentimento Livre e Esclarecido. O período de coleta de dados ocorreu entre os meses de março a junho do ano de 2014.

A amostra foi constituída de 20 enfermeiros que responderam a um questionário sociodemográfico que incluía uma lista de competências gerais e específicas, acrescida de uma escala de Likert onde os participantes deveriam optar por um "item likert" com pontuação disposto entre "discordo totalmente (1), discordo parcialmente (2), neutro (3), concordo parcialmente (4), concordo totalmente (5)" para se obter o grau de concordância. No 
questionário constava uma questão aberta onde o participante poderia acrescentar competências que considerasse pertinente ao consenso e que não foram abarcadas no questionário proposto.

A primeira rodada do Método aconteceu em encontros presenciais agendados por telefone com os enfermeiros onde a pesquisadora, no agendamento, explicou sobre a pesquisa e solicitou a participação dos mesmos. Após a coleta de dados da primeira rodada, esses receberam o tratamento estatístico e foram confrontados com o nível de consenso estipulado de $70 \%$.

A análise dos resultados da primeira rodada revelou que não seria necessária a segunda rodada, pois $100 \%$ das competências obtiveram consenso, e situações expostas na questão aberta, não foram consideradas pertinentes para construção de novas competências, pois se referiam a posicionamentos pessoais generalizados sobre o papel do enfermeiro na condução dos cuidados paliativos na atenção domiciliar.

Os dados foram expressos em frequência simples e percentual. Para a análise estatística de confiabilidade da lista de competências foi aplicado o coeficiente alfa de Cronbach considerando-se o conjunto das competências gerais e específicas.

$\mathrm{O}$ desenvolvimento do estudo atendeu as normas nacionais e internacionais de ética em pesquisa envolvendo seres humanos.

\section{Resultados}

A amostra de 20 enfermeiros foi composta de $95 \%$ do sexo feminino, $5 \%$ do sexo masculino, com média etária de 38,5 anos e desvio-padrão de 8,99. Dentre eles 65\% eram graduados em enfermagem há menos de 10 anos, 25\% tinham de 11 a 20 anos e $10 \%$ entre 21 a 30 anos de formado. A maioria dos enfermeiros (90\%) possuía pós-graduação lato sensu enquanto $10 \%$ não possuíam; $65 \%$ referiram ter participado de cursos que abordassem a temática cuidados paliativos e $35 \%$ negaram tal participação.

A porcentagem do tempo de experiência profissional nos Núcleos Regionais de Atenção Domiciliar foi: de $40 \%$ com 1 mês a 2 anos, $40 \%$ de 3 a 5 anos, $5 \%$ com mais de seis anos e $15 \%$ não informou o tempo de experiência. Dentre os profissionais, $25 \%$ possuíam outro vínculo empregatício e $75 \%$ somente trabalhavam em um único vínculo.

Das 43 competências apresentadas para julgamento dos enfermeiros, obtiveram consenso favorável, com porcentagem acima de 75\%, 18 competências gerais e 25 competências específicas. Na tabela 1 e tabela 2 observa-se coeficiente alfa de Cronbach acima de 0,7 para todas as competências elencadas. 
Os resultados apontaram consenso no grau de concordância total para 17 das competências gerais e apenas 01 competência ("constatar mudanças dinâmicas na demografia da população") obteve consenso com o grau de concordância parcial. No que tange as competências específicas estas obtiveram consenso na sua totalidade no grau de concordância total.

Tabela 1. Competências gerais

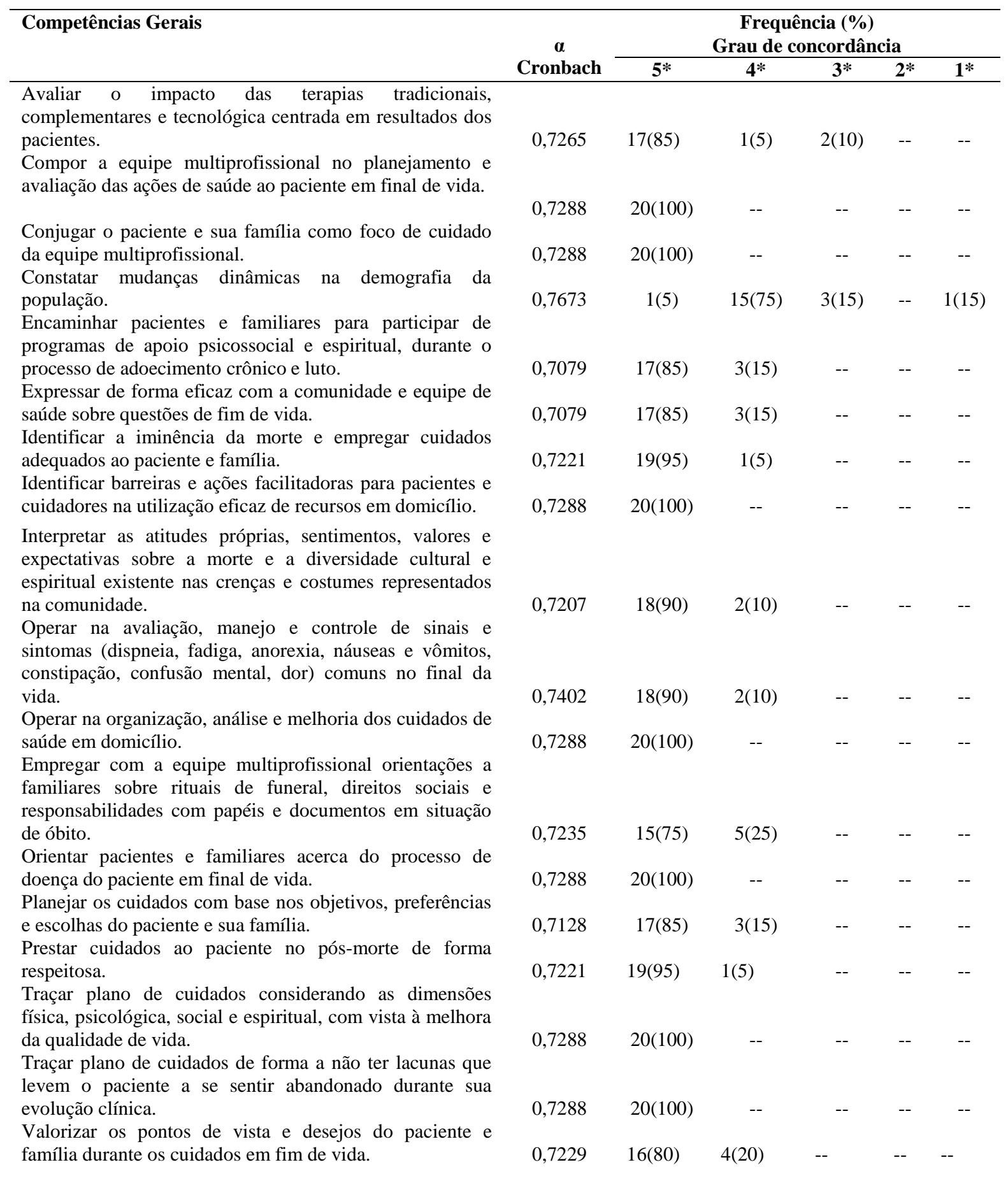

*Grau de concordância - 5(concordo totalmente), 4(concordo parcialmente), 3(neutra), 2(discordo parcialmente) e 1(discordo totalmente) 
Tabela 2. Competências específicas.

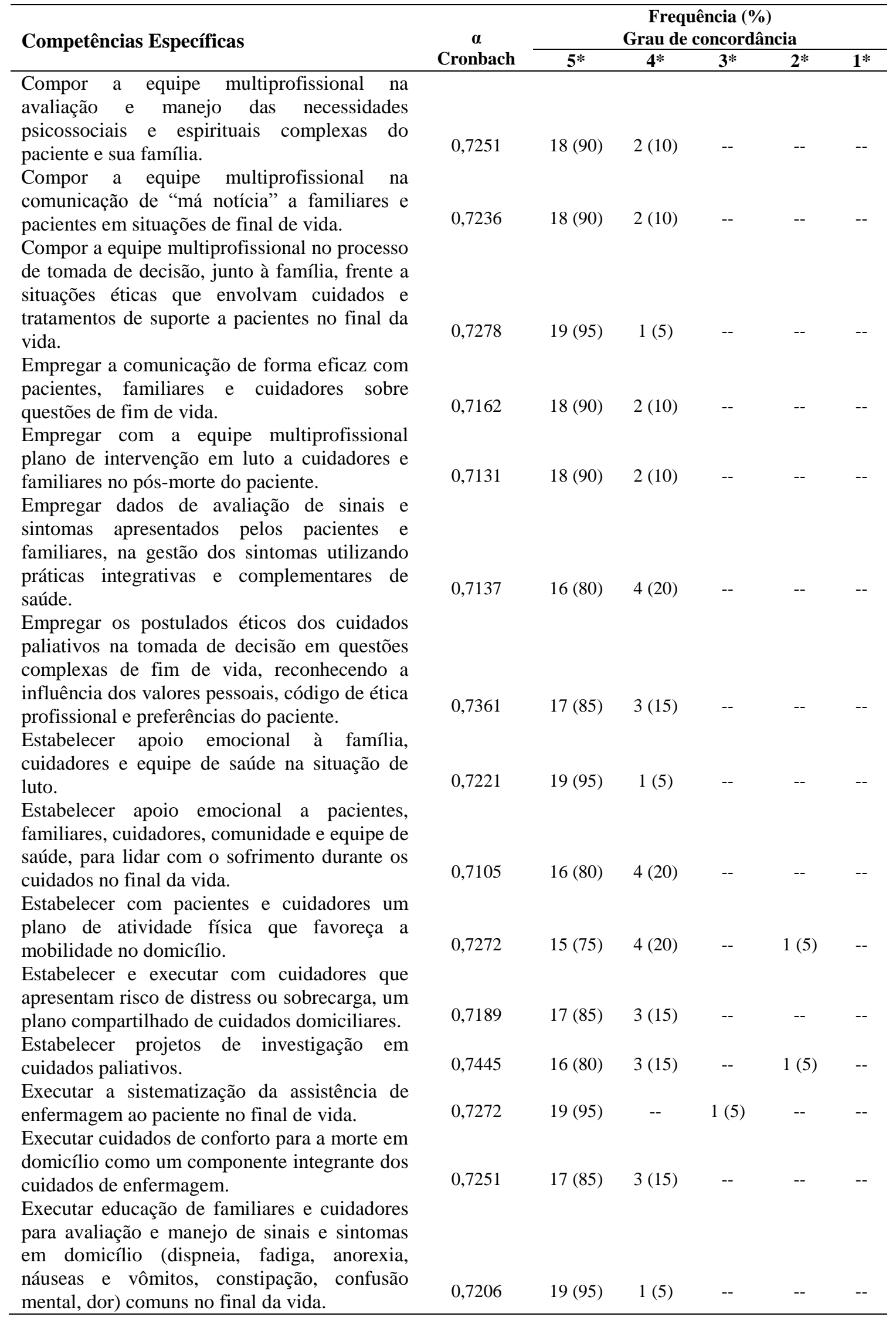

(continua) 
(continuação tabela 2)

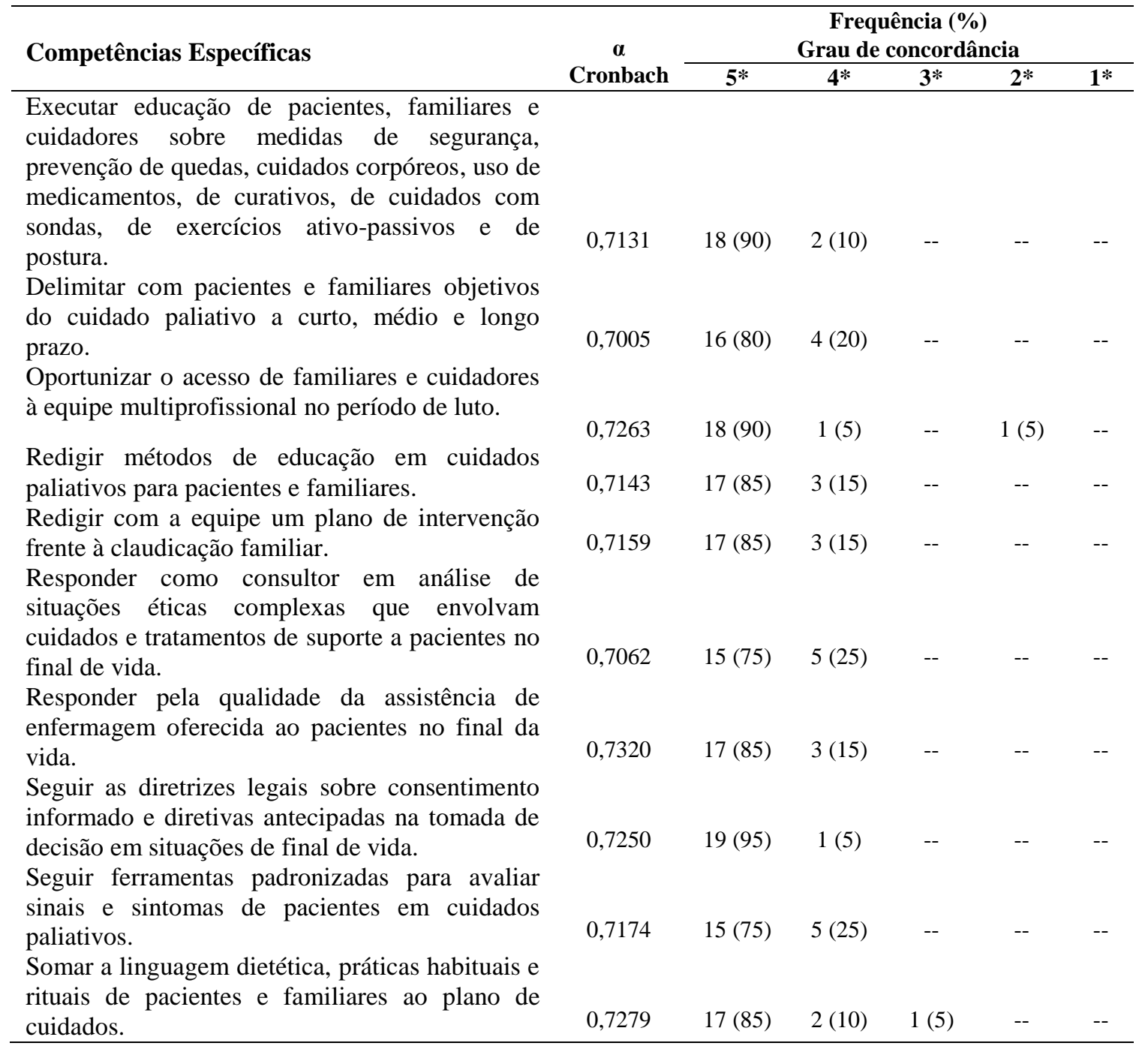

* Grau de concordância - 5(concordo totalmente), 4(concordo parcialmente), 3(neutra), 2(discordo parcialmente) e 1(discordo totalmente)

\section{Discussão}

Os limites deste estudo consistem no número de participantes, delimitados pelo método Delphi, restringindo a amostra aos Enfermeiros lotados nas Equipes Multiprofissionais de Atenção Domiciliar do Distrito Federal.

Os resultados oferecem subsídios a instituições quando na formulação de competências esperadas do profissional enfermeiro na assistência domiciliar, assim como, aponta limites dessa atuação no contexto interdisciplinar da atenção domiciliar. Contribui como ponto de partida para construção de competências em enfermagem de cuidados paliativos e reforça a necessidade de preparação específica para se garantir adequada implementação dos cuidados paliativos no cenário nacional. 
Para realizar uma atividade com competência o profissional constrói um esquema operacional próprio que lhe permite executar atividades com competência, organizando sua conduta profissional. Neste caminho, regras são cumpridas e servem para dizer para onde devemos ir, indicando que o percurso é singular, pois impera a possibilidade de se resolver um problema com competência de diversas formas. ${ }^{(8)}$

Na resolução de um problema o indivíduo implementa o que aprendeu a organizar durante a sua experiência profissional, e na possibilidade de situações repetidas ele não deveria fazer igual, mas poderá responder de forma semelhante. Diante disso, chama-se a atenção para o risco de um perfil comportamental único, que engesse o profissional numa postura assistencial que impossibilite a singularidade, o inesperado ou o inusitado contido nos eventos. A competência se revela em saber como agir, no aqui e agora, para além do que está prescrito, quando defrontamos com eventos de aparência conhecida, mas de expressão inesperada. $^{(8)}$

No contexto dos cuidados paliativos, a atenção domiciliar é imprescindível para garantir a continuidade do processo de cuidados e dar respostas às múltiplas necessidades sociossanitárias que apresentam os pacientes que enfrentam doenças que ameaçam a vida, principalmente em países onde há limitações de recursos na saúde e acesso reduzido a cuidados institucionais. O desafio nessa modalidade de assistência consiste em evitar a fragmentação assistencial por meio de práticas organizativas e de integração de serviços de saúde e sociais. ${ }^{(10)}$

No estudo, o consenso unânime em 6 competências gerais (Tabela 1) expõe a concordância dos enfermeiros com a postura paliativista de trabalho interdisciplinar, com foco nas necessidades do paciente e família, na busca da melhor qualidade de vida. Cabe ressaltar o desafio aqui posto pelo trabalho em equipe, que consiste no partilhar uma filosofia comum de cuidados e objetivos comuns. ${ }^{(11)}$

O coeficiente alfa de Cronbach que avalia a magnitude em que os itens de um instrumento estão correlacionados revelou que o lista de competências proposta apresentou confiabilidade na amostra onde foi aplicado. As competências gerais e específicas consensuadas pelos enfermeiros do estudo corroboram aos achados na literatura por refletirem a autonomia, dignidade, comunicação, relação entre doente e profissional de cuidados de saúde, abordagem multiprofissional, qualidade de vida, posição em relação à vida e à morte, perda e luto, e educação pública como elementos centrais para assistência em cuidado paliativo. $^{(12-14)}$

A competência geral identificada "constatar mudanças dinâmicas na demografia da 
população", obteve consenso no grau de concordância parcial pela maioria dos enfermeiros, o que pode indicar que o conhecimento sobre a abordagem da territorialidade é incipiente enquanto saberes e fazeres a serem compartilhados na multidisciplinaridade. Esse conhecimento contribui para a produção do cuidado à saúde, assim como, para a constituição das redes de cuidado, na medida em que reconhece e utiliza os equipamentos sociais nos fluxos assistenciais. A doença que limita a vida tem impacto nas relações interpessoais dos doentes e famílias, e perceber quando e como referenciar para uma ajuda especializada, oportuniza o acesso a recursos adicionais pra que pacientes e familiares sejam capazes de manter uma boa qualidade de vida no fim da vida. ${ }^{(4,11,12)}$

$\mathrm{O}$ contido nos enunciados das competências foi reconhecido enquanto saberes e fazeres do enfermeiro em cuidados paliativos. O consenso nas competências específicas no grau de concordância total aponta uma confiança no potencial paliativista do enfermeiro por afirmarem serem capazes de antecipar e responder as necessidades de cuidados paliativos, bem como compreender as suas próprias limitações e a necessidade de procurarem ajuda para ações complexas. ${ }^{(4)}$

O baixo percentual assinalado pelos enfermeiros no grau de concordância parcial e discordância em algumas competências específicas (Tabela 2), pode indicar a necessidade de aquisição de conhecimentos acerca dos cuidados paliativos para manter e desenvolver suas próprias competências profissionais. A maioria dos enfermeiros afirmou ter participado de cursos que abordassem a temática cuidados paliativos, e a literatura aponta que todos os profissionais de saúde devem adquirir educação sobre os princípios e as práticas dos cuidados paliativos, num crescente que perpasse a formação inicial chegando a um nível de conhecimento especializado, principalmente aqueles cujo trabalho está focado na prestação de cuidados paliativos. ${ }^{(13)}$

A originalidade desta pesquisa impele a novos estudos nesse contexto, onde espera-se que a comunidade acadêmica refute ou amplie a reflexão dos resultados apresentados, contribuindo para a consolidação dos cuidados paliativos enquanto disciplina e especialidade em enfermagem.

\section{Conclusão}

O consenso favorável obtido nas competências propostas indica o reconhecimento do cuidado paliativo como prática assistencial de enfermagem na atenção domiciliar, e fornece afirmações assertivas sobre a competência do enfermeiro em cuidado paliativo na atenção domiciliar. 


\section{Colaborações}

SOUSAJM participou da concepção do projeto, coleta e interpretação dos dados, redação do artigo e aprovação final da versão a ser publicada. Alves ED contribuiu nas etapas de concepção do projeto, revisão crítica relevante do conteúdo intelectual e aprovação final da versão a ser publicada.

\section{Referências}

1. Mutto EM, et al. Nursing Education: The Experience, Attitudes, and Impact of Caring for Dying Patients by Undergraduate Argentinian Nursing Students. Journal of Palliative Medicine. 2010; 13(12): 1445-50.

2.Worldwide Palliative Care Alliance. Global Atlas of Palliative Care at the End of Life. [Internet]. 2014 [cited 2014 Jun 20]. Available from: http://www.who.int/cancer/publications/palliative-care-atlas/en/

3. Porto AR, Thofehrn MB, Amestoy SC, Gonzáles RIC, Oliveira NA. The essence of interdisciplinary practice in palliative care delivery to cancer patients. Invest. Educ. Enferm. [Internet]. 2012 [cited 2014 Out 07]; 30(2):231-9. Available from: http://aprendeenlinea.udea.edu.co/revistas/index.php/iee/article/view/8362/11361

4. Slatten K, Hatlevik O, Fagerstrom L. Validation of a new instrument for self-assessment of Nurses' core competencies in palliative care. Nurs Res Pract. [Internet]. 2014 [cited 2014 Out 07]; 2014: 615.498. Available from: http://www.ncbi.nlm.nih.gov/pmc/articles/PMC4124716/pdf/NRP2014-615498.pdf

5. Kirby E, Broom A, Good P. The role and significance of nurses in managing transitions to palliative care: a qualitative study. BMJ Open [Internet]. 2014 [cited 2014 Out 07]; 4(9): e006026. Available from: http://bmjopen.bmj.com/content/4/9/e006026.full.pdf+html

6. Powazki R, Walsh D, Cothren B, Rybicki L, Thomas S, Morgan G, et al. Karius D, Mellar P. The Care of the Actively Dying in an Academic Medical Center: A Survey of Registered Nurses'. AM J HOSP PALLIAT CARE [Internet]. 2014 [cited 2014 Out 07]; 31: 619. Available from: http://ajh.sagepub.com/content/31/6/619

7.Le Boterf G. [Évaluer les compétences: quels jugements? quels critères? quelles instances?]. Education permanente [Internet]. 1998 [cited 2014 Jun 20]; 135:143-15.Available from:http://www.academia.edu/747449/Evaluer_les_competences_quels_jugements_quels_cr iteres_quelles_instances. Francês

8. Le Boterf G. [Apprendre à agir et à interagir en professionnel compétent et responsible]. Education Permanente [Internet]. 2011 [cited 2014 Out 07]; 188(3):97-112. Available from: https://www.usherbrooke.ca/ssf/fileadmin/sites/ssf/Perspectives_SSF/article_entretien_Guy_L e_Boterf_sur_professionnalisation.pdf. Francês

9. Sinha IP, Smyth RL, Williamson PR. Using the Delphi Technique to Determine Which Outcomes to Measure in Clinical Trials: Recommendations for the Future Based on a Systematic Review of Existing Studies. PLoS Med [Internet]. 2011 [ cited 2014 Out 07]; 8 (1): e1000393. Available from: http://www.plosmedicine.org/article/fetchObject.action?uri=info\%3Adoi\%2F10.1371\%2Fjou rnal.pmed.1000393\&representation=PDF 
10.Nevado DC, Barbarro AA, Lozano MAR. [Continuidad de cuidados, innovación y redefinición de papeles profesionales en la atención a pacientes crónicos y terminales. Informe SESPAS 2012]. Gac Sanit, [Internet]. 2012 [cited 2014 Ago 20]; 26(s):63-68. Available from:http://www.sciencedirect.com/science/article/pii/S0213911111003700 .Espanhol

11. Vissers KCP, Brand MWM, Jacobs J, Groot M, Veldhoven C, Verhagen C, et al. Palliative Medicine Update: a multidisciplinary approach. Pain Practice [Internet]. 2013 [cited 2014 Out 07]; 13(7):576-588. Available from: http://onlinelibrary.wiley.com/doi/10.1111/papr.12025/pdf

12. Docherty SL, Thaxton C, Allison C, Barfield RC, Tamburro RF.The nursing dimension of providing palliative care to children and adolescents with cancer. Clinical Medicine Insights: Pediatrics [Internet]. 2012 [cited 2014 Out 07]; 6:75-88. Available from: http://www.ncbi.nlm.nih.gov/pmc/articles/PMC3620813/pdf/cmped-6-2012-075.pdf

13.Gamondi G, Larkin P, Payne S. Core competencies in palliative care: an EAPC White Paper on palliative care education - part 1. European Journal of Palliative Care [Internet].2013 [cited 2014 Jun 20]; 20(2): 86-91. Available from: http://www.eapcnet.eu/LinkClick.aspx?fileticket=jtSAxBB-azI\%3D

14.Gamondi G, Larkin P, Payne S. Core competencies in palliative care: an EAPC White Paper on palliative care education - part 2. European Journal of Palliative Care [Internet].2013 [cited 2014 Jun 20]; 20(3): 140-145. Available from: http://www.eapcnet.eu/LinkClick.aspx?fileticket=jtSAxBB-azI\%3D 


\begin{abstract}
ANEXOS
ANEXO A - Diretrizes Curriculares Nacionais do Curso de Graduação em Enfermagem

\author{
CONSELHO NACIONAL DE EDUCAÇÃO(*) \\ CÂMARA DE EDUCAÇÃO SUPERIOR
}

RESOLUÇÃO CNE/CES Nº 3, DE 7 DE NOVEMBRO DE 2001.

Institui Diretrizes Curriculares Nacionais do Curso de Graduação em Enfermagem.
\end{abstract}

O Presidente da Câmara de Educação Superior do Conselho Nacional de Educação, tendo em vista o disposto no Art. $9^{\circ}$, do $\S 2^{\circ}$, alínea "c", da Lei n ${ }^{\circ} 9.131$, de 25 de novembro de 1995, e com fundamento no Parecer CNE/CES 1.133, de 7 de agosto de 2001, peça indispensável do conjunto das presentes Diretrizes Curriculares Nacionais, homologado pelo Senhor Ministro da Educação, em $1^{\circ}$ de outubro de 2001,

\title{
RESOLVE:
}

Art. $1^{\circ}$ A presente Resolução institui as Diretrizes Curriculares Nacionais do Curso de Graduação em Enfermagem, a serem observadas na organização curricular das Instituições do Sistema de Educação Superior do País.

Art. $2^{\circ}$ As Diretrizes Curriculares Nacionais para o Ensino de Graduação em Enfermagem definem os princípios, fundamentos, condições e procedimentos da formação de enfermeiros, estabelecidas pela Câmara de Educação Superior do Conselho Nacional de Educação, para aplicação em âmbito nacional na organização, desenvolvimento e avaliação dos projetos pedagógicos dos Cursos de Graduação em Enfermagem das Instituições do Sistema de Ensino Superior.

Art. $3^{\circ}$ O Curso de Graduação em Enfermagem tem como perfil do formando egresso/profissional:

I - Enfermeiro, com formação generalista, humanista, crítica e reflexiva. Profissional qualificado para o exercício de Enfermagem, com base no rigor científico e intelectua 1 e pautado em princípios éticos. Capaz de conhecer e intervir sobre os problemas/situações de saúde-doença mais prevalentes no perfil epidemiológico nacional, com ênfase na sua região de atuação, identificando as dimensões bio-psicosociais dos seus determinantes. Capacitado a atuar, com senso de responsabilidade social e compromisso com a cidadania, como promotor da saúde integral do ser humano; e

II - Enfermeiro com Licenciatura em Enfermagem capacitado para atuar na Educação Básica e na Educação Profissional em Enfermagem.

Art. $4^{\circ}$ A formação do enfermeiro tem por objetivo dotar o profissional dos conhecimentos requeridos para o exercício das seguintes competências e habilidades gerais:

I - Atenção à saúde : os profissionais de saúde, dentro de seu âmbito profissional, devem estar aptos a desenvolver ações de prevenção, promoção, proteção e reabilitação da saúde, tanto em nível individual quanto coletivo. Cada profissional deve assegurar 
CNE/CES 3/2001. Diário Oficial da União, Brasília, 9 de Novembro de 2001. Seção 1, p. 37. que sua prática seja realizada de forma integrada e contínua com as demais instâncias do sistema de saúde, sendo capaz de pensar criticamente, de analisar os problemas da sociedade e de procurar soluções para os mesmos.

Os profissionais devem realizar seus serviços dentro dos mais altos padrões de qualidade e dos princípios da ética/bioética, tendo em conta que a responsabilidade da atenção à saúde não se encerra com o ato técnico, mas sim, com a resolução do problema de saúde, tanto em nível individual como coletivo;

II - Tomada de decisões: o trabalho dos profissionais de saúde deve estar fundamentado na capacidade de tomar decisões visando o uso apropriado, eficácia e custo-efetividade, da força de trabalho, de medicamentos, de equipamentos, de procedimentos e de práticas. Para este fim, os mesmos devem possuir competências e habilidades para avaliar, sistematizar e decidir as condutas mais adequadas, baseadas em evidências científicas;

III - Comunicação: os profissionais de saúde devem ser acessíveis e devem manter a confidencialidade das informações a eles confiadas, na interação com outros profissionais de saúde e o público em geral. A comunicação envolve comunicação verbal, não-verbal e habilidades de escrita e leitura; o domínio de, pelo menos, uma língua estrangeira e de tecnologias de comunicação e informação;

IV - Liderança: no trabalho em equipe multiprofissional, os profissionais de saúde deverão estar aptos a assumir posições de liderança, sempre tendo em vista o bem-estar da comunidade. A liderança envolve compromisso, responsabilidade, empatia, habilidade para tomada de decisões, comunicação e gerenciamento de forma efetiva e eficaz;

V - Administração e gerenciamento: os profissionais devem estar aptos a tomar iniciativas, fazer o gerenciamento e administração tanto da força de trabalho quanto dos recursos físicos e materiais e de informação, da mesma forma que devem estar aptos a serem empreendedores, gestores, empregadores ou lideranças na equipe de saúde; e

VI - Educação permanente: os profissionais devem ser capazes de aprender continuamente, tanto na sua formação, quanto na sua prática. Desta forma, os profissionais de saúde devem aprender a aprender e ter responsabilidade e compromisso com a sua educação e o treinamento/estágios das futuras gerações de profissionais, mas proporcionando condições para que haja benefício mútuo entre os futuros profissionais e os profissionais dos serviços, inclusive, estimulando e desenvolvendo a mobilidade acadêmico/profissional, a formação e a cooperação por meio de redes nacionais e internacionais.

Art. $5^{\circ}$ A formação do enfermeiro tem por objetivo dotar o profissional dos conhecimentos requeridos para o exercício das seguintes competências e habilidades específicas:

I - atuar profissionalmente, compreendendo a natureza humana em suas dimensões, em suas expressões e fases evolutivas;

II - incorporar a ciência/arte do cuidar como instrumento de interpretação profissional;

III - estabelecer novas relações com o contexto social, reconhecendo a estrutura e as formas de organização social, suas transformações e expressões;

IV - desenvolver formação técnico-científica que confira qualidade ao exercício profissional; $\mathrm{V}$ - compreender a política de saúde no contexto das políticas sociais, reconhecendo os perfis epidemiológicos das populações;

VI - reconhecer a saúde como direito e condições dignas de vida e atuar de forma a garantir a integralidade da assistência, entendida como conjunto articulado e contínuo das ações e 
serviços preventivos e curativos, individuais e coletivos, exigidos para cada caso em todos os níveis de complexidade do sistema;

VII - atuar nos programas de assistência integral à saúde da criança, do adolescente, da mulher, do adulto e do idoso;

VIII - ser capaz de diagnosticar e solucionar problemas de saúde, de comunicar-se, de tomar decisões, de intervir no processo de trabalho, de trabalhar em equipe e de enfrentar situações em constante mudança;

IX - reconhecer as relações de trabalho e sua influência na saúde;

$\mathrm{X}$ - atuar como sujeito no processo de formação de recursos humanos;

XI - responder às especificidades regionais de saúde através de intervenções planejadas estrategicamente, em níveis de promoção, prevenção e reabilitação à saúde, dando atenção integral à saúde dos indivíduos, das famílias e das comunidades;

XII - reconhecer-se como coordenador do trabalho da equipe de enfermagem;

XIII - assumir o compromisso ético, humanístico e social com o trabalho multiprofissional em saúde.

XIV - promover estilos de vida saudáveis, conciliando as necessidades tanto dos seus clientes/pacientes quanto às de sua comunidade, atuando como agente de transformação social;

XV - usar adequadamente novas tecnologias, tanto de informação e comunicação, quanto de ponta para o cuidar de enfermagem;

XVI - atuar nos diferentes cenários da prática profissional, considerando os pressupostos dos modelos clínico e epidemiológico;

XVII - identificar as necessidades individuais e coletivas de saúde da população, seus condicionantes e determinantes;

XIII - intervir no processo de saúde-doença, responsabilizando-se pela qualidade da assistência/cuidado de enfermagem em seus diferentes níveis de atenção à saúde, com ações de promoção, prevenção, proteção e reabilitação à saúde, na perspectiva da integralidade da assistência;

XIX - coordenar o processo de cuidar em enfermagem, considerando contextos e demandas de saúde;

XX - prestar cuidados de enfermagem compatíveis com as diferentes necessidades apresentadas pelo indivíduo, pela família e pelos diferentes grupos da comunidade;

XXI - compatibilizar as características profissionais dos agentes da equipe de enfermagem às diferentes demandas dos usuários;

XXII - integrar as ações de enfermagem às ações multiprofissionais;

XXIII - gerenciar o processo de trabalho em enfermagem com princípios de Ética e de Bioética, com resolutividade tanto em nível individual como coletivo em todos os âmbitos de atuação profissional;

XXIV - planejar, implementar e participar dos programas de formação e qualificação contínua dos trabalhadores de enfermagem e de saúde;

XXV - planejar e implementar programas de educação e promoção à saúde, considerando a especificidade dos diferentes grupos sociais e dos distintos processos de vida, saúde, trabalho e adoecimento;

XXVI - desenvolver, participar e aplicar pesquisas e/ou outras formas de produção de conhecimento que objetivem a qualificação da prática profissional;

XXVII - respeitar os princípios éticos, legais e humanísticos da profissão;

XXIII - interferir na dinâmica de trabalho institucional, reconhecendo-se como agente desse processo;

XXIX - utilizar os instrumentos que garantam a qualidade do cuidado de enfermagem e da assistência à saúde; 
XXX - participar da composição das estruturas consultivas e deliberativas do sistema de saúde;

XXXI - assessorar órgãos, empresas e instituições em projetos de saúde;

XXXII - cuidar da própria saúde física e mental e buscar seu bem-estar como cidadão e como enfermeiro; e

XXXIII - reconhecer o papel social do enfermeiro para atuar em atividades de política e planejamento em saúde.

Parágrafo Único. A formação do Enfermeiro deve atender as necessidades sociais da saúde, com ênfase no Sistema Único de Saúde (SUS) e assegurar a integralidade da atenção e a qualidade e humanização do atendimento.

Art. $6^{\mathbf{0}}$ Os conteúdos essenciais para o Curso de Graduação em Enfermagem devem estar relacionados com todo o processo saúde-doença do cidadão, da família e da comunidade, integrado à realidade epidemiológica e profissional, proporcionando a integralidade das ações do cuidar em enfermagem. Os conteúdos devem contemplar:

I - Ciências Biológicas e da Saúde - incluem-se os conteúdos (teóricos e práticos) de base moleculares e celulares dos processos normais e alterados, da estrutura e função dos tecidos, órgãos, sistemas e aparelhos, aplicados às situações decorrentes do processo saúde-doença no desenvolvimento da prática assistencial de Enfermagem;

II - Ciências Humanas e Sociais - incluem-se os conteúdos referentes às diversas dimensões da relação indivíduo/sociedade, contribuindo para a compreensão dos determinantes sociais, culturais, comportamentais, psicológicos, ecológicos, éticos e legais, nos níveis individual e coletivo, do processo saúde-doença;

III - Ciências da Enfermagem - neste tópico de estudo, incluem-se:

a) Fundamentos de Enfermagem: os conteúdos técnicos, metodológicos e os meios e instrumentos inerentes ao trabalho do Enfermeiro e da Enfermagem em nível individual e coletivo;

b) Assistência de Enfermagem: os conteúdos (teóricos e práticos) que compõem a assistência de Enfermagem em nível individual e coletivo prestada à criança, ao adolescente, ao adulto, à mulher e ao idoso, considerando os determinantes sócio-culturais, econômicos e ecológicos do processo saúde-doença, bem como os princípios éticos, legais e humanísticos inerentes ao cuidado de Enfermagem;

c) Administração de Enfermagem: os conteúdos (teóricos e práticos) da administração do processo de trabalho de enfermagem e da assistência de enfermagem; e

d) Ensino de Enfermagem: os conteúdos pertinentes à capacitação pedagógica do enfermeiro, independente da Licenciatura em Enfermagem.

$\S \mathbf{1}^{\circ}$ Os conteúdos curriculares, as competências e as habilidades a serem assimilados e adquiridos no nível de graduação do enfermeiro devem conferir-lhe terminalidade e capacidade acadêmica e/ou profissional, considerando as demandas e necessidades prevalentes e prioritárias da população conforme o quadro epidemiológico do país/região.

$\$ 2^{\mathbf{0}}$ Este conjunto de competências, conteúdos e habilidades deve promover no aluno e no enfermeiro a capacidade de desenvolvimento intelectual e profissional autônomo e permanente.

Art. $7^{\mathbf{0}} \mathrm{Na}$ formação do Enfermeiro, além dos conteúdos teóricos e práticos desenvolvidos ao longo de sua formação, ficam os cursos obrigados a incluir no currículo o estágio supervisionado em hospitais gerais e especializados, ambulatórios, rede básica de serviços de saúde e comunidades nos dois últimos semestres do Curso de Graduação em Enfermagem.

Parágrafo Único. Na elaboração da programação e no processo de supervisão do aluno, em estágio curricular supervisionado, pelo professor, será assegurada efetiva participação dos enfermeiros do serviço de saúde onde se desenvolve o referido estágio. A carga horária mínima do estágio curricular supervisionado deverá totalizar $20 \%$ (vinte por cento) da carga 
horária total do Curso de Graduação em Enfermagem proposto, com base no Parecer/Resolução específico da Câmara de Educação Superior do Conselho Nacional de Educação.

Art. $\mathbf{8}^{\circ}$ O projeto pedagógico do Curso de Graduação em Enfermagem deverá contemplar atividades complementares e as Instituições de Ensino Superior deverão criar mecanismos de aproveitamento de conhecimentos, adquiridos pelo estudante, através de estudos e práticas independentes, presenciais e/ou a distância, a saber: monitorias e estágios; programas de iniciação científica; programas de extensão; estudos complementares e cursos realizados em outras áreas afins.

Art. $9^{\circ} \mathrm{O}$ Curso de Graduação em Enfermagem deve ter um projeto pedagógico, construído coletivamente, centrado no aluno como sujeito da aprendizagem e apoiado no professor como facilitador e mediador do processo ensino-aprendizagem. Este projeto pedagógico deverá buscar a formação integral e adequada do estudante através de uma articulação entre o ensino, a pesquisa e a extensão/assistência.

Art. 10. As Diretrizes Curriculares e o Projeto Pedagógico devem orientar o Currículo do Curso de Graduação em Enfermagem para um perfil acadêmico e profissional do egresso. Este currículo deverá contribuir, também, para a compreensão, interpretação, preservação, reforço, fomento e difusão das culturas nacionais e regionais, internacionais e históricas, em um contexto de pluralismo e diversidade cultural.

$\S 1^{\mathbf{0}}$ As diretrizes curriculares do Curso de Graduação em Enfermagem deverão contribuir para a inovação e a qualidade do projeto pedagógico do curso.

$\S 2^{\mathbf{0}}$ O Currículo do Curso de Graduação em Enfermagem deve incluir aspectos complementares de perfil, habilidades, competências e conteúdos, de forma a considerar a inserção institucional do curso, a flexibilidade individual de estudos e os requerimentos, demandas e expectativas de desenvolvimento do setor saúde na região.

Art. 11. A organização do Curso de Graduação em Enfermagem deverá ser definida pelo respectivo colegiado do curso, que indicará a modalidade: seriada anual, seriada semestral, sistema de créditos ou modular.

Art. 12. Para conclusão do Curso de Graduação em Enfermagem, o aluno deverá elaborar um trabalho sob orientação docente.

Art. 13. A Formação de Professores por meio de Licenciatura Plena segue Pareceres e Resoluções específicos da Câmara de Educação Superior e do Pleno do Conselho Nacional de Educação.

Art. 14. A estrutura do Curso de Graduação em Enfermagem deverá assegurar:

I - a articulação entre o ensino, pesquisa e extensão/assistência, garantindo um ensino crítico, reflexivo e criativo, que leve a construção do perfil almejado, estimulando a realização de experimentos e/ou de projetos de pesquisa; socializando o conhecimento produzido, levando em conta a evolução epistemológica dos modelos explicativos do processo saúde-doença;

II - as atividades teóricas e práticas presentes desde o início do curso, permeando toda a formação do Enfermeiro, de forma integrada e interdisciplinar;

III - a visão de educar para a cidadania e a participação plena na sociedade;

IV - os princípios de autonomia institucional, de flexibilidade, integração estudo/trabalho e pluralidade no currículo;

V - a implementação de metodologia no processo ensinar-aprender que estimule o aluno a refletir sobre a realidade social e aprenda a aprender;

VI - a definição de estratégias pedagógicas que articulem o saber; o saber fazer e o saber conviver, visando desenvolver o aprender a aprender, o aprender a ser, o aprender a fazer, o aprender a viver juntos e o aprender a conhecer que constitui atributos indispensáveis à formação do Enfermeiro;

VII - o estímulo às dinâmicas de trabalho em grupos, por favorecerem a discussão coletiva e 
as relações interpessoais;

VIII - a valorização das dimensões éticas e humanísticas, desenvolvendo no aluno e no enfermeiro atitudes e valores orientados para a cidadania e para a solidariedade; e IX - a articulação da Graduação em Enfermagem com a Licenciatura em Enfermagem.

Art. 15. A implantação e desenvolvimento das diretrizes curriculares devem orientar e propiciar concepções curriculares ao Curso de Graduação em Enfermagem que deverão ser acompanhadas e permanentemente avaliadas, a fim de permitir os ajustes que se fizerem necessários ao seu aperfeiçoamento.

$\S \mathbf{1}^{\mathbf{0}}$ As avaliações dos alunos deverão basear-se nas competências, habilidades e conteúdos curriculares desenvolvidos, tendo como referência as Diretrizes Curriculares.

§ $2^{\circ}$ O Curso de Graduação em Enfermagem deverá utilizar metodologias e critérios para acompanhamento e avaliação do processo ensino-aprendizagem e do próprio curso, em consonância com o sistema de avaliação e a dinâmica curricular definidos pela IES à qual pertence.

Art. 16. Esta Resolução entra em vigor na data de sua publicação, revogadas as disposições em contrário.

Arthur Roquete de Macedo Presidente da Câmara de Educação Superior 
ANEXO B - Parecer Consubstanciado do CEP

\section{COMITÊ DE ÉTICA EM 15.- \\ PARECER CONSUBSTAIICIADO DO CEP}

DADOS DO PROJETO DE PESQUISA

Título da Pesquisa: Competências requeridas do Enfermeiro para o Cuidado Paliativo na Atenção Domiciliar.

Pesquisador: Janaina Meirelles Sousa

Area Temática:

Versão: 1

CAAE: 13320913.0 .0000 .5553

Instituição Proponente: FUNDAÇÃO DE ENSINO PESQUISA

Patrocinador Principal: Financiamento Próprio

\section{DADOS DO PARECER}

Número do Parecer: 204.480

Data da Relatoria: 25/02/2013

\section{Apresentação do Projeto:}

O cenário da saúde no Brasil evidencia a necessidade de formar profissionais capazes de criar novos cenários de atuação segundo as necessidades da realidade local em que está inserido e de novas propostas do sistema de saúde. Cuidados Paliativos é um novo campo de atuação, que vislumbra novos cenários de atuação e novas formas de relação entre serviços de saúde e comunidade. Os cuidados paliativos constituem um campo interdisciplinar de cuidados totais, ativos e integrais, dispensados aos pacientes com doenças avançadas e em fase terminal.

Objetivo da Pesquisa:

Identificar as competências gerais e especificas requeridas dos enfermeiros, que atuam na Atenção Domiciliar, para o Cuidado Paliativo.

Objetivo Secundário: Analisar as competências gerais e es jecíficas para o Cuidado Paliativo, requeridas dos enfermeiros que atuam na Atenção Domiciliar, sob a óica

das Diretrizes Curriculares Nacionais do Curso de Graduação em Enfermagem. Elencar competências gerais e específicas para o ensino de Cuidados Paliativos no nível de graduação em enfermagem.

\section{Avaliação dos Riscos e Benefícios:}

Espera-se que esta pesquisa proporcione recursos para a melhoria da assistência de enfermagem

\begin{tabular}{|c|c|c|}
\hline \multicolumn{3}{|c|}{ Endereço: SMHN 2 Qd 501 BLOCO A - FEPECS } \\
\hline $\begin{array}{l}\text { Bairro: ASA NORTE } \\
\text { UF: DF } \quad \text { Municíplo: }\end{array}$ & BRASILIA & $70.710-904$ \\
\hline $\begin{array}{l}\text { UF: DF } \\
\text { Telefone: } \\
\text { (61)3325-4955 }\end{array}$ & Fax: $\quad(33) 3325-4955$ & E-mail: cepsesdf@saude.df.gov.br \\
\hline
\end{tabular}




\section{COMITÊ DE ÉTICA EM 63.}

prestada às pessoas, assim como para a educação continuada em serviço.

Risco estimado.Amostra estimada.

Critérios de inclusão e exclusão definidos.

Comentários • Considerações sobre a Pesquisa:

A Atenção Domiciliar no Distrito Federal abarca Equipes Multiprofissionais de Atenção Domiciliar da Secretaria de Saúde EMAD, denominadas Núcleos Regionais de Atenção Domiciliar (NRAD), com reuniões mensais na Gerência de Atenção Domiciliar- GEAD.

Trata-se de uma pesquisa descritiva, exploratória, de abordagem quantitativa, com aplicação de um questionário aos enfermeiros participantes.

Considerações sobre os Termos de apresentação obrigitória:

Folha de rosto: apresentado

Termo de concordância: apresentado

TCLE:apresentado

Curriculo do pesquisador: apresentado

Cronograma da pesquisa: apresentado

Planilha de Orçamento: apresentado

TCLE: apresentado

Recomendações:

Sugere-se retirar o paragrafo que aponta o risco do sujeito de participar expondo suas informações pessoais.

Conclusões ou Pendências e Lista de Inadequações:

Projeto aprovado

Situação do Parecer:

Aprovado

Necessita Apreciação da CONEP:

Não

Considerações Finais a critério do CEP: 


\section{COMITÊ DE ÉTICA EM PESQUISA - FEPECSS/SES-DF

BRASILIA, 25 de Fevereiro de 2013

Assinador por:

Maria Rita Carvalho Ga rbi Novaes

(Coordenador)

Endereço: SMHN 2 Qd 501 BLOCO A - FEPECS

Bairro: ASA NORTE

CEP: $70.710-904$

UF: DF Municipio: BRASILIA

Telefone: (61)3325-4955 Fax: (33)3325-4955

E-ma il: cepsesdf@saude.df.gov.br 